Florida International University FIU Digital Commons

\title{
Assessment of the Occurrence and Potential Effects of Pharmaceuticals and Personal Care Products in South Florida Waters and Sediments
}

Chengtao Wang

Florida International University, cwang003@fiu.edu

DOI: $10.25148 /$ etd.FI12080614

Follow this and additional works at: https://digitalcommons.fiu.edu/etd

\section{Recommended Citation}

Wang, Chengtao, "Assessment of the Occurrence and Potential Effects of Pharmaceuticals and Personal Care Products in South Florida Waters and Sediments" (2012). FIU Electronic Theses and Dissertations. 689.

https://digitalcommons.fiu.edu/etd/689 


\title{
FLORIDA INTERNATIONAL UNIVERSITY
}

Miami, Florida

\section{ASSESSMENT OF THE OCCURRENCE AND POTENTIAL EFFECTS OF PHARMACEUTICALS AND PERSONAL CARE PRODUCTS IN SOUTH FLORIDA WATERS AND SEDIMENTS}

\author{
A dissertation submitted in partial fulfillment of \\ the requirements for the degree of \\ DOCTOR OF PHILOSOPHY \\ in \\ CHEMISTRY \\ by
}

Chengtao Wang

2012 
To: Dean Kenneth G. Furton

College of Arts and Sciences

This dissertation, written by Chengtao Wang, and entitled Assessment of the Occurrence and Potential Effects of Pharmaceuticals and Personal Care Products in South Florida Waters and Sediments, having been approved in respect to style and intellectual content, is referred to you for judgment.

We have read this dissertation and recommend that it be approved.

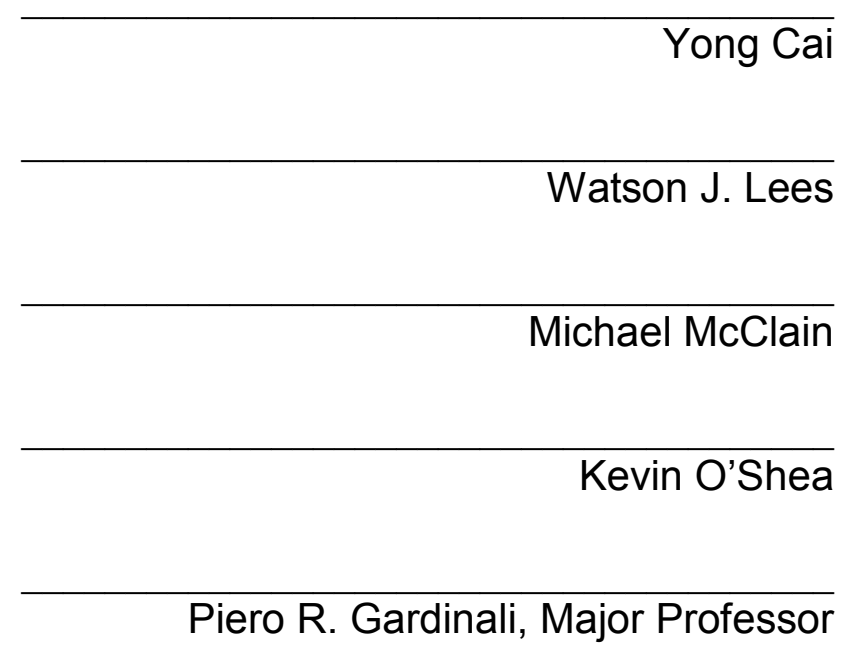

Date of Defense: July 18, 2012

The dissertation of Chengtao Wang is approved.

Dean Kenneth G. Furton College of Arts and Sciences

Dean Lakshmi N. Reddi University Graduate School

Florida International University, 2012 
(C) Copyright 2012 by Chengtao Wang

All rights reserved. 


\section{DEDICATION}

It is not easy to start pursuing a Ph.D and it becomes even harder towards the end. It is a kind of job that makes me start to question myself; it is a period of time in my life that I am desperate to call for help. But I am indeed blessed.

I dedicate this dissertation to my parents, without their understanding and support and most of all love, it is impossible for me to walk so far on my way of pursuing my dream. They not only gave me life but also taught me how to become a better person.

I dedicate this dissertation to my husband, without him, I will never know the colorful and beautiful part of life. He lets me feel peaceful and powerful when I face difficulties. 


\section{ACKNOWLEDGMENTS}

First, I would like to thank my major professor, Dr. Gardinali. He always provides great idea for my research and encourages me to try many different methods. He can always solve mechanical problems and he always spends time to help me fix instruments. He tells me to enjoy the process of doing research. Without his guidance, encouragement and support over these years, I would not achieve so much. His wonderful personality makes everyone comfortable to work with him. $\mathrm{He}$ is the best advisor I have ever met. Also, I would like to thank to my committee members, Dr. Cai, Dr. Lees, Dr. McClain and Dr. O'Shea, for their helpful advices of my research, and insightful comments to my dissertation.

Second, I would like to thank my colleagues in the lab. Thanks to Adolf and Ingrid who make the lab like a family. I got my first training from Luis, whenever I had question, he stopped his work and came to help me. Jian, shared a lot of his experience with me. I learned a lot from Ceser about how to do the research. I also want to thank many people who I worked with in the past several years, including Sudha, Venkat, Nubia, Mark, Natalia, Elsa, Eli, Kathia, Patricia and Maria.

Third, I want to thank my friends, all of them. They are at different parts of the world, but whenever I need them, they always listen to me, share their experience and offer me help. 
I would like to acknowledge Department of Chemistry \& Biochemistry and Florida International University for the financial support and copyright permissions. Finally, I wish to express my appreciation to those who has helped me in any respect during my study at FIU. 


\section{ABSTRACT OF THE DISSERTATION \\ ASSESSMENT OF THE OCCURRENCE AND POTENTIAL EFFECTS OF \\ PHARMACEUTICALS AND PERSONAL CARE PRODUCTS IN SOUTH \\ FLORIDA WATERS AND SEDIMENTS}

by

Chengtao Wang

Florida International University, 2012

Miami, Florida

Professor Piero R. Gardinali, Major Professor

A LLE-GC-MS method was developed to detect PPCPs in surface water samples from Big Cypress National Park, Everglades National Park and Biscayne National Park in South Florida. The most frequently found PPCPs were caffeine, DEET and triclosan with detected maximum concentration of $169 \mathrm{ng} / \mathrm{L}, 27.9 \mathrm{ng} / \mathrm{L}$ and $10.9 \mathrm{ng} / \mathrm{L}$, respectively. The detection frequencies of hormones were less than PPCPs. Detected maximal concentrations of estrone, 17ß-estradiol, coprostan-3-ol, coprostane and coprostan-3-one were $5.98 \mathrm{ng} / \mathrm{L}, 3.34 \mathrm{ng} / \mathrm{L}, 16.5$ $\mathrm{ng} / \mathrm{L}, 13.5 \mathrm{ng} / \mathrm{L}$ and $6.79 \mathrm{ng} / \mathrm{L}$, respectively.

An ASE-SPE-GC-MS method was developed and applied to the analysis of the sediment and soil area where reclaimed water was used for irrigation. Most analytes were below detection limits, even though some of analytes were detected in the reclaimed water at relatively high concentrations corroborating the fact that PPCPs do not significantly partition to mineral phases. 
An online SPE-HPLC-APPI-MS/MS method and an online SPE-HPLC-HESIMS/MS method were developed to analyze reclaimed water and drinking water samples. In the reclaimed water study, reclaimed water samples were collected from the sprinkler for a year-long period at Florida International University Biscayne Bay Campus, where reclaimed water was reused for irrigation. Analysis results showed that several analytes were continuously detected in all reclaimed water samples. Coprostanol, bisphenol A and DEET's maximum concentration exceeded $10 \mu \mathrm{g} / \mathrm{L}(\mathrm{ppb})$. The four most frequently detected compounds were diphenhydramine (100\%), DEET (98\%), atenolol (98\%) and carbamazepine $(96 \%)$. In the study of drinking water, 54 tap water samples were collected from the Miami-Dade area. The maximum concentrations of salicylic acid, ibuprofen and DEET were $521 \mathrm{ng} / \mathrm{L}, 301 \mathrm{ng} / \mathrm{L}$ and $290 \mathrm{ng} / \mathrm{L}$, respectively. The three most frequently detected compounds were DEET (93\%), carbamazepine (43\%) and salicylic acid (37\%), respectively. Because the source of drinking water in MiamiDade County is the relatively pristine Biscayne aquifer, these findings suggest the presence of wastewater intrusions into the delivery system or the onset of direct influence of surface waters into the shallow aquifer. 


\section{TABLE OF CONTENTS}

CHAPTER

PAGE

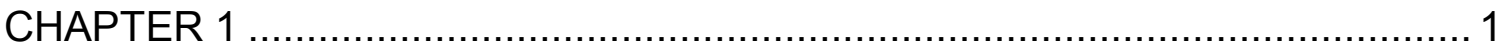

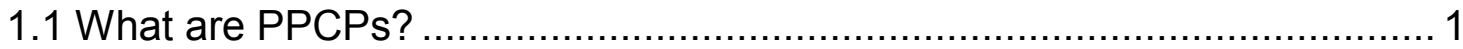

1.2 Why do we need to monitor them? ....................................................... 1

1.3 What are the typical procedures to detect them? ................................ 5

1.3.1 Sample preparation for aqueous samples........................................ 6

1.3.2 Sample preparation for solid samples ....................................... 8

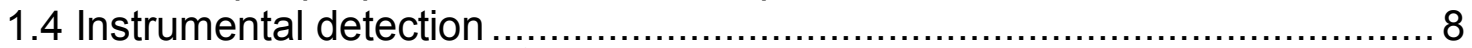

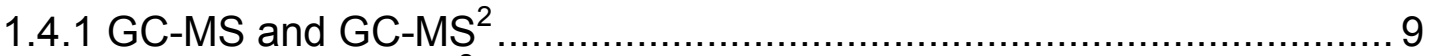

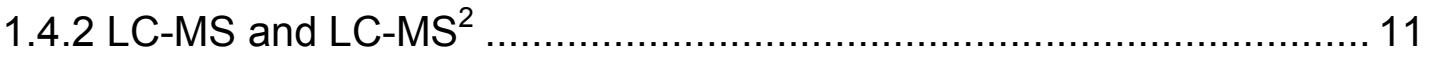

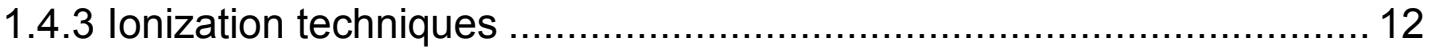

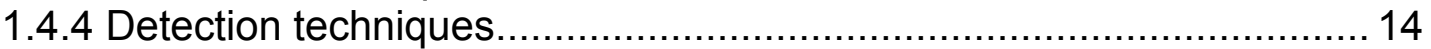

1.5 What is the concentration and fate of PPCPs in the environment? .......... 15

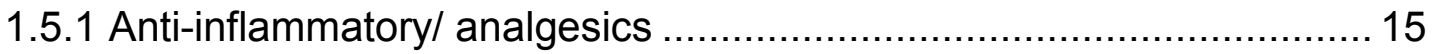

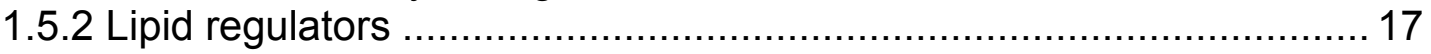

1.5.3 Antidepressants and anticonvulsants.............................................. 17

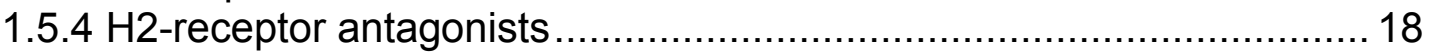

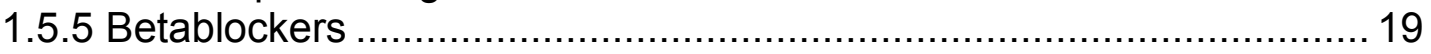

1.5.6 Industrial chemicals and personal care products ............................ 20

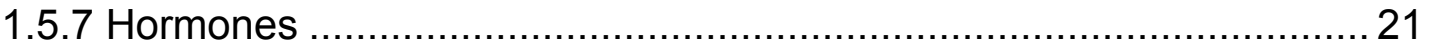

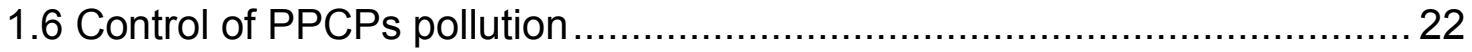

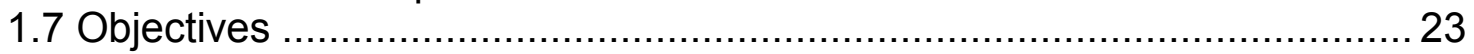

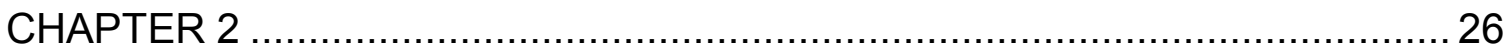

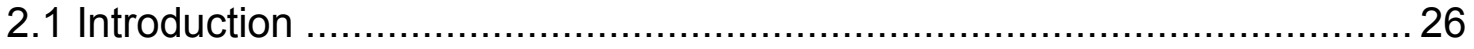

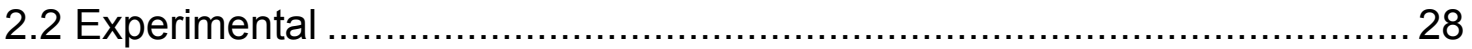

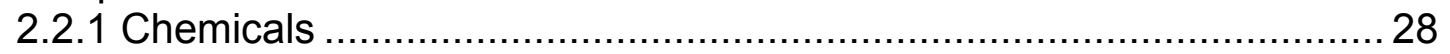

2.2.2 Sample collection and sample treatment ....................................... 31

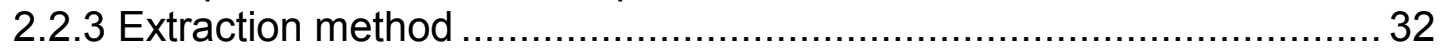

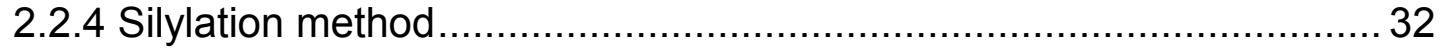

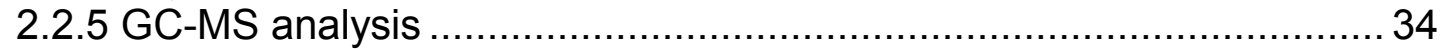

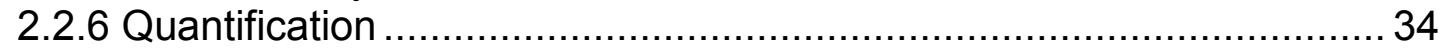

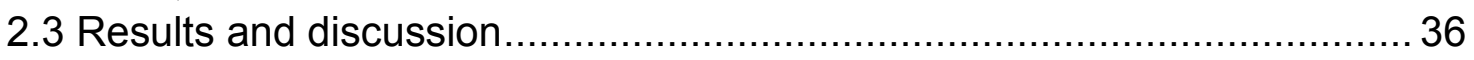

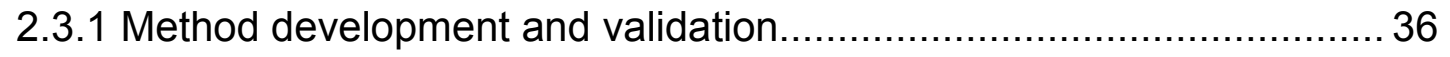

2.3.2 Analysis of real samples .............................................................. 39

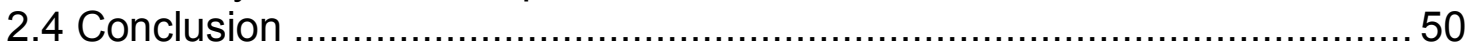

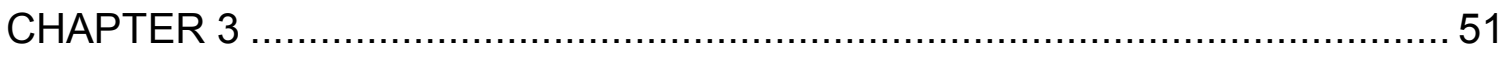

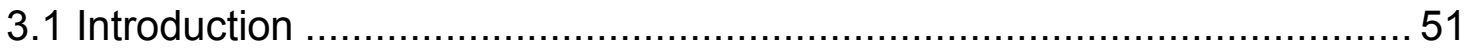

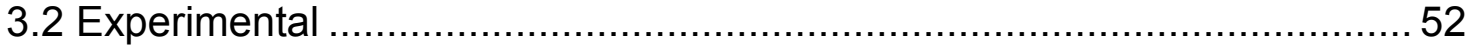

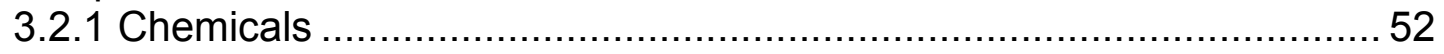

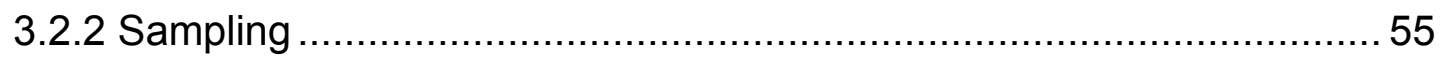




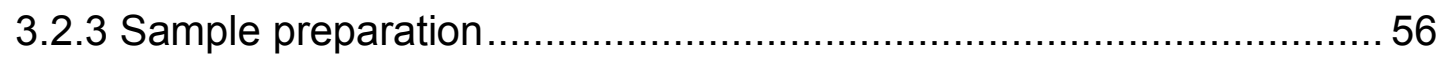

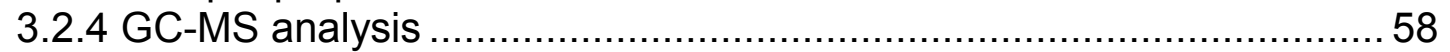

3.2.5 Extraction recovery and method detection limit............................... 58

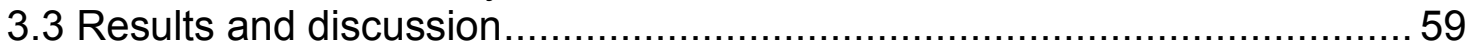

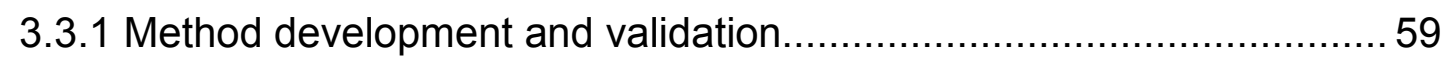

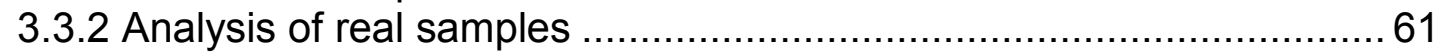

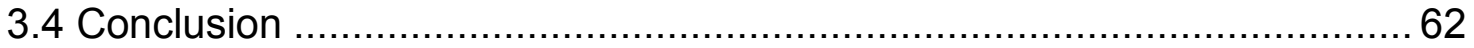

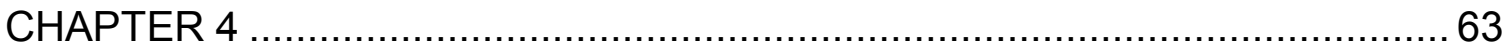

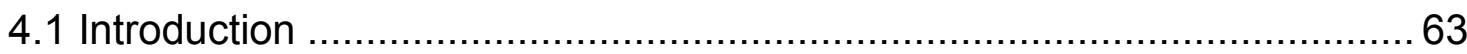

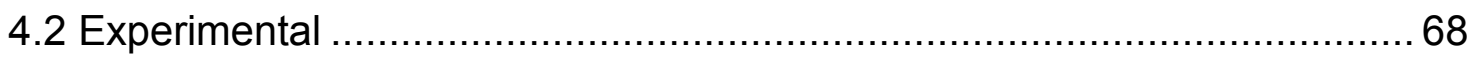

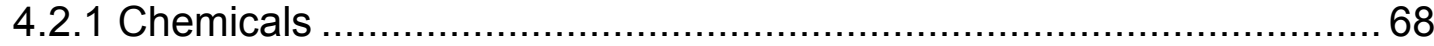

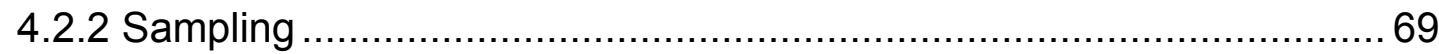

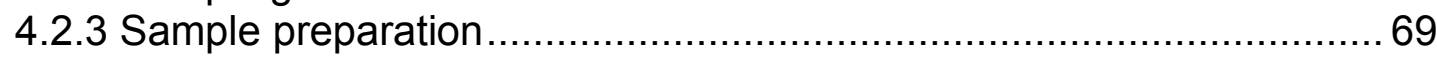

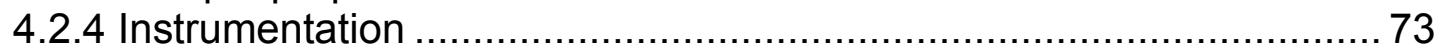

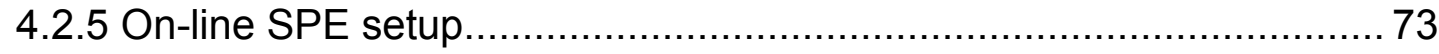

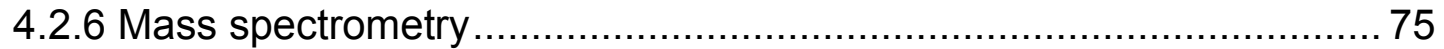

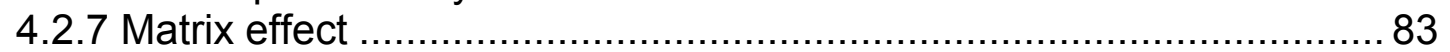

4.2.8 Extraction recovery and method detection limit................................ 83

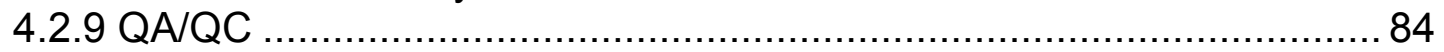

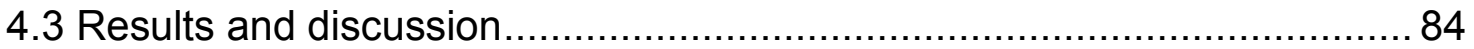

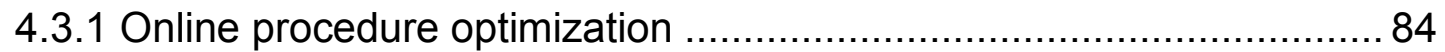

4.3.2 Comparisons of different ion sources based on MDLs...................... 87

4.3.3 Pharmaceuticals and personal care products ................................. 87

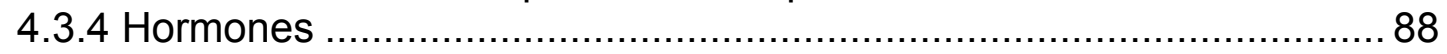

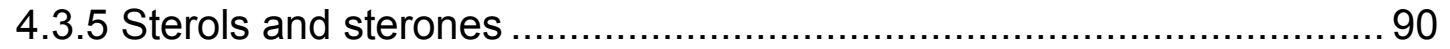

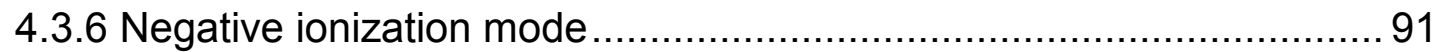

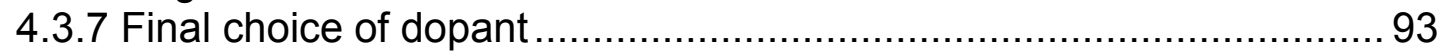

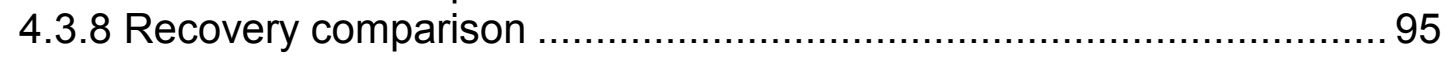

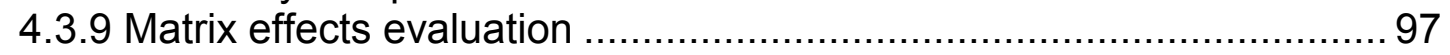

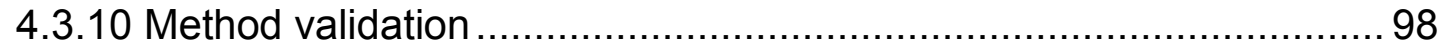

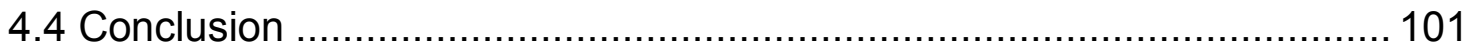

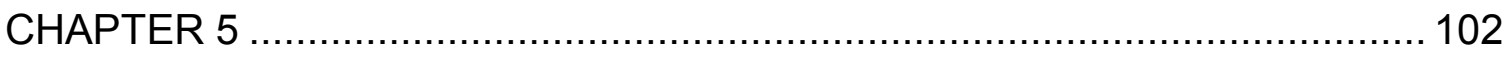

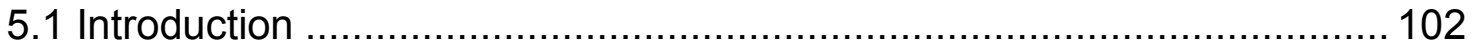

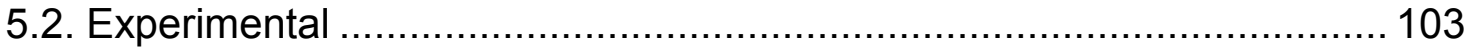

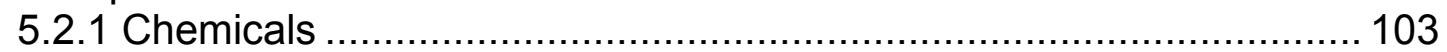

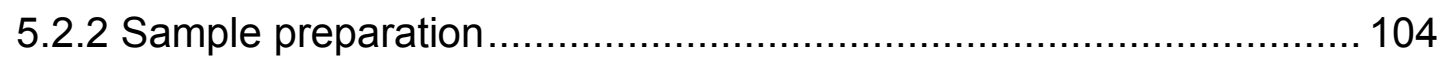

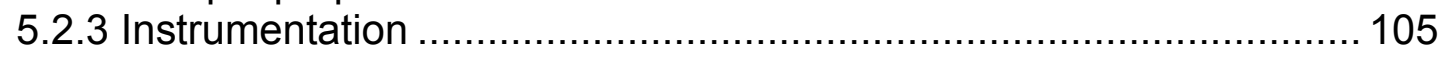

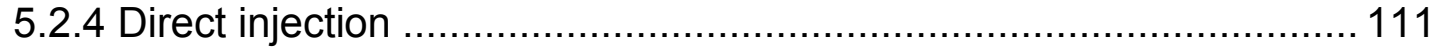

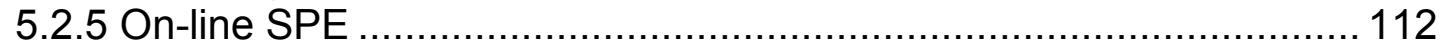

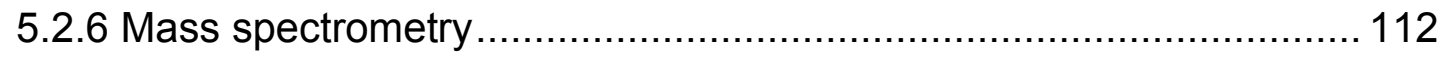

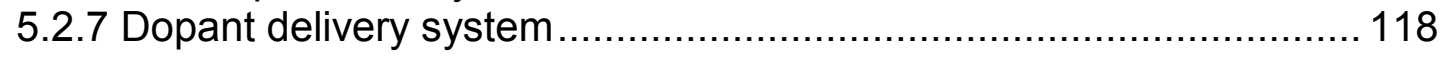

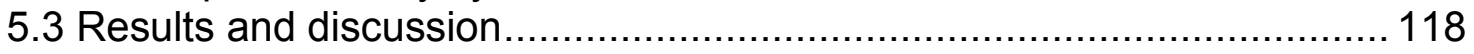

5.3.1 Optimization of online SPE procedure ........................................ 118 
5.3.2 Comparison of different API techniques........................................ 124

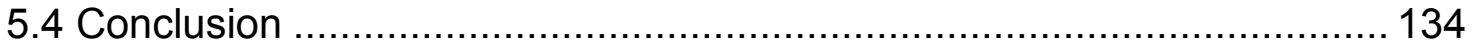

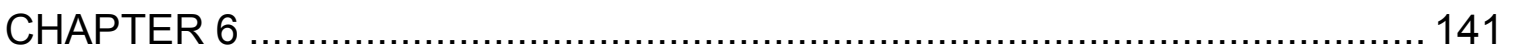

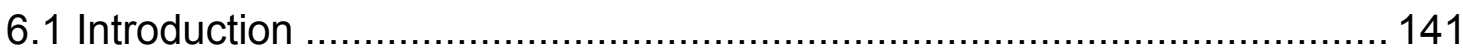

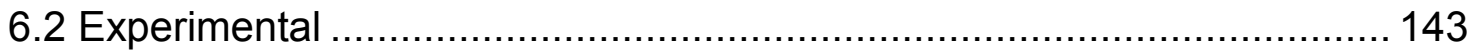

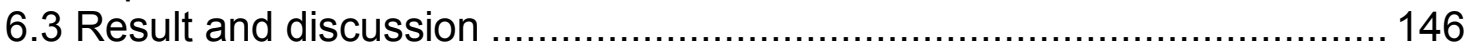

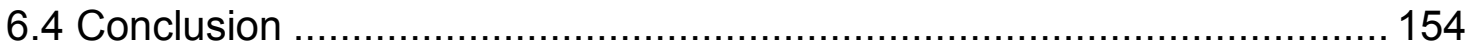

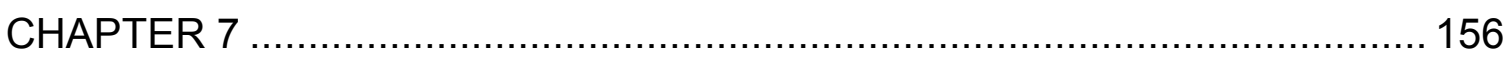

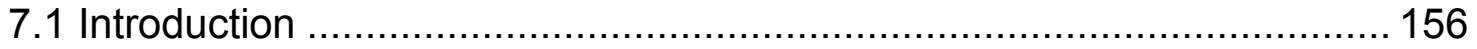

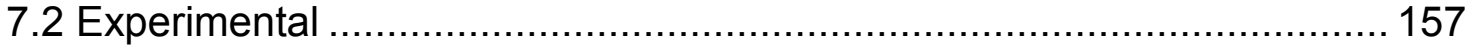

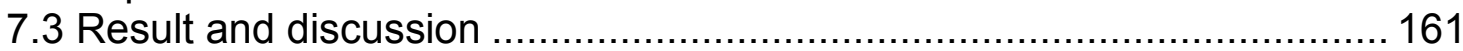

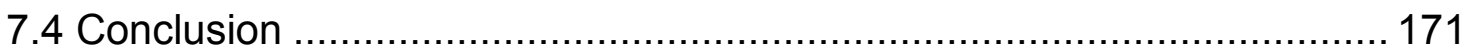

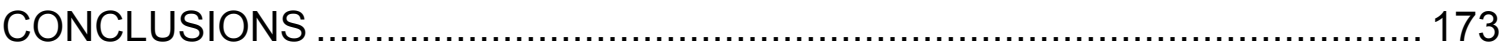

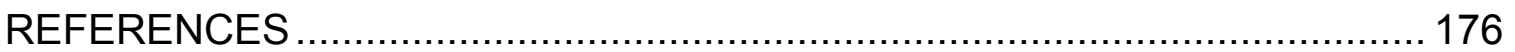

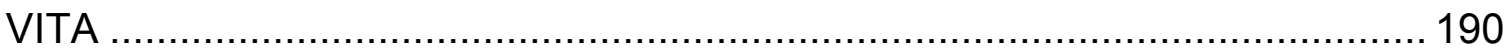




\section{LIST OF FIGURES}

FIGURE

PAGE

Figure 1. Possible sources and pathways for the occurrence of PPCPs residues in the environment

Figure 2. Typical analysis procedure for aqueous and solid samples................. 6

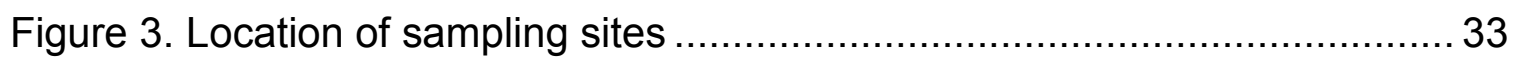

Figure 4. Recovery of PPCPs when extraction at different $\mathrm{pH} \ldots \ldots \ldots \ldots \ldots \ldots \ldots \ldots . . . . . . . . . . .37$

Figure 5. Concentrations and frequencies of detection of selected

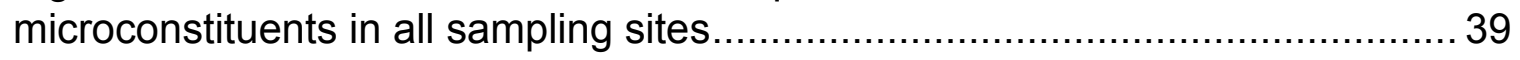

Figure 6. Map showing the distribution of average concentrations................... 45

Figure 7. Sampling sites of sediment and soil ............................................ 56

Figure 8. Sample preparation procedure for sediments and soils....................57

Figure 9. Recoveries of analytes in sodium sulfate, pre-extracted sediment and

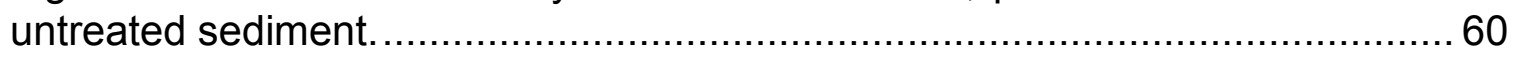

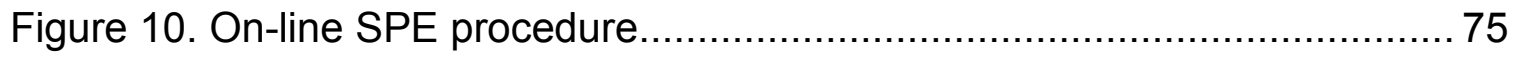

Figure 11. Recovery of analytes during the washing step after loading............. 86

Figure 12. MDLs of pharmaceuticals for all ionization mechanisms tested ........ 88

Figure 13. MDLs of hormones for all ionization mechanisms tested.................. 89

Figure 14. MDLs of sterols and sterones for all ionization mechanisms tested .. 91

Figure 15. MDLs of analytes in negative mode for all ionization mechanisms

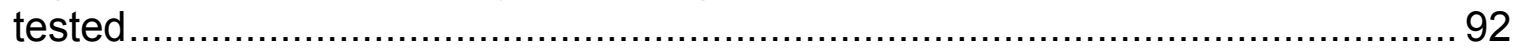

Figure 16. Recovery of analytes at different spike levels ............................... 96

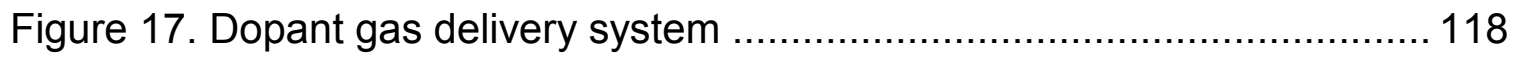


Figure 18a. Absolute recovery of analytes at different load speeds in the positive mode 120

Figure 18b. Absolute recovery of analytes at different load speeds in the negative mode 121

Figure 19a. Absolute recovery of analytes in positive mode with different wash volume 122

Figure 19b. Absolute recovery of analytes in negative mode with different wash volume..... 123

Figure 20. Chromatography of compounds in HESI- and APPI+ 126

Figure 21. Number of compounds with MDL in $0-5 \mathrm{ng} / \mathrm{L}, 5-10 \mathrm{ng} / \mathrm{L}$ and $>10 \mathrm{ng} / \mathrm{L}$ in HESI and APPI with toluene as dopant 131

Figure 22. Chromatography of ketoprofen in HESI- and APPI+ 132

Figure 23. Analytes that can be ionized in HESI, APPI or both 134

Figure 24. Detected concentration ranges for all compounds in reclaimed water samples. 147

Figure 25. Maximum concentration and detection frequency of compounds in reclaimed water samples 148

Figure 26. Detection frequency as a percent of different classes in reclaimed water samples 152

Figure 27. Percent of total measured concentration for each group of compounds in reclaimed water samples 153

Figure 28. Map showing the collection sites of drinking water samples. 160

Figure 29. Concentrations of PPCPs in the drinking water samples collected from Miami-Dade County. 163

Figure 30. Maximum concentrations and detection frequencies of PPCPs in drinking water samples 165

Figure 31. Detection frequency as percent of different classes in drinking water samples 166 
Figure 32. Percentage of total concentration of each class in drinking water samples

Figure 33. Distribution of total concentration of analytes in Miami-Dade County 169

Figure 34. Comparison of average concentration of analytes in drinking water samples and reclaimed water samples... 171 


\section{LIST OF TABLES}

TABLE

PAGE

Table 1. Target PPCPs, structure, CAS and intended usage ......................... 29

Table 2. Molecular weight, retention time, quantitation ion and confirmation ion of PPCPs 35

Table 3. Performance data for PPCPs (linearity, method limit of detection, spike level and recovery) 38

Table 4. Description of sampling sites and concentrations of PPCPs 47

Table 5. Name, structure, CAS and intended usage of analytes 53

Table 6. MDLs of PPCPs and hormones in sediment................................. 61

Table 7. Concentrations of PPCPs in reclaimed water, sediment and soil .........62

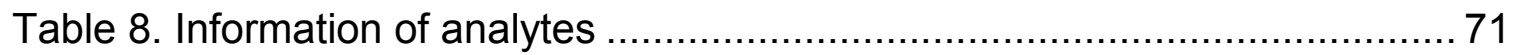

Table 9. Gradient of load pump and analytical pump …............................... 76

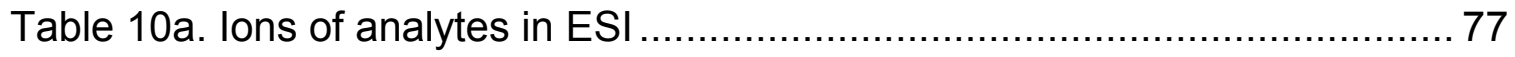

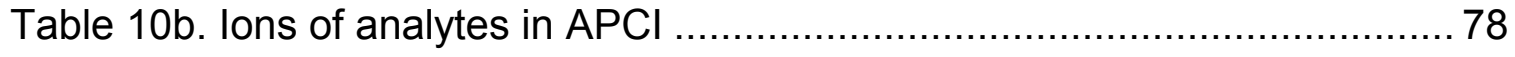

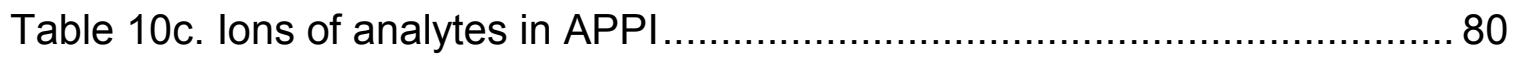

Table 11. Evaluation of the APPI Matrix effect …........................................... 98

Table 12. Calibration range, linearity, spike levels and MDLs ...................... 100

Table 13. Information of pharmaceuticals.................................................. 106

Table 14. Accurate mass and mass spectrometry parameters of analytes ......114

Table 15. Comparison of analyte responses under different ionization conditions 127

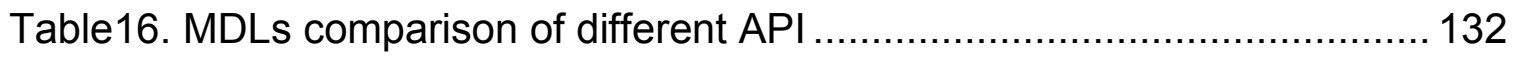

Table 17. Comparison of GC/MS, LC/MS with different ionization sources for analytes 136 
Table 18. Analytes in reclaimed water samples.......................................... 143

Table 19. Sample name, sampling date and location .................................. 158

Table 20. Maximum concentration of analytes detected in Miami-Dade area and other parts of the world (ng/L) .................................................................. 162 


\section{LIST OF ABBREVIATIONS}

ABBREVIATION

$\mathrm{APCl}$

APPI

ASE

BCNP

BNP

BSTFA

CE

$\mathrm{Cl}$

DA

DEET

E1

E2

EDCs

EE2

El

ENP

EPA

EQuan

ESI
FULLNAME

atmospheric pressure chemical ionization atmospheric pressure photoionization accelerated solvent extraction Big Cypress National Preserve Biscayne National Park

N,O-bis- (trimethylsilyl)trifluoroacetamide Capillary electrophoresis Chemical ionization dopant-assisted N,N-Diethyl-3-methylbenzamide Estrone $17 \beta$-estraiol endocrine disrupting compounds

$$
\begin{array}{r}
\text { ethynylestradiol } \\
\text { electron impact } \\
\text { Everglades National Park } \\
\text { Environmental Protection Agency } \\
\text { Environmental Quantitation } \\
\text { electrospray ionization }
\end{array}
$$



lowest observable effect level mass spectrometry polychlorinated biphenyls

$\mathrm{PI}$ positive ionization

PLE pressurized liquid extraction PPCPs Pharmaceuticals and Personal Care Products QqQ Triple quadrupole RRF relative response factor $\mathrm{S} / \mathrm{N}$ signal to noise 
SPME

SPE

SIM

TMCS

TMSI

TOF

UAE

WWTPs solid phase microextraction solid phase extraction selective ion monitoring trimethylchlorosilane trimiethylsilylimidazole time of flight

ultrasonic assisted extraction wastewater treatment plants 


\section{CHAPTER 1}

\section{INTRODUCTION}

\subsection{What are PPCPs?}

Pharmaceuticals and Personal Care Products (PPCPs) are defined as any product used by individuals for personal health or cosmetic reasons or used by agribusiness to enhance growth or health of livestock. Pharmaceuticals and Personal Care Products comprise a diverse collection of thousands of chemical substances, including prescription and nonprescription drugs, veterinary drugs, fragrances, and cosmetics (URL1). Pharmaceuticals and Personal Care Products are a wide variety of important "unrecognized" or "emerging" pollutants in everyday urban activities. The United States Environmental Protection Agency (EPA) defines emerging pollutants as new chemicals without regulatory status and the influence of emerging pollutants on environmental and human health are poorly understood to say the least.

\subsection{Why do we need to monitor them?}

Many pharmaceuticals are not completely eliminated by the human body and often are excreted only slightly transformed or even unchanged (Reddersen et al., 2002). The disposal of unused medication via a household sink or toilet brings pharmaceuticals directly to the wastewater treatment plants (WWTPs) in relatively high concentrations. Several investigations have shown that current wastewater treatment processes (physical and biological) could not remove PPCPs completely from effluents of WWTPs (Ingrand et al., 2003; Esperanza et 
al., 2004; Sui et al., 2010; Lacey et al., 2011; Ryu et al., 2011). The typical rate of removal of analgesics, anti-inflammatories and beta-blockers are $30 \%$ to $40 \%$. The average rate of removal is about $50 \%$ for antibiotics and $71 \%$ for compounds like bisphenol A (Deblonde et al., 2011). More recent research indicates that advanced treatment steps (e.g., ultrafiltation, flocculation, ozonation, advanced oxidation or osmosis) are usually required to increase removal of micropolluants (Fatta-Kassinos et al., 2010). However, these treatment steps are seldom used in the WWTPs because of their high costs. Therefore, the effluents of wastewater treatment plants bring pharmaceuticals to the surface waters when the effluents are discharged into rivers, lakes or oceans. If the effluent is reused for irrigation or landscape, PPCPs may be transferred to soil and enter to surface water through runoff (Heberer et al., 2002). When active recharge is used, PPCPs may also leach into an aquifer and be transported into ground waters, which are potential drinking water sources. That is likely the main reason of why PPCPs are reported in the ground water and drinking water samples. The presence of PPCPs in the ground water may also be caused by the influence of landfill leachates. Meanwhile, large use of veterinary drugs may also cause the occurrence of PPCPs residues in the environment. Figure 1 shows the possible sources and pathways of PPCPs in the environment. 


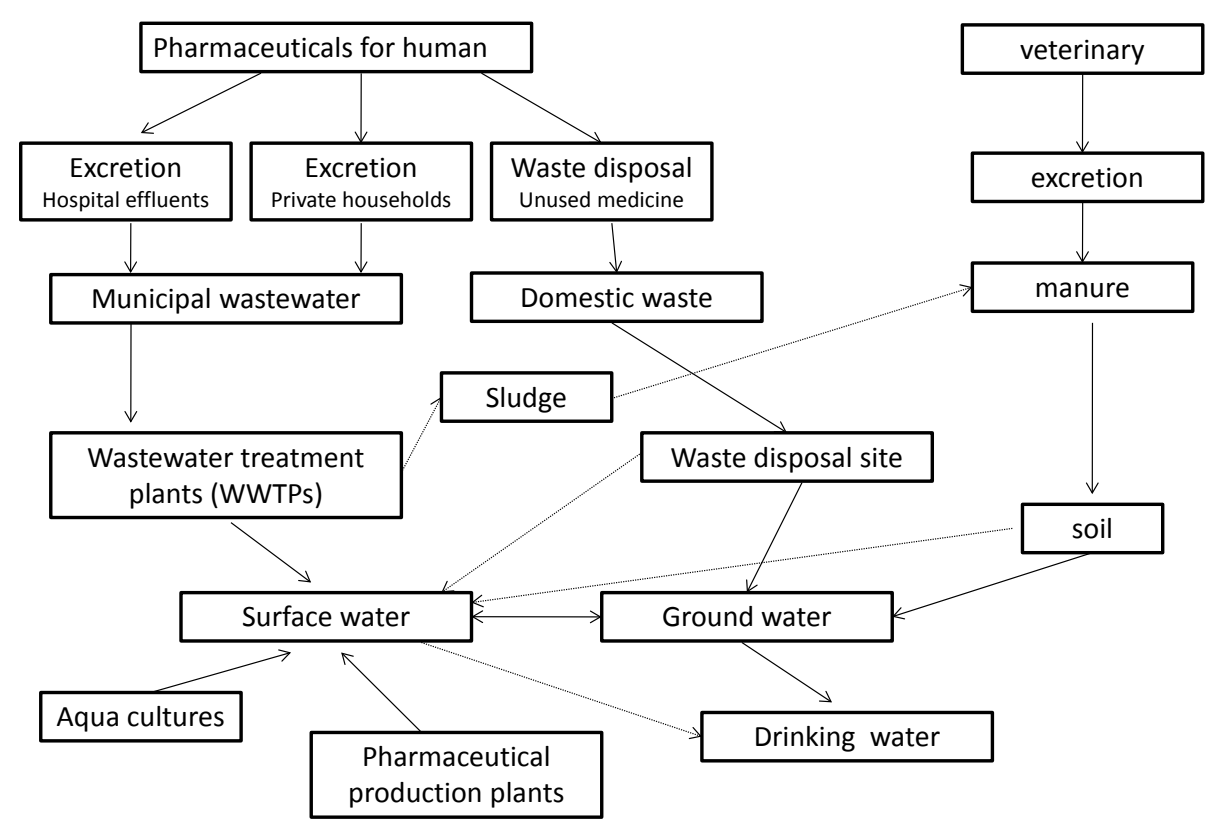

Figure 1. Possible sources and pathways for the occurrence of PPCPs residues in the environment

One issue about PPCPs present in the environment is that the endocrine disrupting effect of some PPCPs may occur even at very low concentration (Caliman and Gavrilescu, 2009). Until now, very little is known about the longterm effect of PPCPs on aquatic organisms. For most human pharmaceuticals, it is unlikely that they will have acute effects on aquatic organisms except for the cases of a direct spill/disposal. However, understanding the chronic effects and toxicity of pharmaceuticals mixtures are more important because many aquatic species are continuously exposed to PPCPs over their entire life cycle. Despite this, there is very little data about chronic effects of pharmaceuticals on the aquatic organisms except for ethynylestradiol (EE2). Ethynylestradiol shows estrogenic effects in many fish at extremely low concentrations. For fathead 
minnows, egg fertilization of female was significantly decreased at extremely low concentration of $0.32 \mathrm{ng} / \mathrm{L}$ ethynylestradiol. For males, demasculinization (decreased male secondary sex characteristic index) happened when males exposed to EE2 at a concentration of $0.96 \mathrm{ng} / \mathrm{L}$ (Parrott and Blunt, 2005). In addition, life exposure of zebrafish to EE2 at a concentration of $0.05 \mathrm{ng} / \mathrm{L}$ caused the secondary sexual characteristics of males to become significantly feminized (Larsen et al., 2008). Very few chronic effect data of analgesics, non-steroid antiinflammatories and beta-blockers are available. Diclofenac was found to have chronic histopathological effects in rainbow trout at a concentration of $5 \mu \mathrm{g} / \mathrm{L}$ (Schwaiger et al., 2004). Propranolol has chronic toxicity for fish not only on the cardiovascular system but also on reproduction. Reproduction of C.dubia and $H$. azteca was affected by propranolol at $250 \mu \mathrm{g} / \mathrm{L}$ and $100 \mu \mathrm{g} / \mathrm{L}$ after 14 days of exposure, respectively (Huggett et al., 2002). Typically toxicity of single compound may show no or only little effects at certain concentration, but mixtures of many pharmaceuticals may have effects at the same concentrations due to synergistic effects. Study on mixtures of NSAID (diclofenac, ibuprofen, naproxen, acetylsalicylic acid) on Daphnia and algae demonstrated the mixture followed the concept of concentration addition (Michael, 2003). Even though the reported lowest observed effect concentrations (LOEC) of PPCPs are usually higher than measured concentrations in the effluent of WWTPs or surface water, monitoring PPCPs in the environment is still an urgent need. The general lack of chronic toxicity data on pharmaceuticals requires not only more investigation about potential ecotoxicological effects such as endocrine disruption, 
immunological status, or gene activation and silencing during long-term exposure but also the development of robust, low-level, selective, high throughput analytical techniques.

Besides aquatic organisms like fish, plants may also be affected, to a lesser extent, by PPCPs when treated wastewater is reused for irrigation. It is not clear the negative effects on plants are from direct damage of PPCPs to plant or from the indirect damage of PPCPs to the soil microorganisms (Sabourin et al., 2009; Matamoros and Salvado, 2012).

Another important issue is the presence of chronic levels of antibiotics in the environment. Presence of antibiotics is often suggested as a potential link to the development of antibiotic-resistant bacteria. The resistant bacteria can be transferred to human via water or food if plants are irrigated by reclaimed water, surface water or sludge with antibiotic-resistant bacteria which have escaped from treatment (Fatta-Kassinos et al., 2010).

\subsection{What are the typical procedures to detect them?}

The two key challenges for the detection of emerging microconstituents is interference from complex matrices and the relatively low concentration of analytes in the environment. However, with the development of sophisticated and sensitive analytical protocol, such as more efficient extraction techniques and 
more sensitive detectors, trace level PPCPs can be detected in the environment. Typical analysis procedure for aqueous and solid samples is shown in figure 2 .

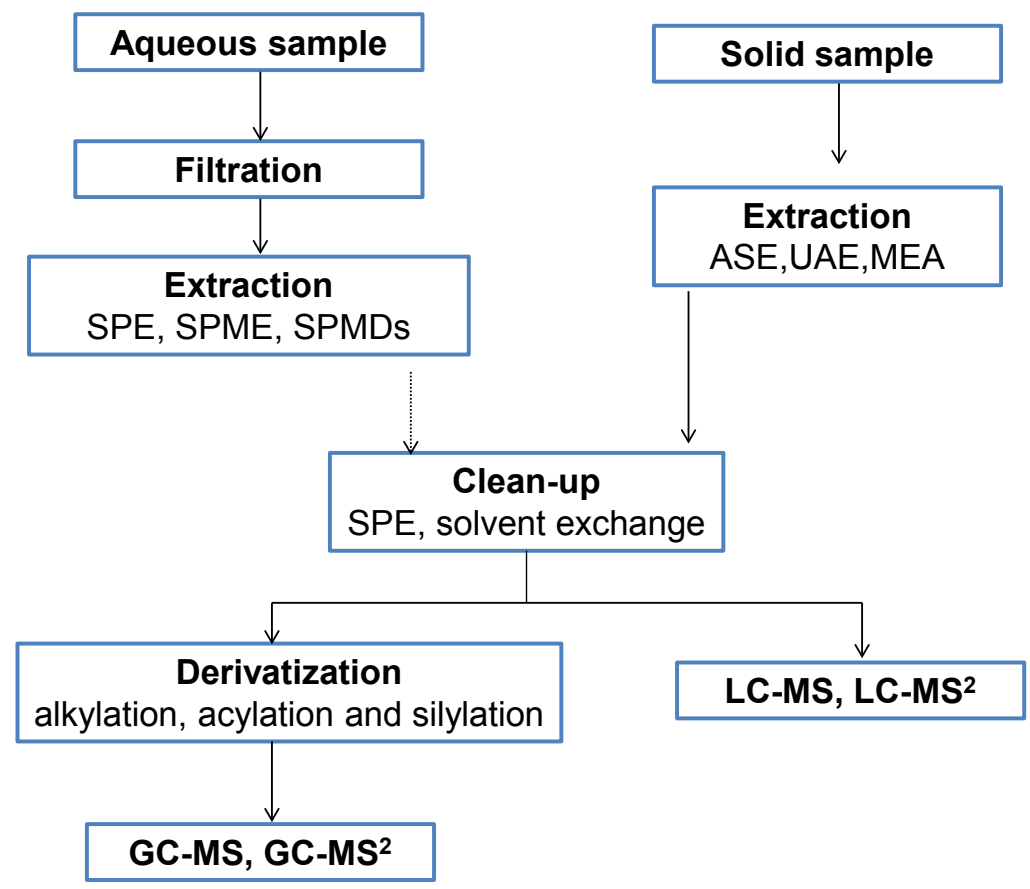

Figure 2. Typical analysis procedure for aqueous and solid samples

\subsubsection{Sample preparation for aqueous samples}

Currently, available extraction techniques for aqueous samples (e.g., tap water, surface water and wastewater) include Liquid-liquid extraction (LLE) (Zafra et al., 2003), solid phase extraction (SPE) (Zaharie, 2006; Gómez et al., 2007; Gros et al., 2009) and solid phase microextraction (SPME) (Pablo Lamas et al., 2004) etc. Solid phase extraction is the most widely used extraction method. Solid phase extraction cartridge sorbents include non-polar phase, ion-exchange phase and polymeric phase. Among them, the Oasis HLB (Waters Corp, HydrophilicLipophilic Balanced phase) cartridge is able to extract both polar and nonpolar 
analytes under the same conditions and improve simultaneous detection of analytes with markedly different chemical properties. In order to increase the capacity of multiple-residues extraction, several researches started to use tandem or serial mixed-mode cartridges to increase analyte recoveries (Gros et al., 2009; Laven et al., 2009). The development of on-line SPE simplifies the extraction procedure and reduces the sample preparation time. Therefore, more and more studies begin to focus on on-line SPE method development (Segura et al., 2007; Garcia-Ac et al., 2009; Lopez-Serna et al., 2010). Because of the repeated use of the SPE mini-cartridges, development of on-line methods require many additional optimization of parameters, such as sample size, the sample loading flow, and wash step, but the additional work is clearly offset by the gain in processing speed as a result of the system automation.

Solid phase microextraction is another extraction technique that starts to attract interest for the analysis of many organic compounds in aqueous samples. Solid phase microextraction extracts target compounds from sample to an absorptive layer of sorbent coated on a fiber. The quantity of target compounds extracted is proportional to the concentration of target compounds in the sample. After extraction, the fiber can be transferred to the injection port of GC, where desorption happens and analysis starts. The advantage of SPME is solvent free and very simple sample preparation (Carballa et al., 2004; Pablo Lamas et al., 2004; Fatta-Kassinos et al., 2010). However, the use of SPME is still limited by the fiber activation and cleanup steps and is much more difficult to automate. 


\subsubsection{Sample preparation for solid samples}

For solid matrices (e.g., soils, sediments, sludge and fish tissues), accelerated solvent extraction (ASE) or pressurized liquid extraction (PLE), ultrasonic assisted extraction (UAE) and microwave-assisted extraction (MEA) have been used to enhance extraction efficiency (Löffler and Ternes, 2003; Burkhardt et al., 2005; Xu et al., 2008; Jelic et al., 2009; Vazquez-Roig et al., 2010). Usually SPE is used as a clean-up step after the extraction mentioned above to reduce the interference from environmental samples due to the complexity of matrices.

\subsection{Instrumental detection}

Detection and quantification of PPCPs in the environment were a big challenge several years ago because of the complexity of matrices and PPCPs' low concentration of occurrence. Currently, gas chromatography (GC), coupled with mass spectrometry (MS) and high performance liquid chromatography (HPLC), coupled with MS, provide the opportunity to detect PPCPs down to extremely low concentrations in the $\mathrm{ng} / \mathrm{L}$ (parts per trillion) range. The choice of GC or HPLC depends on the chemical properties of the target compounds. Generally, GC is appropriate for identification and quantification of volatile or volatizable compounds, while HPLC is used to determine more polar and less volatile compounds. For the investigation of PPCPs in the environment, GC-MS, GCMS $^{2}$, LC-MS, LC-MS ${ }^{2}$ have become indispensable tools. Capillary electrophoresis (CE) also is used to analyze pharmaceuticals and personal care products. However, CE without preconcentration can only reach concentrations 
in the $\mu \mathrm{g} / \mathrm{L}$ range limiting its application. Therefore, GC or LC coupled with MS is still the primary tools for analysis of PPCPs in the environment.

\subsubsection{GC-MS and GC-MS ${ }^{2}$}

The use of GC-MS to determine PPCPs in the environment started in the nineteen seventies (Garrison et al., 1976). Nowadays, GC-MS and GC-MS ${ }^{2}$ are still the most widely used techniques because of their availability in environmental laboratories. The major advantage of GC coupled with MS is that the ionization modes like electron impact $(\mathrm{EI})$ or chemical ionization $(\mathrm{Cl})$ are generally less affected by the sample matrix than electrospray ionization (ESI), the main ionization mode used for liquid chromatography mass spectrometry.

A derivatization step is usually needed for highly-polar, thermally-fragile compounds to make them suitable for GC analysis. Usually, GC-MS analysis after derivatization is an effective alternative to liquid chromatography mass spectrometry. Derivatization is usually done by substitution on the polar functional group and the most common reactions are alkylation, acylation and silylation (Shareef et al., 2006; Schummer et al., 2009). The largest limitation to this approach is the derivatization step itself. The efficiency of derivatization is influenced by the derivatizing agent and solvent, reaction temperature and reaction time. These parameters need to be optimized to increase the signal to noise $(\mathrm{S} / \mathrm{N})$ for analytes. The most commonly used derivatization technique is silylation, and common reagents include trimethylchlorosilane (TMCS), 
trimiethylsilylimidazole (TMSI), N-methyl-trimethylsilyltrifluoroacetamide (MSTFA), $\mathrm{N}, \mathrm{O}-$ bis-(trimethylsilyl)trifluoroacetamide (BSTFA) and $\mathrm{N}$-(t-butyldimethylsilyl)-Nmethyltrifluoroacetamide (MTBSTFA), where the last two are the most frequently reported in the analysis of PPCPs (Boyd et al., 2003; Rice and Mitra, 2007; Xu et al., 2008; Durán-Alvarez et al., 2009).

The column used to separate PPCPs in GC analysis includes DB5, DB5-MS, HP5-MS and their equivalents. The dimension of the column is usually $30 \mathrm{~m} \times$ $0.25 \mathrm{~mm} \times 0.25 \mu \mathrm{m}$ and longer columns or thicker film phases can be used to improve the separation of PPCPs. Normal injection volume is 1-2 $\mu \mathrm{L}$. While large volume injection has been reported to decrease the method detection limits (MDLs) of GC analysis the introduction of co-extractants and residues from the derivatizing agents do compromise the column integrity so its use is not widespread. Typical temperature program is from $50{ }^{\circ} \mathrm{C}$ to $300{ }^{\circ} \mathrm{C}$ with a run time of 30 - 45 mins (Boyd et al., 2003; Zafra et al., 2003; Weigel et al., 2004; Gibson et al., 2007; Gómez et al., 2007).

Most of the publications focused on El with $-70 \mathrm{eV}$ standard ionization energy. Electrons are continuously emitted from a heated filament $\left(200-280{ }^{\circ} \mathrm{C}\right)$ and collide with analytes that elute from the end of the GC column. Qualification analysis of PPCPs and their metabolites can be achieved by full-scan mass spectra with the help of computer libraries, which have thousands of standard mass spectra. Quantification analysis is usually achieved by compounds 
molecular ions and fragment ions in selective ion monitoring (SIM). Selective ion monitoring improves sensitivity of target compounds by only acquiring data of target compounds with no attempt to acquire data of non-target compounds (Boyd et al., 2003; Zafra et al., 2003; Weigel et al., 2004; Lishman et al., 2006; Gibson et al., 2007).

Gas chromatography tandem mass spectrometry is able to achieve excellent selectivity and sensitivity by suppression of matrix backgrounds. The $\mathrm{MS}^{2}$ experiment can be implemented by ion-trap and triple-quadrupole mass analyzers. The precursor ions are selected and the fragmentations are optimized to obtain the best $\mathrm{S} / \mathrm{N}$ ratio. Therefore, $\mathrm{MS}^{2}$ has been used for the detection of trace level analytes present in complex matrices like wastewater, sediment and sludge (Verenitch et al., 2006; Gómez et al., 2007).

\subsubsection{LC-MS and LC-MS ${ }^{2}$}

Although MS has the ability to simultaneously identify target compounds, LC separation is still needed, especially for isomeric chemicals. Reversed-phase analytical columns are most commonly used to separate pharmaceuticals and personal care products. The typical particle size of analytical columns is between $1.9 \mu \mathrm{m}$ and $3 \mu \mathrm{m}$. The organic mobile phase includes methanol, acetonitrile or a combination of these two solvents, while the aqueous phase is water with the addition of formic acid, acetic acid, ammonium hydroxide, ammonium formate or ammonium acetate to adjust $\mathrm{pH}$. 


\subsubsection{Ionization techniques}

High performance liquid chromatography mass spectrometry has been shown as a valuable alternative for detection of PPCPs and EDCs to overcome the drawbacks of GC-MS (Gardinali and Zhao, 2002; Gentili et al., 2002; Ingrand et al., 2003; Cahill et al., 2004; Castiglioni et al., 2005; Schlüsener and Bester, 2005; Martnez Bueno et al., 2007; Gros et al., 2009; Laven et al., 2009; Huerta-Fontela et al., 2010; Jian-lin et al., 2010). Electrospray ionization (ESI), atmospheric pressure chemical ionization (APCl) and atmospheric pressure photoionization (APPI) are the three most common ionization techniques coupled with liquid chromatography (Marchi et al., 2009). Electrospray ionization dominates the field of environmental analysis at trace level because of its simplicity and versatility.

Electrospray ionization and atmospheric pressure chemical ionization have both been widely used for analysis of polar molecules in the aqueous environmental samples in many studies (Cahill et al., 2004; Castiglioni et al., 2005; Gros et al., 2009). Several studies that described multi-target detection of up to 74 compounds by ESI have been recently published in the literature (Gros et al., 2009; Lopez-Serna et al., 2010). However, ESI and APCI also have many critical limitations. For example, some steroids, and generally nonpolar compounds, such as PAHs, are poorly ionized or cannot be ionized by ESI or APCI (Hanold et al., 2004). Therefore, it is not surprising that most of the studies using ESI are focused on the most polar, easily ionizable pharmaceuticals. Only a handful of studies have tried to detect steroid hormones that are difficult to ionize by ESI or 
APCl with marginal results (Jeannot et al., 2002; Ingrand et al., 2003). Not surprisingly, there is abundant literature for compounds ameanable to ESI but reports are scarce for those that present an ionization challenge. The critical issue is that the most EDC active compounds are not well ionized by electrospray ionization.

Atmospheric pressure photoionization is based on the interaction of a photon beam created by a discharge lamp with the vapors of a nebulized liquid solution (Marchi et al., 2009). Atmospheric pressure photoionization is a technique that has the capability to ionize compounds with a wide range of polarities while being remarkably tolerant of matrix components of HPLC additives. The rapidly growing number of publications in this area clearly demonstrates the advantages of atmospheric pressure photoionization (Raffaelli and Saba, 2003; Bos et al., 2006; Marchi et al., 2009). At the beginning, APPI was introduced as a complement of ESI and APCI. So far, APPI has been proved to be a valuable tool for analytes which are poorly ionized or not ionized by ESI and APCI. In particular APPI was shown to be able to detect steroid hormones down to several $\mathrm{ng} / \mathrm{L}$ and had been proven to have much higher sensitivity than ESI. (Yamamoto et al., 2006; Viglino et al., 2008). Atmospheric pressure photoionization is the ionization of choice for PAHs and showed results comparable to gas chromatography mass spectrometry (Itoh et al., 2006; Cai et al., 2009). Indeed, APPI not only gives superior performance on nonpolar compounds but also works great for analytes which are out of the reach of ESI and APCI. Cai et al. demonstrated that APPI 
could be considered as a universal ionization method since APPI was able to ionize more compounds, with greater structural diversity, than ESI and APCI (Cai et al., 2005). Because of APPl's capacity to ionize compounds with various polarities, it has been increasingly applied in the environmental and pharmaceutical areas.

\subsubsection{Detection techniques}

In single quadrupole MS, SIM is the mode used for qualitative and quantitative analysis of target compounds (Cahill et al., 2004). Compared with MS, $\mathrm{MS}^{2}$ can reduce more interference from matrix. The unique ability of ion trap-MS (IT-MS) for $\mathrm{MS}^{\mathrm{n}}$ makes it an ideal tool in identification of analytes of interest (Ingrand et al., 2003) but because of its space-charge limitations is not generally used for quantitation. Triple quadrupole $(\mathrm{QqQ})$ is the most frequently used $\mathrm{MS}^{2}$ detector in the muti-residue analysis of pharmaceuticals and EDCs in the environmental samples (Trenholm et al., 2008). For quantitative analysis, QqQ is excellent, but qualitative information, which is needed for structure identification, is lost. The drawback of $\mathrm{QqQ}$ can be overcome by using triple quadrupole time of flight (QqTOF) or quadrupole linear iontrap (QqLIT). Triple quadrupole time of flight is appropriate for identification of unknown compounds or metabolites due to its ability of providing exact mass. Quadrupole linear iontrap is excellent for both due to the unique capabilities of linear ion traps. LIT can run in two different modes, acting as the classical triple quadruple scan or sensitive ion trap scan. However, QqTOF and QqLIT are not widely available in environmental analysis 
so far due to their extremely high cost. Only a few papers reported on their application for trace lever determination of emerging contaminants (Gros et al., 2009; Laven et al., 2009; Huerta-Fontela et al., 2010).

\subsection{What is the concentration and fate of PPCPs in the environment?}

With the development of sensitive detection techniques, a wealth of information about the occurrence of PPCPs in the complex environment samples have been produced in the last decade (Verenitch et al., 2006; Gómez et al., 2007; DuránAlvarez et al., 2009; Xu et al., 2009). Pharmaceutical and personal care products have been documented in almost every water resource around the world. Pharmaceutical and personal care products are generally divided into several groups based on their mode of action including anti-inflammatory/analgesics, lipid regulators, $\mathrm{H}_{2}$-receptor antagonists, betablockers, personal care products and hormones.

\subsubsection{Anti-inflammatory/ analgesics}

Pharmaceuticals in this section are primarily used as painkillers. The most prominent drugs of this group are aspirin, ibuprofen and naproxen. Large amounts of painkillers are sold without prescription as "over-the-counter" (OTC) drugs. Because of the diversity of manufacturers it is hard to estimate the amount of OTC drugs sold worldwide. Acetaminophen (paracetamol) is one of the most frequently used OTC painkillers all over the world. About 140 tons of acetaminophen was dispensed in Wales (Kasprzyk-Hordern et al., 2008) and 
more than 500 tons were sold in Germany (Thomas, 2002). In the investigation of 139 surface streams in the U.S., acetaminophen was detected in $23.8 \%$ of samples at a maximum concentration of 10,000 $\mathrm{ng} / \mathrm{L}$ (Kolpin et al., 2002). Acetaminophen is easily degraded and removed by WWTPs but it was still frequently detected in the environmental samples because its large usage. For example groundwater samples collected from 18 states from the USA, showed maximum concentration of acetaminophen of $380 \mathrm{ng} / \mathrm{L}$ (Barnes et al., 2008). Acetaminophen was even detected in drinking water in France at concentrations as high as of $210 \mathrm{ng} / \mathrm{L}$ (Mompelat et al., 2009).

Ibuprofen is also a popular painkiller. Ibuprofen was detected in $50 \%$ of samples from UK estuaries at the maximal concentration of $928 \mathrm{ng} / \mathrm{L}$ and the median concentration of $48 \mathrm{ng} / \mathrm{L}$. It was detected in 139 streams in the U.S. at the maximum concentration of $1000 \mathrm{ng} / \mathrm{L}$ with $9.5 \%$ detection frequency. The high concentration of ibuprofen in surface water is not surprising because it has been reported at a high concentration in effluents of wastewater treatment plants. The high concentration of ibuprofen WWTP effluents is because of a combination of the high usage and low degree of human metabolism. In the WWTPs, ibuprofen was detected at concentrations from 14.3 to $22,700 \mathrm{ng} / \mathrm{L}$ in the influent and from 30 to $12,600 \mathrm{ng} / \mathrm{L}$ in the effluent of WWTPs, respectively (Deblonde et al., 2011). Ibuprofen has also been detected in drinking water with maximal concentrations of $3.0 \mathrm{ng} / \mathrm{L}, 0.6 \mathrm{ng} / \mathrm{L}, 8.5 \mathrm{ng} / \mathrm{L}$ and $1350 \mathrm{ng} / \mathrm{L}$ in Germany, France, Finland and the USA, respectively (Mompelat et al., 2009). 
Other than these compounds mentioned above, naproxen, diclofenac, indomethacine, ketoprofen are also in high demand and were also widely reported in the wastewaters and surface waters (Mompelat et al., 2009; Deblonde et al., 2011).

\subsubsection{Lipid regulators}

Clofibric acid, the active metabolite of the blood regulator clofibrate, has been widely reported in the effluents of WWTPs and has a removal rate of $40 \%$ (Metcalfe et al., 2003; Deblonde et al., 2011). Clofibric acid has been reported in surface waters at concentrations of $100 \mathrm{ng} / \mathrm{L}$ in UK estuaries (Thomas and Hilton, 2004) and 0.4-18 ng/L in the river samples from Ebro River Basin (Gros et al., 2009). In tap water, clofibric acid was reported up to $270 \mathrm{ng} / \mathrm{L}$ in distribution systems in Germany (Mompelat et al., 2009).

The metabolites of fenofibrate-gemfibrozil, bezafibrate and fenofibric acidhave been routinely detected up to $\mu \mathrm{g} / \mathrm{L}$ in WWTPs effluents and surface waters (Thomas, 2002; Metcalfe et al., 2003; Kim et al., 2007; Deblonde et al., 2011). In drinking water, gemfibrozil was detected up to $70 \mathrm{ng} / \mathrm{L}$ in Canada (Mompelat et al., 2009).

\subsubsection{Antidepressants and anticonvulsants}

Antidepressants are a psychiatric medication used to alleviate mood disorders. Fluoxetine is a widely used antidepressant. Although the relative removal of 
fluoxetine is higher than other pharmaceuticals ( 98\%) (Deblonde et al., 2011), fluoxetine was still reported in many surface water and groundwater samples. In national reconnaissance of the USA, the maximum concentration of fluoxetine in streams, groundwater and sources of drinking water were $12 \mathrm{ng} / \mathrm{L}, 56 \mathrm{ng} / \mathrm{L}$ and ND, respectively (Kolpin et al., 2002; Barnes et al., 2008; Focazio et al., 2008).

Anticonvulsants are used in the treatment of epileptic seizures. Carbamazepine is one the most frequently detected anticonvulsants in wastewater, surface waters and drinking water. Because of its environmental stability carbamazepine is one of the most commonly detected PPCPs in surface waters worldwide. In WWTPs, the mean concentrations of carbamazepine in the influent and effluent were $732 \mathrm{ng} / \mathrm{L}$ and $774 \mathrm{ng} / \mathrm{L}$, respectively, which indicated that carbamazepine had an extremely low removal rate in WWTPs (Deblonde et al., 2011). The concentrations of carbamazepine had been detected up to $1075 \mathrm{ng} / \mathrm{L}$ in surface waters in Germany (Heberer et al., 2002). Carbamazepine has even been detected in ground waters and drinking waters because of its persistence. The maximal concentrations of carbamazepine detected in drinking water were 24 ng/L, $258 \mathrm{ng} / \mathrm{L}, 43.2 \mathrm{ng} / \mathrm{L}$ and $60 \mathrm{ng} / \mathrm{L}$ in Canada, France, Germany and the USA, respectively (Mompelat et al., 2009).

\subsubsection{H2-receptor antagonists}

The function of $\mathrm{H} 2$ receptor antagonists is to block the action of histamine on parietal cells in the stomach. Cimetidine, ranitidine, famotidine and nizatidine are 
the available OCT H2 receptor antagonists in the USA. Ranitidine was detected in streams in the USA at a maximum concentration of $10 \mathrm{ng} / \mathrm{L}$ with the detection frequency of $1.2 \%$ (Kolpin et al., 2002). In surface water in South Wales, concentrations of ranitidine were reported up to $8 \mathrm{ng} / \mathrm{L}$ (Kasprzyk-Hordern et al., 2008). Until now, ranitidine was not detected in groundwater or sources of drinking water in national reconnaissance in the United States (Barnes et al., 2008; Focazio et al., 2008).

\subsubsection{Betablockers}

Betablockers are used to manage cardiac dysrhythmia, cardioprotection after heart attack and hypertension. Betablockers are not very widely studied in wastewater. Concentration of metoprolol and propranolol in the influent of WWTPs ranged from 20 to $4900 \mathrm{ng} / \mathrm{L}$ and 36 to $510 \mathrm{ng} / \mathrm{L}$, respectively. In the effluent of WWTPs the concentration of metoprolol and propranolol ranged from 19 to $1700 \mathrm{ng} / \mathrm{L}$ and 30 to $180 \mathrm{ng} / \mathrm{L}$, respectively. The removal rate was about $60 \%$ (Deblonde et al., 2011). Propranolol was detected up to $56 \mathrm{ng} / \mathrm{L}$ in UK estuaries in $40 \%$ of the samples (Thomas and Hilton, 2004). Kasprzyk-Hordern's study suggests that betablockers, like atenolol, propranolol and metoprolol, are very persistent in the aqueous environment because they were present in $100 \%$ of the samples collected downstream from a wastewater discharge point and showing very small decreases in concentration with distance from the wastewater discharge point (Kasprzyk-Hordern et al., 2008). 


\subsubsection{Industrial chemicals and personal care products}

Bisphenol $A$ is used to make polycarbonate polymers and epoxy resins, which are used to make plastic along with other materials. Over six million tons of bisphenol A are produced worldwide each year (Welshons et al., 2006). The concentration of bisphenol A ranged from 88 to $11800 \mathrm{ng} / \mathrm{L}$ in the influent of wastewater treatment plants. With the removal rate of $71 \%$, the concentration of bisphenol A was between 6 and $4090 \mathrm{ng} / \mathrm{L}$ in the effluent (Deblonde et al., 2011). Because of the incomplete removal of bisphenol A in the WWTPs, it also been detected in surface waters, ground waters and drinking waters. Bisphenol A was detected in $41.2 \%$ of samples collected from 139 streams in the USA and the maximum concentration was $12000 \mathrm{ng} / \mathrm{L}$ (Kolpin et al., 2002). In the groundwater in the USA, bisphenol A was detected up to $2550 \mathrm{ng} / \mathrm{L}$ with $29.8 \%$ detection frequency (Barnes et al., 2008). In the Australia, bisphenol A was detected up to $600 \mathrm{ng} / \mathrm{L}$ in surface water and $930 \mathrm{ng} / \mathrm{L}$ in groundwater. Water samples were collected from 27 surface water sites and 59 groundwater sites all across Australia (Hohenblum et al., 2004).

Personal care products are used for beautification and in personal hygiene. Triclosan is an antimicrobial disinfectant. Triclosan was detected up to $2300 \mathrm{ng} / \mathrm{L}$ with a very high detection frequency $(57.6 \%)$ in streams in the United States (Kolpin et al., 2002). The removal rate of triclosan was $76.8 \%$ (Deblonde et al., 2011) and the incomplete removal of triclosan from effluents brought triclosan to the surface waters or even the drinking water. Triclosan's maximum 
concentrations were $95 \mathrm{ng} / \mathrm{L}$ in South Wales' river water (Kasprzyk-Hordern et al., 2008) and $56.7 \mathrm{ng} / \mathrm{L}$ in Romania's river water (Zaharie, 2006). Triclosan was detected in drinking water sample in the USA with the maximal concentration of 734 ng/L (Mompelat et al., 2009).

\subsubsection{Hormones}

A hormone is a chemical released by a cell or a gland in one part of the body, which can affect cells of other parts of the body by triggering chemically induced messages. Hormones, which can behave as endocrine disruptors in the environment, may induce unexpected effect in no-mammalian organism in the aqueous environment, such as algae, invertebrate and fish. Disturbance of reproductive system and hormone system, immune depression, neurobehavioral changes may have effects on the population level (Fent et al., 2006). Estrone (E1), 17ß-estradiol (E2) and ethynylestradiol (EE2) are the three hormones that have been studied most. The natural and environmental concentrations of hormones are lower than many other pharmaceuticals, but we still need to pay attention to them because they have endocrine disrupting effect at the $\mathrm{ng} / \mathrm{L}$ level. A study of WWTPs located at Galicia, Spain showed that the concentration of E2 in the influent was $3 \mathrm{ng} / \mathrm{L}$ and in the effluent of plant the concentration was below detection limit (1 $\mathrm{ng} / \mathrm{L})$. The overall removal rate of E2 in WWTPs was around $65 \%$, but E2 is usually converted to E1 during secondary treatment (conventional activated sludge) (Carballa et al., 2004), which explains why sometimes E1 was detected at a higher concentration in the effluent of WWTPs than E2 (Kim et al., 
2007; Ryu et al., 2011). Estrone was detected in the surface water and ground water up to $4.6 \mathrm{ng} / \mathrm{L}$ and $1.6 \mathrm{ng} / \mathrm{L}$, respectively, in Australia (Hohenblum et al., 2004). In the study of U.S. drinking water, the maximum concentrations of E1, E2 and E3 were $0.9 \mathrm{ng} / \mathrm{L}, 17 \mathrm{ng} / \mathrm{L}$ and $1.4 \mathrm{ng} / \mathrm{L}$ in the source water, respectively. But none of them were above the detection limit $(0.2 \mathrm{ng} / \mathrm{L}, 0.5 \mathrm{ng} / \mathrm{L}$ and $1.0 \mathrm{ng} / \mathrm{L}$, respectively) in the finished water (Benotti et al., 2009).

\subsection{Control of PPCPs pollution}

More efforts need to be made to decrease the pollution in the environment with PPCPs. Several methods, including segregation of source, improvement of the disposal system for expired medicines, application of the pharmaceutical return program and the development of "green" pharmaceuticals, can be used to prevent the release of PPCPs into the environment. Source segregation can be an effective way to prevent pharmaceuticals from entering the environment. Wastewater from hospitals can be separated from domestic wastewater and advanced treatment can be applied to wastewater form hospitals to remove pharmaceutical and personal care products. Presently, most of the expired medicines are disposed of via sinks or toilets, ending up in WWTPs or household waste ending up in landfill sites. The US federal prescription drug-disposal guidelines (2007) allow flushing certain drugs if it is safe, but suggests returning unused, unneeded, or expired medicines to pharmaceutical take-back locations for safe disposal (URL2). Development of "green" pharmaceuticals requires more efforts and time but would be an effective way to increase the rapid removal of 
PPCPs from the environment. Keeping in mind that these compounds are produced with an intended biological effect, in the absence of good data describing their ecological effects caution should be exerted to prevent their chronic release into environmental systems. Because of the lack of an environmental regulatory framework continued efforts to document their occurrence is still the best approach to keep the discussion going. The work presented here is a step in that direction and provides a set of tools and findings to advance the knowledge on the environmental occurrence of these chemicals in sensitive areas in South Florida. Water resources in Florida are under persistent stress due to the continued expansion of the urban population, the constant changes of land use and the competition for good quality water between the human population and ecosystem sustainability.

\subsection{Objectives}

The overall objective of this study is to monitor the PPCPs and hormones in reclaimed waters, surface waters, drinking waters, sediments and soils in South Florida in order to provide a general overview of the quality of these resources.

In order to accomplish this task, specific aims include to:

- Develop a GC-MS method for the detection of PPCPs and hormones in surface waters, sediments and soils.

- Because GC-MS systems are still the most widely used instrument in environmental labs. A sensitive GC-MS method is still valuable 
for the analysis of PPCPs in the environment samples. (Chapters 2 and 3)

- Develop a fully automated, high throughput online SPE-LC-MS/MS method for the detection of PPCPs and hormones in different water matrices to avoid sample preparation.

- The online SPE method simplified sample preparation procedure and increased the productivity of analysis. Tandem MS enhanced both the selectivity and sensitivity. The online SPE-LC-MS/MS method largely increased the efficiency of analysis compared to GC-MS method. (Chapters 4 and 5)

- Compare different ionization sources including HESI, APCI and APPI on the ionization efficiency for PPCPs and hormones and produce a single, yet comprehensive method for the analysis of multiple compounds at environmentally relevant concentrations. (Chapters 4 and 5 )

- Assess the occurrence of the target compounds in surface, reclaimed and drinking waters in South Florida and provide information regarding the present state of the quality of water resources with respect to PPCPs.

- A better understanding of distributions of PPCPs in South Florida can be achieved by analyzing the results from surface water samples. By analyzing reclaimed water, more information will be 
provided about the potential effects of water reuse. Results from drinking water samples will offer information about current water quality in South Florida and the implications for system integrity. (Chapters 6 and 7 ) 


\section{CHAPTER 2}

\section{Detection of PPCPs and hormones in aqueous samples using GC-MS}

\subsection{Introduction}

The wide spread occurrence of pharmaceuticals and personal care products (PPCPs) and endocrine disrupting compounds (EDCs) have shifted the attention of environmental and toxicological research beyond traditional environmental pollutants, such as polychlorinated biphenyls (PCBs), dioxins, and pesticides.

Pharmaceuticals and personal care products are continuously released into the environment in vast quantities from many sources but in general municipal wastewater has been recognized as one of the main routes bringing human pharmaceuticals into the environment. Traditional wastewater treatment processes, such as aerated lagoons, conventional activated sludge and filtration, do not completely remove drugs and estrogens from their effluents (Lishman et al., 2006; Verenitch et al., 2006; Gibson et al., 2007; Gros et al., 2009). Many PPCPs and hormones have been detected in the effluent of wastewater treatment plants (WWTPs) (Boyd et al., 2003; Gibson et al., 2007) as well as in the receiving surface water (Kolpin et al., 2002). The residue of hormones can have adverse effects on organisms in the environment at very low concentrations (1-10 ng/L). These endocrine disrupting compounds (EDCs) can influence the endocrine system under long-term chronic exposure. Synthetic estrogens such as mestranol and ethynylestradiol (EE2) have the lowest observable effect level (LOEL) on the order of $1 \mathrm{ng} / \mathrm{L}$ (Christiansen, 2002). Concentrations above LOEL 
have already been found in surface water (Kolpin et al., 2002) and current data suggests that hormones can travel considerable distance from the source of pollution (Barel-Cohen et al., 2006). Therefore, it is essential to monitor concentrations of PPCPs and EDCs in the aquatic environment at trace levels to provide adequate risk evaluation.

The most common difficulties for the detection of PPCPs are low occurrence concentration levels $(\mu \mathrm{g} / \mathrm{L}$ or $\mathrm{ng} / \mathrm{L})$, which requires highly sensitive instruments and the interference coextraction of environment samples, which made it very difficult to identify and quantify target compounds. Therefore, proper clean-up procedures are required during sample preparation. In addition, there is a need for detection of diverse PPCPs in a single run. Therefore, this chapter reviews simultaneous detection of PPCPs in the environment.

The analysis of trace level contamination in environmental samples can be achieved by sophisticated analytical techniques such as liquid chromatography (LC) coupled to tandem mass spectrometry (MS/MS). Ionization sources such as electrospray ionization (ESI) and atmospheric chemical ionization (APCI) that are coupled to LC can ionize polar and non-volatile compounds (Kolpin et al., 2002; Cahill et al., 2004). The high selectivity of tandem mass allows simple sample preparation of complex matrix samples such as wastewater (Ingrand et al., 2003; Vanderford et al., 2003; Weigel et al., 2004; Castiglioni et al., 2005; Verenitch et al., 2006; Gómez et al., 2007; Gros et al., 2009). However, those sophisticated 
analytical techniques are still not as common as GC-MS because of their high cost. In addition, certain steroids such as coprostan-3-ol and coprostanone, are very hard to be ionized in ESI or APCl. Gas chromatography mass spectrometry is still a very useful common technique to simultaneously detect trace level hormones and PPCPs in the environment, despite the fact that GC-MS may require an extra derivatization step during sample preparation (Kolpin et al., 2002; Boyd et al., 2003; Weigel et al., 2004; Lishman et al., 2006; Gibson et al., 2007).

In my study, I developed a reliable method to simultaneously detect 20 PPCPs in surface water using liquid-liquid extraction followed by GC-MS analysis. I detected 20 PPCPs of different properties in a single run. The method was used to detect compounds in water samples from Big Cypress National Preserve, Everglades National Park and Biscayne National Park in south Florida in order to understand the current status with respect to PPCPs occurrence and potential sources. The research investigates the influence of human activities on the surface waters from national parks and provides information on overall water quality in South Florida.

\subsection{Experimental}

\subsubsection{Chemicals}

Caffeine was purchased from Fisher Scientific (Suwannee, GA, USA). N,NDiethyl-3-methylbenzamide (DEET), 4-nonylphenol, triclosan, bisphenol A, androsterone, 17a-estradiol, estrone, equilin, 17ß-estradiol, testosterone, 17a- 
ethynylestradiol, coprostane, progesterone, estriol, coprostan-3-ol, coprostan-3one and cholesterol were purchased as solids from Sigma and Aldrich (St. Louis, MO, USA). Mestranol and equilenin were purchased as a certified standard solution from Dr. Ehrenstorfer (Augsburg, Germany). Caffeine $-{ }^{13} \mathrm{C}_{3}$ used as surrogate was purchased from Cambridge Isotope Laboratories, Inc (Andover, MA, USA). Deuterated 17 $\beta$-estradiol (17 $\beta$-estradiol-d5), bisphenol A (bisphenol A-d16), estrone (estrone-d4) and progesterone (progesterone-d9) were purchased from CDN Isotopes (Pointe-Claire, Quebec, Canada). All the reference standards were $>95 \%$ purity. Detailed information of selected PPCPs is shown in table 1. Intermediate solutions were prepared at concentrations of 200 ppm in methanol and stored in the dark below $4^{\circ} \mathrm{C}$. All laboratory materials were either made of glass or Teflon to avoid contamination. Glassware used in extraction was cleaned with soap and rinsed with DI water and combustion took place at $450{ }^{\circ} \mathrm{C}$ for at least six hours. Teflon materials were rinsed with methanol, acetone, methylene chloride and hexane before use.

Table 1. Target PPCPs, structure, CAS and intended usage

Nonylphenol




\begin{tabular}{|c|c|c|c|}
\hline Name & Structure & CAS & Use \\
\hline Triclosan & & $3380-34-5$ & antibiotic \\
\hline Bisphenol A & & $80-05-7$ & Polymer additive \\
\hline Androsterone & & $53-41-8$ & androgen \\
\hline 17a-estradiol & & $57-91-0$ & estrogen \\
\hline Estrone & & $53-16-7$ & estrogen \\
\hline Equilin & & $474-86-2$ & $\begin{array}{l}\text { Estrogen } \\
\text { replacement }\end{array}$ \\
\hline $17 \beta$-estradiol & & $50-28-2$ & estrogen \\
\hline Testosterone & & $58-22-0$ & androgen \\
\hline Mestranol & & $72-33-3$ & $\begin{array}{l}\text { Ovulation } \\
\text { inhibitor }\end{array}$ \\
\hline Equilenin & & $517-09-9$ & $\begin{array}{l}\text { Estrogen } \\
\text { replacement }\end{array}$ \\
\hline
\end{tabular}




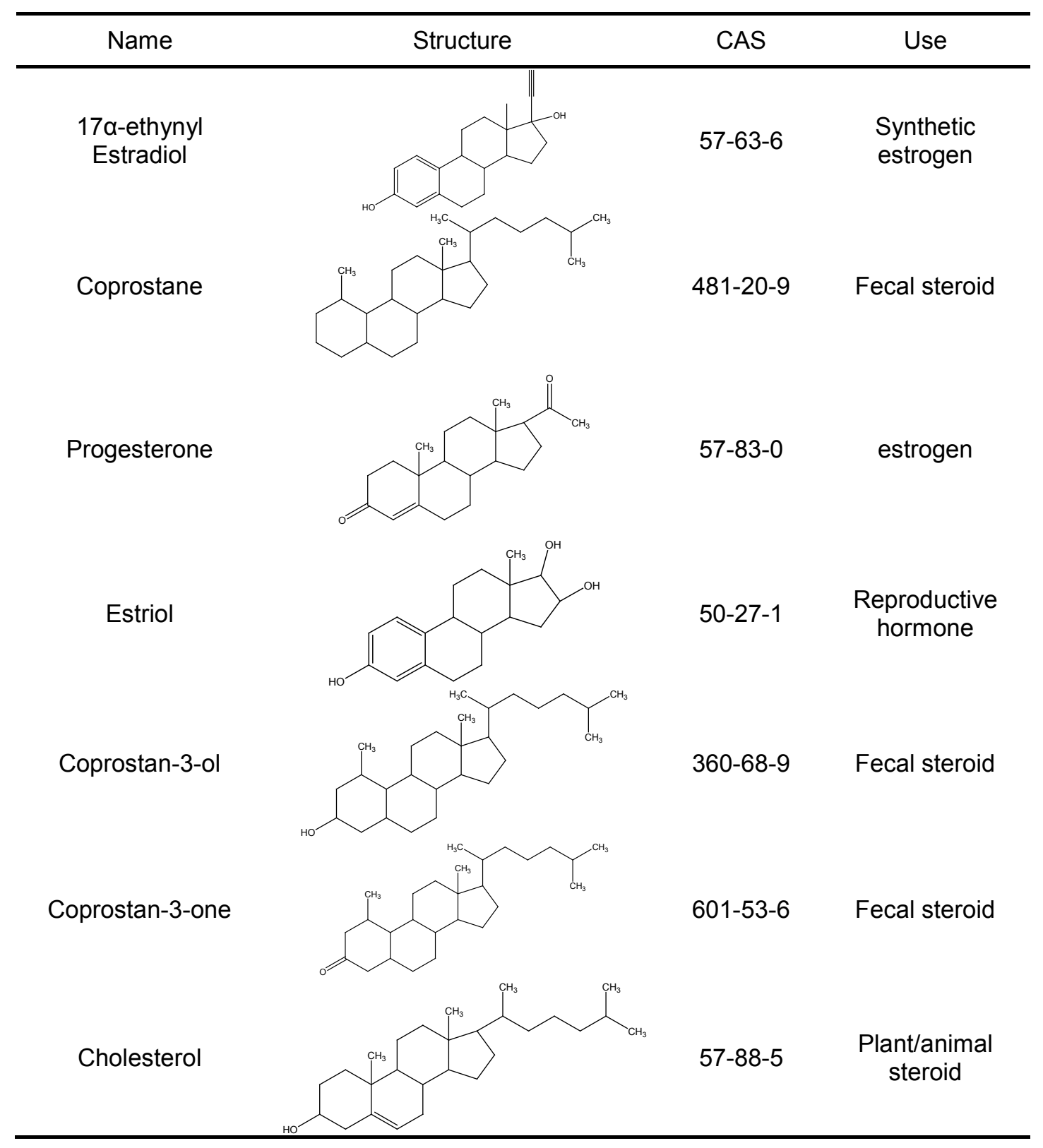

\subsubsection{Sample collection and sample treatment}

Samples were collected from three different protected areas in South Florida, Big Cypress National Preserve (BCNP), Everglades National Park (ENP) and Biscayne National Park (BNP). The sampling sites are shown in figure 3. Soap, beverages, sun screen, repellent, caffeinated drinks and pharmaceuticals were 
not allowed to be used during sampling to minimize potential contamination of samples. Water samples were collected in previously combusted glass bottles to avoid contamination. Samples were filtered through $0.45 \mu \mathrm{m}$ before being transferred into separatory funnels. The walls of the glass bottles were rinsed with methylene chloride to guarantee that all analytes were transferred into the separatory funnels.

\subsubsection{Extraction method}

Each $1 \mathrm{~L}$ water sample was extracted by liquid-liquid extraction (LLE) using a separatory funnel equipped with Teflon cap and stopper. Samples were fortified with surrogate standards (caffeine- ${ }^{13} \mathrm{C}_{3}$, bisphenol A-d16, estrone-d4, 17ßestradiol-d5 and progesterone-d9) and extracted three times using $50 \mathrm{~mL}$ methylene chloride. All the organic layers were dried over anhydrous sodium sulfate and collected in a $250 \mathrm{~mL}$ flat-bottom round flask. Extracts were evaporated to about $10 \mathrm{~mL}$ in a water bath at $65^{\circ} \mathrm{C}$, transferred to concentration tubes, concentrated to $1 \mathrm{~mL}$ under nitrogen gas, transferred into $1.5 \mathrm{~mL}$ amber vial and brought to dryness using nitrogen gas.

\subsubsection{Silylation method}

$\mathrm{N}, \mathrm{O}-$ bis(trimethysilyl)trifluoroacetamide (BSTFA) $(100 \mu \mathrm{L})$ was added to each amber vial and samples were heated at $60{ }^{\circ} \mathrm{C}$ for $45 \mathrm{~min}$ in the $\mathrm{GC}$ oven. Internal standard (chrysene-d12) working solution $(100 \mu \mathrm{L})$ was added to the sample extracts before injection to gas chromatography mass spectrometry. 


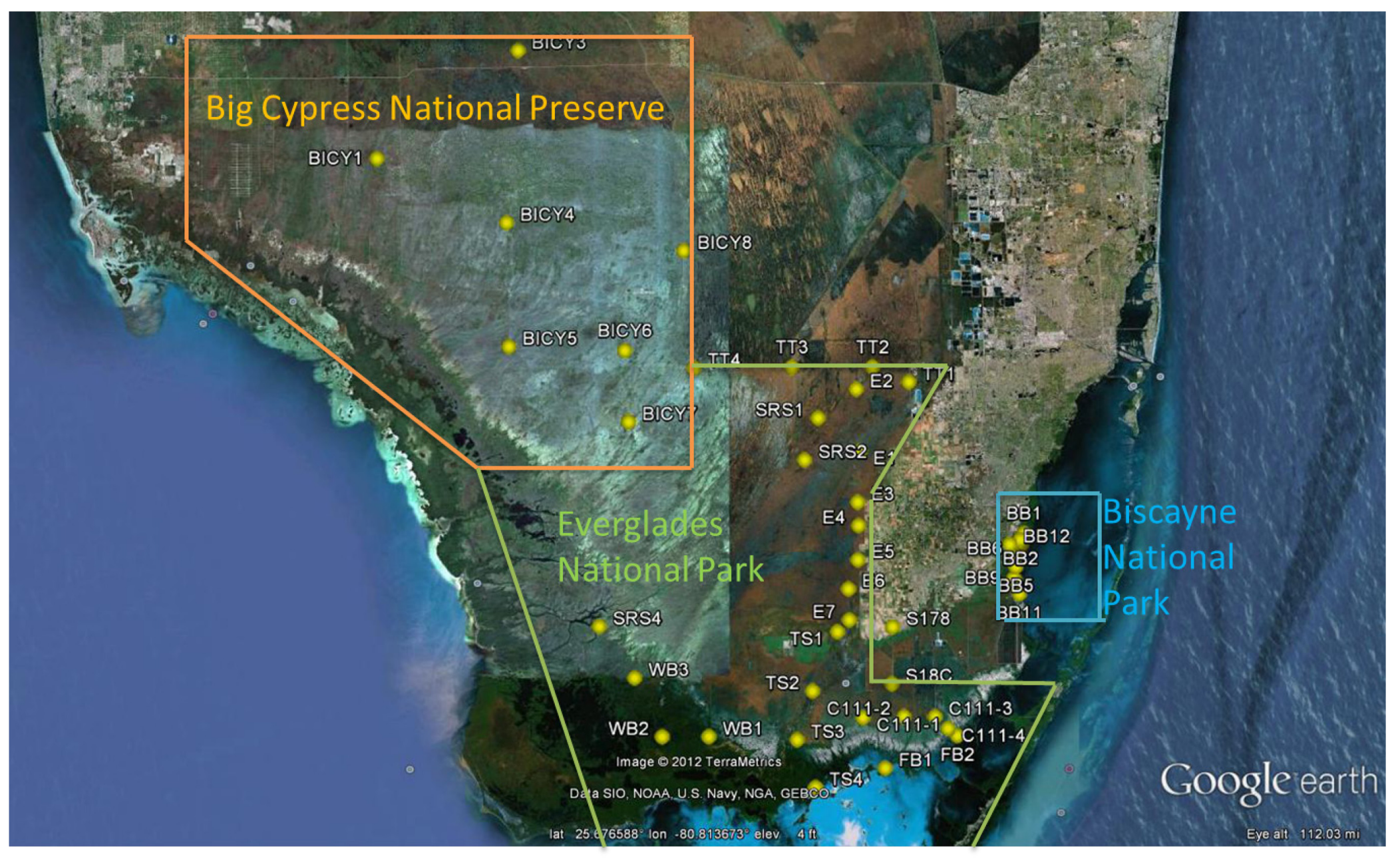

Figure 3. Location of sampling sites 


\subsubsection{GC-MS analysis}

All the chromatographic measurements were performed using a Thermo GC/MS system comprised of a Finnigan Trace GC Ultra fitted with an autosampler AS 3000 and a Finnigan Trace DSQ operated in an El at $70 \mathrm{eV}$. Derivatized sample extracts $(2 \mu \mathrm{L})$ were injected into a DB-5MS column $(30 \mathrm{~m}$ with $0.5 \mu \mathrm{m}$ film thickness and $0.25 \mathrm{~mm}$ I.D.) under the splitless mode. The helium flow rate was held constant at $1.2 \mathrm{~mL} / \mathrm{min}$ and the $\mathrm{GC}$ oven was programmed from $85^{\circ} \mathrm{C}(1$ min hold) at a rate of $15{ }^{\circ} \mathrm{C} / \mathrm{min}$ to $270{ }^{\circ} \mathrm{C}(1 \mathrm{~min}$ hold $)$, then at a rate of $5^{\circ} \mathrm{C}$ Imin to $300{ }^{\circ} \mathrm{C}(10$ mins hold $)$. The transfer line was $280{ }^{\circ} \mathrm{C}$. The MS operated in EI mode using selected ion monitoring (SIM) to enhance sensitivity.

\subsubsection{Quantification}

Quantification of target compounds was accomplished by isotope dilution. The target compound was identified by retention time and ions (usually one quantitation ion and one or two confirmation ions). The quantitation ion and confirmation ion of target compounds are shown in table 2 . The ion ratio was monitored to distinguish the matrix interference from the target compounds. In each sequence of samples, relative response factor (RRF) was calculated by calibration solutions. Seven calibration solutions with concentration of target compounds representing $5 \mathrm{ng} / \mathrm{L}$ to $1000 \mathrm{ng} / \mathrm{L}$ were run before samples. A continuous calibration check was also performed after each set of samples to assure the instrument's stability through the run. 
Table 2. Molecular weight, retention time, quantitation ion and confirmation ion of PPCPs

\begin{tabular}{|c|c|c|c|c|c|c|}
\hline Name & type & $\begin{array}{c}\text { Molecular } \\
\text { weight }\end{array}$ & $\begin{array}{c}\mathrm{RT} \\
(\mathrm{min})\end{array}$ & $\begin{array}{l}\text { Quantitati } \\
\text { on ion }\end{array}$ & $\begin{array}{l}\text { Confirm } \\
\text { ation ion }\end{array}$ & $\begin{array}{l}\text { Confirmat } \\
\text { ion ion }\end{array}$ \\
\hline DEET & Analyte & 191.27 & 14.33 & 190 & 191 & 119 \\
\hline Caffeine $-{ }^{13} \mathrm{C}_{3}$ & Surrogate & 197.21 & 17.51 & 197 & 196 & 198 \\
\hline Caffeine & Analyte & 194.19 & 17.51 & 194 & 195 & 109 \\
\hline Nonylphenol & Analyte & 220.3 & 18.08 & 292 & 179 & 180 \\
\hline Triclosan & Analyte & 289.54 & 20.72 & 360 & 347 & 345 \\
\hline Bisphenol A- $d_{16}$ & Surrogate & 244.38 & 21.55 & 368 & 386 & \\
\hline Bisphenol A & Analyte & 228.29 & 21.67 & 357 & 358 & 372 \\
\hline Chrysene-d ${ }_{12}$ & $\begin{array}{l}\text { Internal } \\
\text { standard }\end{array}$ & 240.37 & 26.26 & 240 & 239 & 236 \\
\hline Androsterone & Analyte & 290.00 & 26.50 & 272 & 271 & 347 \\
\hline 17a-estradiol & Analyte & 272.38 & 28.21 & 416 & 285 & \\
\hline Estrone- $d_{4}$ & Surrogate & 274.39 & 28.35 & 346 & 347 & 261 \\
\hline Estrone & Analyte & 270.37 & 28.41 & 342 & 218 & 257 \\
\hline Equilin & Analyte & 268.35 & 28.55 & 340 & 341 & 242 \\
\hline $17 \beta$-estradiol- $\mathrm{d}_{5}$ & Surrogate & 277.42 & 28.78 & 421 & 422 & 287 \\
\hline $17 \beta$-estradiol & Analyte & 272.38 & 28.83 & 416 & 285 & \\
\hline Testosterone & Analyte & 288.42 & 29.23 & 270 & 360 & 226 \\
\hline Mestranol & Analyte & 310.43 & 29.73 & 227 & 242 & 367 \\
\hline Equilenin & Analyte & 266.33 & 29.83 & 338 & 339 & 295 \\
\hline $\begin{array}{c}\text { 17a-ethynyl } \\
\text { estradiol }\end{array}$ & Analyte & 296.4 & 30.48 & 425 & 426 & 285 \\
\hline Coprostane & Analyte & 372.67 & 31.06 & 217 & 218 & 357 \\
\hline Progesterone- $d_{9}$ & Surrogate & 323.52 & 31.50 & 323 & 324 & 279 \\
\hline Progesterone & Analyte & 314.46 & 31.70 & 314 & 272 & 229 \\
\hline Estriol & Analyte & 288.38 & 31.75 & 311 & 345 & 504 \\
\hline Coprostan-3-ol & Analyte & 388.67 & 35.32 & 370 & 355 & 371 \\
\hline Coprostan-3-one & Analyte & 386.65 & 37.33 & 231 & 232 & 386 \\
\hline Cholesterol & Analyte & 386.65 & 37.55 & 329 & 368 & 458 \\
\hline
\end{tabular}




\subsection{Results and discussion}

\subsubsection{Method development and validation}

\subsubsection{1 $\mathrm{pH}$ range experiment}

The $\mathrm{pH}$ is an important factor that affects the recovery of analytes when analytes with different functional groups are presented in the sample. Compounds in neutral form are more willing to partition to the organic phase, while in their ionized form they prefer to stay in the aqueous phase. The $\mathrm{pH}$ was adjusted to $3.0,6.0$ and 10 to assess recoveries across the $\mathrm{pH}$ range. Recoveries of target analytes are shown in Figure 4. Recovery did not differ significantly at different $\mathrm{pH}$ values expect for androsterone, equilin, testosterone, and coprostan-3-ol, whose recoveries were lower at $\mathrm{pH}=10$. Therefore, $\mathrm{pH}$ was not adjusted for the real samples. Additionally, there were many advantages of doing extraction at natural $\mathrm{pH}$ : (1) It simplified sample handling: no extra steps were required to remove acid or base; (2) The $\mathrm{pH}$ is amenable to the derivatization step; (3) It eliminated the risk of acidic hydrolysis of susceptible analytes during sample preparation. 


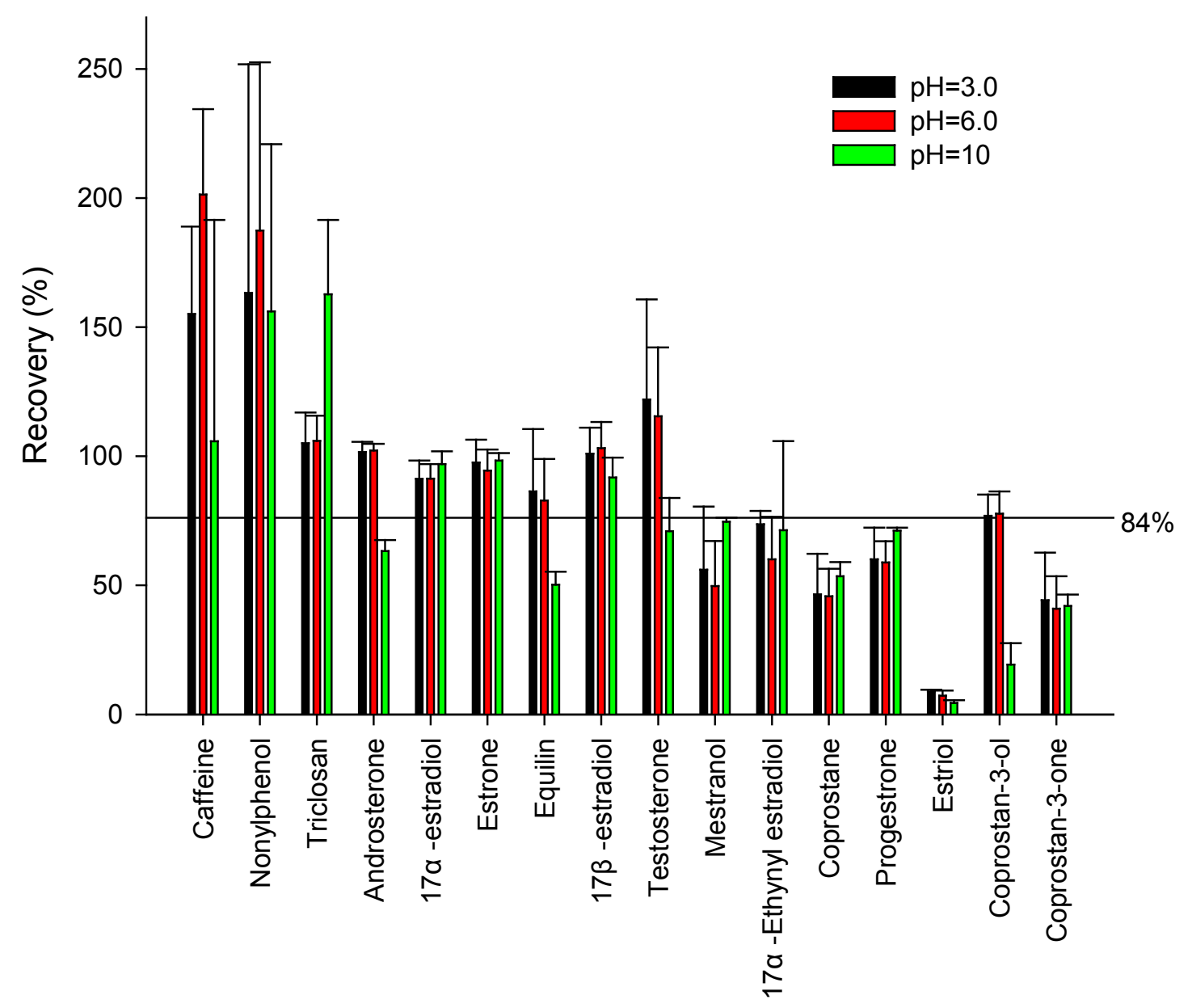

Figure 4. Recovery of PPCPs when extraction at different $\mathrm{pH}$

\subsubsection{Method validation}

Batch quality assurance and quality control included a method blank, a fortified blank, one matrix spike sample and one duplicate sample per set of 20 samples or less analysis. Recoveries of the matrix spike were consistent between analytes. The duplicate sample agreed within $30 \%$ of target compounds except for cholesterol. Method detection limits (MDLs) are shown in table 3. Analytes 
were spiked in DI water at environmental concentrations ranging from $2.00 \mathrm{ng} / \mathrm{L}$ to $20.0 \mathrm{ng} / \mathrm{L}$ ) and MDLs were between $0.14 \mathrm{ng} / \mathrm{L}$ and $2.61 \mathrm{ng} / \mathrm{L}$, respectively. The average recovery of analtyes was $79 \%$.

Table 3. Performance data for PPCPs (linearity, method limit of detection, spike level and recovery)

\begin{tabular}{|c|c|c|c|c|c|c|}
\hline Analyte & Surrogate & RRF & $\mathrm{R}^{2}$ & $\begin{array}{l}\text { Spike } \\
\text { level } \\
\text { (ng/L) }\end{array}$ & $\begin{array}{l}\text { MDL } \\
\text { (ng/L) }\end{array}$ & $\begin{array}{c}\text { Recovery } \\
(\%)\end{array}$ \\
\hline DEET & Caffeine $-{ }^{13} \mathrm{C}_{3}$ & 0.7251 & 0.9744 & 2.00 & 0.24 & 87 \\
\hline Caffeine & Caffeine $-{ }^{13} \mathrm{C}_{3}$ & 1.0351 & 0.9990 & 2.00 & 2.61 & 96 \\
\hline Nonylphenol & Bisphenol A-d16 & 0.2575 & 0.9980 & 2.00 & 0.47 & 67 \\
\hline Triclosan & Bisphenol A-d16 & 0.0918 & 0.9973 & 2.00 & 1.20 & 145 \\
\hline Bisphenol A & Bisphenol A-d16 & 1.3781 & 0.9986 & 2.00 & 1.46 & 89 \\
\hline Androsterone & Estrone-d4 & 0.5796 & 0.9973 & 2.00 & 0.21 & 107 \\
\hline $17 \alpha$-estradiol & $17 \beta$-Estradiol-d5 & 1.0726 & 0.9999 & 2.00 & 0.14 & 90 \\
\hline Estrone & Estrone-d4 & 1.5556 & 0.9964 & 2.00 & 0.22 & 81 \\
\hline Equilin & Estrone-d4 & 0.6110 & 0.9975 & 2.00 & 1.09 & 60 \\
\hline $17 \beta$-estradiol & $17 \beta$-Estradiol-d5 & 1.1809 & 0.9999 & 2.00 & 0.18 & 93 \\
\hline Testosterone & Estrone-d4 & 0.0526 & 0.9989 & 4.00 & 0.37 & 64 \\
\hline Mestranol & Estrone-d4 & 0.2421 & 0.9914 & 4.00 & 2.00 & 107 \\
\hline Equilenin & Estrone-d4 & 1.6533 & 0.9963 & 2.00 & 0.33 & 56 \\
\hline 17a-ethynylestradiol & $17 \beta$-Estradiol-d5 & 0.2845 & 0.9964 & 4.00 & 0.65 & 94 \\
\hline Coprostane & Progesterone-d9 & 1.5742 & 0.9994 & 8.00 & 0.48 & 85 \\
\hline Progesterone & Progesterone-d9 & 2.4044 & 0.9953 & 8.00 & 0.41 & 83 \\
\hline Estriol & $17 \beta$-Estradiol-d5 & 0.3663 & 0.9957 & 2.00 & 0.29 & $10^{\mathrm{b}}$ \\
\hline Coprostan-3-ol & Estrone-d4 & 1.0304 & 0.9944 & 4.00 & 0.51 & $45^{\mathrm{b}}$ \\
\hline Coprostan-3-one & Progesterone-d9 & 0.6814 & 0.9974 & 8.00 & 1.45 & 60 \\
\hline Cholesterol & Estrone-d4 & 0.5336 & 0.9962 & $a$ & 150 & 63 \\
\hline
\end{tabular}

RRF- relative response factor

$\mathrm{R}^{2}$-coefficient of determination of a linear regression

MDL- method detection limit

a MDL was set at $150 \mathrm{n} / \mathrm{L}$ because cholesterol is a common contamination on the glassware $b$ recovery of estriol is low because of no proper surrogate for it. 


\subsubsection{Analysis of real samples}

The method was successfully applied to 80 samples from surface water collected from three protected areas in South Florida. The detailed description of the sampling sites and the concentrations of PPCPs are summarized in table 4 . Detection frequencies and concentrations of PPCPs are shown in figure 5.

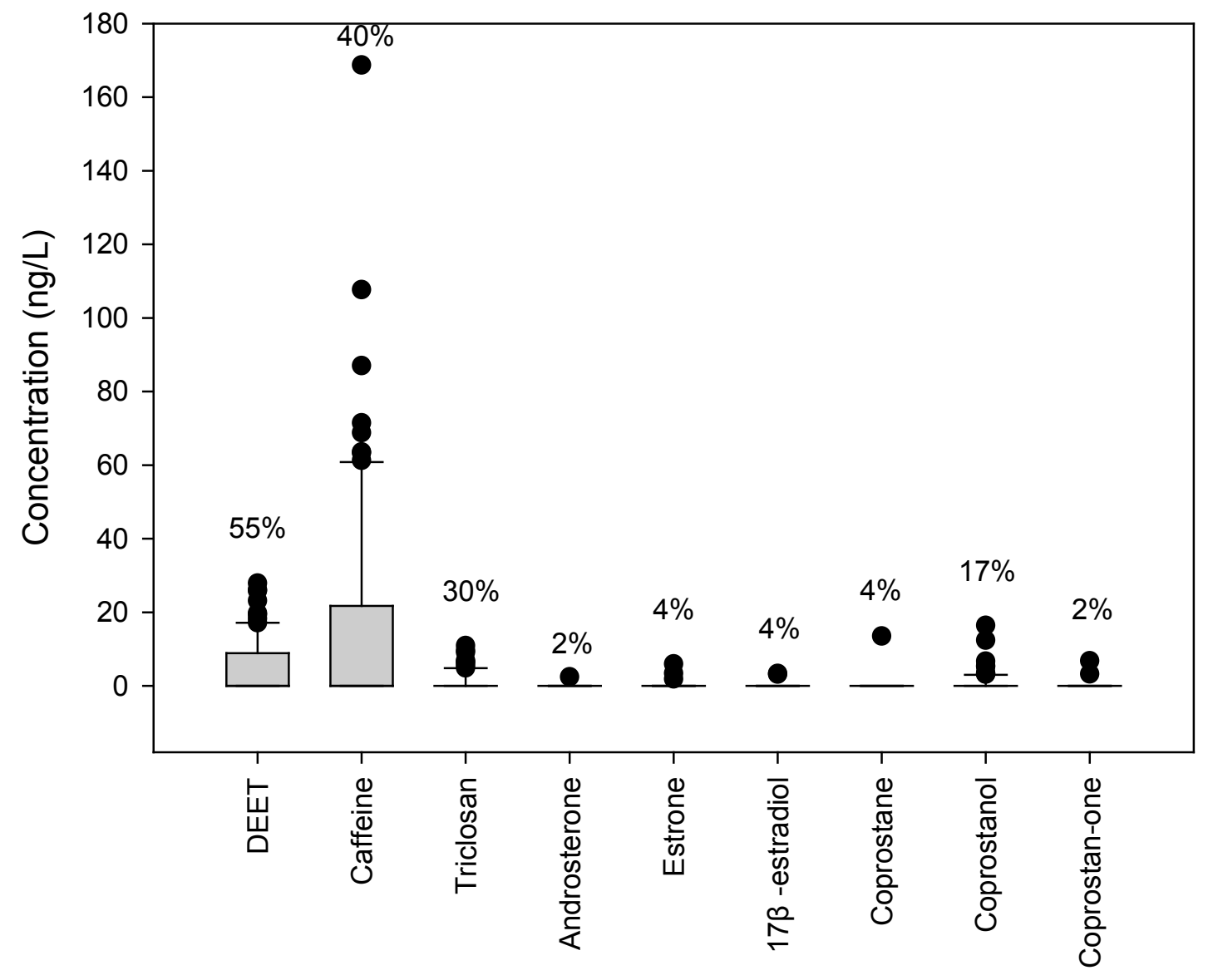

Figure 5. Concentrations and frequencies of detection of selected microconstituents in all sampling sites 
DEET was detected in $55 \%$ of sampling sites with concentrations ranging from ND to $27.9 \mathrm{ng} / \mathrm{L}$. DEET is the most common active ingredient in insect repellents. On the basis of the 1990-1999 estimates, approximately four to seven million pounds of DEET are used every year in the U.S. (Cahill et al., 2004). Therefore, it is not surprising that DEET is the most frequently detected pollutant in ground water in the United States (Barnes et al., 2008). Concentrations as high as 1100 ng/L have been reported for U.S. streams (Kolpin et al., 2002). Nevertheless, concentrations of DEET are usually related to recreational use and not an indicator of water quality issues related to wastewater intrusion.

Caffeine was detected in $40 \%$ of the sampling sites with concentrations ranging from ND to $169 \mathrm{ng} / \mathrm{L}$. Caffeine was one of the most frequently detected compounds in this study and results are consistent with previous studies in the area (Gardinali and Zhao, 2002; Singh et al., 2010) and other similar areas such as the Herault watershed, where caffeine was not completely degraded either in the wastewater treatment plant or in river water (Rabiet et al., 2006). Caffeine has been associated with coral bleaching at concentrations between $30 \times 10^{6}$ $\mathrm{ng} / \mathrm{L}$ and $75 \times 10^{6} \mathrm{ng} / \mathrm{L}$ (Pollack et al., 2009). Although the concentrations are orders of magnitude larger than the concentration of caffeine detected in the sampling sites, potential impacts of chronic exposure effect at low concentrations and possible additive effect with other chemical pollutants should still be of concern. Caffeine was neither detected in the sampling sites in Big Cypress National Preserve nor in the sampling sites in the Everglades National Park like 
SRS3, SRS4, WB1, WB2 and WB3. Caffeine was detected in the sampling sites along the canals and in the Biscayne Bay National Park, which are affected by human activities. Therefore, caffeine can be used as a valuable indicator of human activities.

Triclosan was detected in $30 \%$ of the sampling sites, ranging from ND to 10.9 ng/L. Triclosan is an antibacterial agent added to detergents and soap formulas. The annual production of triclosan exceeded a million pounds in the late 1990s (Vanderford et al., 2003). Triclosan is hard to be removed during primary clarification, aeration basin and secondary clarification stages of wastewater treatment. Concentrations of triclosan from a Louisiana treatment plant effluent were between 10 to $21 \mathrm{ng} / \mathrm{L}$, which were similar to the concentrations we detected (Boyd et al., 2003). Additionally, triclosan was detected at less than 50 $\mathrm{ng} / \mathrm{L}$ in the surface water in South Wales, UK (Thomas and Hilton, 2004) and found at $4.2 \mathrm{ng} / \mathrm{L}$ in surface water from Hamburg, Germany (Weigel et al., 2004).

Androsterone was detected at only one site at a concentration of $2.44 \mathrm{ng} / \mathrm{L}$ (C111-2). Few studies included androsterone in their target compounds. Nevertheless, androsterone is an important weak androgenic steroid hormone, which comes from the metabolism of testosterone. Androsterone was detected in $14.3 \%$ of U.S. streams at a maximal concentration $214 \mathrm{ng} / \mathrm{L}$ and a median concentration of $17 \mathrm{ng} / \mathrm{L}$ (Kolpin et al., 2002). The source for androsterone in the area is unknown. 
Estrone (E1) was detected in only $4 \%$ of the sampling sites at a maximal concentration of $5.98 \mathrm{ng} / \mathrm{L}$ (BB09). These results are much lower than the concentrations detected by Kolpin et al. in U.S. streams (112 ng/L) (Kolpin et al., 2002). Such high concentrations have not seen in any other studies. The study of Edward et al. detected estrone in an agricultural region at a maximal concentration of $0.9 \mathrm{ng} / \mathrm{L}$ in river waters and $17 \mathrm{ng} / \mathrm{L}$ in irrigation canals (Kolodziej et al., 2004). Estrone detected in BB09 indicated that leaks from the landfill or WWTP area nearby may be affecting the quality of surface water. Caffeine, DEET, bisphenol A and coprostan-3-ol were also detected in BB09.

Estradiol was detected at two sampling sites at a maximal concentration of 3.34 ng/L. By contrast, $17 \beta$-estradiol was detected in U.S. streams at a maximal concentration of $93 \mathrm{ng} / \mathrm{L}$ at $10.0 \%$ frequency of detection (Kolpin et al., 2002). However, such high concentrations were not seen in other studies. Estradiol was detected in spring water in Mexico City at a concentration of $0.17 \mathrm{ng} / \mathrm{L}$ (Gibson et al., 2007). No 17ß-estradiol was detected in surface water in the Mississippi River (Boyd et al., 2003), effluents from various WWTPs in Italy (Castiglioni et al., 2005), or effluents from 12 municipal wastewater treatment plants along the Thames River in Canada (Lishman et al., 2006).

Coprostan-3-ol, copostane and coprostan-3-one are metabolites of cholesterol generated by fecal bacteria (Jeannot et al., 2002). Cholesterol was detected at sampling sites at a maximal concentration of $2736 \mathrm{ng} / \mathrm{L}$. Cholesterol can be 
produced from both nonanthropogenic and anthropogenic sources (Kolpin et al., 2002). Therefore, chlolesterol was detected at all sampling sites. Similar concentrations also were found in the Danube River (Sebok et al., 2009). Coprostan-3-ol was detected in $17 \%$ of the sampling sites at a maximal concentration of $16.5 \mathrm{ng} / \mathrm{L}$ (C111-4). Previously, bacterial indicators were used to determine the quality of water and the stress from anthropogenic activities. Nucleic acid sequences were detected in $93.3 \%$ of coral surface microlayer samples from Florida Bay. It indicated the accumulation of entire microorganisms in the reef environment may be a risk to public and environmental health (Lipp et al., 2002). However, bacteria indicators have their limitations, such as being timeconsuming and lacking specificity. Therefore, chemical indicators of human feces were an alternative to identifying human sewage contaminations in water bodies. The fecal steroid coprostan-3-ol was first suggested to be an indicator of fecal pollution (Glassmeyer et al., 2005). Coprostane was detected only at one sampling site (TS1) at a maximal concentration of $13.5 \mathrm{ng} / \mathrm{L}$. Coprostane was detected in river samples at $20 \mathrm{ng} / \mathrm{L}$ (Jeannot et al., 2002). Coprostan-3-one was detected at two sampling sites at a maximal concentration of $6.79 \mathrm{ng} / \mathrm{L}$.

Average concentrations of analytes detected in each sampling site were shown in figure 6 using different colors. Average concentrations between ND and 10 $\mathrm{ng} / \mathrm{L}$ were displayed in blue color. Average concentrations between 10 and 25 $\mathrm{ng} / \mathrm{L}$ were displayed in green color. Average concentrations between 25 and 50 $\mathrm{ng} / \mathrm{L}$ were displayed in yellow color. Average concentrations between 50 and 100 
$\mathrm{ng} / \mathrm{L}$ were displayed in red color. Result in figure 6 showed that average concentrations in BCNP were lower than the other two protected areas. The reason is there are almost no residents in BNP area and human activities in BNP are much less than the other two protected areas. 


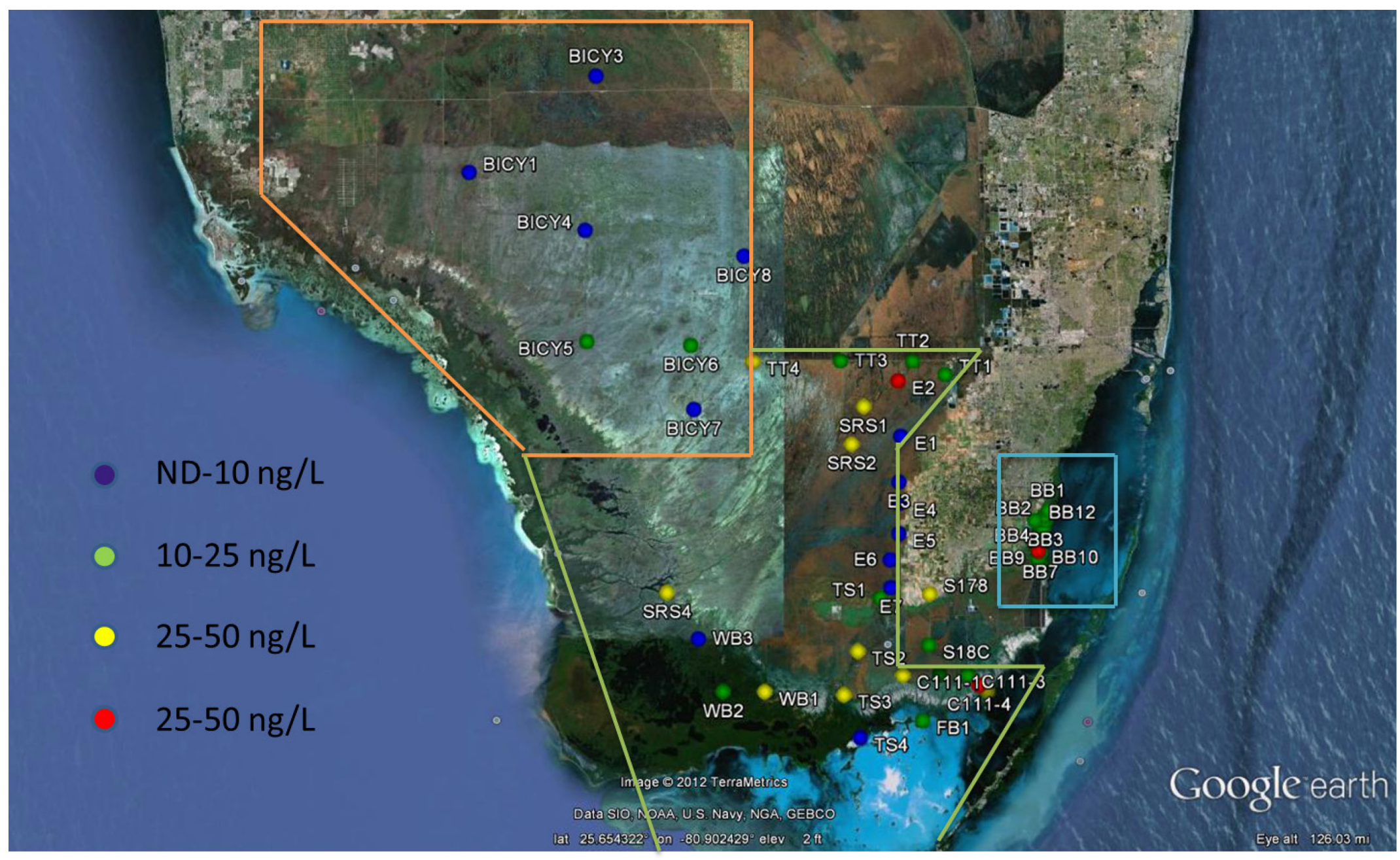

Figure 6. Map showing the distribution of average concentrations. ND-10 ng/L, blue dot; 10-25 ng/L, green dot; 25-50 ng/L, yellow dot; $50-100 \mathrm{ng} / \mathrm{L}$, red dot. 
In summary, the three most frequently detected compounds were DEET, caffeine and triclosan, if we do not consider cholesterol. The greater frequency of detection of these three compounds may be derived from their greater annual use. Mixture of PPCPs was prevalent during this study because forty three percent of sampling sites had more than three target compounds. Research has shown that certain chemical combinations can have additive toxic effects to organisms (Pomati et al., 2008). Therefore, the toxicity research should not only focus on individual compound effect but also the mixture of these compounds. 
Table 4. Description of sampling sites and concentrations of PPCPs

\begin{tabular}{|c|c|c|c|c|c|c|c|c|c|c|c|}
\hline $\begin{array}{l}\text { STATION } \\
\text { ID }\end{array}$ & $\begin{array}{c}\text { STATION } \\
\text { DESCRIPTOR }\end{array}$ & DEET & Caffeine & Triclosan & $\begin{array}{l}\text { Androst } \\
\text { erone }\end{array}$ & Estrone & $\begin{array}{c}17 \beta- \\
\text { estradiol }\end{array}$ & Coprostane & $\begin{array}{c}\text { Coprostan- } \\
\text { 3-ol }\end{array}$ & $\begin{array}{l}\text { Coprosta } \\
\text { n-3-one }\end{array}$ & $\begin{array}{c}\text { Cholester } \\
\text { ol }\end{array}$ \\
\hline BB01 & $\begin{array}{c}\text { Biscayne } \\
\text { Bay }\end{array}$ & $\begin{array}{l}\text { ND- } \\
8.87\end{array}$ & $\begin{array}{l}\text { ND- } \\
54.1\end{array}$ & ND & ND & ND & ND & ND & ND & ND & ND-276 \\
\hline BB02 & $\begin{array}{l}\text { Biscayne } \\
\text { Bay }\end{array}$ & $\begin{array}{l}\text { ND- } \\
10.2\end{array}$ & ND & ND & ND & ND & ND & ND & ND & ND & ND-418 \\
\hline BB03 & $\begin{array}{c}\text { Biscayne } \\
\text { Bay }\end{array}$ & $\begin{array}{l}\text { ND- } \\
25.9\end{array}$ & ND & ND & ND & ND & ND & ND & ND & ND & ND -242 \\
\hline BB04 & $\begin{array}{c}\text { Biscayne } \\
\text { Bay }\end{array}$ & $\begin{array}{l}\text { ND- } \\
18.3\end{array}$ & ND & ND & ND & ND & ND & ND & ND & ND & $215-274$ \\
\hline BB05 & $\begin{array}{c}\text { Biscayne } \\
\text { Bay }\end{array}$ & $\begin{array}{l}\text { ND- } \\
8.76\end{array}$ & ND & ND & ND & ND & ND & ND & ND & ND & ND -312 \\
\hline BB06 & $\begin{array}{c}\text { Biscayne } \\
\text { Bay }\end{array}$ & $\begin{array}{l}\text { ND- } \\
6.21\end{array}$ & ND & ND & ND & ND & ND & ND & ND -1.32 & ND & $208-420$ \\
\hline BB07 & $\begin{array}{l}\text { Biscayne } \\
\text { Bay }\end{array}$ & $\begin{array}{l}3.63- \\
19.3\end{array}$ & $\begin{array}{l}\text { ND- } \\
38.5\end{array}$ & ND & ND & ND & ND & ND & ND & ND & $342-445$ \\
\hline BB09 & $\begin{array}{c}\text { Biscayne } \\
\text { Bay }\end{array}$ & $\begin{array}{l}\text { ND- } \\
6.29\end{array}$ & $\begin{array}{l}\text { ND- } \\
25.4\end{array}$ & ND & ND & $\begin{array}{l}\text { ND- } \\
5.98\end{array}$ & ND & ND & ND -12.4 & ND & $\begin{array}{l}289- \\
2337\end{array}$ \\
\hline BB10 & $\begin{array}{l}\text { Biscayne } \\
\text { Bay }\end{array}$ & $\begin{array}{l}\text { ND- } \\
9.29\end{array}$ & ND & ND & ND & ND & ND & ND & ND & ND & ND -269 \\
\hline BB11 & $\begin{array}{l}\text { Biscayne } \\
\text { Bay }\end{array}$ & $\begin{array}{l}\text { ND- } \\
13.2\end{array}$ & $\begin{array}{l}\text { ND- } \\
22.9\end{array}$ & ND & ND & ND & ND & ND & ND & ND & ND -279 \\
\hline BB12 & $\begin{array}{l}\text { Biscayne } \\
\text { Bay }\end{array}$ & ND & ND & ND & ND & ND & ND & ND & ND & ND & $321-389$ \\
\hline BICY1 & $\begin{array}{c}\text { Big } \\
\text { Cypress }\end{array}$ & ND & ND & ND & ND & ND & ND & ND & ND & ND & ND \\
\hline BICY3 & $\begin{array}{c}\text { Big } \\
\text { Cypress }\end{array}$ & 17.2 & ND & ND & ND & ND & ND & ND & ND & ND & ND \\
\hline BICY4 & $\begin{array}{c}\text { Big } \\
\text { Cypress }\end{array}$ & ND & ND & ND & ND & ND & ND & ND & 3.16 & ND & ND \\
\hline BICY5 & $\begin{array}{c}\text { Big } \\
\text { Cypress }\end{array}$ & $\begin{array}{l}\text { ND- } \\
16.8\end{array}$ & ND & ND & ND & ND & ND & ND & ND & ND & ND -423 \\
\hline
\end{tabular}




\begin{tabular}{|c|c|c|c|c|c|c|c|c|c|c|c|}
\hline $\begin{array}{l}\text { STATION } \\
\text { ID }\end{array}$ & $\begin{array}{c}\text { STATION } \\
\text { DESCRIPTOR }\end{array}$ & DEET & Caffeine & Triclosan & $\begin{array}{l}\text { Androst } \\
\text { erone }\end{array}$ & Estrone & $\begin{array}{c}17 \beta- \\
\text { estradiol }\end{array}$ & Coprostane & $\begin{array}{c}\text { Coprostan- } \\
\text { 3-ol }\end{array}$ & $\begin{array}{l}\text { Coprosta } \\
\text { n-3-one }\end{array}$ & $\begin{array}{c}\text { Cholester } \\
\text { ol }\end{array}$ \\
\hline BICY6 & $\begin{array}{c}\text { Big } \\
\text { Cypress }\end{array}$ & ND & ND & ND & ND & ND & ND & ND & ND & ND & 203-319 \\
\hline BICY7 & $\begin{array}{c}\text { Big } \\
\text { Cypress }\end{array}$ & ND & ND & ND & ND & ND & ND & ND & ND & ND & ND \\
\hline BICY8 & $\begin{array}{c}\text { Big } \\
\text { Cypress }\end{array}$ & ND & ND & ND & ND & ND & ND & ND & ND & ND & ND \\
\hline C111-1 & C111 Basin & ND & 22.9 & 2.66 & ND & ND & 3.34 & ND & ND & ND & 545 \\
\hline C111-2 & C111 Basin & ND & 10.6 & 4.34 & 2.44 & ND & ND & ND & ND & ND & 353 \\
\hline C111-3 & $\begin{array}{l}\text { C111 } \\
\text { Canal }\end{array}$ & ND & ND & 9.10 & ND & ND & ND & ND & ND & ND & ND -434 \\
\hline C111-4 & $\begin{array}{l}\text { Highway } \\
\text { Creek }\end{array}$ & $\begin{array}{c}6.71- \\
17.2\end{array}$ & $\begin{array}{l}\text { ND - } \\
35.5\end{array}$ & ND & ND & $\begin{array}{l}\text { ND- } \\
3.42\end{array}$ & ND & ND & $1.59-16.5$ & ND & $\begin{array}{l}287- \\
2736\end{array}$ \\
\hline E1 & $\begin{array}{c}\text { East } \\
\text { Boundary }\end{array}$ & ND & ND & ND & ND & ND & ND & ND & ND & ND & ND \\
\hline E2 & $\begin{array}{c}\text { East } \\
\text { Boundary }\end{array}$ & 12.1 & 39.6 & ND & ND & ND & ND & ND & ND & ND & 1561 \\
\hline E3 & $\begin{array}{c}\text { East } \\
\text { Boundary }\end{array}$ & ND & 33.6 & ND & ND & ND & ND & ND & ND & ND & ND \\
\hline E4 & $\begin{array}{c}\text { East } \\
\text { Boundary }\end{array}$ & ND & ND & 10.9 & ND & ND & ND & ND & ND & ND & ND \\
\hline E5 & $\begin{array}{c}\text { East } \\
\text { Boundary }\end{array}$ & ND & 61.3 & ND & ND & ND & ND & ND & ND & ND & ND \\
\hline E6 & $\begin{array}{c}\text { East } \\
\text { Boundary }\end{array}$ & ND & 68.8 & ND & ND & ND & ND & ND & ND & ND & ND \\
\hline E7 & $\begin{array}{c}\text { East } \\
\text { Boundary }\end{array}$ & ND & ND & 9.66 & ND & ND & ND & ND & ND & ND & ND \\
\hline FB1 & Florida Bay & ND & ND & ND & ND & ND & ND & ND & ND & ND & 164 \\
\hline FB2 & Florida Bay & 11.5 & ND & ND & ND & ND & ND & ND & ND & ND & 553 \\
\hline S178 & $\begin{array}{c}\text { Structure } \\
178\end{array}$ & ND & $\begin{array}{l}\text { ND - } \\
18.4\end{array}$ & $\begin{array}{l}\text { ND - } \\
1.33\end{array}$ & ND & ND & ND & ND & ND- 5.46 & ND-3.22 & $309-859$ \\
\hline S18C & $\begin{array}{c}\text { Structure } \\
18 \mathrm{C}\end{array}$ & ND & $\begin{array}{c}63.5- \\
169\end{array}$ & ND & ND & ND & ND & ND & ND & ND & $158-274$ \\
\hline
\end{tabular}




\begin{tabular}{|c|c|c|c|c|c|c|c|c|c|c|c|}
\hline $\begin{array}{l}\text { STATION } \\
\text { ID }\end{array}$ & $\begin{array}{c}\text { STATION } \\
\text { DESCRIPTOR }\end{array}$ & DEET & Caffeine & Triclosan & $\begin{array}{l}\text { Androst } \\
\text { erone }\end{array}$ & Estrone & $\begin{array}{c}17 \beta- \\
\text { estradiol }\end{array}$ & Coprostane & $\begin{array}{l}\text { Coprostan- } \\
\text { 3-ol }\end{array}$ & $\begin{array}{l}\text { Coprosta } \\
\text { n-3-one }\end{array}$ & $\begin{array}{c}\text { Cholester } \\
\text { ol }\end{array}$ \\
\hline SRS1 & $\begin{array}{c}\text { Shark } \\
\text { River } \\
\text { Slough } \\
\text { Shark }\end{array}$ & 6.25 & 87.0 & ND & ND & ND & ND & ND & ND & ND & 642 \\
\hline SRS2 & $\begin{array}{l}\text { River } \\
\text { Slough }\end{array}$ & 23.2 & 40.8 & ND & ND & ND & ND & ND & ND & ND & 719 \\
\hline SRS4 & $\begin{array}{l}\text { Shark } \\
\text { River }\end{array}$ & ND & ND & ND-1.72 & ND & ND & ND & ND & ND & ND & $\begin{array}{l}\text { ND - } \\
1149\end{array}$ \\
\hline TS1 & $\begin{array}{l}\text { Taylor } \\
\text { Slough }\end{array}$ & $\begin{array}{l}3.02- \\
7.24\end{array}$ & $\begin{array}{c}56.7- \\
108\end{array}$ & ND-9.66 & ND & ND & ND & 13.5 & ND -3.26 & ND & ND -623 \\
\hline TS2 & $\begin{array}{l}\text { Taylor } \\
\text { Slough }\end{array}$ & ND & 12.1 & 4.86 & ND & ND & 3.16 & ND & 6.72 & ND & 702 \\
\hline TS3 & $\begin{array}{l}\text { Taylor } \\
\text { Slough }\end{array}$ & ND & 15.3 & ND & ND & ND & ND & ND & ND & ND & 456 \\
\hline TS4 & Florida Bay & ND & ND & ND & ND & ND & ND & ND & ND & ND & 183 \\
\hline TT1 & $\begin{array}{l}\text { Tamiami } \\
\text { Trail }\end{array}$ & $\begin{array}{l}\text { ND - } \\
10.9\end{array}$ & $\begin{array}{l}51.2- \\
71.5\end{array}$ & ND-6.20 & ND & ND & ND & ND & ND & ND & $284-367$ \\
\hline TT2 & $\begin{array}{l}\text { Tamiami } \\
\text { Trail }\end{array}$ & ND & 54.7 & ND & ND & ND & ND & ND & ND & ND & 191 \\
\hline TT3 & $\begin{array}{l}\text { Tamiami } \\
\text { Trail }\end{array}$ & $\begin{array}{l}11.9- \\
19.8\end{array}$ & ND & ND-5.54 & ND & ND & ND & ND & ND & ND & $234-568$ \\
\hline TT4 & $\begin{array}{l}\text { Tamiami } \\
\text { Trail }\end{array}$ & $\begin{array}{l}\text { ND - } \\
26.1\end{array}$ & ND & ND-6.66 & ND & ND & ND & ND & ND & ND & $183-899$ \\
\hline WB1 & $\begin{array}{c}\text { West } \\
\text { Boundary }\end{array}$ & $\begin{array}{l}\text { ND - } \\
8.91\end{array}$ & ND & ND & ND & ND & ND & ND & $3.49-5.20$ & 6.79 & $150-855$ \\
\hline WB2 & $\begin{array}{l}\text { West } \\
\text { Boundary }\end{array}$ & $\begin{array}{l}11.6- \\
27.9\end{array}$ & ND & ND-2.61 & ND & ND & ND & ND & ND & ND & ND -274 \\
\hline WB3 & $\begin{array}{c}\text { West } \\
\text { Boundary }\end{array}$ & $\begin{array}{l}\text { ND - } \\
4.37\end{array}$ & ND & ND-6.84 & ND & ND & ND & ND & ND & ND & ND -178 \\
\hline
\end{tabular}




\subsection{Conclusion}

The present study gave an overview of the occurrence of PPCPs and hormones in South Florida surface waters. Although there were a few reports about the occurrence of microconstituents in several typical environments in South Florida (Gardinali and Zhao, 2002; Singh et al., 2010), it was the first time to report the occurrence of PPCPs and hormones in surface waters from Big Cypress National Preserve, Everglades National Park and Biscayne National Park.

Pharmaceuticals and personal care products were detected at higher concentrations and higher frequencies compared to hormones. Caffeine can be used as an indicator of human activities. Potential impact of chronic exposure effects of caffeine at detected concentrations is still unknown. In our study, the highest detected concentration of estrone (5.98 $\mathrm{ng} / \mathrm{L}$ detected in BB09) was high enough to require further investigation because of the toxicological implications for fish and probably other aquatic organisms. Results suggested that leakage from the landfill area and WWTP nearby may affect the quality of surface water. Results also indicated that future toxicity research should not only focus on the effect of individual compounds, but also on the influence of mixtures of compounds, since $43 \%$ of sampling sites have more than 3 compounds detected. 


\section{CHAPTER 3}

\section{Detection of PPCPs and hormones in sediment samples using GC-MS}

\subsection{Introduction}

Current WWTPs do not completely remove PPCPs from wastewater. Measuring the concentration of PPCPs in the influent and effluent of WWTPs is insufficient to evaluate the efficiency of removal, because many PPCPs may be incorporated into sludge, which is used for landfill or as the fertilizer in agriculture (Jelic et al., 2009). No matter how the sludge is disposed of, PPCPs may enter the environment with the sludge and leach into sediment or soil. Moreover, PPCPs could enter surface water by runoff or enter groundwater through leaching from leakage. Therefore, it is essential to develop new methods for detection of PPCPs in the mineral phases, such as sediment, soil and sludge. By analyzing sediment or soil samples from the environment, the fate of PPCPs in the environment can be better understood.

The difficulty of sediment or soil sample analysis is because of the low concentration of PPCPs and the complex effect of matrices. The low concentration of analytes requires extensive extraction techniques and large concentration rates of samples. Accelerated solvent extraction (ASE) has demonstrated more advantages than Soxhlet extraction on automation, reduced extraction time and lower solvent consumption. Reduction of matrix effects requires proper cleanup steps (Löffler and Ternes, 2003; Burkhardt et al., 2005; Peng et al., 2006). Currently, SPE is the most widely used as cleanup step for 
environmental sediment and soil samples (Burkhardt et al., 2005; Peng et al., 2006; Rice and Mitra, 2007; Xu et al., 2008; Durán-Alvarez et al., 2009). For instrument analysis, $\mathrm{MS}^{2}$ or high resolution $\mathrm{MS}$ are preferred to decrease the interference from matrices (Löffler and Ternes, 2003; Gómez et al., 2007; Jelic et al., 2009). However, single quadrupole is still able to do the quantitation if proper cleanup steps are applied (Burkhardt et al., 2005; Rice and Mitra, 2007; Xu et al., 2008; Durán-Alvarez et al., 2009).

In the present study, a method to simultaneously determine many environmentally relevant PPCPs and steroid hormones in sediments and soils using ASE-SPE-GC-MS was developed. Recoveries of most analytes were adequate even when the matrix became complex at very low spike levels. MDLs are low enough to detect the target compounds at environmentally relevant levels.

\subsection{Experimental}

\subsubsection{Chemicals}

Caffeine was purchased from Fisher Scientific (Suwannee, GA, USA). Naproxen, ibuprofen, gemfibrozil, triclosan, bisphenol-A, 4-n-nonylphenol, androsterone, estrone, equilin, 17ß-estradiol, 17a-estradiol, testosterone, 17a-ethynylestradiol, coprostane, progesterone, estriol, coprostane, coprostan-3-ol and coprostan-3one were purchased as neat compounds from Sigma-Aldrich (St. Louis, MO, USA). Equilenin were purchased as certified standard solutions from Dr. Ehrenstorfer (Augsburg, Germany). Surrogate standard caffeine-trimethyl- ${ }^{13} \mathrm{C}_{3}$ 
was purchased from Cambridge Isotope Laboratories Inc (Andover, MA, USA); DEET-d7, triclosan-d3, 4-n-nonylphenol-d4, equilin-d4, 17ß-estradiol-d5, estroned4, 17a-ethynylestradiol-d4, norgestrel-d6, progesterone-d9 and 5a-cholestan$3 \beta$-ol-d5 were purchased from CDN Isotopes (Pointe-Claire, Quebec, Canada). Bisphenol A-d16 was purchased from Sigma-Aldrich (St. Louis, MO, USA). All the reference standards were $>95 \%$ purity. Detailed information of analytes is shown in table 5.

Table 5. Name, structure, CAS and intended usage of analytes

Ibuprofen




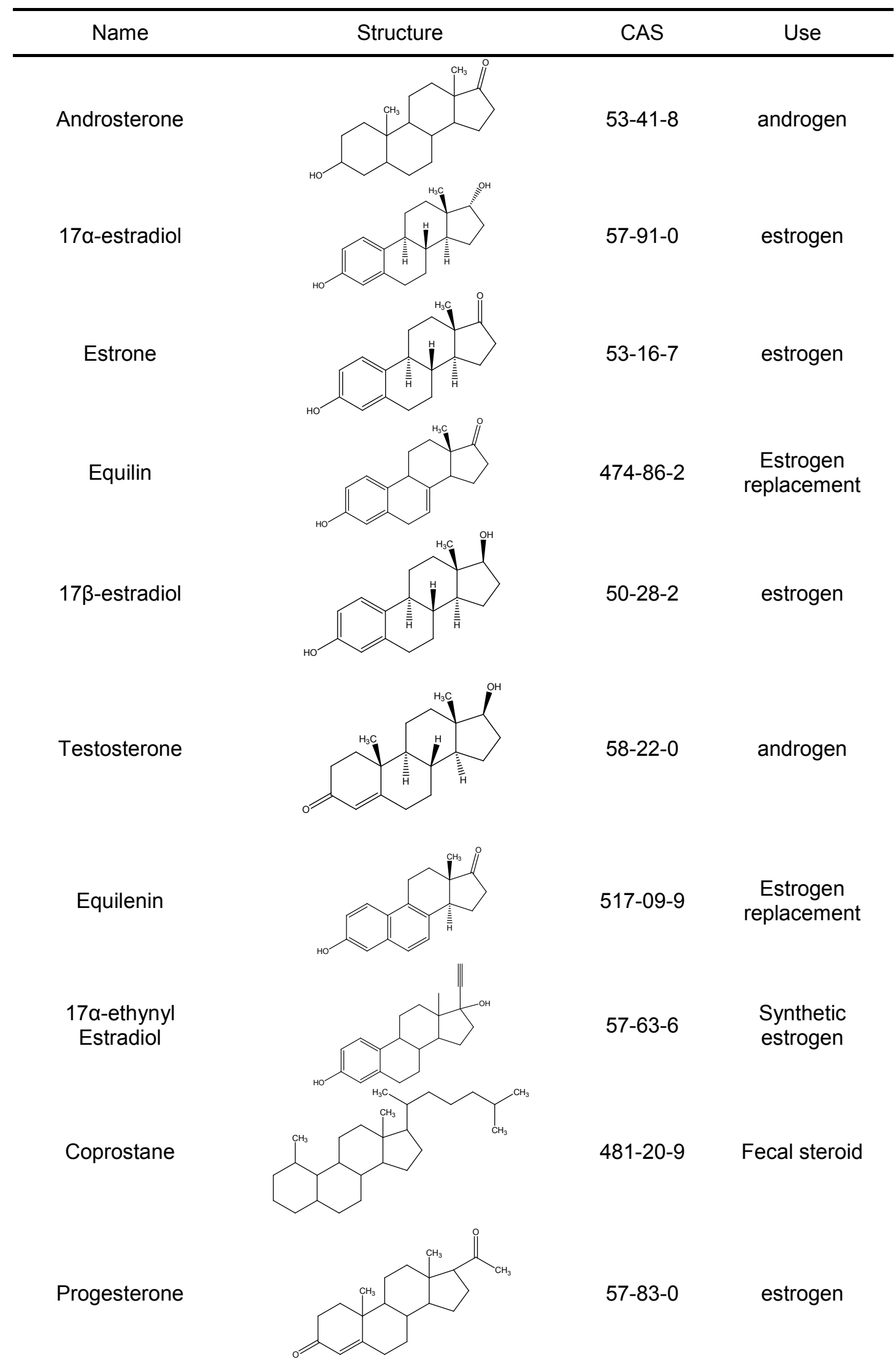




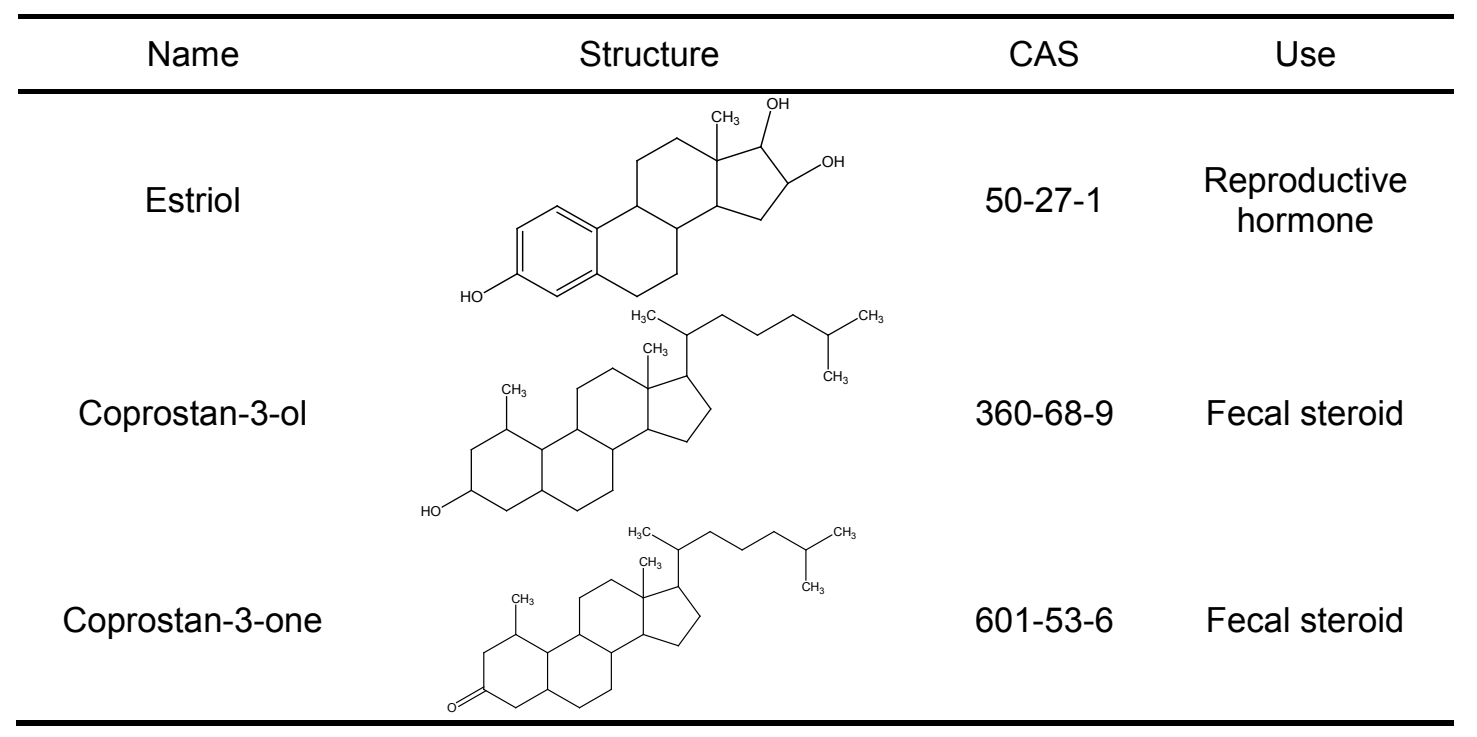

\subsubsection{Sampling}

Reclaimed water used for irrigation was collected directly from a sprinkler system using $500 \mathrm{~mL}$ PETE bottles and was stored in the freezer at $<10^{\circ} \mathrm{C}$. The source of reclaimed water used in this study is the Miami-Dade Water and Sewer Department North District Wastewater Treatment Plant. The wastewater treatment plant was designed to have a flow of 120 million gallons per day (MGD) with average daily flow around 112.5 million gallons per day. Pure oxygen activated-sludge is used in the WWTP as the main secondary treatment process (Kasprzyk-Hordern et al., 2008). Extra filtration and disinfection are applied to effluents before release to make the reclaimed water ready for use in irrigation. Sediments and soil samples were collected in and near a fresh water pond in FIU Biscayan Bay Campus (Figure 7). Soil samples were collected under the sprinkler and on the side of the pond. Sediment samples were collected at the bottom of the pond. 


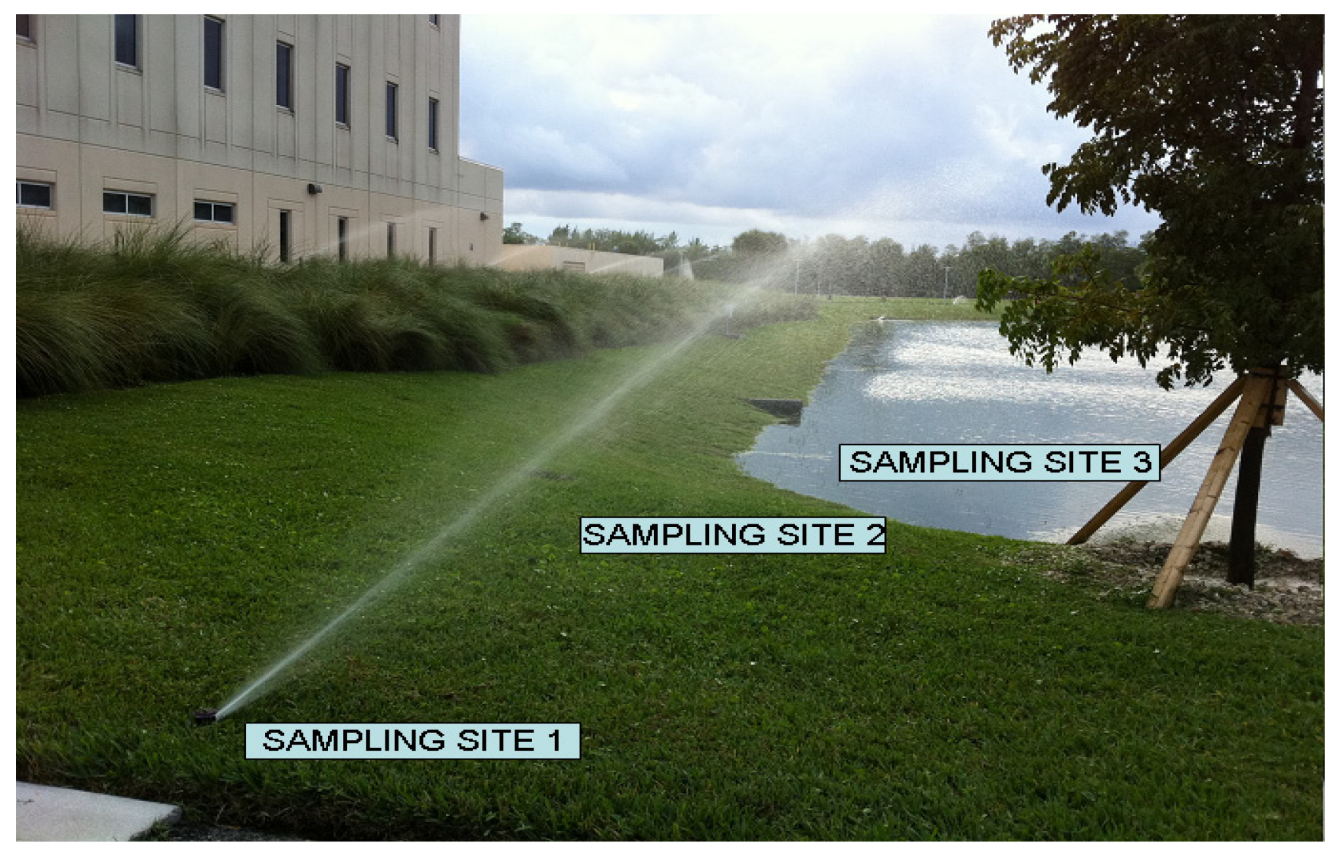

Figure 7. Sampling sites of sediment and soil

\subsubsection{Sample preparation}

Samples were extracted using a Dionex ASE 200 accelerated solvent extraction system. Extraction cells were filled with $20 \mathrm{~g}$ of anhydrous sodium sulfate and 2 grams of the freeze-dried sediment sample. Blanks consisted of $20 \mathrm{~g}$ of sodium sulfate. The most efficient solvent tested for extraction was methanol and ASE conditions used were as follow: pre-heat ( $0 \mathrm{~min})$, heating time (5 mins), 60\% flush, 1 cycle. Temperature was held at $100{ }^{\circ} \mathrm{C}$ and pressure was 1500 psi. Solvent was evaporated to dryness and samples were reconstituted in $60 \mathrm{~mL}$ of DI water. $\mathrm{NH}_{4} \mathrm{OH}(60 \mu \mathrm{L})$ was added to adjust $\mathrm{pH}$ to 10 . Oasis MAX cartridges (225 mg) were conditioned with $5 \mathrm{~mL}$ of methanol followed by $5 \mathrm{~mL}$ of $\mathrm{DI}$ water (pH 10). Samples were loaded to the cartridges at a rate of $1-2 \mathrm{~mL} / \mathrm{min}$. The first fraction (5 $\mathrm{mL}$ of methanol: water 1:1) contained polar analytes. The second 
fraction ( $5 \mathrm{~mL}$ of acetone and $5 \mathrm{~mL}$ of acetone with $4 \%$ formic acid) contained the steroid hormones. Hormone concentrations are usually lower than pharmaceuticals in environmental samples and the fractionation helped to decrease the background interferences in the gas chromatograph mass spectrometry. Fractions were evaporated to dryness using nitrogen gas. Pyridine $(100 \mu \mathrm{L})$ and BSTFA $(50 \mu \mathrm{L})$ were added to the residue. Compounds were derivatized at $60{ }^{\circ} \mathrm{C}$ for 45 minutes and analyzed on a Thermo Trace DSQ GC/MS. The procedure is shown in figure 8 .

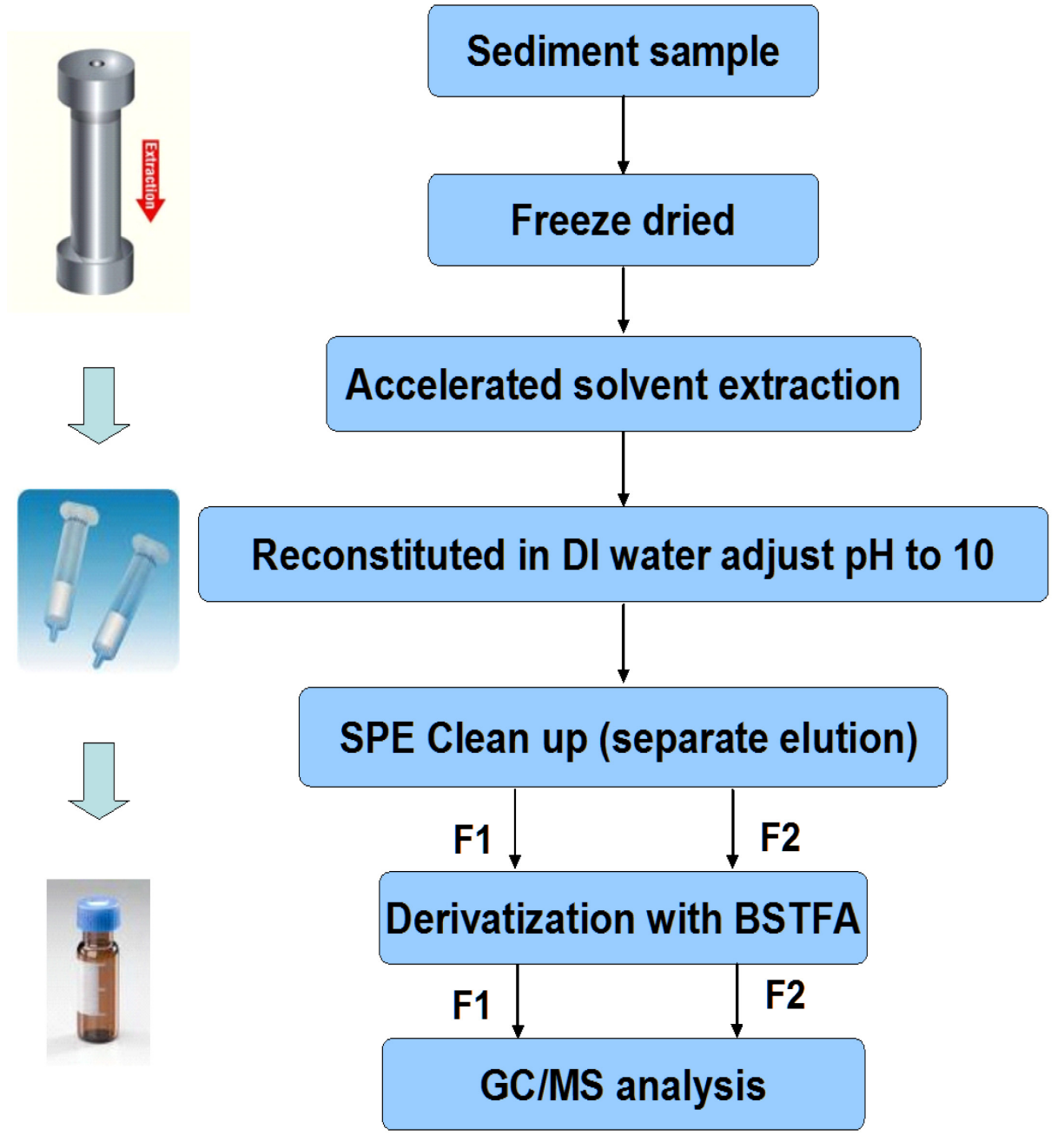

Figure 8. Sample preparation procedure for sediments and soils 


\subsubsection{GC-MS analysis}

All the chromatographic measurements were performed using a Thermo GC/MS system comprised of a Finnigan Trace GC Ultra fitted with an autosampler AS 3000 and a Finnigan Trace DSQ operated in an El at $70 \mathrm{eV}$. Derivatized sample extracts $(2 \mu \mathrm{L})$ were injected into a DB-5MS column $(30 \mathrm{~m}$ with $0.5 \mu \mathrm{m}$ film thickness and $0.25 \mathrm{~mm}$ I.D.) under the splitless mode. The helium flow rate was held constant at $1.2 \mathrm{~mL} / \mathrm{min}$ and the $\mathrm{GC}$ oven was programmed from $85^{\circ} \mathrm{C}(1$ min hold) at a rate of $15{ }^{\circ} \mathrm{C} / \mathrm{min}$ to $270{ }^{\circ} \mathrm{C}(1 \mathrm{~min}$ hold $)$, then at a rate of $5^{\circ} \mathrm{C}$ Imin to $300{ }^{\circ} \mathrm{C}\left(10\right.$ mins hold). The transfer line was $280{ }^{\circ} \mathrm{C}$. The MS operated in El mode using selected ion monitoring (SIM) to enhance sensitivity. Recoveries of PPCPs in different matrices and method detection limits (MDLs) were performed for method validation.

\subsubsection{Extraction recovery and method detection limit}

Analytes were spiked to sodium sulfate, pre-extracted sediment and sediment to check the recovery of method. Fortification concentrations are: caffeine, bisphenol A, ibuprofen, gemifibrozil, naproxen, nonylphenol, triclosan, estrone, equilin, equilenin androsterone, 17ß-estradiol, 17a-estradiol, and estriol were spiked at $4.4 \mathrm{ng} / \mathrm{g}$. Testosterone, coprostan-3-ol, 17a-ethynylestradiol were spiked at $8.9 \mathrm{ng} / \mathrm{g}$. Progesterone, coprostan-3-one and coprostane were spiked at $17.8 \mathrm{ng} / \mathrm{g}$. 
Method detection limits (MDLs) were determined according to EPA guidelines (Ripp, 1996). Eight replicate pre-extracted sediment samples spiked with all compounds with concentration ranging from one to eight times of the tested detection limit (DL). Standard deviations (SD) were calculated from replicates and $\mathrm{MDL}=2.998 \mathrm{SD}$.

\subsection{Results and discussion}

\subsubsection{Method development and validation}

3.3.1.1 Recovery of analytes from different matrices

Pharmaceuticals and personal care products and hormones were spiked into sodium sulfate, pre-extracted sediments and untreated sediments at very low fortification levels. Recoveries of PPCPs are shown in figure 9. Recoveries were not affected as the matrix complexity increased even for such low fortification levels. With the exception of equilin, naproxen and progesterone the method was very reliable for the rest of the compounds. 


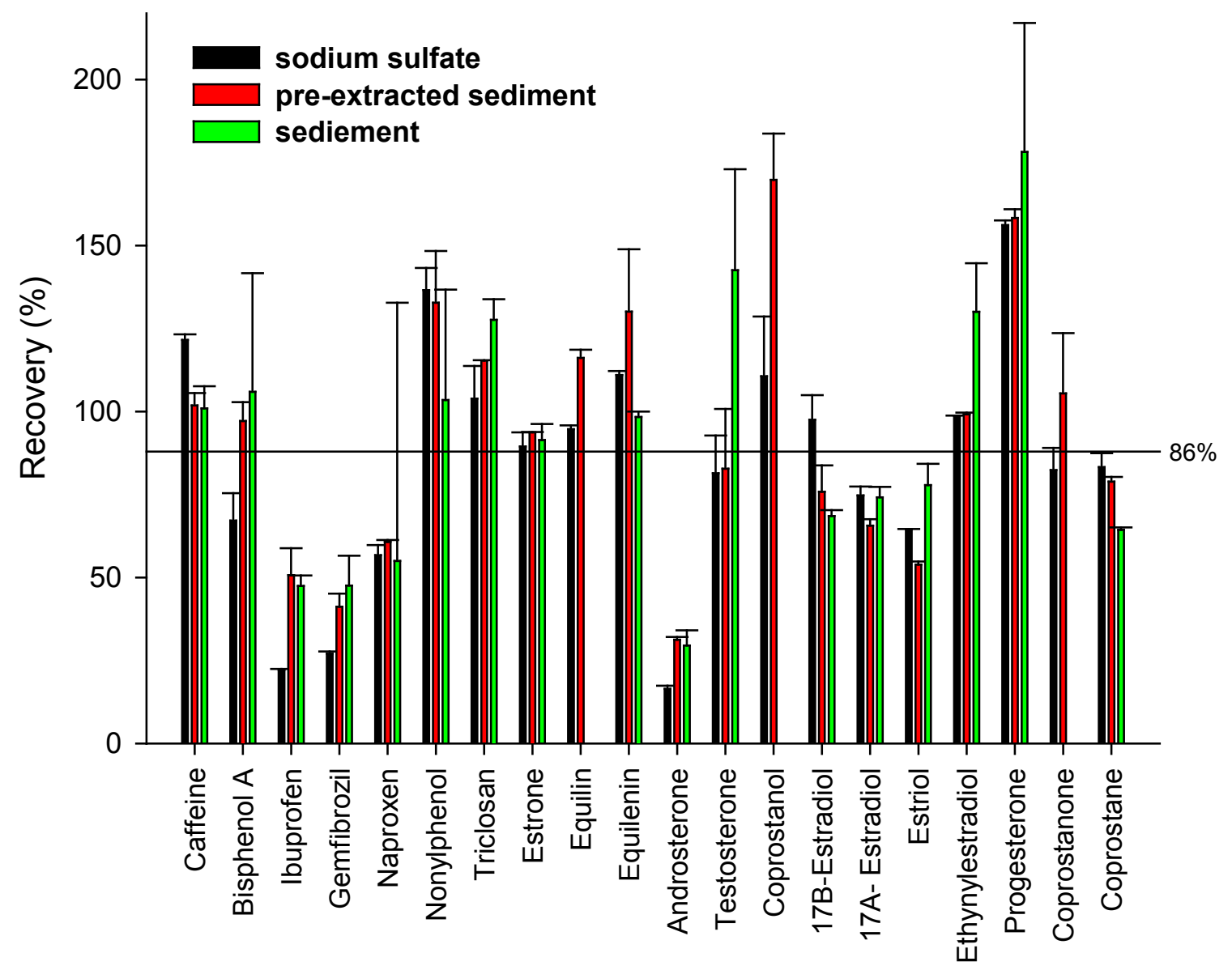

Figure 9. Recoveries of analytes in sodium sulfate, pre-extracted sediment and untreated sediment.

\subsubsection{Method detection limit}

Method detection limits of analytes in sediment and soil are shown in table 6. Method detection limits were low but varied among pharmaceuticals and hormones. Method detection limits for ibuprofen, gemfibrozil and naproxen were $1.86 \mathrm{ng} / \mathrm{g}, 1.96 \mathrm{ng} / \mathrm{g}$ and $0.85 \mathrm{ng} / \mathrm{g}$, respectively. The detection limits for estrogen 
hormones were between $1.27 \mathrm{ng} / \mathrm{g}$ and $14.5 \mathrm{ng} / \mathrm{g}$. Faecal steroids' detection limits were between $3.58 \mathrm{ng} / \mathrm{g}$ and $15.5 \mathrm{ng} / \mathrm{g}$.

Table 6. MDLs of PPCPs and hormones in sediment

\begin{tabular}{cccc}
\hline analytes & $\mathrm{MDL}(\mathrm{ng} / \mathrm{g})$ & analytes & $\mathrm{MDL}(\mathrm{ng} / \mathrm{g})$ \\
\hline caffeine & 1.85 & equilin & 2.11 \\
bisphenol A & 2.51 & equilenin & 2.64 \\
ibuprofen & 1.86 & androsterone & 2.99 \\
gemfibrozil & 1.96 & testosterone & 8.61 \\
naproxen & 0.85 & 17a-ethynylestradiol & 6.68 \\
4-n-nonylphenol & 3.34 & estriol & 1.27 \\
tricolsan & 1.35 & coprostan-3-ol & 5.50 \\
estrone & 2.30 & progesterone & 14.5 \\
17ß-estradiol & 2.05 & coprostan-3-one & 15.5 \\
17a-estradiol & 1.66 & coprostane & 3.58 \\
\hline
\end{tabular}

\subsubsection{Analysis of real samples}

The detected concentration of PPCPs and hormones are shown in table 7 . Results of reclaimed water samples are analyzed by online SPE-LC-MS/MS method, which is shown in chapter 6.3. Most of analytes were below detection limits even though some of analytes were detected in the reclaimed water at relatively high concentrations. Results indicated that the higher the logkow value, the more possible that the compounds attach to the sediment or soil. Coprostanol was detected at sediment from the bottom of ponds but concentrations were below detection limit on soil samples from side of pond and under sprinkler. The most possible explanation is selective partition combined with degradation, probably aided by the microbial activity in the soil, the high temperatures of the region and long exposure to sunlight. 
Table 7. Concentrations of PPCPs in reclaimed water, sediment and soil

\begin{tabular}{cccccc}
\hline Logkow & $\begin{array}{c}\text { Reclaimed water } \\
(\mathrm{ng} / \mathrm{L})\end{array}$ & $\begin{array}{c}\text { Sampling site } \\
1 \\
\text { Soil under the } \\
\text { sprinkler } \\
(\mathrm{ng} / \mathrm{g})\end{array}$ & $\begin{array}{c}\text { Sampling site } \\
2\end{array}$ & $\begin{array}{c}\text { Sampling site } \\
\text { Soil on the } \\
\text { side of the } \\
\text { pond }(\mathrm{ng} / \mathrm{g})\end{array}$ & $\begin{array}{c}\text { Sediment at } \\
\text { the bottom of } \\
\text { pond }(\mathrm{ng} / \mathrm{g})\end{array}$ \\
\hline triclosan & 4.76 & $\mathrm{ND}-1035$ & 3.78 & 4.22 & 7.66 \\
caffeine & $<0$ & $\mathrm{ND}-3249$ & $\mathrm{ND}$ & $\mathrm{ND}$ & $\mathrm{ND}$ \\
bisphenol A & 3.3 & $\mathrm{ND}-14306$ & 6.14 & $\mathrm{ND}$ & $\mathrm{ND}$ \\
gemfibrozil & 4.75 & $\mathrm{ND}-4177$ & $\mathrm{ND}$ & $\mathrm{ND}$ & $\mathrm{ND}$ \\
Coprostan-3-ol & 8.2 & $\mathrm{ND}-17197$ & $\mathrm{ND}$ & $\mathrm{ND}$ & 235 \\
\hline
\end{tabular}

\subsection{Conclusion}

A robust, reliable and sensitive analytical method was developed for the simultaneous determination of many environmentally relevant hormones, steroids and pharmaceuticals in sediments and soils. Good recoveries were achieved for different matrices except for equilin, coprostanol and coprostanone. Method detection limits were low enough to detect at environmentally relevant analysis. Compounds with low logkow value are willing to stay in the water and compounds with relatively high logkow value are more possible to attach to the sediment or soil. Even though some of analytes were detected in the reclaimed water at relatively high concentrations, most analytes were below detection limits in the sediment and soil samples. The microbial activity in the soil, the high temperatures of the region and long exposure to sun light may cause the degradation of analyte in the soil samples. 


\section{CHAPTER 4}

\section{Detection of PPCPs and hormones in aqueous samples using online SPE-}

\section{LC-MS/MS assessing the utility of APPI for non ionizable compounds}

\subsection{Introduction}

Because traditional wastewater treatment processes cannot completely remove drugs and estrogens from the final effluent of conventional wastewater treatment plants (WWTPs), pharmaceuticals and personal care products (PPCPs) could be continuously released into the environment in rather large quantities (Esperanza et al., 2004). It is particularly important when reuse water is used for irrigation. Many PPCPs, also named microconstituents or organic waste indicators, have been detected in both effluent of wastewater treatment plants and in the receiving surface waters (Jeannot et al., 2002; Boyd et al., 2003; Cahill et al., 2004; Weigel et al., 2004). Several PPCP residues even when present at trace levels may have adverse effects on organisms in particular those with endocrine disrupting capability (Ben-Jonathan and Steinmetz, 1998). Research has indicated that endocrine disrupting compounds (EDCs) can interact with the endocrine system of fish at very low concentrations by long-term exposure (BenJonathan and Steinmetz, 1998; Pollack et al., 2009). Therefore, it is very important to accurately monitor concentrations of PPCPs and EDCs in the aquatic environment at environmental relevant concentrations (ng/L).

Gas chromatography mass spectrometry (GC-MS) has been traditionally used to detect many PPCPs and EDCs in aquatic matrices in a number of studies (Boyd 
et al., 2003; Weigel et al., 2004; Lishman et al., 2006; Verenitch et al., 2006; Gibson et al., 2007; Gómez et al., 2007; Markman et al., 2007). Gas chromatography mass spectrometry is a very widely used and mature technique; however, it requires collection of large sample volumes, extensive use of solvent for extraction, several evaporation steps and in many cases, derivatization steps to make polar compounds amenable to gas chromatography. High performance liquid chromatography coupled to mass spectrometry has been shown as a valuable alternative for detection of PPCPs and EDCs to overcome the drawbacks of GC-MS (Gardinali and Zhao, 2002; Gentili et al., 2002; Ingrand et al., 2003; Cahill et al., 2004; Castiglioni et al., 2005; Schlüsener and Bester, 2005; Martnez Bueno et al., 2007; Gros et al., 2009; Laven et al., 2009; Huerta-Fontela et al., 2010; Jian-lin et al., 2010). Electrospray ionization (ESI), atmospheric pressure chemical ionization (APCl) and atmospheric pressure photoionization (APPI) are the three most common ion sources coupled with HPLC/UPLC. Electrospray ionization however because of its versatility dominates the field of environmental analysis at trace level (Hilton and Thomas, 2003; Martnez Bueno et al., 2007; Lopez-Serna et al., 2010).

Electrospray ionization and APCI have both been widely used for analysis of polar molecules in aqueous environmental samples in many studies (Cahill et al., 2004; Castiglioni et al., 2005; Gros et al., 2009; Lopez-Serna et al., 2010). However, ESI and APCI also have many limitations: 1. Because ionization efficiencies are charge affinity dependent, certain classes of compounds cannot 
be ionized (some steroids, nonpolar compounds like PAHs, etc); 2. Adducts with common cations $\left(\mathrm{Na}^{+}\right.$and $\left.\mathrm{K}^{+}\right)$, routinely form during $\mathrm{ESI}$, and these chargebearing salt compounds could not only increase the chemical background but reduce the analyte signal (Hanold et al., 2004). 3. Target analyte molecules are often not ionized because of competition with other compounds with higher charge affinity. Therefore, most of the studies using ESI are focused on pharmaceuticals, which are readily ionizable by electrospray ionization. Fewer studies have tried to detect steroid hormones, which are difficult to ionize by ESI or APCl, with marginal results (Jeannot et al., 2002; Ingrand et al., 2003). Not surprisingly, several studies often rely on the use of chemical derivatization to increase sensitivity, even for LC/MS (Palmgren et al., 2005; Lien et al., 2009; Wang and Schnute, 2010).

Atmospheric pressure photoionization is on the basis of the interaction of a photon beam created by a high intensity discharge lamp with the vapors of a nebulized liquid solution entering the MS source (Marchi et al., 2009). Atmospheric pressure photoionization is an ionization technique that has the capability to ionize compounds with various polarities while being remarkably tolerant of matrix additives (Cai et al., 2005; Viglino et al., 2008). The rapidly growing number of publications in this area clearly demonstrates the advantages of atmospheric pressure photoionization (Raffaelli and Saba, 2003; Bos et al., 2006; Marchi et al., 2009). Atmospheric pressure photoionization was introduced as a complement of ESI and APCI. Currently, APPI has proven to be a valuable 
tool for analytes, which are poorly or not ionized by ESI and APCI. Examples of the progress were shown in recent studies. For example, Viglino and coworkers developed a fully automated online method using LC-APPI-MS/MS to simultaneously detect selected natural and synthetic hormones at concentrations as low as $5 \mathrm{ng} / \mathrm{L}$ (Viglino et al., 2008). Yamanoto et al. compared detection of steroidal hormones using ESI and APPI and they found that APPI displayed higher sensitivity than ESI for most of the unconjugated steroids examined, with much greater sensitivity for testosterone and 4-androstene-3, 17-dione (Yamamoto et al., 2006). Itoh and coworker was able to detect 16 common polycyclic aromatic hydrocarbons (PAHs) with MDLs as low as $0.79-168 \mathrm{ng} / \mathrm{L}$ using LC/dopant-assisted (DA) APPI/MS (Itoh et al., 2006). Cai and his coworkers demonstrated a robust method to detect 16 priority PAHs in $3.5 \mathrm{~min}$ at low pictogram using chlorobenzene as the dopant. (Cai et al., 2009). Indeed, APPI not only gives superior performance on nonpolar compounds but also works well for many analytes which are properly ionized by ESI and APCI. Cai et al. suggested that APPI could be considered as a more universal ionization method since APPI was able to ionized more compounds, with greater structural diversity, than ESI and APCI (Cai et al., 2005). Because of the capacity of APPI to ionize compounds with various polarities, it has been successfully applied frequently to environmental and pharmaceutical samples (Cai et al., 2005; Yamamoto et al., 2006; Viglino et al., 2008; Garcia-Ac et al., 2011). 
Most sample preparation protocols for the analysis of microconstituents in water samples uses off-line extraction as the main sample preparation. Although relatively straightforward, the disadvantages of off-line extraction are: lengthy extractions, and solvent evaporation and dervatization effects on reproducibility. Therefore, there is considerable interest in developing on-line sample extraction procedures that mainly overcome the need for the time consuming evaporation and reconstitution steps in the off-line procedure. Many recent articles have described on-line SPE procedure for detection of EDCs (Segura et al., 2007; Viglino et al., 2008; Garcia-Ac et al., 2009; Lien et al., 2009). However, further development in environmental monitoring should target simultaneous detection of multiple classes of compounds with diverse properties using a combination of online SPE and tandem MS to achieve high sample throughput.

In this work, a novel fully automated on-line preconcentration method coupled to HPLC-APPI-MS/MS was developed for a comprehensive list of analytes with environmental relevance for water tracking in semi pristine environment. The online procedure was optimized for cleanup efficiency and analyte retention. Different ionization methods, including HESI, APCI and APPI, were explored. Atmospheric pressure photoionization was evaluated with different dopants (acetone, anisole, chlorobenzene and toluene). Statistically determined MDLs for analytes in each method were generated to cross-evaluate the method's capability. Reclaimed water is often the released end product of a WWTP treatment. As a results of water scarcity, use of reclaimed water for agricultural 
and landscape irrigation has been become increasing popular. However, the use of reclaimed water has received much less attention than WWTP effluent, and little is known about the risk of contamination of surface water and groundwater by this kind of source (Wang et al., 2005; Kinney et al., 2006). A comprehensive method should be capable of analyzing both source (reclaimed water) and the receiving water with equal robustness.

\subsection{Experimental}

\subsubsection{Chemicals}

Caffeine was purchased from Fisher Scientific (Suwannee, GA, USA). Acetaminophen, naproxen, carbamazepine, primidone, DEET (N,N-Diethyl-3methylbenzamide), triclosan, bisphenol-A, gemfibrozil, androsterone, estrone, equilin, 17ß-estradiol, testosterone, 17 $\alpha$-ethynylestradiol, coprostane, progesterone, estriol, coprostan-3-ol and coprostan-3-one were purchased as neat compounds from Sigma-Aldrich (St. Louis, MO, USA). 4-tert-octylphenol was from Restek (Bellefonte, PA, USA). Mestranol (ethynylestradiol 3-methyl ether) and equilenin were purchased as certified standard solutions from Dr. Ehrenstorfer (Augsburg, Germany); Surrogate standard caffeine-trimethyl- ${ }^{13} \mathrm{C}_{3}$ was purchased from Cambridge Isotope Laboratories Inc (Andover, MA, USA); DEET-d7, triclosan-d3, carbamazepine-d10, 4-n-nonylphenol-d4, equilin-d4, 17ßestradiol-d5, estrone-d4, 17a-ethynylestradiol-d4, norgestrel-d6, progesterone-d9 and $5 \alpha$-cholestan-3 $\beta$-ol-d5 were purchased from CDN Isotopes (Pointe-Claire, Quebec, Canada). Bisphenol A-d16 was purchased from Sigma-Aldrich (St. 
Louis, MO, USA). All the reference standards were $>95 \%$ purity. Detailed information for all analytes is shown in Table 8. Stock solutions were prepared at concentrations of $200 \mu \mathrm{g} / \mathrm{mL}$ in methanol and stored below $0{ }^{\circ} \mathrm{C}$ in the dark. All laboratory materials were either made of glass or Teflon to avoid contamination. All glassware used in extraction was cleaned with soap and rinsed with water before combustion. Glassware was combusted at $450{ }^{\circ} \mathrm{C}$ for at least six hours before using it. Teflon materials were washed with DI water, rinsed with methanol, acetone, methylene chloride and hexane before use.

\subsubsection{Sampling}

Reclaimed water used for irrigation was collected directly from a sprinkler system using $500 \mathrm{~mL}$ PETE bottles and was stored in the freezer at $<10^{\circ} \mathrm{C}$. The source of reclaimed water used in this study is the Miami-Dade Water and Sewer Department North District Wastewater Treatment Plant. The wastewater treatment plant was designed to have a flow of 120 million gallons per day (MGD) with average daily flow around 112.5 million gallons per day. Pure oxygen activated-sludge is used in the WWTP as the main secondary treatment process (Kasprzyk-Hordern et al., 2008). Extra filtration and disinfection are applied to effluents before release to make the reclaimed water ready for use in irrigation.

\subsubsection{Sample preparation}

Water samples were allowed to reach room temperature, filtered through glass fiber filters with a pore size of $0.5 \mu \mathrm{m}$ without loss of analytes and samples were 
analyzed within 14 days in order to avoid potential degradation and transformation of analytes. No additional sample preparation was required beyond the addition of surrogates. 
Table 8. Information of analytes

\begin{tabular}{|c|c|c|c|c|c|}
\hline compound & CAS & Usage/source & compound & CAS & Usage/ source \\
\hline acetaminophen & $103-90-2$ & $\begin{array}{l}\text { analgesic and anti- } \\
\text { inflammatory }\end{array}$ & testosterone & $58-22-0$ & natural hormone \\
\hline caffeine & $58-08-2$ & stimulant drug & progesterone & $57-83-0$ & natural hormone \\
\hline primidone & $125-33-7$ & anticonvulsants & androsterone & $53-41-8$ & natural hormone \\
\hline estriol & $50-27-1$ & Hormone & mestranol & $72-33-3$ & synthetic hormone \\
\hline carbamazepine & $298-46-4$ & anticonvulsant & coprostan-3-one & $601-53-6$ & fecal sterol \\
\hline DEET & $134-62-3$ & insect repellent & coprostan-3-ol & $360-68-9$ & fecal sterol \\
\hline equilenin & $517-09-9$ & natural hormone & bisphenol A & $80-05-7$ & $\begin{array}{l}\text { intermediate in } \\
\text { synthesis of plastics }\end{array}$ \\
\hline naproxen & $\begin{array}{l}22204-53- \\
1\end{array}$ & $\begin{array}{c}\text { analgesic and anti- } \\
\text { inflammatory }\end{array}$ & ibuprofen & $15687-27-1$ & $\begin{array}{l}\text { analgesic and anti- } \\
\text { inflammatory }\end{array}$ \\
\hline $\begin{array}{l}17 \alpha- \\
\text { ethynylestradiol }\end{array}$ & $57-63-6$ & synthetic hormone & triclosan & $3380-34-5$ & $\begin{array}{l}\text { antibacterial and } \\
\text { antifungal agent }\end{array}$ \\
\hline equilin & $474-86-2$ & natural hormone & 4-tert-octylphenol & $27193-28-8$ & $\begin{array}{c}\text { degradation of } \\
\text { octylphenolethoxylates }\end{array}$ \\
\hline
\end{tabular}




\begin{tabular}{cccccc}
\hline compound & CAS & Usage/source & compound & CAS & Usage/ source \\
\hline $17 \beta$-estradiol & $50-28-2$ & natural hormone & gemfibrozil & $25812-30-0$ & Lipid regulator \\
estrone & $53-16-7$ & natural hormone & & \\
\hline
\end{tabular}




\subsubsection{Instrumentation}

An EQuan Environmental Quantitation system manufactured by Thermo Fisher Scientific was used to preconcentrate microconstituents from reclaimed water. The EQuan ${ }^{\mathrm{TM}}$ system is based on a dual switching-column system, which consists of a sample delivery system, a switching-column array and an LCMS/MS system. Its sample delivery system consists of an autosampler manufactured by CTC analytics AG (Zwingen, Switzerland) and an Accela 600 loading pump (Thermo Fisher Scientific, San Jose, CA, USA). Its columnswitching array is composed of a Rheodyne $7750 \mathrm{E}-205$ six-port switching valve system made by IDEX (Oak Arbor, WA, USA), a preconcentration column and an analytical column. A Thermo Hypersil aQ $(20 \mathrm{~mm} \times 2.1 \mathrm{~mm}, 12 \mu \mathrm{m}$ particle size $)$ was used as the loading column and a Thermo Hypersil Gold $(50 \mathrm{~mm} \times 2.1 \mathrm{~mm}$, $1.9 \mu \mathrm{m}$ particle size) was used as the analytical column. Mass spectrometry analysis was performed using a TSQ Quantum Access triple quadrupole mass spectrometer (Thermo Fisher Scientific, San Jose, CA, USA).

\subsubsection{On-line SPE setup}

Depending on the expected target analyte concentration, $5 \mathrm{~mL}$ or $20 \mathrm{~mL}$ samples were injected into the sample loop (step 1 in figure 10) and then loaded to the preconcentration column at a flow rate of $1 \mathrm{~mL} / \mathrm{min}$ (step 2 in figure 10). This loading rate allowed good overall recoveries of analytes. The preconcentration column was washed by $1000 \mu \mathrm{L}$ of water with varied amount of methanol and connected to the analytical column after the valve had switched to the inject 
position. The loading column and analytical column underwent the same gradient in the positive ionization $(\mathrm{PI})$ mode or negative ionization ( $\mathrm{NI}$ ) mode (step 3 in figure 10). The gradient details are shown in Table 9.

\section{Step 1}

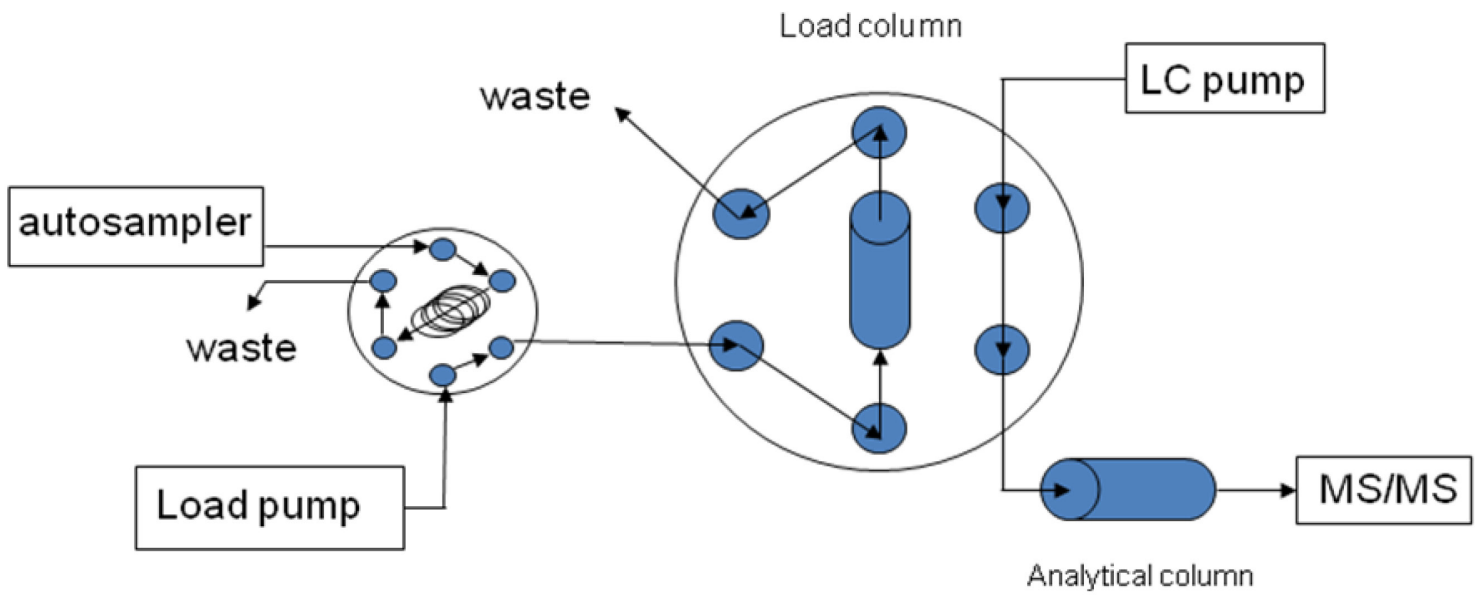

Step 2

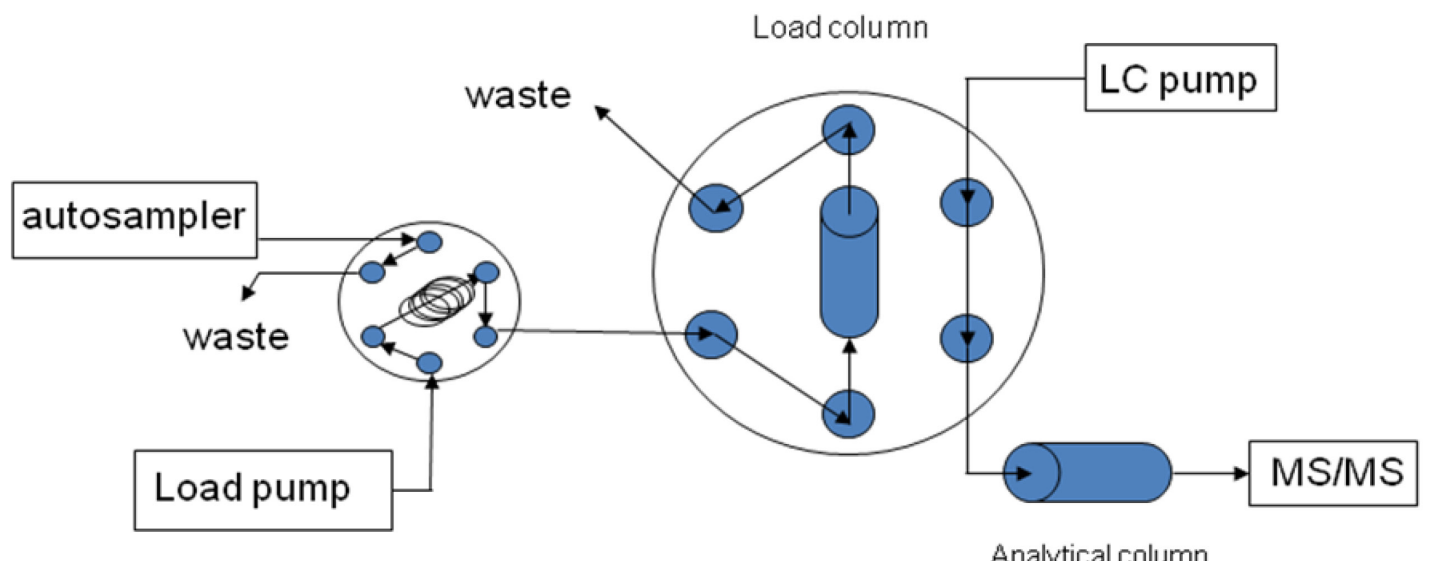

Analytical column 
Step 3

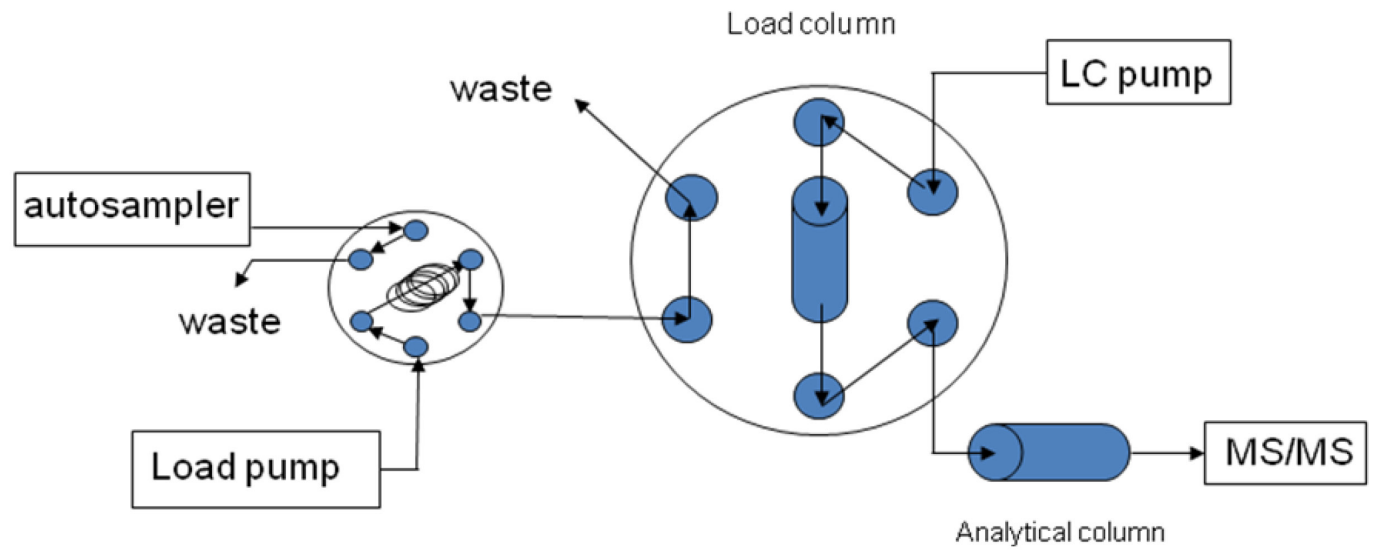

Figure 10. On-line SPE procedure

\subsubsection{Mass spectrometry}

Mass spectrometry analysis was performed using a TSQ Quantum Access QqQ Mass Spectrometer (Thermo Scientific, San Jose, CA, USA). Quantitation for all sources was performed using selected reaction monitoring. Instrument control and data acquisition were performed using Xcalibur software (rev. 2.1, Thermo Scientific, San Jose, CA, USA). Source parameters for analytes were optimized using $\mathrm{HESI}, \mathrm{APCl}$ and $\mathrm{APPI}$ independently. A mobile phase of $0.1 \%$ fomic acid/MeOH $(50: 50, v / v)$ was used for the positive ionization mode and water $/ \mathrm{MeOH}(50: 50, \mathrm{v} / \mathrm{v})$ was used for the negative ionization mode. Each analyte and surrogate was injected to the ion source at a concentration of 10 $\mu \mathrm{g} / \mathrm{mL}$. Compound-dependent parameters such as tube lens and collision energy were optimized to obtain maximum signals. The APPI source was further 
optimized for the dopants described before. Results are shown in Table 10a, 10b and 10c.

Table 9. Gradient of load pump and analytical pump

\begin{tabular}{|c|c|c|c|c|c|c|c|}
\hline \multirow[b]{2}{*}{$\begin{array}{l}\text { Time } \\
(\min )\end{array}$} & \multicolumn{3}{|c|}{ Load Pump } & \multicolumn{3}{|c|}{ Analytical Pump } & \multirow{2}{*}{$\begin{array}{l}\text { Valve } \\
\text { position }\end{array}$} \\
\hline & $\begin{array}{c}\text { Solvent A } \\
\text { water } \\
(\%)\end{array}$ & $\begin{array}{l}\text { Solvent B } \\
\text { methanol } \\
(\%)\end{array}$ & $\begin{array}{c}\text { Flow } \\
\text { rate } \\
(\mu \mathrm{L} \\
\left.\mathrm{min}^{-1}\right)\end{array}$ & $\begin{array}{l}\text { Solvent B } \\
\text { methanol } \\
(\%)\end{array}$ & $\begin{array}{c}\text { Solvent D } \\
0.1 \% \mathrm{FA} \\
\text { in water } \\
(\%)\end{array}$ & $\begin{array}{c}\text { Flow } \\
\text { rate } \\
\left(\mu L_{1} \min ^{-}\right.\end{array}$ & \\
\hline & \multicolumn{7}{|c|}{ PI mode } \\
\hline 0.0 & 75 & 25 & 1000 & 10 & 90 & 200 & Load \\
\hline 6.0 & 75 & 25 & 1000 & & 1 & & Inject \\
\hline 6.1 & 0 & 100 & 250 & & & & \\
\hline 7.0 & & & & 10 & 90 & & \\
\hline 14.0 & & & & 100 & 0 & & \\
\hline 26.0 & & & $\downarrow$ & 100 & 0 & & \\
\hline 27.0 & $\downarrow$ & $\downarrow$ & 250 & 10 & 90 & & Load \\
\hline 27.1 & 0 & 100 & 1000 & 1 & & & \\
\hline 28.0 & 0 & 100 & & & & & \\
\hline 28.1 & 100 & 0 & & $\downarrow$ & $\downarrow$ & $\downarrow$ & \\
\hline \multirow[t]{2}{*}{33.0} & 100 & 0 & $\downarrow$ & 10 & 90 & 200 & \\
\hline & $\begin{array}{c}\text { Solvent A } \\
\text { water } \\
(\%)\end{array}$ & $\begin{array}{l}\text { Solvent B } \\
\text { methanol } \\
(\%)\end{array}$ & $\begin{array}{l}\text { Flow } \\
\text { rate } \\
(\mu \mathrm{L} \\
\left.\mathrm{min}^{-1}\right)\end{array}$ & $\begin{array}{l}\text { mode } \\
\text { Solvent A } \\
\text { water } \\
(\%)\end{array}$ & $\begin{array}{l}\text { Solvent B } \\
\text { methanol } \\
(\%)\end{array}$ & $\begin{array}{c}\text { Flow } \\
\text { rate } \\
\left(\mu L_{1} \min ^{-}\right.\end{array}$ & \\
\hline 0.0 & 25 & 75 & 1000 & 50 & 50 & 200 & Load \\
\hline 6.0 & 25 & 75 & 1000 & & 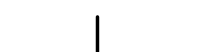 & & Inject \\
\hline 6.1 & 0 & 100 & 720 & $\downarrow$ & & & \\
\hline 7.0 & 1 & & & 50 & 50 & & \\
\hline 8.0 & & & & 0 & 100 & & \\
\hline 12.0 & $\downarrow$ & $\downarrow$ & & 0 & 100 & & \\
\hline 14.0 & 0 & 100 & 720 & 50 & 50 & & \\
\hline 14.1 & 0 & 100 & 1000 & & & & Load \\
\hline 15.0 & 0 & 100 & & & & & \\
\hline 15.1 & 100 & 0 & & $\downarrow$ & $\downarrow$ & $\downarrow$ & \\
\hline 20.0 & 100 & 0 & & 50 & 50 & 200 & \\
\hline
\end{tabular}


Table 10a. Ions of analytes in ESI

\begin{tabular}{lccccccccc}
\hline Analyte & & \multicolumn{7}{c}{ ESI parameter } \\
\hline \multirow{2}{*}{ acetaminophen } & Precursor ion & $\mathrm{m} / \mathrm{z}$ & SRM1 & CE1 & SRM2 & CE2 & SRM3 & CE3 & tube lens \\
\cline { 2 - 10 } Caffeine & {$[\mathrm{M}+\mathrm{H}]+$} & 150.0 & 107.2 & 22 & 118.1 & 33 & 132.1 & 24 & 49 \\
Primidone & {$[\mathrm{M}+\mathrm{H}]+$} & 195.1 & 138.2 & 18 & 110.2 & 22 & 83.3 & 26 & 67 \\
Estriol & {$[\mathrm{M}+\mathrm{H}]+$} & 219.1 & 91.2 & 28 & 162.2 & 12 & 117.2 & 23 & 68 \\
Carbamazepine & {$[\mathrm{M}-\mathrm{H}]-$} & 287.1 & 145.2 & 41 & 171.1 & 37 & 159.2 & 40 & 94 \\
DEET & {$[\mathrm{M}+\mathrm{H}]+$} & 237.1 & 194.1 & 19 & 192.1 & 25 & & & 61 \\
Equilenin & {$[\mathrm{M}+\mathrm{H}]+$} & 192.1 & 91.3 & 25.0 & 119.2 & 11.0 & 65.3 & 36.0 & 72 \\
Naproxen & {$[\mathrm{M}-\mathrm{H}]-$} & 265.1 & 193.1 & 47 & 221.1 & 35 & 181.1 & 40 & 81 \\
17a-ethynylestradiol & {$[\mathrm{M}-\mathrm{H}]-$} & 229.0 & 170.1 & 18 & 185.2 & 11 & & & 60 \\
Equilin & {$[\mathrm{M}-\mathrm{H}]-$} & 295.2 & 145.1 & 23 & 143.2 & 45 & 267.2 & 15 & 99 \\
$17 \beta-e s t r a d i o l$ & {$[\mathrm{M}-\mathrm{H}]-$} & 267.1 & 143.1 & 36 & 115.2 & 47 & 145.1 & 30 & 70 \\
estrone & {$[\mathrm{M}-\mathrm{H}]-$} & 271.1 & 145.1 & 45 & 146.2 & 35 & 158.0 & 33 & 79 \\
Testosterone & {$[\mathrm{M}-\mathrm{H}]-$} & 269.1 & 145.1 & 40 & 159.1 & 37 & 143.2 & 56 & 78 \\
Androsterone & {$[\mathrm{M}+\mathrm{H}]+$} & 289.2 & 109.2 & 25 & 97.2 & 25 & 79.3 & 39 & 109 \\
& {$[\mathrm{M}+\mathrm{H}]+$} & 291.2 & 273.2 & 8 & 255.2 & 13 & 199.1 & 19 & 97
\end{tabular}




\begin{tabular}{lccccccccc}
\hline Analyte & & \multicolumn{7}{c}{ ESI parameter } \\
\hline $\begin{array}{l}\text { Progesterone } \\
\text { Mestranol }\end{array}$ & {$[\mathrm{M}+\mathrm{H}]+$} & 315.2 & 109.2 & 25 & 97.2 & 24 & 79.3 & 41 & 98 \\
$\begin{array}{l}\text { coprostan-3-one } \\
\text { coprostan-3-ol }\end{array}$ & {$[\mathrm{M}+\mathrm{H}]+$} & 387.3 & 369.4 & 11 & 95.2 & 30 & 119.3 & 32 & 129 \\
bisphenol A & & & & & & & & & \\
Ibuprofen & {$[\mathrm{M}-\mathrm{H}]-$} & 227.1 & 212.4 & 20 & 133.3 & 28 & 158.7 & 11 & 94 \\
$\begin{array}{l}\text { Triclosan } \\
\text { 4-tert-octylphenol }\end{array}$ & {$[\mathrm{M}-\mathrm{H}]-$} & 205.1 & 161.3 & 10 & & & & & 51 \\
Gemfibrozil & {$[\mathrm{M}-\mathrm{H}]-$} & 286.9 & 142.1 & 34 & 160.9 & 38 & 35.4 & 11 & 111 \\
\hline & {$[\mathrm{M}-\mathrm{H}]-$} & 205.1 & 133.1 & 26 & 134.1 & 21 & 117.1 & 72 & 99 \\
\hline
\end{tabular}

Table 10b. Ions of analytes in APCI

\begin{tabular}{lccccccccc}
\hline Analyte & \multicolumn{10}{c}{ APCl parameter } \\
\hline \multirow{3}{*}{ Acetaminophen } & Precursor ion & $\mathrm{m} / \mathrm{z}$ & SRM1 & CE1 & SRM2 & CE2 & SRM3 & CE3 & tube lens \\
\cline { 2 - 9 } Caffeine & {$[\mathrm{M}+\mathrm{H}]+$} & 152.0 & 110.1 & 16 & 93.1 & 24 & 65.3 & 29 & 82 \\
Primidone & {$[\mathrm{M}+\mathrm{H}]+$} & 195.1 & 138.0 & 19 & 110.1 & 23 & 123.0 & 31 & 87 \\
& {$[\mathrm{M}+\mathrm{H}]+$} & 219.1 & 91.2 & 28 & 162.0 & 12 & 119.1 & 16 & 83
\end{tabular}




\begin{tabular}{lccccccccc}
\hline Analyte & & \multicolumn{7}{c}{$\mathrm{APCl}$ parameter } \\
\hline Estriol & {$[\mathrm{M}-\mathrm{H} 2 \mathrm{O}+\mathrm{H}]+$} & 271.1 & 253.0 & 12 & 157.0 & 21 & 133.0 & 23 & 76 \\
Carbamazepine & {$[\mathrm{M}+\mathrm{H}]+$} & 237.0 & 193.9 & 19 & 192.9 & 33 & 191.9 & 24 & 93 \\
DEET & {$[\mathrm{M}+\mathrm{H}]+$} & 192.1 & 119.1 & 17 & 91.2 & 28 & 65.3 & 43 & 76 \\
Equilenin & {$[\mathrm{M}+\mathrm{H}]+$} & 267.1 & 209.0 & 18 & 249.0 & 12 & 165.0 & 50 & 70 \\
Naproxen & {$[\mathrm{M}+\mathrm{H}]+$} & 231.0 & 184.9 & 14 & 170.0 & 25 & 141.0 & 44 & 91 \\
17a-ethynylestradiol & {$[\mathrm{M}-\mathrm{H} 2 \mathrm{O}+\mathrm{H}]+$} & 279.1 & 133.0 & 16 & 159 & 21.0 & 105.1 & 32 & 78 \\
Equilin & {$[\mathrm{M}+\mathrm{H}]+$} & 269.1 & 251.0 & 13 & 211.0 & 18 & 181.0 & 40 & 78 \\
17ß-estradiol & {$[\mathrm{M}-\mathrm{H} 2 \mathrm{O}+\mathrm{H}]+$} & 255.2 & 159.1 & 18 & 133.1 & 22 & 144.1 & 37 & 76 \\
estrone & {$[\mathrm{M}+\mathrm{H}]+$} & 271.2 & 253.0 & 12 & 157.0 & 19 & 159.0 & 22 & 78 \\
Testosterone & {$[\mathrm{M}+\mathrm{H}]+$} & 289.2 & 97.1 & 24 & 109.1 & 26 & 253.0 & 16 & 83 \\
Androsterone & {$[\mathrm{M}-\mathrm{H} 2 \mathrm{O}+\mathrm{H}]+$} & 273.2 & 255.2 & 10 & 91.129 & 38 & 105.1 & 35 & 90 \\
Progesterone & {$[\mathrm{M}+\mathrm{H}]+$} & 315.2 & 109.1 & 27 & 97.1 & 25 & 297.0 & 14 & 81 \\
Mestranol & {$[\mathrm{M}-\mathrm{H} 2 \mathrm{O}+\mathrm{H}]+$} & 285.2 & 267.0 & 14 & 171.0 & 19 & 173.0 & 23 & 66 \\
coprostan-3-one & {$[\mathrm{M}+\mathrm{H}]+$} & 387.3 & 369.3 & 10 & 95.12 & 33 & 147.0 & 25 & 94 \\
coprostan-3-ol & {$[\mathrm{M}-\mathrm{H} 2 \mathrm{O}+\mathrm{H}]+$} & 371.3 & 95.1 & 30 & 81.2 & 31 & 109.1 & 27.0 & 90 \\
bisphenol A & {$[\mathrm{M}-\mathrm{H}]-$} & 227.1 & 211.9 & 21 & 133.0 & 31 & 210.9 & 34 & 88
\end{tabular}




\begin{tabular}{lcccccccccc}
\hline Analyte & \multicolumn{10}{c}{ APCl parameter } \\
\hline Ibuprofen & {$[\mathrm{M}-\mathrm{H}]-$} & 205.2 & 161.2 & 10 & & & & & 58 \\
Triclosan & {$[\mathrm{M}-\mathrm{Cl}-2 \mathrm{H}]-$} & 250.9 & 214.9 & 26 & 186.9 & 32.0 & 159.0 & 31.0 & 75 \\
4-tert-octylphenol & {$[\mathrm{M}-\mathrm{H}]-$} & 205.1 & 133.1 & 29 & 134.1 & 21 & 117.1 & 64 & 94 \\
Gemfibrozil & {$[\mathrm{M}+\mathrm{H}]+$} & 251.1 & 232.8 & 5 & 129.0 & 8 & 83.2 & 13 & 87 \\
\hline
\end{tabular}

Table 10c. Ions of analytes in APPI

\begin{tabular}{|c|c|c|c|c|c|c|c|c|c|c|}
\hline \multirow[t]{2}{*}{ Analyte } & \multirow[t]{2}{*}{$\mathrm{RT}$ (min) } & \multicolumn{9}{|c|}{ APPI parameter } \\
\hline & & Precursor ion & $\mathrm{m} / \mathrm{z}$ & SRM1 & CE1 & SRM2 & CE2 & SRM3 & CE3 & tube lens \\
\hline Acetaminophen & 8.2 & {$[\mathrm{M}+\mathrm{H}]+$} & 152.1 & 110.1 & 15 & 65.3 & 31 & 93.2 & 23 & 100 \\
\hline Caffeine & 11.46 & {$[\mathrm{M}+\mathrm{H}]+$} & 195.1 & 138.1 & 19 & 110.2 & 22 & 123.1 & 31 & 100 \\
\hline Primidone & 12.44 & {$[\mathrm{M}+\mathrm{H}]+$} & 219.1 & 162.1 & 13 & 91.2 & 34 & 119.1 & 18 & 98 \\
\hline Estriol & 13.28 & {$[\mathrm{M}-\mathrm{H} 2 \mathrm{O}+\mathrm{H}]+$} & 271.1 & 253.1 & 12 & 133 & 30 & 159.1 & 30 & 75 \\
\hline Carbamazepine & 13.66 & {$[\mathrm{M}+\mathrm{H}]+$} & 237.1 & 194.1 & 18 & 192.1 & 23 & 179.1 & 35 & 87 \\
\hline DEET & 14.09 & {$[\mathrm{M}+\mathrm{H}]+$} & 192.1 & 119.1 & 17 & 91.2 & 31 & 65.3 & 43 & 88 \\
\hline Equilenin & 14.59 & {$[\mathrm{M}+\mathrm{H}]+$} & 267.1 & 209.1 & 18 & 249.1 & 11 & 165.1 & 52 & 93 \\
\hline
\end{tabular}




\begin{tabular}{lllllllllll}
\hline Analyte & RT $(\mathrm{min})$ & & \multicolumn{7}{c}{ APPI parameter } \\
\hline Naproxen & 14.62 & {$[\mathrm{M}-\mathrm{COOH}]+$} & 185.1 & 170.1 & 17 & 141.1 & 33 & 115.1 & 49 & 84 \\
17a-ethynylestradiol & 14.66 & {$[\mathrm{M}-\mathrm{H} 2 \mathrm{O}+\mathrm{H}]+$} & 279.1 & 133.1 & 17 & 159 & 19 & 105.1 & 37 & 82 \\
Equilin & 14.67 & {$[\mathrm{M}+\mathrm{H}]+$} & 269.1 & 251.1 & 14 & 211.1 & 18 & 181 & 38 & 103 \\
17ß-estradiol & 14.69 & {$[\mathrm{M}-\mathrm{H} 2 \mathrm{O}+\mathrm{H}]+$} & 255.1 & 159 & 17 & 133.1 & 19 & 144 & 36 & 76 \\
estrone & 14.76 & {$[\mathrm{M}+\mathrm{H}]+$} & 271.1 & 2531.1 & 12 & 159 & 21 & 157 & 19 & 90 \\
Testosterone & 15.06 & {$[\mathrm{M}+\mathrm{H}]+$} & 289.2 & 97.1 & 23 & 109.1 & 24 & 253.2 & 16 & 107 \\
Androsterone & 15.96 & {$[\mathrm{M}-\mathrm{H} 2 \mathrm{O}+\mathrm{H}]+$} & 273.2 & 255.2 & 13 & 105.2 & 39 & 161.1 & 23 & 104 \\
Progesterone & 15.64 & {$[\mathrm{M}+\mathrm{H}]+$} & 315.2 & 109.1 & 22 & 97.1 & 21 & 297.3 & 15 & 68 \\
Mestranol & 16.18 & {$[\mathrm{M}+\mathrm{H}]+$} & 293.2 & 147.1 & 18 & 173.1 & 21 & 158.1 & 34 & 91 \\
coprostan-3-one & 22.04 & {$[\mathrm{M}+\mathrm{H}]+$} & 387.3 & 369.3 & 16 & 95.2 & 35 & 109.1 & 28 & 104 \\
coprostan-3-ol & 22.09 & {$[\mathrm{M}-\mathrm{H} 2 \mathrm{O}+\mathrm{H}]+$} & 371.3 & 95.2 & 31 & 81.2 & 34 & 109.1 & 26 & 103 \\
bisphenol A & 12.14 & {$[\mathrm{M}-\mathrm{H}]-$} & 227.1 & 212 & 22 & 211 & 35 & 133.1 & 34 & 87 \\
Ibuprofen & 13.20 & {$[\mathrm{M}-\mathrm{H}]-$} & 205.1 & 161.1 & 11 & & & & 56 \\
Triclosan & 13.43 & {$[\mathrm{M}-\mathrm{Cl}-2 \mathrm{H}]-$} & 250.9 & 215 & 22 & 187 & 31 & 159 & 29 & 100 \\
4-tert-octylphenol & 13.59 & {$[\mathrm{M}-\mathrm{H}]-$} & 205.1 & 133.1 & 28 & 134.1 & 20 & 117.2 & 62 & 98 \\
Gemfibrozil & 13.69 & {$[\mathrm{M}-\mathrm{H}]-$} & 249.1 & 121.1 & 17 & 127.1 & 14 & 106.2 & 45 & 73 \\
\hline & & & & & & & & \\
\hline
\end{tabular}


To avoid introducing additional variability, ionization techniques were performed using a common Ion MAX source housing (Thermo Scientific, San Jose, CA, USA). Source-dependent parameters for optimal HESI detection were as follows: capillary temperature $\left(300{ }^{\circ} \mathrm{C}\right)$, vaporizer temperature $\left(350{ }^{\circ} \mathrm{C}\right)$, sheath gas pressure (35 arbitrary units), aux gas pressure ( 5 arbitrary units), ion sweep gas pressure (8 arbitrary units) and spray voltage $(+4000 \mathrm{~V}$ and $-3500 \mathrm{~V})$.

Source-dependent parameters for optimal APCI detection were as follows: capillary temperature $\left(270{ }^{\circ} \mathrm{C}\right)$, vaporizer temperature $\left(400{ }^{\circ} \mathrm{C}\right)$, sheath gas pressure (30 arbitrary units), aux gas pressure ( 5 arbitrary units), ion sweep gas pressure ( 0 arbitrary units) and discharge current $(4 \mu \mathrm{A})$ for both positive and negative polarity.

The photoionization lamp used for APPI was a Syagen krypton UV lamp which emits photons at $10 \mathrm{eV}$ and $10.6 \mathrm{eV}$ (Syagen Technology Inc., Tustin, CA, USA). The source-dependent parameters for optimal detection were as follows: capillary temperature $\left(270{ }^{\circ} \mathrm{C}\right)$, vaporizer temperature $\left(400{ }^{\circ} \mathrm{C}\right)$, sheath gas pressure (30 arbitrary units), aux gas pressure (5 arbitrary units), ion sweep gas pressure (0 arbitrary units) and discharge current $(0 \mu \mathrm{A})$. Four different dopants, acetone, anisole, chlorobenzene and toluene, were tested to find the best one for the analytes. 


\subsubsection{Matrix effect}

Signal suppression or enhancement effects have been widely reported in the literature when complicated matrices are tested in API (Viglino et al., 2008). Therefore, matrix effects were evaluated using the following equation 1.

matrixeffect $(\%)=\left(\frac{R W s-R W n s}{D I s}\right) \times 100 \%$

$\mathrm{RWs}$ is the analyte peak area in the spiked reclaimed water, RWns is the analyte peak area in the non-spiked reclaimed water and DIs is the analyte peak area in DI water spiked with a known amount of analytes. Signal enhancement is indicated by matrix effect values more than $100 \%$, while signal suppression is indicated by matrix effect values less than 100\% (Garcia-Ac et al., 2009). Three replicate samples were run to determine the relative standard deviation (RSD). Spike level of analytes were four times of the spike level used to calculate MDLs, which is shown in table 11.

\subsubsection{Extraction recovery and method detection limit}

Analyte recovery was evaluated by measuring $5 \mathrm{~mL}$ spiked tap water samples since it is more comparable to environmental waters than DI water. The spiked level of analytes for method detection limits is shown in table 11. For each compound, three different spike levels from low to high were tested to evaluate how different spike amounts would affect recovery of compounds. Method detection limits (MDLs) were determined according to EPA guidelines (Ripp, 1996). Eight replicate tap water samples spiked with all compounds with 
concentration ranging from one to eight times of the tested detection limit (DL). Standard deviations (SD) were calculated from replicates and MDL $=2.998$ SD. MDLs were calculated for $5 \mathrm{~mL}$ sample size and $20 \mathrm{~mL}$ sample size.

\subsubsection{QA/QC}

Blanks were run with each batch to check for potential contamination and assess background levels of native analytes. Spiked blanks (LBS) and matrix spikes (MS) were also run with each analytical batch to check the recovery of analytes. Isotopic dilution was used to increase the precision and accuracy of analytsis. A five-point calibration curve was constructed with each batch of 20 or less samples to check for linearity and analytical sensitivity. Calibration range is shown in table 11.

\subsection{Results and discussion}

\subsubsection{Online procedure optimization}

Optimization of key parameters is essential in the development of a robust online procedure: mobile phase flow rate, sample volume, loading flow rate, wash flow rate, wash volume and organic composition of the wash solvent were all tested. Based on previous study (Lien et al., 2009), the analytical mobile phase flow was set at $200 \mu \mathrm{L} / \mathrm{min}$ to produce better analyte signal strength. $1 \mathrm{~mL} / \mathrm{min}$ was chosen as the optimum loading flow rate since it allowed good overall recoveries of analytes and higher flow rates have shown to affect the long-term functioning

of loading columns (Garcia-Ac et al., 2009). The presence of dissolved organic 
substances in environmental waters could introduce severe interference and make quantitation complicated (Viglino et al., 2008). Thus, a wash step was used after the loading step. To avoid introducing pressure change, the washing flow rate was kept the same as the loading step $(1 \mathrm{~mL} / \mathrm{min})$. The amount of washing time (0.5 and 1.0 mins) and percentages of methanol $(25 \%, 50 \%, 75 \%$ and $100 \%)$ were changed for all target compounds using $5 \mathrm{~mL}$ sample size. Results from this optimization are shown in Figure 11. When washing with a volume of $500 \mu \mathrm{L}$ ( $0.5 \mathrm{~min})$, all the compounds except acetaminophen were effectively retained on the loading column independent of the percentage of methanol used (Figure 11a). Acetaminophen is very water soluble and was not well retained on the column even after washing with only $500 \mu \mathrm{L}$ of pure water (recovery was $56 \% \pm 5 \%$ ). Therefore, the Hypersil aQ column is not a good choice to retain acetaminophen. When the preconcentration column was washed with a volume of $1000 \mu \mathrm{L}(1.0$ min), caffeine and primidone recoveries decreased for methanol content above $25 \%$ (Figure 11b). Quantification of hormones is also difficult because of the organic matter interference background when the wash step was eliminated, but it improves significantly after the preconcentration column is washed. Therefore, a wash step of $1000 \mu \mathrm{L}$ water with $25 \%$ methanol was finally used because it represents the best overall performance for recoveries and sensitivities, except for acetaminophen, that is poorly recovered under most conditions tested. In negative mode, analytes were retained on the preconcentration column very well and $1000 \mu \mathrm{L}$ water with $75 \%$ methanol was used as the wash step. 


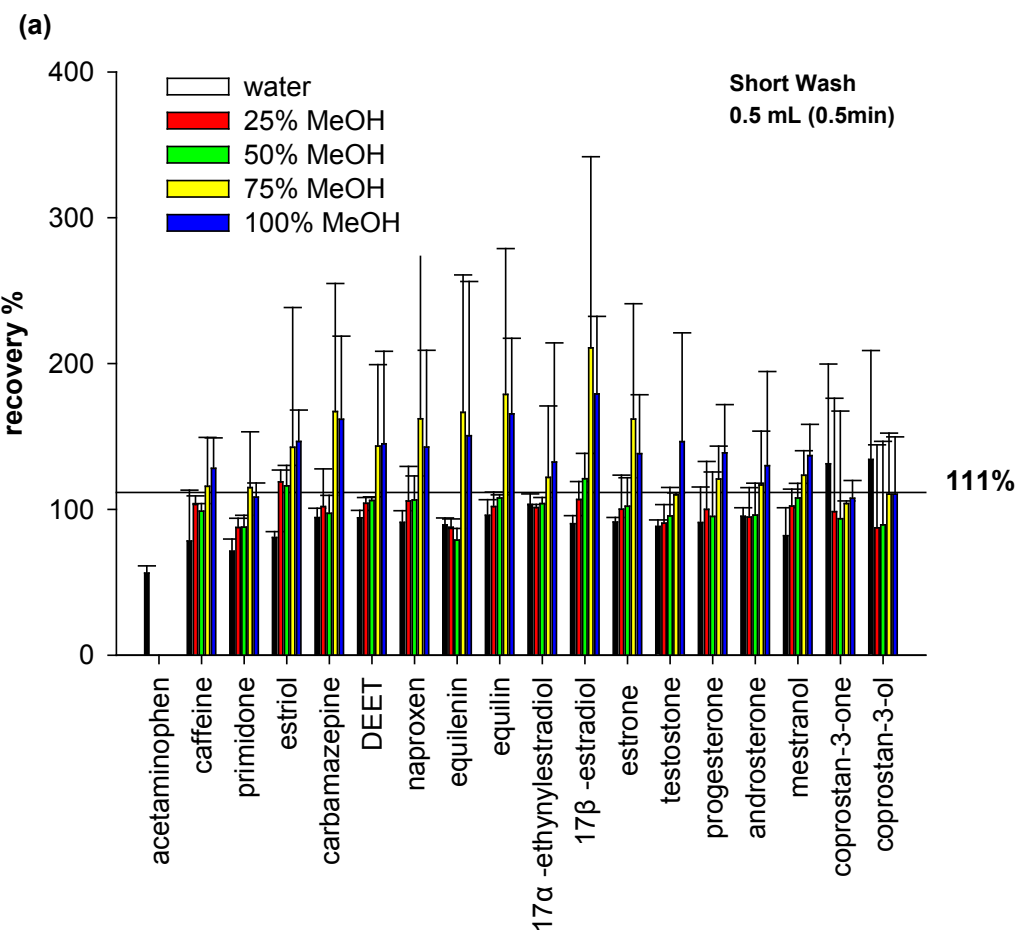

(b)

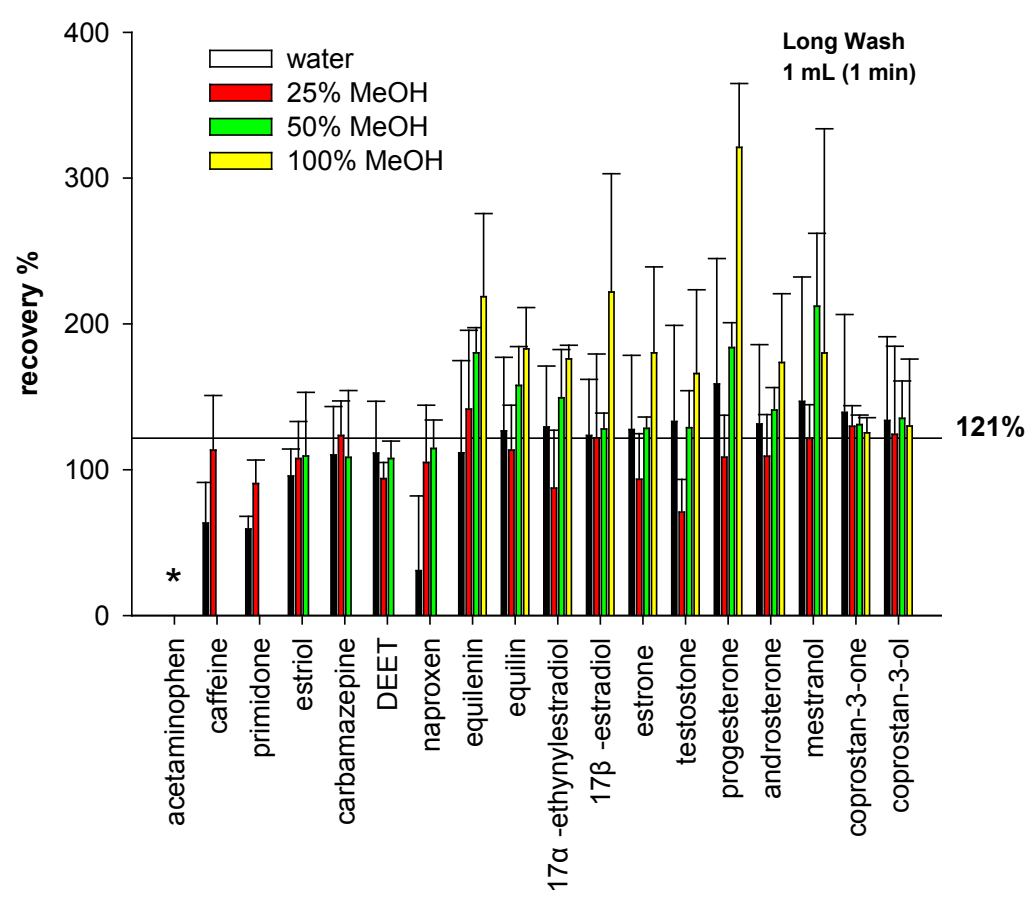

Figure 11. Recovery of analytes during the washing step after loading. (a) 500 $\mu \mathrm{L}$ wash with increasing methanol composition And (b) $1000 \mu \mathrm{L}$ wash with increasing methanol composition. Asterisk $\left(^{*}\right)$ indicates not recovered. Spike levels are shown in table 11. 


\subsubsection{Comparisons of different ion sources based on MDLs}

Analytes detected in positive mode were separated into three categories according to their chemical functionalities and general properties: the pharmaceuticals, the hormones and the sterols. Because MDLs were dramatically different between categories, MDLs were compared for compounds within each category with $5 \mathrm{~mL}$ sample size. The best ionization source was determined by direct comparison of the MDLs. Analytes detected in the negative ionization mode were separated into a fourth category. In each group, compounds were ordered based on the average MDL of the different ionization methods. Results are summarized in Figure 12,13 and 14.

\subsubsection{Pharmaceuticals and personal care products}

The first three compounds of the six compounds in this category, carbamazepine, DEET and caffeine, are easily detected in all ion sources (Figure 12). Previous studies indicate that these three compounds are better detected using ESI (Castiglioni et al., 2005; Trenholm et al., 2008). Our results indicate that APPI with toluene is also an excellent alternative. MDLs for the next three compounds, naproxen, acetaminophen and primidone, were higher than the first three compounds. For naproxen, acetaminophen and primidone, the best detection methods were APPI with toluene $(15.4 \mathrm{ng} / \mathrm{L}), \mathrm{APCl}(1.92 \mathrm{ng} / \mathrm{L})$ and APPI with toluene $(38.3 \mathrm{ng} / \mathrm{L})$, respectively. Despite the fact that $\mathrm{ESI}$ and $\mathrm{APCl}$ showed advantage for certain compounds in the category, APPI with toluene is a good overall choice to detect them. 


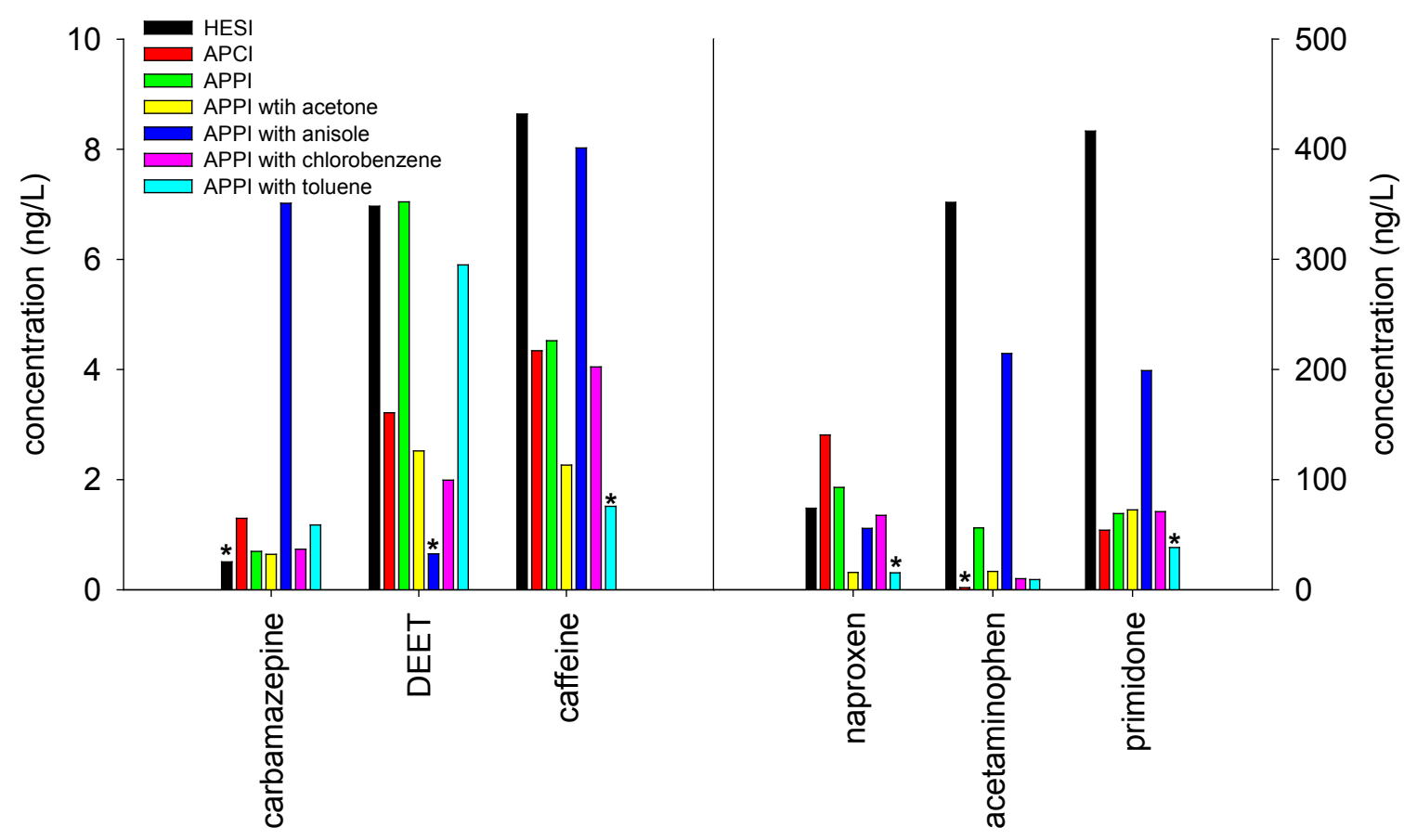

Figure 12. MDLs of pharmaceuticals for all ionization mechanisms tested. Note the different axes. Asterisk $\left({ }^{*}\right)$ indicates best performance

\subsubsection{Hormones}

Ten natural and synthetic hormones were investigated in this category. Seven out of ten compounds, testosterone, equilenin, equilin, 17a-ethynylestradiol, androsterone, estriol and mestranol, were best detected using APPI with toluene (Figure 13). Two out of ten compounds, progesterone, $17 \beta$-estradiol were best detected using APPI with chlorobenzene. One out of ten compounds, estrone, was best detected using APPI with acetone. However, for this category, APPI significantly outperformed all other ionization modes. 


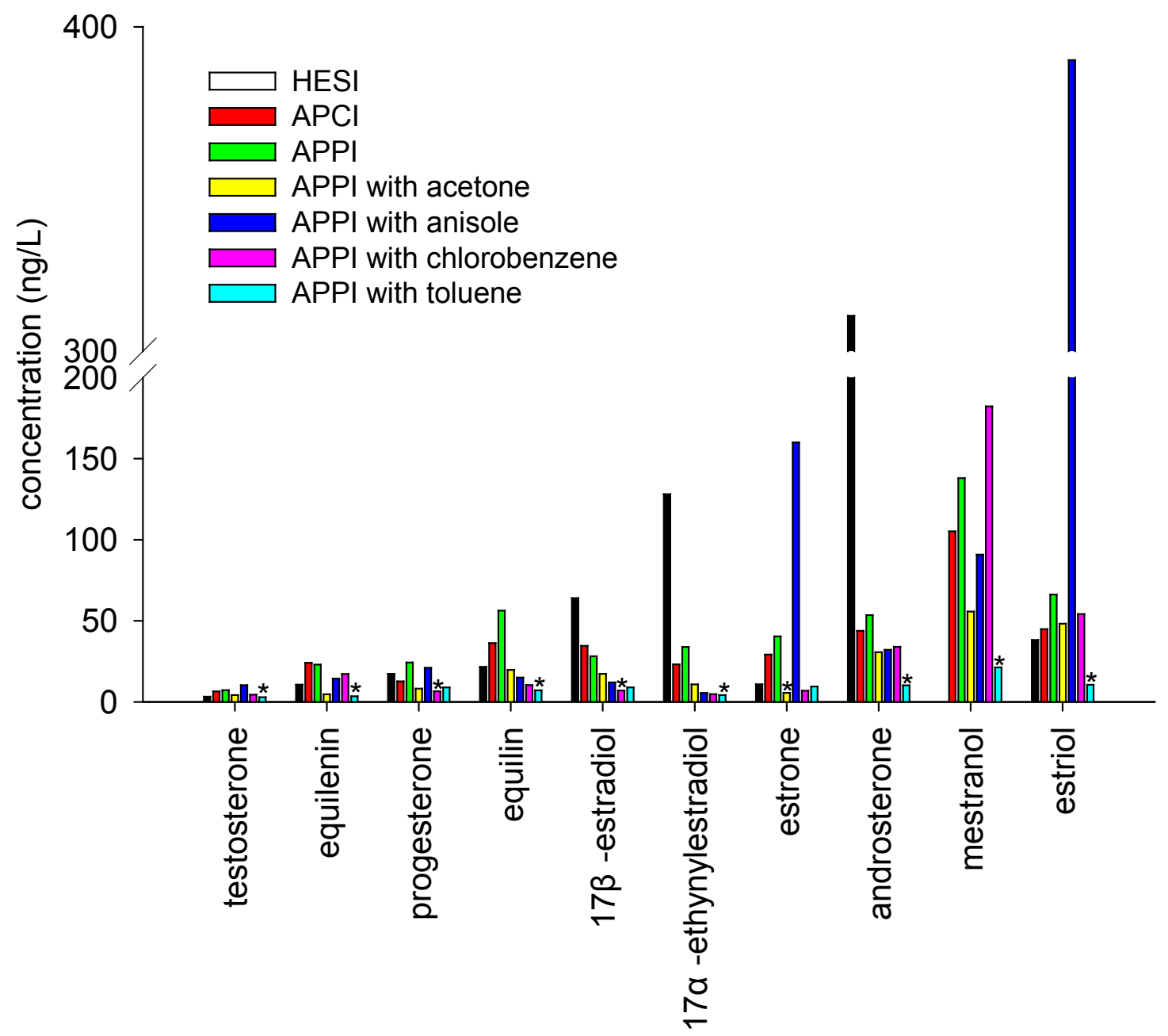

Figure 13. MDLs of hormones for all ionization mechanisms tested

Testosterone and progesterone behaved slightly differently. The two compounds showed overall low detection limits for all ion sources tested. A one way ANOVA comparison showed that there was no significant difference between ion sources. Equilenin and equilin required presence of dopants to improve the MDLs. The best dopant for them was toluene with MDLs of $3.44 \mathrm{ng} / \mathrm{L}$ and $7.15 \mathrm{ng} / \mathrm{L}$, respectively. 17ß-estradiol, 17a-ethynylestradiol (EE2), androsterone and 
mestranol had similar results. These four analytes were extremely hard to ionize in HESI and mestranol even did not yield a signal in HESI. MDLs improved slightly when APCI and APPI were used but dramatically decreased when dopants were added. Toluene was the best dopant for all of them, except for $17 \beta$-estradiol. Based on the results, it is clear that dopant chemistry and proton affinity are important for this compound category.

\subsubsection{Sterols and sterones}

Two model compounds were investigated in the sterol category. Sterols showed much higher MDLs compared with the other two categories (Figure 14). The Conventional ESI method is not well suited to ionize sterols because their highly lipophilicity and the lack of multiple polar functional groups. APCI however has been successfully used for the detection of sterols. A recent study showed that APPI was particularly sensitive for cholesterol, sitosterol and sitostanol (Palmgren et al., 2005). Coprostan-3-ol could not be ionized in HESI. APPI, however, was much better, and MDLs using chlorobenzene (36.7 ng/L) and toluene (43.9 ng/L) were low enough for trace analysis. Coprostan-3-one was marginally ionized by HESI with an MDL of $2090 \mathrm{ng} / \mathrm{L}$, but APPI with acetone dramatically decreased MDL to $118 \mathrm{ng} / \mathrm{L}$. All these results point out again the benefit of using a single ionization method for trace environmental analysis. 


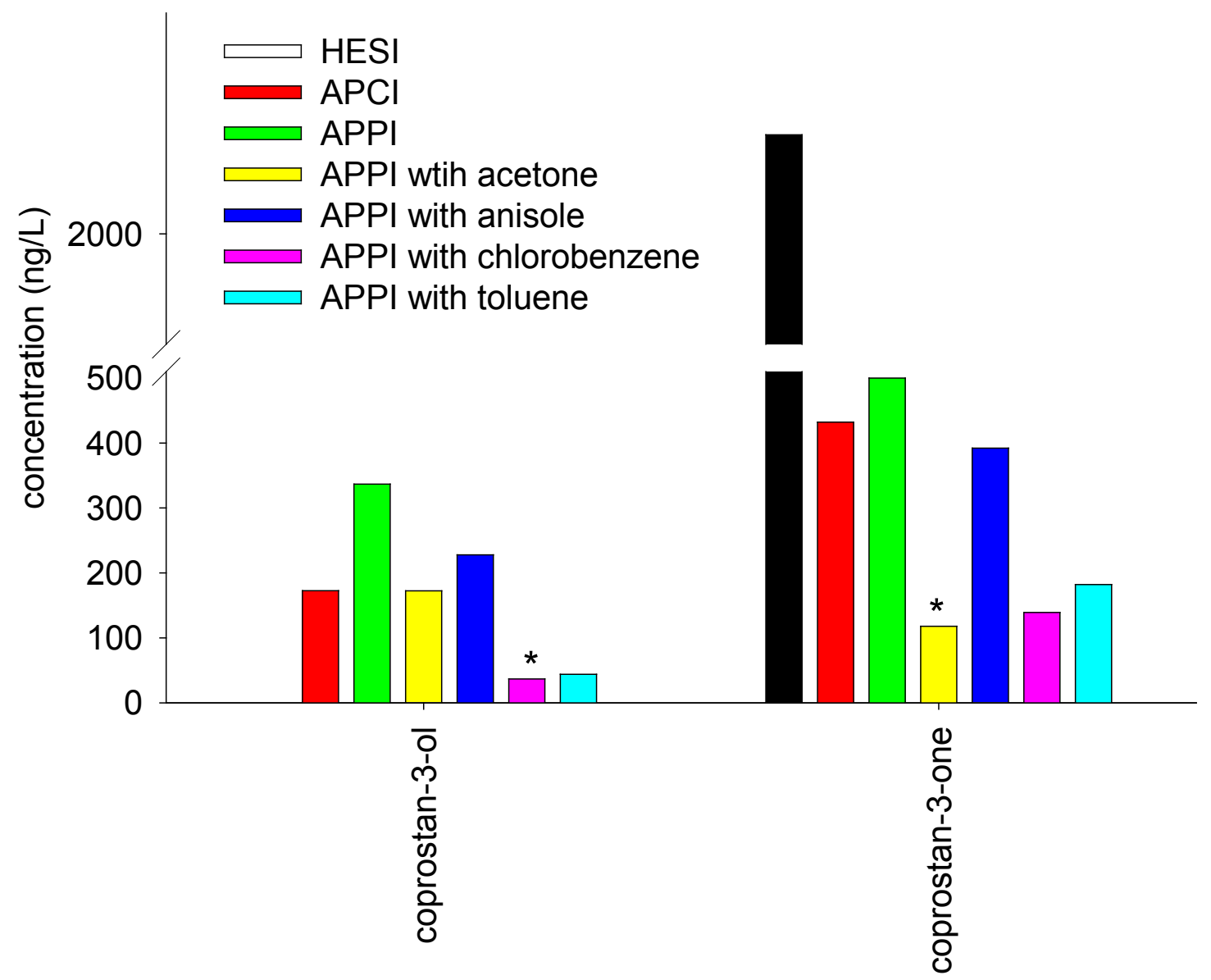

Figure 14. MDLs of sterols and sterones for all ionization mechanisms tested

\subsubsection{Negative ionization mode}

Five compounds were detected in the negative ionization mode: bisphenol A, ibuprofen, triclosan, gemfibrozil and 4-tert-octylphenol. All of them were detected by HESI, APCl and APPI with dopants. Results are shown in Figure 15. 


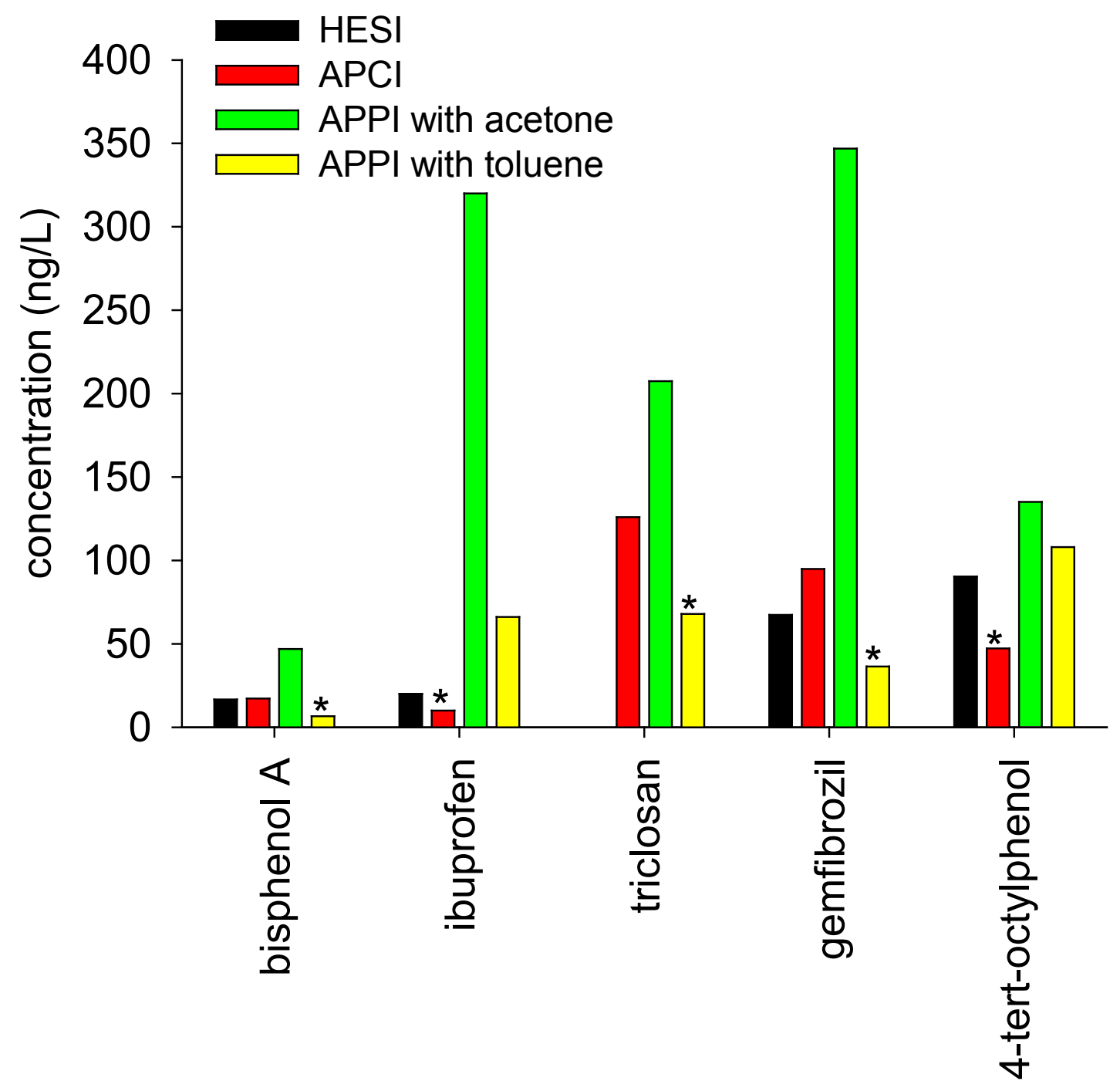

Figure 15. MDLs of analytes in negative mode for all ionization mechanisms tested

For bisphenol A, APPI with toluene was the best ionization with an MDL of 6.56 ng/L. For ibuprofen, both HESI and APCI were better choices. Ibuprofen is a very polar and small compound; therefore, Atmospheric pressure photoionization did not provide an effective method. Triclosan could not be ionized by HESI. APCI 
improved the ionization of triclosan yielding an MDL of $126 \mathrm{ng} / \mathrm{L}$. APPI with toluene as dopant lowered the MDL by half to $67.9 \mathrm{ng} / \mathrm{L}$. Gemfibrozil was detected in the negative ionization mode in all the ion sources except for APCl. APPI with toluene was the best ionization method, with an MDL of $36.4 \mathrm{ng} / \mathrm{L}$. The best ionization method for 4-tert-octylphenol was APCI with an MDL of $47.3 \mathrm{ng} / \mathrm{L}$.

Three of the compounds were best detected in APPI with toluene as dopant. However, for polar compounds like ibuprofen or medium polar compounds like 4tert-octylphenol, APPI was not the best choice. This is one of the few examples where HESI or APCI outperform the APPI source.

\subsubsection{Final choice of dopant}

A key goal of this study was to compare ionization sources and provide an overall solution in a single run. APPI with toluene as dopant was the choice because it provided the lowest MDLs for most analytes. Our results indicate that dopant flow is critical in controlling source stability but does not influence signal intensity. Different flows of toluene were tested, ranging from $5 \mu \mathrm{L} / \mathrm{min}$ to 50 $\mu \mathrm{L} / \mathrm{min}$ in a constant mobile phase flow rate of $200 \mu \mathrm{L} / \mathrm{min}$. Analyte signals did not increase as the flow rate of the dopant increased for the positive mode; however, analyte signals became more stable when the flow was set at 25 $\mu \mathrm{L} / \mathrm{min}$. In the negative mode, we observed that the signals of bisphenol $\mathrm{A}$, ibuprofen and 4-tert-octylphenol were negatively affected when adding more than $10 \mu \mathrm{L} / \mathrm{min}$ toluene. Therefore, flow rate was kept under $5 \mu \mathrm{L} / \mathrm{min}$. Dopants have 
been used since 1994 to enhance photoionization performance (Marchi et al., 2009). The ionization mechanism usually depends on the PA of the dopant, solvent and analyte. There are two possible mechanisms: charge transfer, dominated by electron affinity (EA) and proton transfer. In addition, solvent molecules having the right proton affinities actively participate in the reaction to enhance the ionization efficiency (Equation 2 and 3). Based on the results shown in table 10c, where all the target analytes preferentially produced protonated or deprotonated molecular ions, the likely mechanism seen in the APPI source is probably dominated chemical ionization by solvent molecules (equation 3) with the dopant being used to promote the transfer of energy from krypton lamp to the solvent rather than to produce direct ionization of the analytes by proton transfer.

$D^{\circ+}+n S \rightarrow[D-H]^{\circ}+\left[S_{n}+H\right]^{+}$if $\left.P_{S}>P A_{[D-H}\right]^{\cdot}$

$\left[S_{n}+H\right]^{+}+M \rightarrow n S+[M+H]^{+} \quad$ if $P A_{M}>P A_{S}$

The IE of four dopants, anisole (8.2 eV), toluene (8.3 eV), chlorobenzene (9.07 $\mathrm{eV}$ ) and acetone $(9.7 \mathrm{eV})$, are clearly below the IE provided by the lamp and lower than of water $(12.6 \mathrm{eV})$ and methanol $(10.8 \mathrm{eV})$, thus formation of the radical cation from the dopants will dominate in the source. The PA of four dopants are anisole $(839.6 \mathrm{~kJ} / \mathrm{mol})>$ acetone $(812.0 \mathrm{~kJ} / \mathrm{mol})>$ toluene $(784.0$ $\mathrm{kJ} / \mathrm{mol})>$ chlorobenzene $(753.1 \mathrm{~kJ} / \mathrm{mol})$ (Marchi et al., 2009). Although PAs for the compounds targeted in this study are not available in the literature, it is likely that will range above the PAs for both water and methanol. Because most analytes formed $[\mathrm{M}+\mathrm{H}]^{+}$ions under the optimized conditions tested, the 
predominant mechanism for our analytes was likely the reaction of dopant photoions with solvent molecules, followed by solvent based ionization of the analytes by proton transfer as suggested by previous studies for a watermethanol-toluene system (Kauppila et al., 2002; Kauppila et al., 2004). Although acetone have a high IE, its high PA $(812.0 \mathrm{~kJ} / \mathrm{mol})$ cause it less effective than toluene $(784.0 \mathrm{~kJ} / \mathrm{mol})$ in proton transfer mechanism. Chlorobenzene has often been described as the best APPI dopant. However, in this study, toluene generated better results and has the advantage of being less toxic than chlorobenzene (Marchi et al., 2009). Therefore, toluene was chosen as the dopant for all analytes

\subsubsection{Recovery comparison}

Three spike levels $(1 \times \mathrm{MDL}$ level, $5 \times \mathrm{MDL}$ level and $10 \times \mathrm{MDL}$ level) were used to assess recoveries. A summary of the results are present in Figure 16. Analyte recoveries in the positive mode ranged from $70 \%$ to $152 \%$ when spike levels were close to MDLs. The recoveries ranged from $86 \%$ to $121 \%$ when the spike level was increased to the $5 \times \mathrm{MDL}$ level and ranged from $79 \%$ to $126 \%$ when spike level was increased to the $10 \times M D L$ level. No significant differences were seen between the 3 spiking concentrations (average recovery 105\%). Results indicated that analytes were retained at the preconcentration column very well. When spike levels were close to the detection limit, recoveries were more variable than at high spike levels. RSD's of all the spiked samples were less than $20 \%$, except testosterone and equilenin that spiked at the MDL level $(24 \%$ and 
$21 \%$ ). Recoveries of analytes detected in negative mode were less reproducible and clearly affected by the spike levels. Analyte recoveries in the negative mode ranged from $44 \%$ to $216 \%$ except for ibuprofen when spike levels were close to MDLs. The recoveries ranged from $76 \%$ to $163 \%$ when the spike level was increased to the $5 \times \mathrm{MDL}$ level and ranged from $67 \%$ to $155 \%$ when spike level was increased to the $10 \times \mathrm{MDL}$ level. There is no difference between the $5 \times$ and $10 \times$ MDL fortification levels but method performance was less robust at concentrations near the MDLs.

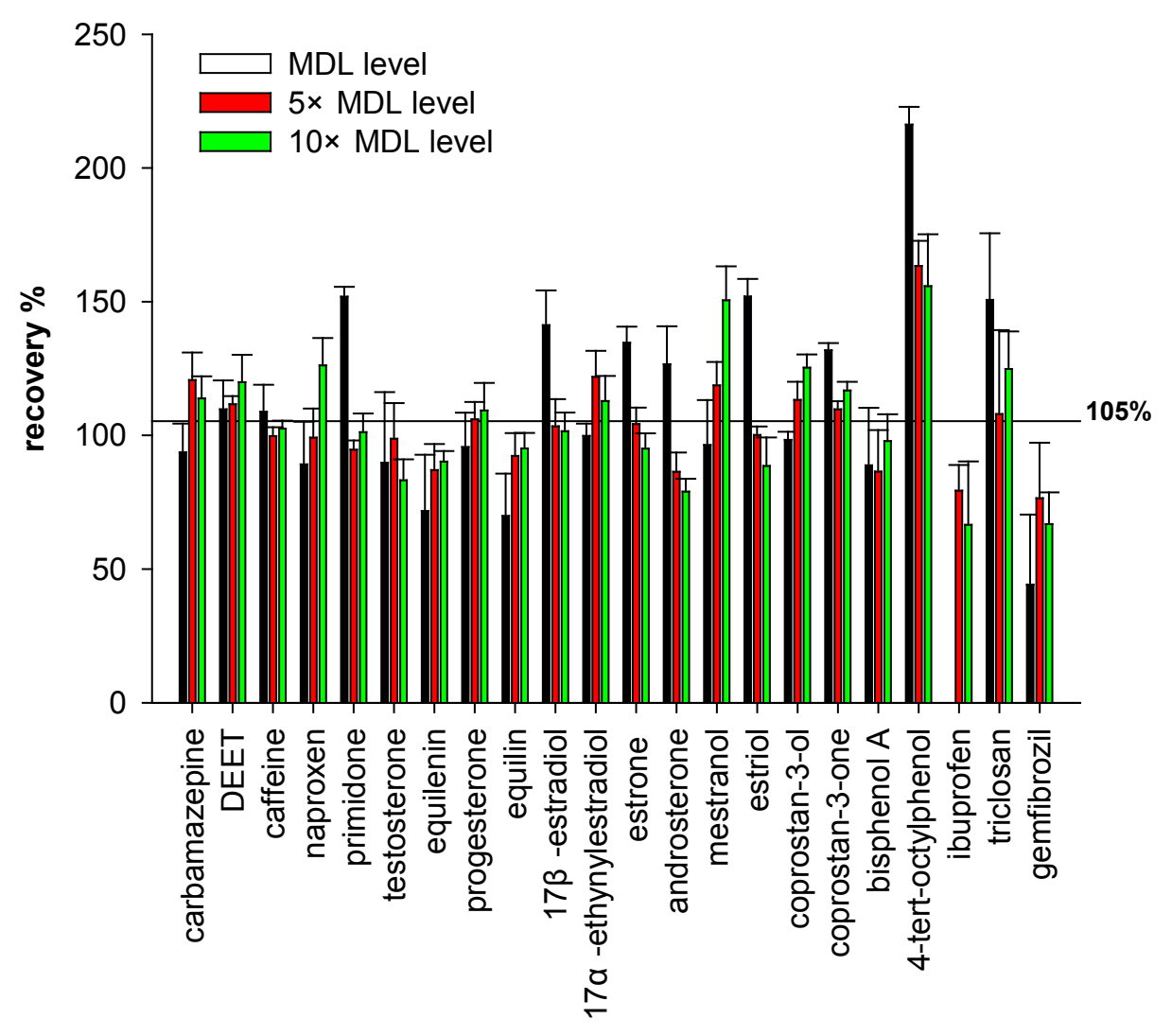

Figure 16. Recovery of analytes at different spike levels 


\subsubsection{Matrix effects evaluation}

Results in Table 11 indicated that $70 \%$ of the analyte's signals were enhanced because of matrix effects in APPI, while $30 \%$ of analyte's signals were suppressed because of matrix effects. Two compounds, androsterone and ibuprofen, were not detected in the spiked reclaimed water sample because of high background interference. Compared to other ionization sources (ESI and APCI), APPI is not generally considered susceptible to the matrix effect (Hanold et al., 2004). However, results in our study showed otherwise, since signal intensity were significantly influenced by matrix for most analytes $(127 \%$ average). For example, the enhancement for mestranol and triclosan were more than $200 \%$ and suppression of 4 -tert-octylphenol was $55 \%$. Enhancement and suppression were observed in both positive and negative mode. This is a clearly indication that the contribution of the solvent and other ionization producing procedure described in equation 2 is likely the controlling factor while the participation of the dopant is a secondary process. Results also pointed out that the wash procedure was essential in eliminating the interference from wastewater samples but was a compromise for early eluting highly-polar compounds that are more influenced by rinsing with a stronger organic phase. 
Table 11. Evaluation of the APPI Matrix effect

\begin{tabular}{lcc}
\hline Analyte & matrix effect (\%) & RSD \\
\hline \multicolumn{3}{c}{ PI mode } \\
Caffeine & 179 & 7 \\
Primidone & 131 & 12 \\
Estriol & 118 & 1 \\
carbamazepine & 172 & 4 \\
DEET & 120 & 11 \\
Equilenin & 70 & 8 \\
17a-ethynylestradiol & 117 & 15 \\
Equilin & 95 & 12 \\
17ß-estradiol & 106 & 13 \\
Estrone & 113 & 3 \\
Naproxen & 121 & 15 \\
Testosterone & 113 & 17 \\
Progesterone & 116 & 5 \\
Mestranol & 247 & 7 \\
coprostan-3-one & 69 & 17 \\
coprostan-3-ol & 96 & 21 \\
& $\mathrm{NI}$ mode & \\
bisphenol A & 126 & 8 \\
Triclosan & 222 & 60 \\
Gemfibrozil & 156 & 11 \\
4-tert-octylphenol & 55 & 12 \\
\hline
\end{tabular}

\subsubsection{Method validation}

The method was validated by using APPI with toluene as a dopant. Calibration range, linearity, spike levels and MDLs of $5 \mathrm{~mL}$ and $20 \mathrm{~mL}$ are shown in Table 12 . The linearities of all analytes were above 0.99 , except gemfibrozil, triclosan and 4-tert-octylphenol, which were all detected in the negative ionization mode. DEET was commonly detected in the reagent water at a concentration of about $2 \mathrm{ng} / \mathrm{L}$. DEET can be transferred via dirty hands or gloves (Capdeville and Budzinski, 2011). Therefore, $10 \mathrm{ng} / \mathrm{L}$ was used as the starting calibration point of DEET and 
MDLs were corrected to $5.9 \mathrm{ng} / \mathrm{L}$. When sample size was increased from $5 \mathrm{~mL}$ to $20 \mathrm{~mL}$, some analytes lost their recovery on column since they were washed away at loading procedure. Acetaminophen and caffeine cannot be detected when sample size was increased to $20 \mathrm{~mL}$. The MDLs of bisphenol $A$ and triclosan of $20 \mathrm{~mL}$ were higher than $5 \mathrm{~mL}$ because of the recovery lost. Statistical MDLs were comparable to previous research (Viglino et al., 2008) for estradiol, estrone, 17a-ethinylestradiol and progesterone, however the method reported here expanded significantly the list of analytes that could be detected simultaneously by APPI. Despite the fact that without using dopant (Viglino et al., 2008), the improvement for specific compounds like estriol (15 $\times$ ) combined with the detection of fecal sterols at low $\mathrm{ng} / \mathrm{L}$ levels constitue an important improvement justifying the use of dopant. 
Table 12. Calibration range, linearity, spike levels and MDLs

\begin{tabular}{|c|c|c|c|c|c|}
\hline & $\begin{array}{l}\text { calibration } \\
\text { range(ng/L) }\end{array}$ & linearity & $\begin{array}{c}\text { spike level } \\
\text { (ng/L) }\end{array}$ & $\begin{array}{c}\text { MDLs(ng/L) } \\
5 \mathrm{~mL} \\
\end{array}$ & $\begin{array}{c}\text { MDLs(ng/L) } \\
20 \mathrm{~mL} \\
\end{array}$ \\
\hline acetaminophen & $100-800$ & 0.9935 & 200 & 9.24 & NA \\
\hline caffeine & $2-2048$ & 0.9946 & 8 & 1.51 & NA \\
\hline primidone & $62.5-4000$ & 0.9905 & 250 & 38.3 & 14.9 \\
\hline estriol & $32-1024$ & 0.9905 & 64 & 10.5 & 1.64 \\
\hline carbamazepine & $1-256$ & 0.9927 & 1 & 1.18 & 0.30 \\
\hline DEET & $10-2560$ & 0.9912 & 10 & 5.90 & 2.83 \\
\hline equilenin & $4-1024$ & 0.9985 & 16 & 3.44 & 3.39 \\
\hline naproxen & $80-5120$ & 0.9943 & 160 & 15.4 & 8.45 \\
\hline $\begin{array}{l}17 \alpha- \\
\text { ethynylestradiol }\end{array}$ & $4-1024$ & 0.9903 & 16 & 4.22 & 1.26 \\
\hline $17 \beta$-estradiol & $4-1024$ & 0.9935 & 16 & 8.94 & 2.57 \\
\hline equilin & $10-1280$ & 0.9939 & 40 & 7.15 & 1.17 \\
\hline estrone & $10-1280$ & 0.9951 & 20 & 9.47 & 1.59 \\
\hline testosterone & $2-1024$ & 0.9916 & 4 & 2.87 & 2.30 \\
\hline progesterone & $10-160$ & 0.9901 & 10 & 8.93 & 1.72 \\
\hline androsterone & $32-512$ & 0.9968 & 32 & 10.2 & 37.0 \\
\hline $\begin{array}{l}\text { mestranol } \\
\text { coprostan-3- }\end{array}$ & $25-800$ & 0.9902 & 100 & 21.3 & 7.89 \\
\hline one & $400-6400$ & 0.9941 & 1600 & 182 & 11.2 \\
\hline Coprostan-3-ol & $200-3200$ & 0.9901 & 200 & 43.9 & 5.44 \\
\hline bisphenol A & $20-5120$ & 0.9925 & 20 & 6.56 & 79.1 \\
\hline ibuprofen & $80-5120$ & 0.9994 & 80 & 69.3 & NA \\
\hline triclosan & $25-800$ & 0.9817 & 100 & 67.9 & 115 \\
\hline $\begin{array}{l}\text { 4-tert- } \\
\text { octylphenol }\end{array}$ & $30-3840$ & 0.9631 & 60 & 108 & 54.7 \\
\hline $\begin{array}{l}\text { gemfibrozil } \\
\text { NA: acetaminoph } \\
\text { Gemfibrozil and }\end{array}$ & $\begin{array}{l}40-5120 \\
\text { and caffein } \\
\text { uprofen can b }\end{array}$ & $\begin{array}{l}0.9866 \\
\text { st recove } \\
\text { letected } k\end{array}$ & $\begin{array}{c}80 \\
\text { when samp } \\
\text { HESI metho }\end{array}$ & $\begin{array}{c}36.4 \\
\text { size was incr }\end{array}$ & $\begin{array}{c}\text { NA } \\
\text { ed to } 20 \mathrm{~mL} \text {. }\end{array}$ \\
\hline
\end{tabular}




\subsection{Conclusion}

A fully automated online preconcentration HPLC-APPI-MS/MS method for simultaneous detection of PPCPs, hormones and sterol steroid was developed. Results indicate that APPI produce great ionization capability for a broad range of compounds, in particular for ionization efficiency of hormones compared to APCl and HESI. The advantages of APPI made it a great alternative for consistent detection of trace level organic microconstituents in the environment. The online preconcentration method minimized the sample preparation procedure, thus producing a reliable and robust method that can be used for routine analysis of clean and complex matrix water samples, such as ground, surface and reclaimed waters. 


\section{CHAPTER 5}

\section{Assessing different ionization techniques for the detection of pharmaceuticals in aqueous samples using online SPE-LC-MS/MS}

\subsection{Introduction}

Liquid chromatography mass spectrometry is one of the fastest growing analytical techniques because of its attribution to new application on life science and biopharmaceuticals (Hans H, 1998; Hanold et al., 2004; Diaz and Barcelo, 2005; Hernández et al., 2005; Petrovic et al., 2005; Nunez et al., 2011). Currently, $\mathrm{ESI}$ and $\mathrm{APCl}$ are the most widely used ionization techniques coupled to Liquid chromatography mass spectrometry. Electrospray ionization and APCl for ionization of polar compounds and have been applied successfully in the environmental analysis of aqueous samples (Cahill et al., 2004; Castiglioni et al., 2005; Martnez Bueno et al., 2007; Gros et al., 2009; Laven et al., 2009; LopezSerna et al., 2010). However, ESI and APCI are not very efficient for ionization of nonpolar compounds. A new ionization technique, atmospheric pressure photoionization (APPI), has been introduced to mass spectrometry (Robb et al., 2000). The application and principle of APPI have been reviewed and the rapidly growing number of publications in this area clearly demonstrates the advantages of APPI (Hanold et al., 2004; Bos et al., 2006). Atmospheric pressure photoionization has proven to be a valuable tool for analytes, which are poorly or not ionized by $\mathrm{ESI}$ and $\mathrm{APCl}$ or in the presence of complex analytical condition (Itoh et al., 2006; Yamamoto et al., 2006; Viglino et al., 2008; Cai et al., 2009). Even though many studies have been conducted to investigate the ability of APPI 
to detect nonpoplar compounds, very little research has focused on the performance of APPI on analytes which are sufficiently ionized by ESI and APCI (Cai et al., 2005; Garcia-Ac et al., 2011).

In the present study, first, I developed an online SPE method for accurate and reliable detection of 52 pharmaceuticals simultaneously in water samples. The online SPE method minimized the sample preparation procedures, and saves solvent, time and labor. Second, I compared the ionization efficiency of two ionization techniques (HESI and APPI) on the basis of absolute signal intensity and also method detection limits (MDLs). It is the first time to compare the efficiency of different ionization techniques based on calculated MDLs, which provide a useful tool for comparing analytical methods.

\subsection{Experimental}

\subsubsection{Chemicals}

Ketoprofen, naproxen, ibuprofen, indomethacin, mefenamic acid, acetaminophen, salicylic acid, antipyrine, gemfibrozil, bezafibrate, fenofibrate, atorvastatin, mevastatin, pravastatin sodium salt hydrate, fluoxetine (hydrochloride), paroxetine (maleate), carbamazepine, primidone, ranitidine (hydrochloride), diphenhydramine (hydrochloride), cimetidine, atenolol, $( \pm)$ metoprolol (+) tartrate, propranolol, betaxolol (hydrochloride), pindolol, nadolol, clenbuterol (hydrochloride), enalapril (maleate), hydrochlorothiazide, lisinopril, furosemide, tamoxifen, clotrimazole, glibenclamide were purchased from Sigma- 
Aldrich (Allentown, PA, USA). Diclofenac, propyphenazone, phenylbutazone, clofibric acid, famotidine, timolol, salbutamol, metronidazole were purchased from Fisher Scientific (Pittsburgh, PA, USA). Codeine, diazepam, lorazepam, butalbital, phenobarbital, pentobarbital, were purchased from Cerilliant (Round Rock, TX, USA). Loratadine, sotalol (hydrochloride), carazolol (hydrochloride) were purchased from Toronto Research Chemicals, Inc. (Ontario, Canada). Isotopically labelled compounds, used as surrogates, were diclofenac-d4 (phenyl-d4), ( $\quad \pm$-ibuprofen-d3, N-(4-hydroxyphenyl-d4) acetamide, $\quad 2-$ hydroxybenzoic-d4 acid, phenylbutazone-d10, clofibric-d4 acid, cimetidine-d3, ( \pm )-atenolol-d7, ( \pm )-albuterol-d3, enalaprilat-d5, tamoxifen-d5, clotrimazole-d5, norfloxacin-d5 were purchased from C/D/N Isotopes Inc. (Quebec, Canada). Diazepam-d5, lorazepam-d4, codeine-d6, phenobarbital-d5, pentobarbital d5 were purchased from Cerilliant (Round Rock, TX, USA). Mefenamic acid-d3, fenirofibrate-d6, atorvastatin-d5 (sodium salt), pravastatin-d3 (sodium salt), ractrans paroxetine-d4 (hydrochloride), ranitidine-d6 (hydrochloride), loratadine-d4, rac timolol-d5 (maleate), hydrochlorothiazide $-{ }^{13} \mathrm{C}, \quad \mathrm{d} 2, \quad$ furosemide-d5, metronidazole-d4, glyburide-d11 were purchased from Toronto Research Chemicals, Inc. (Ontario, Canada). The detail information of analytes is shown in Table 13.

\subsubsection{Sample preparation}

Water samples were filtered through glass fiber filters with a pore size of $0.5 \mu \mathrm{m}$. Samples were analyzed within 14 days in order to avoid potential degradation 
and transformation of analytes. $\mathrm{pH}$ was adjusted to 2 when sample was analyzed in the negative mode.

\subsubsection{Instrumentation}

An Environmental Quantition (EQuan ${ }^{\mathrm{TM}}$ ) system manufactured by Thermo Fisher Scientific was used to preconcentrate microconstituents from reclaimed water. The EQuan ${ }^{\mathrm{TM}}$ system is based on a dual switching-column system, which consists of a sample delivery system, a switching-column array and an LCMS/MS system. Its sample delivery system consists of an autosampler manufactured by CTC analytics AG (Zwingen, Switzerland) and an Accela 600 loading pump (Thermo Fisher Scientific, San Jose, CA, USA). Its columnswitching array is composed of a Rheodyne $7750 \mathrm{E}-205$ six-port switching valve system made by IDEX (Oak Arbor, WA, USA), a preconcentration column and an analytical column. A Thermo Hypersil Gold aQ $(20 \mathrm{~mm} \times 2.1 \mathrm{~mm}, 12 \mu \mathrm{m}$ particle size) was used as the loading column and a Thermo Hypersil Gold aQ (50 mm × $2.1 \mathrm{~mm}, 1.9 \mu \mathrm{m}$ particle size) was used as the analytical column. Mass spectrometry analysis was performed using a TSQ Quantum Access triple quadrupole Mass Spectrometer (Thermo Fisher Scientific, San Jose, CA, USA). 
Table 13. Information of pharmaceuticals

\begin{tabular}{ccccccc}
\hline GROUP & No & Name & CAS Number & Pka & log Kow & Surrogate \\
\hline $\begin{array}{c}\text { Analgesics and } \\
\text { anti-inflammatories }\end{array}$ & 1 & Ketoprofen & $22071-15-4$ & 5.95 & 3.12 & Ibuprofen-d3 \\
& 2 & Naproxen & $22204-53-1$ & 4.2 & 3.18 & Ibuprofen-d3 \\
& 3 & Ibuprofen & $15687-27-1$ & 4.3 & 3.97 & Ibuprofen-d3 \\
& 4 & Indomethacin & $53-86-1$ & 4.5 & 4.27 & Carbamazepine-d10 \\
& 5 & Diclofenac & $15307-86-5$ & 4 & 4.5 & Diclofenac-d4 \\
& 6 & Mefenamic acid & $61-68-7$ & 4.2 & 5.12 & Mefenamic acid-d3 \\
7 & Acetaminophen & $103-90-2$ & 9.51 & 0.46 & Acetaminophen-d4 \\
8 & Salicylic Acid & $69-72-7$ & 2.97 & 2.26 & 2-hydroxybenzoic acid \\
& 9 & Antipyrin & $60-80-0$ & 1.4 & 0.38 & Carbamazepine-d10 \\
10 & Propyphenazone & $479-92-5$ & 4.5 & 1.94 & Phenylbutazone-d10 \\
11 & Phenylbutazone & $50-33-9$ & 4.5 & 2.5 & Phenylbutazone-d10 \\
\hline
\end{tabular}




\begin{tabular}{|c|c|c|c|c|c|c|}
\hline GROUP & No & Name & CAS Number & Pka & log Kow & Surrogate \\
\hline & 12 & Codeine & $76-57-3$ & 8.2 & 1.14 & Codeine-d6 \\
\hline \multirow[t]{7}{*}{$\begin{array}{l}\text { Antihyperlipidemics } \\
\text { - Lipid Regulators }\end{array}$} & 13 & Clofibric Acid & $882-09-7$ & 2.84 & 2.57 & Clofibric Acid-d4 \\
\hline & 14 & Gemfibrozil & $25812-30-0$ & 4.75 & 4.77 & Diclofenac-d4 \\
\hline & 15 & Bezafibrate & 41859-67-0 & 3.29 & 4.25 & Fenirofibrate-d6 \\
\hline & 16 & Fenofibrate & $49562-28-9$ & 5 & 5.19 & Fenirofibrate-d6 \\
\hline & 17 & Atorvastatin & $134523-00-5$ & 4.5 & 6.36 & Atorvastatin-d5 \\
\hline & 18 & Mevastatin & 73537-88-3 & 14.89 & 3.95 & Pravastatin-d3 \\
\hline & 19 & Pravastatin & $81131-70-6$ & 4.7 & 3.95 & Pravastatin-d3 \\
\hline \multirow[t]{4}{*}{$\begin{array}{l}\text { Antidepressants } \\
\text { and anticonvulsants }\end{array}$} & 20 & Fluoxetine & $54910-89-3$ & 9.5 & 3.82 & Fluoxetine-d6 \\
\hline & 21 & Paroxetine & 61869-08-7 & 9.9 & 3.95 & Fluoxetine-d6 \\
\hline & 22 & Diazepam & $439-14-5$ & 3.3 & 2.19 & Diazepam-d5 \\
\hline & 23 & Lorazepam & $846-49-1$ & 0.03 & 2.42 & Lorazepam d4 \\
\hline
\end{tabular}




\begin{tabular}{|c|c|c|c|c|c|c|}
\hline GROUP & No & Name & CAS Number & Pka & log Kow & Surrogate \\
\hline \multirow{6}{*}{ Antihistaminies } & 24 & Carbamazepine & $298-46-4$ & 13.9 & 2.46 & Carbamazepine-d10 \\
\hline & 25 & Primidone & $125-33-7$ & 11.6 & 0.91 & Carbamazepine-d10 \\
\hline & 26 & Famotidine & $76824-35-6$ & 6.89 & -0.64 & Ranitidine-d6 \\
\hline & 27 & Ranitidine & $66357-35-5$ & $\begin{array}{c}2.7 / 8 . \\
2\end{array}$ & 0.27 & Ranitidine-d6 \\
\hline & 28 & Cimetidine & $51481-61-9$ & 6.8 & 0.4 & Cimetidine-d3 \\
\hline & 29 & Loratadine & $79794-75-5$ & 5 & 5.2 & Loratadine-d4 \\
\hline \multirow{3}{*}{$\begin{array}{l}\text { Barbiturates - } \\
\text { Anticonvulsants }\end{array}$} & 30 & Diphehydramine & $88637-37-0$ & 9 & 3.27 & Carbamazepine-d10 \\
\hline & 31 & Butalbital & $77-26-9$ & 12.15 & 1.87 & Phenobarbital-d5 \\
\hline & 32 & Phenobarbital & $50-06-6$ & 7.4 & 1.47 & Phenobarbital-d5 \\
\hline \multirow{3}{*}{$\begin{array}{l}\text { Beta-blockers - } \\
\text { cardiac arrhythmias }\end{array}$} & 33 & Pentobarbital & $76-74-4$ & 8 & 2.1 & Phenobarbital-d5 \\
\hline & 34 & Atenolol & $29122-68-7$ & 9.6 & 0.36 & Atenolol-d7 \\
\hline & 35 & Sotalol & $3930-20-9$ & 9.55 & 0.24 & Atenolol-d7 \\
\hline
\end{tabular}




\begin{tabular}{|c|c|c|c|c|c|c|}
\hline GROUP & No & Name & CAS Number & Pka & $\log$ Kow & Surrogate \\
\hline & 36 & Metoprolol & $37350-58-6$ & 9.7 & 1.8 & Atenolol-d7 \\
\hline & 37 & Propranolol & $525-66-6$ & 9.49 & 3 & Atenolol-d7 \\
\hline & 38 & Timolol & $26839-75-8$ & 9.2 & 1.83 & Timolol-d5 maleate \\
\hline & 39 & Betaxolol & $63659-18-7$ & 9.4 & 2.81 & Atenolol-d7 \\
\hline & 40 & Carazolol & $57775-29-8$ & 9.52 & 3.59 & Atenolol-d7 \\
\hline & 41 & Pindolol & $13523-86-9$ & 8.8 & 1.75 & Atenolol-d7 \\
\hline & 42 & Nadolol & $42200-33-9$ & 9.67 & 0.71 & Atenolol-d7 \\
\hline \multirow[t]{2}{*}{$\begin{array}{l}\text { Bronchodilators - } \\
\text { Beta agonists }\end{array}$} & 43 & Salbutamol & $18559-94-9$ & 9.3 & 0.64 & Albuterol-d3 \\
\hline & 44 & Clenbuterol & $37148-27-9$ & 17.84 & 2 & Albuterol-d3 \\
\hline \multirow[t]{3}{*}{ Antihypertensives } & 45 & Enalapril & $75847-73-3$ & $3 / 5.5$ & 0.07 & Enalaprilat-d5 \\
\hline & 46 & Hydrochlorothiazide & $58-93-5$ & 7.9 & -0.1 & $\begin{array}{l}\text { Hydrochlorothiazide- } \\
13 \mathrm{C}, \mathrm{d} 2\end{array}$ \\
\hline & 47 & Lisinopril & $83915-83-7$ & 2.5 & -1.1 & Carbamazepine-d10 \\
\hline
\end{tabular}




\begin{tabular}{ccccccc}
\hline GROUP & No & Name & CAS Number & Pka & log Kow & Surrogate \\
\hline Diuretics & 48 & Furosemide & $54-31-9$ & 2.03 & 2.03 & Furosemide-d5 \\
Cancer treatment & 49 & Tamoxifen & $10540-29-1$ & 8.85 & 6.3 & Tamoxifen-d5 \\
Antifungals & 50 & Metronidazole & $443-48-1$ & 2.6 & -0.1 & Metronidazole-d4 \\
& 51 & Clotrimazole & $23593-75-1$ & 6.7 & 1.33 & Clotrimazole-d5 \\
Antidiabetic & 52 & Glibenclamide & $10238-21-8$ & 5.3 & 2.4 & Glyburide-d11 \\
\hline
\end{tabular}




\subsubsection{Direct injection}

Standard solution $(25 \mu \mathrm{L})$ at $100 \mathrm{ng} / \mathrm{mL}$ was injected to compare the ionization efficiency of different techniques. The mobile phase flow rate was $200 \mu \mathrm{L} / \mathrm{min}$. The mobile phase used for HESI positive mode was methanol/acetonitrile (50:50, $\mathrm{v} / \mathrm{v}$ ) and $0.1 \%$ formic acid in water. The proportion of the organic solvent was $1 \%$ in the first $2 \mathrm{~min}$, and then organic proportion was increased to $100 \%$ in $5 \mathrm{~min}$ and held for $5 \mathrm{~min}$. After that, organic proportion was decreased to $1 \%$ in $2 \mathrm{~min}$ and held for another $2 \mathrm{~min}$. The mobile phase used for HESI negative mode was methanol and water. The proportion of the organic solvent was $1 \%$ in the first 2 min, and then organic proportion was increased to $100 \%$ in 5 min and held for 5 min. After that, organic proportion was decreased to $1 \%$ in 2 min and hold for another 2 min. The mobile phase used for APPI positive mode was the same as HESI positive mode but the gradient was different. The proportion of the organic solvent was $10 \%$ in the first 2 min, and then organic proportion was increased to $100 \%$ in $5 \mathrm{~min}$ and held for $5 \mathrm{~min}$. After that, organic proportion was decreased to $10 \%$ in 2 min and held for another $2 \mathrm{~min}$. The mobile phase used for APPI negative mode was methanol and water. The proportion of the organic solvent was $10 \%$ in the first $2 \mathrm{~min}$, and then organic proportion was increased to $100 \%$ in $5 \mathrm{~min}$ and held for $3 \mathrm{~min}$. After that, organic proportion was decreased to $10 \%$ in 2 min and held for another 2 min. 


\subsubsection{On-line SPE}

Water samples $(5 \mathrm{~mL})$ were loaded to the preconcentration column at a flow rate of $1 \mathrm{~mL} / \mathrm{min}$. The preconcentration column was washed by $1000 \mu \mathrm{L}$ of water and connected to the analytical column after the valve had switched to inject position. After washing, the loading column and analytical column underwent the same gradient in both positive mode and negative mode.

\subsubsection{Mass spectrometry}

Mass spectrometry analysis was performed using a TSQ Quantum Access triple quadrupole QqQ Mass Spectrometer (Thermo Fisher Scientific, San Jose, CA, USA) equipped with an Ion MAX source housing capable of operating HESI and APPI. Quantitation for all sources was performed using selected reaction monitoring (SRM) mode. Instrument control and data acquisition were performed using Xcalibur software (rev. 2.1, Thermo Fisher Scientific, San Jose, CA, USA). Source parameters for analytes were optimized using Heated Electrospray Ionization (HESI) and Atmospheric Pressure Photoionization (APPI) independently using flow injection with a carrier stream of mobile phase. A mobile phase of $0.1 \%$ fomic acid in water $/ \mathrm{MeOH}(50: 50, \mathrm{v} / \mathrm{v})$ was used for positive mode and water/MeOH (50:50, v/v) was used for negative mode. Each analyte and surrogate was injected to the ion source at a concentration of 10 $\mu \mathrm{g} / \mathrm{mL}$. Compound-dependent parameters such as tube lens and collision energy were optimized to obtain maximum signals in the QqQ system. The precursor ion, fragment ions and mass-dependent parameters are listed in table 14. 
Source-dependent parameters for optimal HESI detection were as follows: capillary temperature $\left(350{ }^{\circ} \mathrm{C}\right)$, vaporizer temperature $\left(250{ }^{\circ} \mathrm{C}\right)$, sheath gas pressure (30 arbitrary units), aux gas pressure (20 arbitrary units), ion sweep gas pressure (5 arbitrary units) and spray voltage (4000 $\mathrm{V}$ for positive polarity and $4000 \mathrm{~V}$ for negative polarity).

The photoionization lamp used for APPI was a Syagen $10 \mathrm{eV}$ krypton UV lamp (Syagen Technology Inc., Tustin, CA, USA). The source-dependent parameters for optimal detection were as follows: capillary temperature $\left(300{ }^{\circ} \mathrm{C}\right)$, vaporizer temperature $\left(400^{\circ} \mathrm{C}\right)$, sheath gas pressure (50 arbitrary units), aux gas pressure (35 arbitrary units), ion sweep gas pressure (0 arbitrary units), discharge current $(0 \mu \mathrm{A})$. Four different dopants, acetone, anisole, chlorobenzene and toluene, were tested to find the best one for the analytes. 
Table 14. Accurate mass and mass spectrometry parameters of analytes

\begin{tabular}{|c|c|c|c|c|c|c|c|c|c|c|c|c|c|c|c|c|c|c|}
\hline \multirow[b]{3}{*}{ compounds } & \multicolumn{9}{|c|}{ HESI } & \multicolumn{9}{|c|}{ APPI } \\
\hline & precursor & & tube & & CE & & CE & & CE & & & tube & & CE & & CE & & $\mathrm{CE}$ \\
\hline & ion & $\mathrm{m} / \mathrm{z}$ & lens & SRM1 & 1 & SRM2 & 2 & SRM3 & 3 & precursor ion & $\mathrm{m} / \mathrm{z}$ & lens & SRM1 & 1 & SRM2 & 2 & SRM3 & 3 \\
\hline Ketoprofen & {$[\mathrm{M}-\mathrm{H}]-$} & 253.1 & 65 & 209.1 & 11 & & & & & {$[\mathrm{M}+\mathrm{H}]+$} & 255.0 & 70 & 209.0 & 13 & 105.1 & 22 & 77.2 & 39 \\
\hline Naproxen & {$[\mathrm{M}-\mathrm{H}]-$} & 229.0 & 60 & 170.1 & 18 & 185.2 & 11 & & & {$[\mathrm{M}+\mathrm{H}-\mathrm{H} 2 \mathrm{O}-\mathrm{CO}]+$} & 185.1 & 84 & 170.1 & 17 & 141.1 & 33 & 115.1 & 49 \\
\hline Ibuprofen & {$[\mathrm{M}-\mathrm{H}]-$} & 205.1 & 51 & 161.3 & 10 & & & & & {$[\mathrm{M}-\mathrm{H}]-$} & 205.1 & 161.1 & 11.0 & & & & & \\
\hline Indomethacin & {$[\mathrm{M}-\mathrm{H}]-$} & 356.1 & 65 & 312.1 & 12 & 297.1 & 21 & 282.1 & 32 & {$[\mathrm{M}+\mathrm{H}]+$} & 357.9 & 61 & 138.9 & 20 & 111.0 & 43 & 174.0 & 12 \\
\hline Diclofenac & {$[\mathrm{M}-\mathrm{H}]-$} & 294.0 & 60 & 250.0 & 14 & 214.0 & 22 & 178.1 & 28 & {$[\mathrm{M}+\mathrm{H}]+$} & 295.9 & 63 & 213.9 & 34 & 249.9 & 13 & 277.9 & 7 \\
\hline Mefenamic acid & {$[\mathrm{M}-\mathrm{H}]-$} & 240.1 & 65 & 196.1 & 19 & 192.1 & 28 & 180.1 & 29 & {$[\mathrm{M}-\mathrm{H} 2 \mathrm{O}+\mathrm{H}]+$} & 224.0 & 97 & 209.0 & 28 & 180.0 & 40 & 208.0 & 36 \\
\hline Acetaminophen & {$[\mathrm{M}-\mathrm{H}]-$} & 150.0 & 49 & 107.2 & 22 & 118.1 & 33 & 132.1 & 24 & {$[\mathrm{M}+\mathrm{H}]+$} & 152.1 & 100 & 110.1 & 15 & 65.3 & 31 & 93.2 & 23 \\
\hline Salicylic Acid & {$[\mathrm{M}-\mathrm{H}]-$} & 137.1 & 48 & 93.1 & 19 & 65.2 & 31 & 75.2 & 37 & {$[\mathrm{M}-\mathrm{H}]-$} & 136.9 & 47 & 93.4 & 20 & & & & \\
\hline Antipyrin & {$[\mathrm{M}+\mathrm{H}]+$} & 189.1 & 72 & 77.2 & 36 & 56.3 & 36 & 131.1 & 22 & {$[\mathrm{M}+\mathrm{H}]+$} & 189.0 & 68 & 77.2 & 37 & 131.1 & 21 & 146.1 & 20 \\
\hline Propyphenazone & {$[\mathrm{M}+\mathrm{H}]+$} & 231.1 & 71 & 201.1 & 24 & 189.1 & 20 & 56.3 & 35 & {$[\mathrm{M}+\mathrm{H}]+$} & 231.1 & 76 & 189.0 & 20 & 146.0 & 25 & 77.2 & 41 \\
\hline Phenylbutazone & {$[\mathrm{M}+\mathrm{H}]+$} & 309.2 & 71 & 120.1 & 19 & 188.1 & 15 & 211.1 & 16 & {$[\mathrm{M}+\mathrm{H}]+$} & 309.1 & 82 & 210.9 & 13 & 132.2 & 29 & 77.3 & 42 \\
\hline Codeine & {$[\mathrm{M}+\mathrm{H}]+$} & 300.2 & 86 & 215.1 & 25 & 152.1 & 65 & 165.1 & 42 & {$[\mathrm{M}+\mathrm{H}]+$} & 300.0 & 81 & 165.0 & 35 & 215.0 & 25 & 153.0 & 44 \\
\hline Clofibric Acid & {$[\mathrm{M}-\mathrm{H}]-$} & 213.1 & 56 & 127.1 & 19 & 85.2 & 12 & 91.3 & 47 & {$[\mathrm{M}-\mathrm{H}]-$} & 213.0 & 79 & 127.2 & 20 & 85.4 & 13 & & \\
\hline
\end{tabular}




\begin{tabular}{|c|c|c|c|c|c|c|c|c|c|c|c|c|c|c|c|c|c|c|}
\hline \multirow[b]{3}{*}{ compounds } & \multicolumn{9}{|c|}{ HESI } & \multicolumn{9}{|c|}{ APPI } \\
\hline & precursor & & tube & & CE & & CE & & CE & & & tube & & CE & & CE & & CE \\
\hline & ion & $\mathrm{m} / \mathrm{z}$ & lens & SRM1 & 1 & SRM2 & 2 & SRM3 & 3 & precursor ion & $\mathrm{m} / \mathrm{z}$ & lens & SRM1 & 1 & SRM2 & 2 & SRM3 & 3 \\
\hline Gemfibrozil & {$[\mathrm{M}-\mathrm{H}]-$} & 249.1 & 65 & 121.2 & 20 & 106.1 & 49 & 120.1 & 44 & {$[\mathrm{M}-\mathrm{H}]-$} & 249.1 & 73 & 121.1 & 17 & 127.1 & 14 & 106.2 & 45 \\
\hline Bezafibrate & {$[\mathrm{M}-\mathrm{H}]-$} & 360.1 & 63 & 274.1 & 20 & 154.0 & 32 & 85.2 & 19 & {$[\mathrm{M}+\mathrm{H}]+$} & 362.1 & 71 & 316.0 & 13 & 276.0 & 13 & 138.9 & 25 \\
\hline Fenofibrate & {$[\mathrm{M}+\mathrm{H}]+$} & 361.2 & 72 & 233.0 & 16 & 139.0 & 31 & 121.0 & 32 & {$[\mathrm{M}+\mathrm{H}]+$} & 361.0 & 73 & 232.9 & 16 & 138.9 & 30 & 111.0 & 50 \\
\hline Atorvastatin & {$[\mathrm{M}+\mathrm{H}]+$} & 559.3 & 88 & 440.3 & 21 & 250.0 & 42 & 276.1 & 40 & {$[\mathrm{M}+\mathrm{H}]+$} & 559.1 & 84 & 440.0 & 21 & 249.9 & 41 & 276.0 & 45 \\
\hline Mevastatin & {$[\mathrm{M}+\mathrm{H}]+$} & 391.3 & 74 & 185.1 & 14 & 229.1 & 13 & 159.1 & 26 & {$[\mathrm{M}+\mathrm{Na}]+$} & 413.1 & 94 & 311.1 & 21 & 296.0 & 26 & 325.3 & 23 \\
\hline Pravastatin & {$[\mathrm{M}+\mathrm{Na}]+$} & 447.3 & 97 & 327.1 & 19 & 309.2 & 22 & & & {$[\mathrm{M}+\mathrm{Na}]+$} & 447.1 & 101 & 327.0 & 19 & 309.0 & 24 & 429.3 & 24 \\
\hline Fluoxetine & {$[\mathrm{M}+\mathrm{H}]+$} & 310.1 & 60 & 44.3 & 13 & 148.1 & 5 & 183.1 & 45 & {$[\mathrm{M}+\mathrm{H}]+$} & 310.1 & 70 & 44.4 & 13 & 148.1 & 5 & 259.0 & 5 \\
\hline Paroxetine & {$[\mathrm{M}+\mathrm{H}]+$} & 330.2 & 71 & 192.1 & 20 & 70.2 & 31 & 135.1 & 37 & {$[\mathrm{M}+\mathrm{H}]+$} & 330.0 & 88 & 192.0 & 20 & 70.2 & 33 & 135.0 & 34 \\
\hline Diazepam & {$[\mathrm{M}+\mathrm{H}]+$} & 285.1 & 77 & 193.1 & 32 & 154.1 & 26 & 222.1 & 26 & {$[\mathrm{M}+\mathrm{H}]+$} & 285.0 & 83 & 193.0 & 31 & 222.1 & 25 & 257.1 & 21 \\
\hline Lorazepam & {$[\mathrm{M}+\mathrm{H}]+$} & 321.1 & 74 & 275.0 & 22 & 303.0 & 15 & 229.1 & 31 & {$[\mathrm{M}+\mathrm{H}]+$} & 320.9 & 76 & 274.9 & 20 & 302.9 & 14 & 228.9 & 29 \\
\hline Carbamazepine & {$[\mathrm{M}+\mathrm{H}]+$} & 237.1 & 61 & 194.1 & 19 & 192.1 & 25 & & & {$[\mathrm{M}+\mathrm{H}]+$} & 237.1 & 87 & 194.1 & 18 & 192.1 & 23 & 179.1 & 35 \\
\hline primidone & {$[\mathrm{M}+\mathrm{H}]+$} & 219.1 & 68 & 91.2 & 28 & 162.2 & 12 & 117.2 & 23 & {$[\mathrm{M}+\mathrm{H}]+$} & 219.1 & 83 & 91.2 & 28 & 162.0 & 12 & 119.1 & 16 \\
\hline Famotidine & {$[\mathrm{M}+\mathrm{H}]+$} & 338.1 & 55 & 189.0 & 20 & 259.1 & 11 & 155.1 & 32 & {$[\mathrm{M}+\mathrm{H}]+$} & 338.2 & 68 & 321.2 & 12 & 303.2 & 11 & 97.1 & 20 \\
\hline Ranitidine & {$[\mathrm{M}+\mathrm{H}]+$} & 315.1 & 65 & 176.0 & 18 & 130.1 & 25 & 102.1 & 34 & {$[\mathrm{M}+\mathrm{H}]+$} & 315.0 & 57 & 176.0 & 17 & 130.0 & 25 & 270.0 & 12 \\
\hline
\end{tabular}




\begin{tabular}{|c|c|c|c|c|c|c|c|c|c|c|c|c|c|c|c|c|c|c|}
\hline \multirow[b]{3}{*}{ compounds } & \multicolumn{9}{|c|}{ HESI } & \multicolumn{9}{|c|}{ APPI } \\
\hline & precursor & & tube & & CE & & CE & & CE & & & tube & & CE & & CE & & CE \\
\hline & ion & $\mathrm{m} / \mathrm{z}$ & lens & SRM1 & 1 & SRM2 & 2 & SRM3 & 3 & precursor ion & $\mathrm{m} / \mathrm{z}$ & lens & SRM1 & 1 & SRM2 & 2 & SRM3 & 3 \\
\hline Cimetidine & {$[\mathrm{M}+\mathrm{H}]+$} & 253.1 & 67 & 159.1 & 14 & 117.2 & 16 & 95.2 & 29 & {$[\mathrm{M}+\mathrm{H}]+$} & 253.0 & 61 & 159.0 & 13 & 117.1 & 16 & 95.1 & 30 \\
\hline Loratadine & {$[\mathrm{M}+\mathrm{H}]+$} & 383.1 & 82 & 337.1 & 23 & 267.1 & 31 & 259.1 & 30 & {$[\mathrm{M}+\mathrm{H}]+$} & 383.0 & 86 & 337.0 & 22 & 266.9 & 31 & 259.0 & 31 \\
\hline diphenhydramine & {$[\mathrm{M}+\mathrm{H}]+$} & 256.2 & 54 & 167.1 & 14 & 165.2 & 37 & 152.1 & 37 & {$[\mathrm{M}+\mathrm{H}]+$} & 256.1 & 51 & 167.0 & 15 & 152.0 & 33 & 165.0 & 44 \\
\hline Butalbital & {$[\mathrm{M}-\mathrm{H}]-$} & 223.1 & 60 & 180.1 & 14 & 42.3 & 20 & 85.2 & 15 & {$[\mathrm{M}+\mathrm{H}]+$} & 225.1 & 70 & 171.1 & 12 & 154.1 & 13 & 169.1 & 14 \\
\hline Phenobarbital & {$[\mathrm{M}-\mathrm{H}]-$} & 231.1 & 61 & 188.2 & 14 & 42.5 & 15 & 85.3 & 15 & {$[\mathrm{M}-\mathrm{H}]-$} & 231.1 & 24 & 188.4 & 13 & 42.6 & 18 & & \\
\hline Pentobarbital & {$[\mathrm{M}-\mathrm{H}]-$} & 225.1 & 60 & 182.1 & 15 & 42.4 & 20 & 138.2 & 19 & {$[\mathrm{M}-\mathrm{H}]-$} & 225.1 & 62 & 182.3 & 15 & & & & \\
\hline Atenolol & {$[\mathrm{M}+\mathrm{H}]+$} & 267.2 & 78 & 145.1 & 26 & 190.1 & 18 & 133.1 & 31 & {$[\mathrm{M}+\mathrm{H}]+$} & 267.1 & 72 & 145.1 & 26 & 190.1 & 18 & 225.1 & 16 \\
\hline Sotalol & {$[\mathrm{M}+\mathrm{H}]+$} & 273.2 & 77 & 255.1 & 11 & 213.1 & 18 & 133.1 & 27 & {$[\mathrm{M}+\mathrm{H}]+$} & 273.1 & 68 & 255.1 & 12 & 213.1 & 18 & 133.1 & 29 \\
\hline Metoprolol & {$[\mathrm{M}+\mathrm{H}]+$} & 268.2 & 77 & 159.1 & 21 & 191.1 & 17 & 133.1 & 26 & {$[\mathrm{M}+\mathrm{H}]+$} & 268.1 & 80 & 116.2 & 17 & 191.1 & 17 & 159.1 & 20 \\
\hline Propranolol & {$[\mathrm{M}+\mathrm{H}]+$} & 260.2 & 78 & 183.1 & 17 & 155.1 & 25 & 157.1 & 20 & {$[\mathrm{M}+\mathrm{H}]+$} & 260.1 & 68 & 116.2 & 18 & 183.0 & 18 & 155.1 & 26 \\
\hline Timolol & {$[\mathrm{M}+\mathrm{H}]+$} & 317.2 & 84 & 261.1 & 16 & 244.1 & 21 & 188.0 & 25 & {$[\mathrm{M}+\mathrm{H}]+$} & 317.1 & 66 & 261.0 & 16 & 244.0 & 20 & 188.0 & 26 \\
\hline Betaxolol & {$[\mathrm{M}+\mathrm{H}]+$} & 308.2 & 82 & 121.1 & 26 & 133.1 & 26 & 91.1 & 39 & {$[\mathrm{M}+\mathrm{H}]+$} & 308.2 & 82 & 116.2 & 19 & 98.2 & 22 & 72.3 & 22 \\
\hline Carazolol & {$[\mathrm{M}+\mathrm{H}]+$} & 299.1 & 70 & 222.1 & 19 & 184.0 & 25 & 194.1 & 29 & {$[\mathrm{M}+\mathrm{H}]+$} & 299.1 & 81 & 116.2 & 21 & 222.0 & 20 & 194.1 & 29 \\
\hline Pindolol & {$[\mathrm{M}+\mathrm{H}]+$} & 249.2 & 72 & 116.1 & 17 & 172.1 & 17 & 144.1 & 25 & {$[\mathrm{M}+\mathrm{H}]+$} & 249.1 & 66 & 116.2 & 17 & 172.1 & 17 & 146.0 & 19 \\
\hline
\end{tabular}




\begin{tabular}{|c|c|c|c|c|c|c|c|c|c|c|c|c|c|c|c|c|c|c|}
\hline \multirow[b]{3}{*}{ compounds } & \multicolumn{9}{|c|}{ HESI } & \multicolumn{9}{|c|}{ APPI } \\
\hline & precursor & & tube & & CE & & CE & & CE & & & tube & & CE & & CE & & CE \\
\hline & ion & $\mathrm{m} / \mathrm{z}$ & lens & SRM1 & 1 & SRM2 & 2 & SRM3 & 3 & precursor ion & $\mathrm{m} / \mathrm{z}$ & lens & SRM1 & 1 & SRM2 & 2 & SRM3 & 3 \\
\hline Nadolol & {$[\mathrm{M}+\mathrm{H}]+$} & 310.2 & 73 & 254.1 & 17 & 201.1 & 22 & 236.1 & 19 & {$[\mathrm{M}+\mathrm{H}]+$} & 310.1 & 70 & 254.1 & 17 & 236.1 & 19 & 201.0 & 23 \\
\hline Salbutamol & {$[\mathrm{M}+\mathrm{H}]+$} & 240.2 & 62 & 148.1 & 18 & 222.1 & 10 & 121.1 & 29 & {$[\mathrm{M}+\mathrm{H}]+$} & 240.1 & 66 & 148.1 & 19 & 166.0 & 12 & 222.1 & 8 \\
\hline Clenbuterol & {$[\mathrm{M}+\mathrm{H}]+$} & 277.1 & 71 & 203.0 & 16 & 259.1 & 10 & 132.1 & 30 & {$[\mathrm{M}+\mathrm{H}]+$} & 277.0 & 60 & 202.9 & 16 & 259.0 & 9 & 132.1 & 28 \\
\hline Enalapril & {$[\mathrm{M}+\mathrm{H}]+$} & 377.2 & 74 & 234.1 & 19 & 303.2 & 17 & 117.1 & 36 & {$[\mathrm{M}+\mathrm{H}]+$} & 377.1 & 71 & 234.1 & 19 & 303.1 & 17 & 117.1 & 36 \\
\hline Hydrochlorothiazide & {$[\mathrm{M}-\mathrm{H}]-$} & 296.0 & 78 & 269.0 & 20 & 205.0 & 23 & 126.1 & 33 & {$[\mathrm{M}-\mathrm{H}]-$} & 295.9 & 60 & 269.0 & 19 & 205.1 & 23 & 126.1 & 23 \\
\hline Lisinopril & {$[\mathrm{M}+\mathrm{H}]+$} & 406.2 & 88 & 84.2 & 33 & 246.1 & 22 & 309.2 & 18 & {$[\mathrm{M}+\mathrm{H}]+$} & 406.1 & 78 & 84.2 & 31 & 246.1 & 19 & 291.1 & 8 \\
\hline Furosemide & {$[\mathrm{M}-\mathrm{H}]-$} & 328.9 & 75 & 285.0 & 17 & 204.9 & 23 & 126.0 & 36 & {$[\mathrm{M}-\mathrm{H}]-$} & 328.9 & 69 & 205.0 & 24 & 285.2 & 20 & 78.2 & 34 \\
\hline Tamoxifen & {$[\mathrm{M}+\mathrm{H}]+$} & 372.2 & 84 & 72.2 & 23 & 129.1 & 26 & 70.2 & 36 & {$[\mathrm{M}+\mathrm{H}]+$} & 372.1 & 86 & 72.3 & 23 & 129.1 & 26 & 70.3 & 36 \\
\hline Metronidazole & {$[\mathrm{M}+\mathrm{H}]+$} & 172.1 & 63 & 128.1 & 13 & 82.2 & 23 & 111.1 & 20 & {$[\mathrm{M}+\mathrm{H}]+$} & 172.1 & 61 & 128.1 & 12 & 82.2 & 25 & 111.2 & 18 \\
\hline Clotrimazole & $\mathrm{C} 3 \mathrm{H} 3 \mathrm{~N} 2]_{+}$ & 277.1 & 60 & 165.1 & 27 & 199.0 & 31 & 242.1 & 20 & [M-C3H3N2]+ & 277.0 & 60 & 165.0 & 23 & 241.0 & 27 & 239.0 & 50 \\
\hline Glibenclamide & {$[\mathrm{M}+\mathrm{H}]+$} & 494.3 & 70 & 369.1 & 14 & 169.0 & 33 & 304.1 & 25 & {$[\mathrm{M}+\mathrm{Na}]+$} & 516.0 & 101 & 390.9 & 19 & 416.9 & 19 & 419.4 & 19 \\
\hline
\end{tabular}




\subsubsection{Dopant delivery system}

Dopant was delivered by Fusion Touch 100 syringe pump from Chemyx (Stafford, TX, USA). Syringe pump was connected to the auxiliary gas and dopant was nebulized to gas phase. The dopant gas delivery system is shown in Figure 17. Compared to mixing dopant with mobile phase, this dopant gas delivery system increased reaction between dopant and analytes.
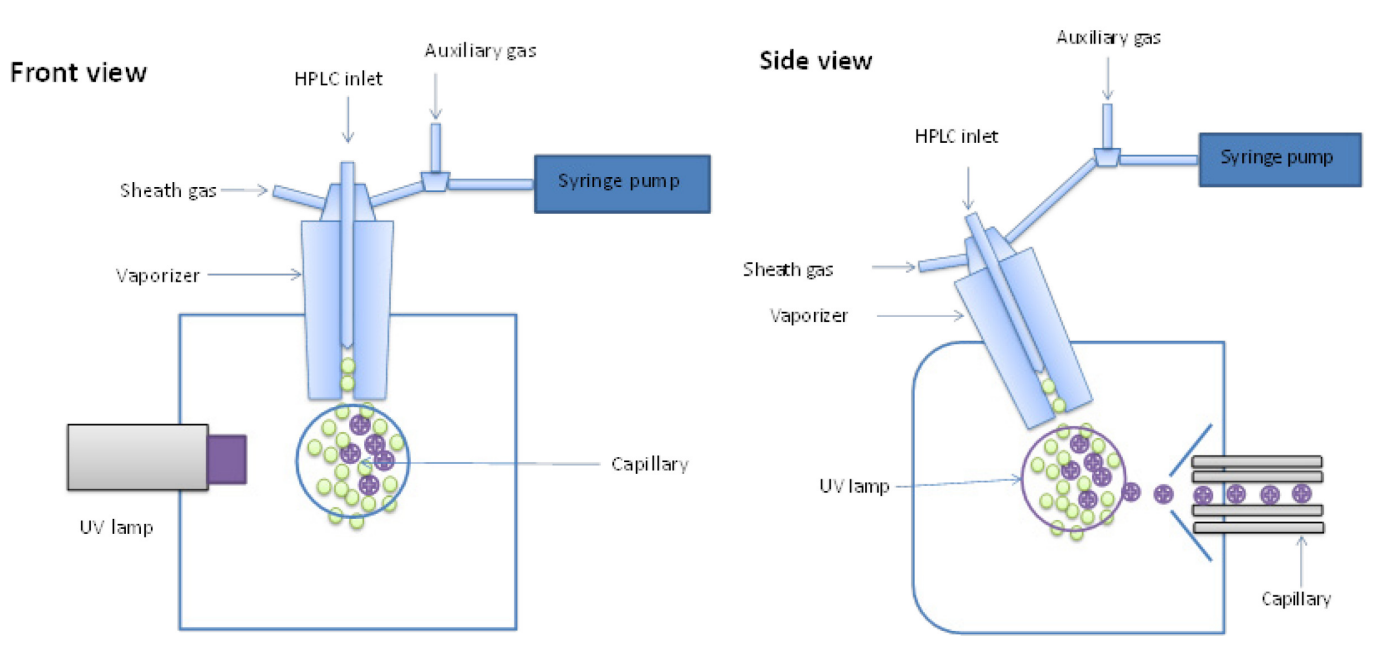

Figure 17. Dopant gas delivery system, modified from (Hanold et al., 2004)

\subsection{Results and discussion}

\subsubsection{Optimization of online SPE procedure}

Water samples $(5 \mathrm{~mL})$ were loaded to the preconcentration column at different flow rates: $500 \mu \mathrm{L} / \mathrm{min}, 1000 \mu \mathrm{L} / \mathrm{min}, 1500 \mu \mathrm{L} / \mathrm{min}$ and $2000 \mu \mathrm{L} / \mathrm{min}$. Absolute recovery of analytes (based on the response only) detected in the positive ion mode is shown in Figure 18a and absolute recovery of analytes detected in the negative mode is shown in Figure 18b. Loading speed of $2000 \mu \mathrm{L} / \mathrm{min}$ and 1000 $\mu \mathrm{L} /$ min was chosen for positive mode and negative mode respectively since 
analytes were recovered most at these two flow rates. In the negative mode, the $\mathrm{pH}$ of samples was adjusted to 2 to increase the recovery of salicylic acid and clofibric acid in the loading column.

In order to reduce matrix effects, a wash step was applied after samples were loaded to the preconcentration column. Only water was used to wash the preconcentration column because some analytes are very soluble in organic solvents. Three different volumes of water $(1 \mathrm{~mL}, 2 \mathrm{~mL}$ and $3 \mathrm{~mL}$ ) were tested in both positive mode and negative mode and results are shown in figure 19a and figure 19b, respectively. In the positive mode, Metronidazole, lisinopril and primidone started to be lost when wash volume was more than $1 \mathrm{~mL}$. Therefore, $1 \mathrm{~mL}$ was chosen as the wash volume in the positive mode. In the negative mode, acetaminophen was not retained in the preconcentration column when the wash volume was more than $1 \mathrm{~mL}$ and the result was consistent with the result shown in 4.3.1. Therefore, the Hypersil aQ column is not a good choice to retain acetaminophen. Hydrochlorothiazide lost its recovery on the preconcentration column when wash volume was more than $1 \mathrm{~mL}$. Thus, $1 \mathrm{~mL}$ was also chosen as the wash volume in the negative mode. 


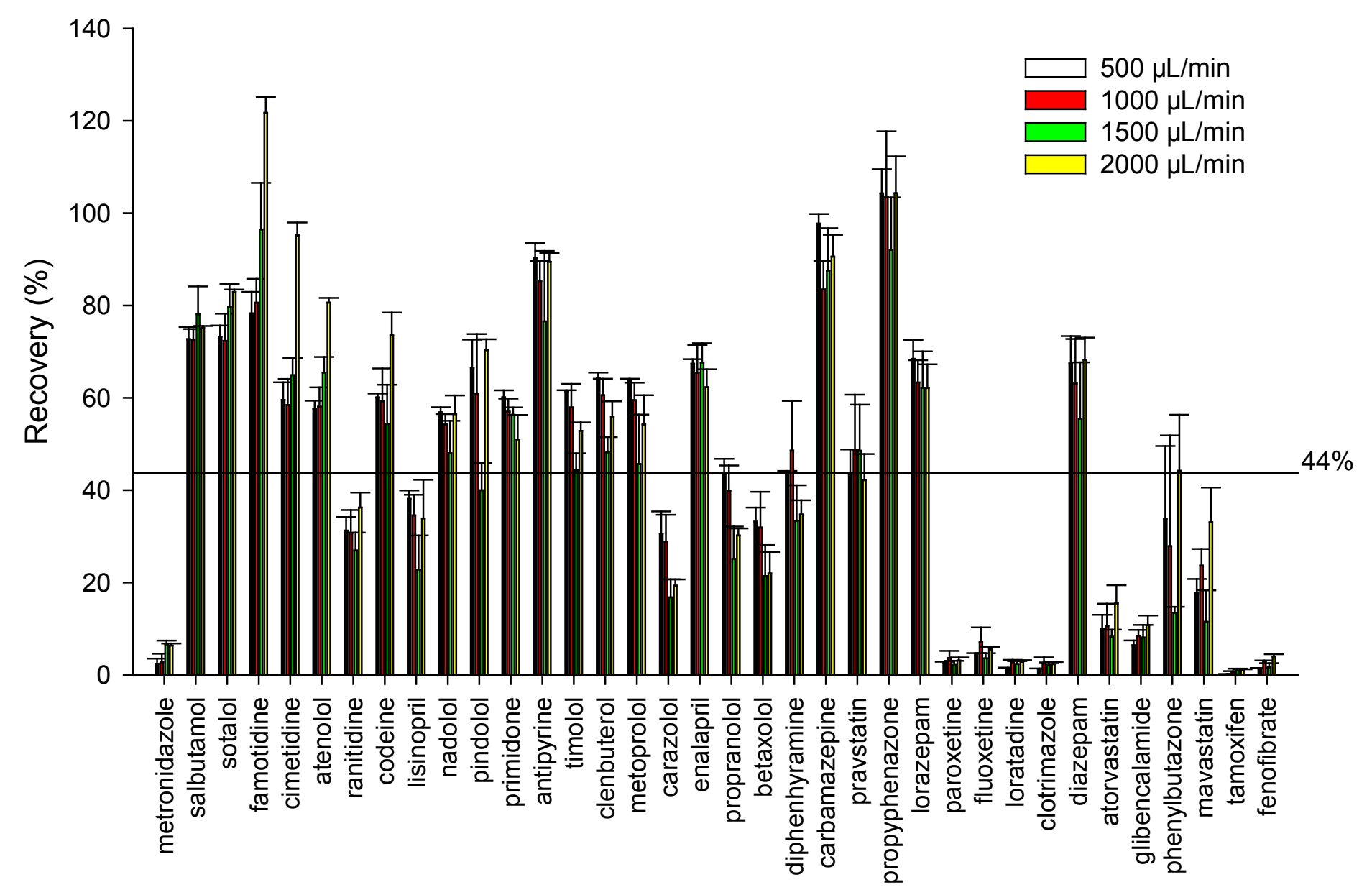

Figure 18a. Absolute recovery of analytes at different load speeds in the positive mode 


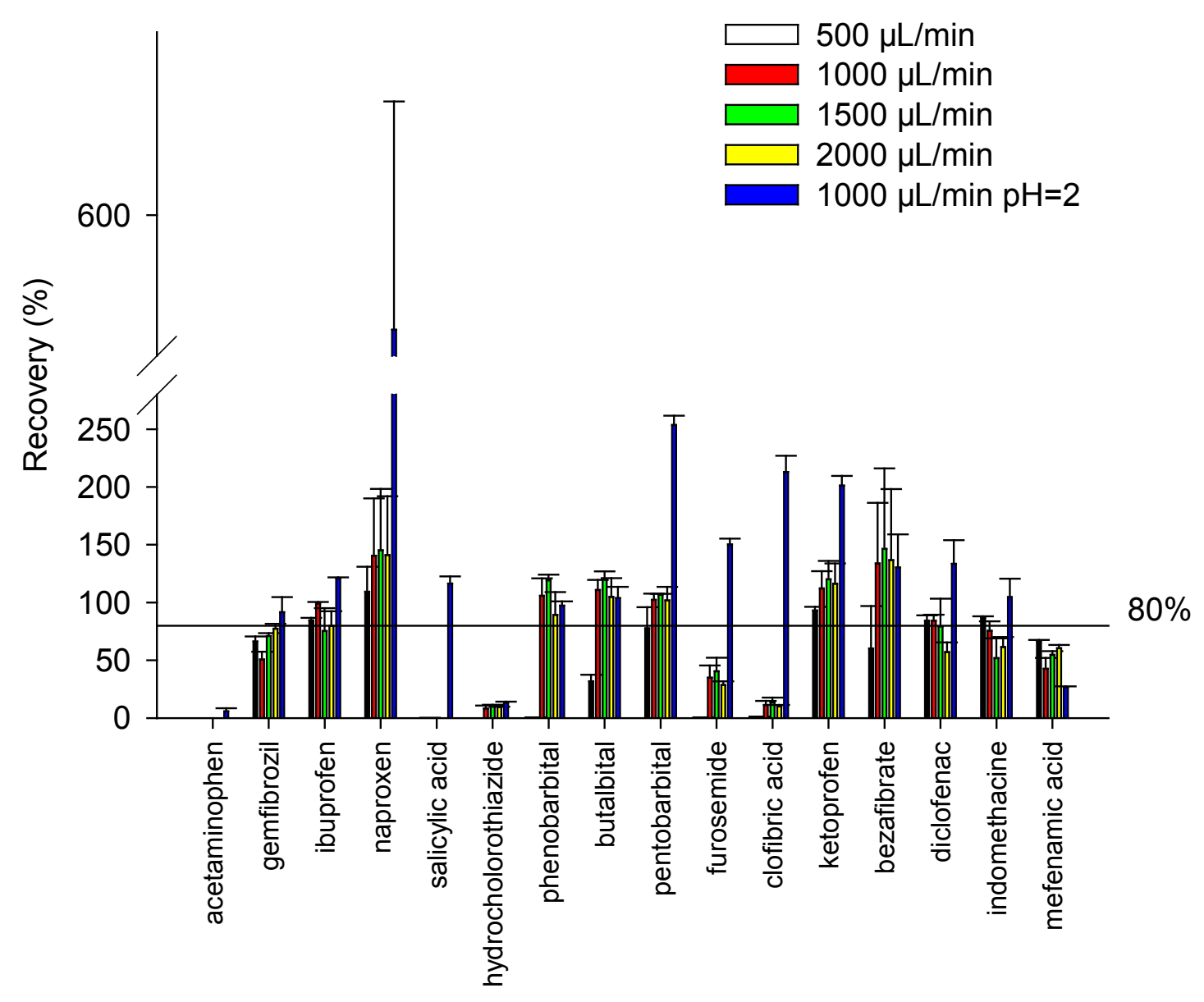

Figure 18b. Absolute recovery of analytes at different load speeds in the negative mode 


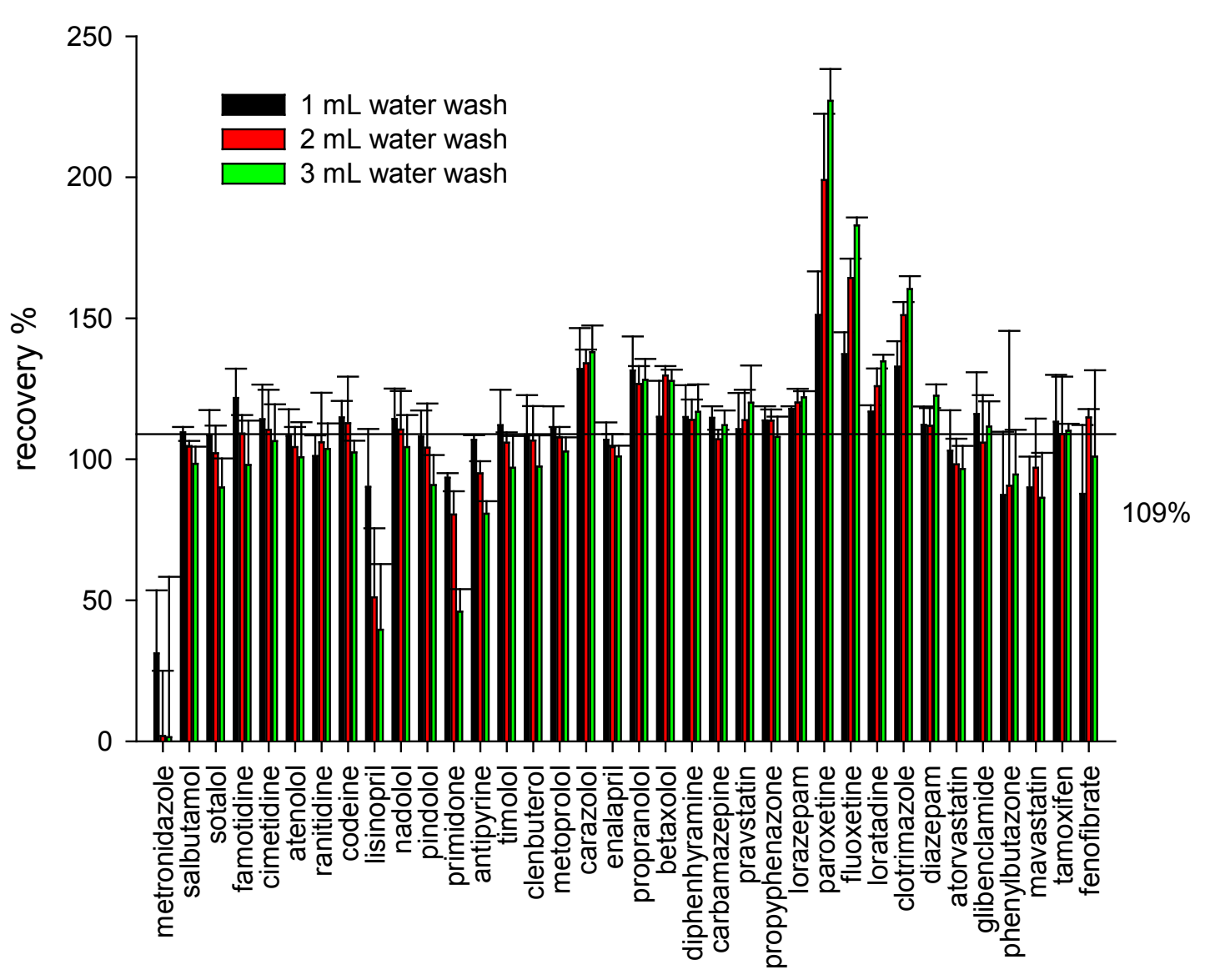

Figure 19a. Absolute recovery of analytes in positive mode with different wash volume 


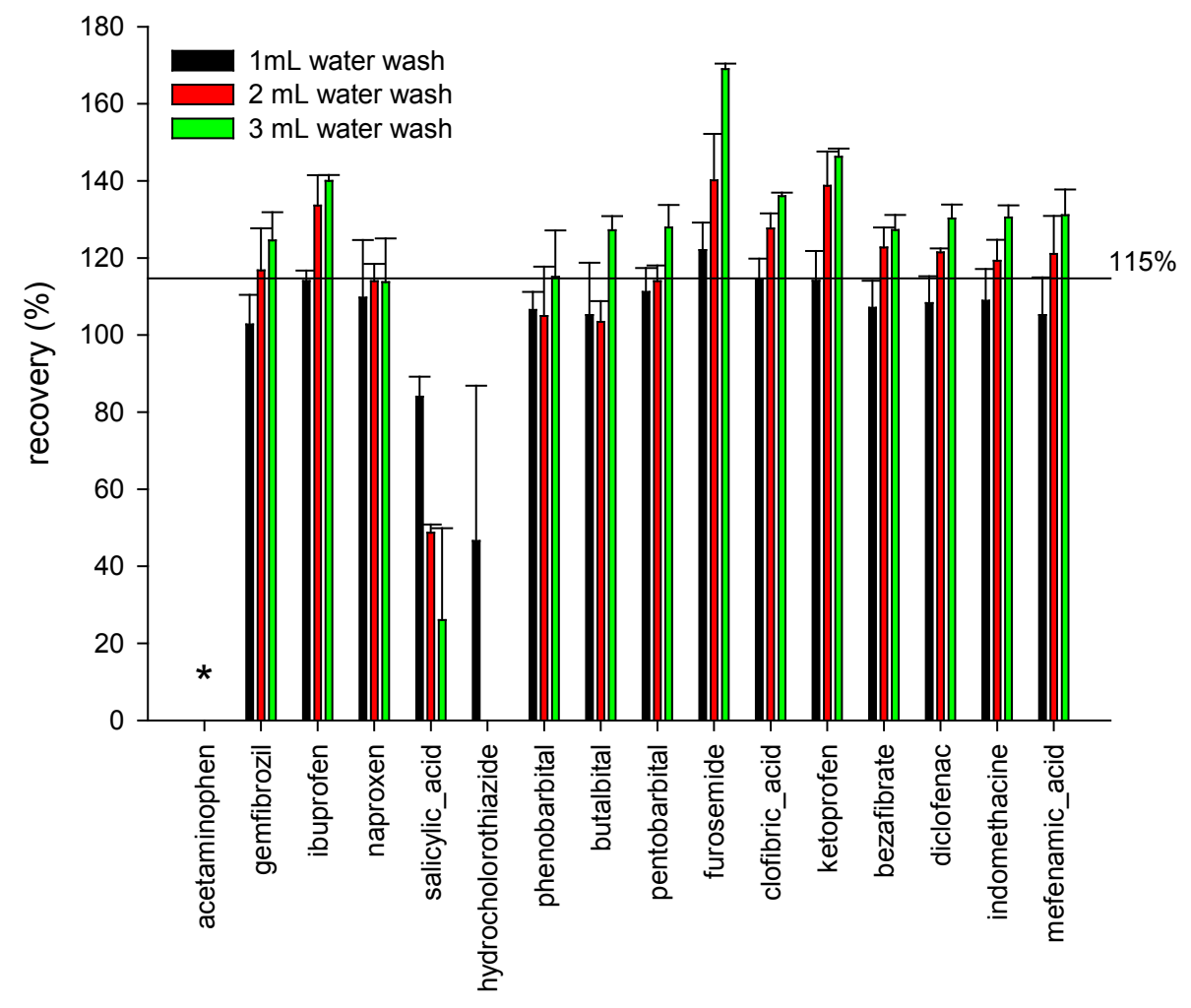

Figure 19b. Absolute recovery of analytes in negative mode with different wash volume. Asterisk $\left({ }^{*}\right)$ indicates not recovered. 


\subsubsection{Comparison of different API techniques}

\subsubsection{Comparison based on absolute signal intensity}

Several studies compared the absolute signal intensity of pharmaceuticals using different ionization methods (Cai et al., 2005; Garcia-Ac et al., 2011). We compared the signal intensity of different ionization methods by direct injection of $2.5 \mathrm{ng}$ standard compounds. The signal intensity of compound detected in the HESI method was treated as $100 \%$. The signal intensity of compounds detected in other ionization methods was compared with the HESI method. Results of comparison are shown in Table 15. The best ionization method is shown in green. For 32 out of 52 compounds, HESI was the best ionization method. 14 out of 52 compounds were best detected by APPI with toluene as dopant. Only 3 analytes were best detected using chlorobenzene as dopant and 3 were best detected in APPI with acetone as dopant. Results indicated that HESI was still a very effective ionization method for the selected target compounds. For some of the compounds usually analyzed in the negative mode in ESI, signal intensity increased remarkablely when they were ionized in the positive mode in APPI. Ketoprofen $([\mathrm{M}-\mathrm{H}]-\rightarrow[\mathrm{M}+\mathrm{H}]+)$, naproxen $([\mathrm{M}-\mathrm{H}]-\rightarrow[\mathrm{M}+\mathrm{H}-\mathrm{H} 2 \mathrm{O}-\mathrm{CO}]+)$, indomethacin $([\mathrm{M}-\mathrm{H}]-\rightarrow[\mathrm{M}+\mathrm{H}]+)$, diclofenac $([\mathrm{M}-\mathrm{H}]-\rightarrow[\mathrm{M}+\mathrm{H}]+)$, mefenamic acid $([\mathrm{M}-\mathrm{H}]-\rightarrow[\mathrm{M}+\mathrm{H}-\mathrm{H} 2 \mathrm{O}]+)$, acetaminophen $([\mathrm{M}-\mathrm{H}]-\rightarrow[\mathrm{M}+\mathrm{H}]+)$ and bezafibrate $([\mathrm{M}-$ $H]-\rightarrow[M+H]+$ ) were in that case (figure 20 ). For acetaminophen, signal intensity increased 80 times when it was ionized by APPI with toluene as dopant. Therefore, APPI with toluene as dopant has two major advantages, firstly, it 
increases the sensitivity and secondly it avoids the need for positive and negative runs for the same sample. 
RT: $0.00-16.01 \mathrm{SM}: 7 \mathrm{~B}$
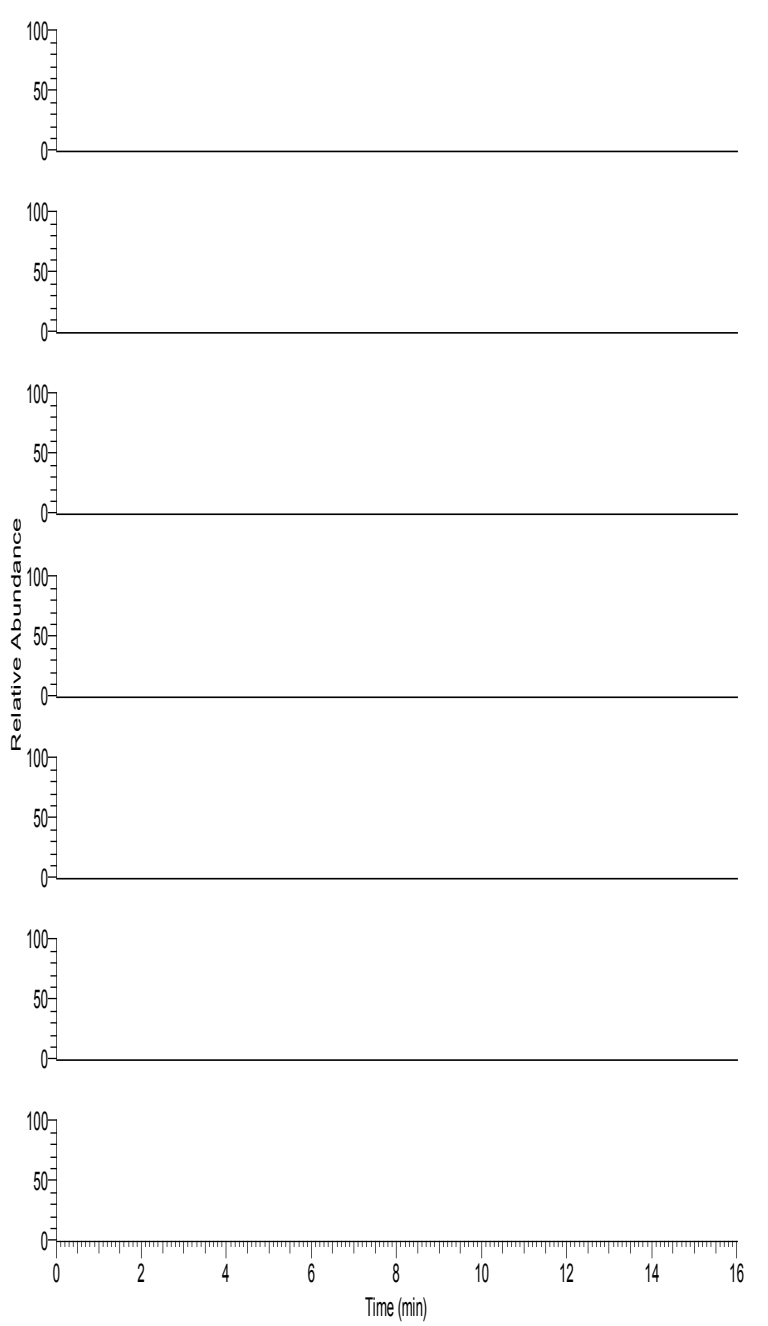

Figure 20. Chromatography of compounds in HESI- and APPI+ 
Table 15. Comparison of analyte responses under different ionization conditions

\begin{tabular}{|c|c|c|c|c|c|c|c|c|c|c|c|c|c|c|c|c|c|c|}
\hline & HESI & & RSD & APPI & & RSD & $\begin{array}{c}\text { APPI } \\
\text { toluene }\end{array}$ & & RSD & $\begin{array}{c}\text { APPI } \\
\text { acetone }\end{array}$ & & RSD & $\begin{array}{c}\text { APPI } \\
\text { anisole }\end{array}$ & & RSD & $\begin{array}{l}\text { APPI } \\
\text { chlor } \\
\text { oben } \\
\text { zene }\end{array}$ & & RSD \\
\hline ketoprofen & 100 & $\begin{array}{l}+ \\
- \\
+\end{array}$ & 10 & 1 & $\begin{array}{l}+ \\
-\end{array}$ & 8 & 234 & $\begin{array}{l}+ \\
- \\
+\end{array}$ & 8 & 55 & $\begin{array}{l}+ \\
- \\
+\end{array}$ & 5 & 41 & $\begin{array}{l}+ \\
-\end{array}$ & 9 & 25 & +- & 9 \\
\hline Naproxen & 100 & - & 22 & ND & & & 73 & - & 5 & 38 & - & 14 & ND & + & & 425 & +- & 11 \\
\hline Ibuprofen & 100 & - & 13 & ND & + & & 6 & - & 8 & 3 & - & 16 & 7 & $\begin{array}{l}- \\
+\end{array}$ & 2 & 5 & +- & 6 \\
\hline Indometacin & 100 & $\overline{+}$ & 11 & 1 & - & 22 & 136 & - & 7 & 80 & - & 3 & 58 & - & 3 & 51 & +- & 5 \\
\hline Diclofenac & 100 & - & 10 & 1 & - & 24 & 112 & - & 1 & 49 & $\begin{array}{l}- \\
+\end{array}$ & 4 & 27 & $\begin{array}{l}- \\
+\end{array}$ & 7 & 20 & +- & 13 \\
\hline Mefenamic acid & 100 & $\begin{array}{l}- \\
+\end{array}$ & 16 & 8 & $\dot{+}$ & 28 & 228 & 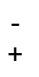 & 2 & 168 & $\begin{array}{l}- \\
+\end{array}$ & 4 & 67 & $\begin{array}{l}- \\
+\end{array}$ & 1 & 53 & +- & 2 \\
\hline Acetaminophen & 100 & $\begin{array}{l}- \\
+\end{array}$ & 19 & 124 & - & 9 & 8059 & - & 9 & 6682 & - & 13 & 1373 & - & 9 & 1111 & +- & 12 \\
\hline Salycilic Acid & 100 & - & 11 & ND & + & & ND & + & & ND & + & & ND & + & & ND & & \\
\hline Antipyrin & 100 & - & 5 & 4 & - & 20 & 166 & - & 19 & 170 & $\begin{array}{l}- \\
+\end{array}$ & 5 & 85 & $\begin{array}{l}- \\
+\end{array}$ & 23 & ND & & \\
\hline Propyphenazone & 100 & - & 4 & 24 & - & 11 & 316 & - & 4 & 257 & $\begin{array}{l}- \\
+\end{array}$ & 3 & 64 & $\begin{array}{l}- \\
+\end{array}$ & 3 & 54 & +- & 12 \\
\hline Phenylbutazone & 100 & - & 8 & 1 & - & 20 & 115 & - & 5 & 54 & $\begin{array}{l}- \\
+\end{array}$ & 3 & 19 & $\begin{array}{l}- \\
+\end{array}$ & 5 & 13 & +- & 33 \\
\hline Codeine & 100 & - & 3 & 4 & - & 12 & 61 & - & 7 & 87 & $\begin{array}{l}- \\
+\end{array}$ & 3 & 32 & $\begin{array}{l}- \\
+\end{array}$ & 14 & 28 & +- & 17 \\
\hline Clofibric Acid & 100 & - & 4 & ND & & & 8 & - & 7 & 5 & $\begin{array}{l}- \\
+\end{array}$ & 2 & 11 & $\begin{array}{l}- \\
+\end{array}$ & 8 & 13 & +- & 11 \\
\hline Gemfibrozil & 100 & - & 15 & ND & + & & 27 & - & 2 & 17 & $\begin{array}{l}- \\
+\end{array}$ & 5 & 31 & $\begin{array}{l}- \\
+\end{array}$ & 2 & 23 & +- & 5 \\
\hline Bezafibrate & 100 & $\begin{array}{l}- \\
+\end{array}$ & 8 & 1 & $\begin{array}{l}- \\
+\end{array}$ & 8 & 67 & - & 4 & 49 & - & 3 & 13 & - & 10 & 9 & +- & 20 \\
\hline Fenofibrate & 100 & $\begin{array}{l}- \\
+\end{array}$ & 0 & 2 & $\begin{array}{l}- \\
+\end{array}$ & 20 & 128 & $\begin{array}{l}- \\
+\end{array}$ & 3 & 84 & $\begin{array}{l}- \\
+\end{array}$ & 5 & 25 & $\begin{array}{l}- \\
+\end{array}$ & 8 & 21 & +- & 14 \\
\hline Atorvastatin & 100 & $\begin{array}{l}- \\
+\end{array}$ & 5 & ND & $\begin{array}{l}- \\
+\end{array}$ & 56 & 3 & $\begin{array}{l}- \\
+\end{array}$ & 13 & 3 & - & 12 & 1 & - & 15 & 1 & +- & 24 \\
\hline Mevastatin & 100 & $\begin{array}{l}- \\
+\end{array}$ & 17 & 14 & - & 6 & 5 & 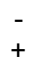 & 13 & 4 & - & 15 & 2 & - & 14 & 2 & +- & 14 \\
\hline Pravastatin & 100 & - & 4 & ND & & & 10 & - & 18 & ND & & & ND & & & ND & & \\
\hline
\end{tabular}




\begin{tabular}{|c|c|c|c|c|c|c|c|c|c|c|c|c|c|c|c|c|c|c|}
\hline & HESI & & RSD & APPI & & RSD & $\begin{array}{c}\text { APPI } \\
\text { toluene }\end{array}$ & & RSD & $\begin{array}{c}\text { APPI } \\
\text { acetone }\end{array}$ & & RSD & $\begin{array}{c}\text { APPI } \\
\text { anisole }\end{array}$ & & RSD & $\begin{array}{l}\text { APPI } \\
\text { chlor } \\
\text { oben } \\
\text { zene }\end{array}$ & & RSD \\
\hline Fluoxetine & 100 & $\begin{array}{l}+ \\
- \\
+\end{array}$ & 3 & ND & $\begin{array}{l}+ \\
- \\
+\end{array}$ & 16 & 6 & $\begin{array}{l}+ \\
- \\
+\end{array}$ & 4 & 4 & $\begin{array}{l}+ \\
+ \\
+\end{array}$ & 6 & 1 & $\begin{array}{l}+ \\
- \\
+\end{array}$ & 9 & 1 & +- & 26 \\
\hline Paroxetine & 100 & + & 3 & 4 & + & 21 & 24 & - & 6 & 19 & - & 7 & 5 & - & 1 & 5 & +- & 8 \\
\hline Diazepam & 100 & - & 4 & 3 & - & 18 & 48 & - & 3 & 34 & - & 4 & 17 & - & 1 & 16 & +- & 8 \\
\hline Lorazepam & 100 & - & 1 & 2 & - & 18 & 91 & - & 3 & 69 & - & 13 & 27 & - & 7 & 21 & +- & 13 \\
\hline Carbamazepine & 100 & - & 1 & 1 & - & 8 & 32 & - & 6 & 31 & - & 3 & 8 & - & 3 & 6 & +- & 15 \\
\hline Primidone & 100 & - & 9 & ND & & & 334 & - & 2 & 74 & - & 4 & 61 & - & 1 & 223 & +- & 1 \\
\hline Famotidine & 100 & - & 3 & ND & + & & ND & + & & 380 & + & 2 & 138 & - & 4 & 110 & +- & 7 \\
\hline Ranitidine & 100 & 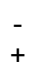 & 6 & 2 & - & 13 & 84 & - & 12 & 83 & - & 9 & 11 & - & 8 & 9 & +- & 8 \\
\hline Cimetidine & 100 & - & 5 & 9 & - & 13 & 336 & - & 8 & 418 & - & 10 & 72 & - & 7 & 59 & +- & 11 \\
\hline Loratadine & 100 & - & 2 & 4 & - & 18 & 30 & - & 4 & 22 & - & 5 & 7 & - & 2 & 6 & +- & 16 \\
\hline diphenhydramine & 100 & - & 2 & ND & & & 5 & - & 4 & 3 & - & 12 & 1 & - & 4 & 1 & +- & 16 \\
\hline Butalbital & 100 & - & 15 & ND & & & 65 & - & 8 & ND & + & & ND & + & & ND & & \\
\hline Phenobarbital & 100 & - & 2 & ND & & & 135 & $\begin{array}{l}- \\
+\end{array}$ & 15 & 77 & $\begin{array}{l}- \\
+\end{array}$ & 5 & 160 & - & 5 & 170 & +- & 23 \\
\hline Pentobarbital & 100 & - & 25 & ND & + & & 349 & - & 15 & 179 & $\begin{array}{l}- \\
+\end{array}$ & 21 & 344 & - & 8 & 379 & +- & 7 \\
\hline Atenolol & 100 & $\begin{array}{l}- \\
+\end{array}$ & 8 & 3 & $\begin{array}{l}- \\
+\end{array}$ & 21 & 176 & $\begin{array}{l}- \\
+\end{array}$ & 9 & 148 & $\begin{array}{l}- \\
+\end{array}$ & 10 & 24 & - & 11 & 22 & +- & 12 \\
\hline Sotalol & 100 & $\begin{array}{l}- \\
+\end{array}$ & 2 & 5 & $\begin{array}{l}- \\
+\end{array}$ & 26 & 228 & - & 8 & 202 & $\begin{array}{l}- \\
+\end{array}$ & 5 & 36 & - & 6 & 31 & +- & 11 \\
\hline Metoprolol & 100 & $\begin{array}{l}- \\
+\end{array}$ & 4 & 3 & $\begin{array}{l}- \\
+\end{array}$ & 8 & 15 & $\begin{array}{l}- \\
+\end{array}$ & 19 & 13 & $\begin{array}{l}- \\
+\end{array}$ & 14 & 2 & - & 20 & 2 & +- & 4 \\
\hline Propranolol & 100 & $\dot{-}+$ & 4 & 4 & $\begin{array}{l}- \\
+\end{array}$ & 27 & 20 & - & 10 & 16 & $\begin{array}{l}- \\
+\end{array}$ & 15 & 3 & - & 11 & 2 & +- & 16 \\
\hline Timolol & 100 & $\overline{-}$ & 1 & 2 & $\begin{array}{l}- \\
+\end{array}$ & 22 & 16 & $\begin{array}{l}- \\
+\end{array}$ & 16 & 12 & $\begin{array}{l}- \\
+\end{array}$ & 19 & 3 & - & 20 & 2 & +- & 27 \\
\hline Betaxolol & 100 & - & 4 & 19 & - & 15 & 72 & - & 5 & 59 & $\begin{array}{l}- \\
+\end{array}$ & 6 & 14 & - & 9 & 14 & +- & 17 \\
\hline Carazolol & 100 & - & 5 & 5 & - & 42 & 28 & - & 8 & 21 & - & 14 & 4 & - & 20 & 3 & +- & 14 \\
\hline
\end{tabular}




\begin{tabular}{|c|c|c|c|c|c|c|c|c|c|c|c|c|c|c|c|c|c|c|}
\hline & HESI & & RSD & APPI & & RSD & $\begin{array}{c}\text { APPI } \\
\text { toluene }\end{array}$ & & RSD & $\begin{array}{c}\text { APPI } \\
\text { acetone }\end{array}$ & & RSD & $\begin{array}{c}\text { APPI } \\
\text { anisole }\end{array}$ & & RSD & $\begin{array}{l}\text { APPI } \\
\text { chlor } \\
\text { oben } \\
\text { zene }\end{array}$ & & RSD \\
\hline Pindolol & 100 & $\begin{array}{l}+ \\
- \\
+\end{array}$ & 7 & 12 & $\begin{array}{l}+ \\
- \\
+\end{array}$ & 7 & 445 & $\begin{array}{l}+ \\
- \\
+\end{array}$ & 15 & 383 & $\begin{array}{l}+ \\
- \\
+\end{array}$ & 11 & 61 & $\begin{array}{l}+ \\
- \\
+\end{array}$ & 5 & 45 & +- & 16 \\
\hline Nadolol & 100 & - & 3 & 6 & $\begin{array}{l}- \\
+\end{array}$ & 8 & 190 & $\begin{array}{l}- \\
+\end{array}$ & 6 & 134 & $\begin{array}{l}- \\
+\end{array}$ & 12 & 26 & - & 9 & 19 & + & 21 \\
\hline Salbutamol & 100 & + & 2 & 1 & - & 24 & 30 & + & 11 & 17 & + & 17 & 5 & + & 4 & 3 & +- & 10 \\
\hline Clenbuterol & 100 & + & 4 & ND & + & & 14 & + & 11 & 9 & + & 11 & 2 & + & 25 & 1 & +- & 18 \\
\hline Enalapril & 100 & + & 3 & 3 & - & 17 & 27 & + & 12 & 15 & - & 10 & 4 & + & 11 & 3 & +- & 8 \\
\hline Hydrochlorothiazide & 100 & + & 13 & ND & & & 5 & - & 53 & 2 & - & 18 & 8 & - & 21 & 14 & +- & 11 \\
\hline Lisinopril & 100 & + & 12 & ND & & & ND & + & & ND & + & & ND & + & & ND & & \\
\hline Furosemide & 100 & + & 9 & ND & + & & 25 & + & 7 & 15 & $\begin{array}{l}- \\
+\end{array}$ & 19 & 30 & - & 3 & 32 & +- & 8 \\
\hline Tamoxifen & 100 & + & 2 & 9 & - & 24 & 14 & - & 2 & 15 & $\begin{array}{l}- \\
+\end{array}$ & 4 & 5 & + & 1 & 4 & +- & 8 \\
\hline Metronidazole & 100 & + & 3 & 5 & + & 8 & 248 & + & 18 & 149 & - & 11 & 45 & + & 17 & 37 & +- & 25 \\
\hline Clotrimazole & 100 & + & 2 & 7 & - & 19 & 20 & - & 2 & 11 & $\begin{array}{l}- \\
+\end{array}$ & 3 & 22 & - & 3 & 21 & +- & 1 \\
\hline Glibenclamide & 100 & - & 1 & ND & & & 1 & - & 17 & 1 & - & 21 & $\mathrm{ND}$ & & & ND & & \\
\hline
\end{tabular}




\subsubsection{Comparison based on MDLs}

For further study, we also compared the MDLs of target compounds. Statistically determined MDLs using fortified matrix matched samples can be used to compare among method and laboratory and truly reflect the performance of the detection method. The study only reported the MDLs comparison for compounds that were detected in the positive mode in APPI because for compounds detected in the negative mode HESI had certainly a better sensitivity. MDLs for target compounds under the different ionization methods are shown in Table 16 and number of compounds with MDLs in 0-5 ng/L, 5-10 ng/L and $>10 \mathrm{ng} / \mathrm{L}$ range are shown in figure 21. For some of the compounds MDLs of APPI were much higher than HESI. Take pravastatin for example, MDLs of HESI was $6.9 \mathrm{ng} / \mathrm{L}$ while MDLs of APPI was more than $500 \mathrm{ng} / \mathrm{L}$. Thus, we still should use HESI as ionization method for these compounds. For some compounds like propyphenazone, gemfibrozil and fenofibrate etc, calculated MDLs didn't decrease much from HESI to APPI with dopant. Therefore, we can use HESI or APPI as the ionization method for these compounds. For compounds that were ionized in the negative mode in HESI but the positive mode in APPI, even thorough MDLs didn't decrease much in APPI, a much better background were observed in APPI. Take ketoprofen for example, MDLs of HESI and APPI with toluene were $10.0 \mathrm{ng} / \mathrm{L}$ and $14.7 \mathrm{ng} / \mathrm{L}$, respectively. However, in the negative ionization mode of $\mathrm{HESI}$, there were two interference peaks very close to the ketoprofen peak. In the positive ionization mode of APPI, there were no interference peaks for ketoprofen at all (figure 22). Thus, we used APPI as 
ionization method for detection of these compounds. In figure 23 , analytes in blue cycle is properly to be ionized by HESI and the analytes in the orange cycle is properly ionized by APPI, while the analytes in overlapped part of two cycles indicated that these analytes can be both ionized by both HESI and APPI. HESI is still an ideal ionizatioin technique for polar compounds except for acetaminophen. APPI is also a competitive ionization method for many polar analytes (overlap part in figure 23). APPI is an excellent ionization method for less polar and nonpolar compounds (analytes in orange cycle from chapter 4). If there is a need to detect polar and non-polar com pounds simultaneously, APPI will be the best ionization technique.

HESI

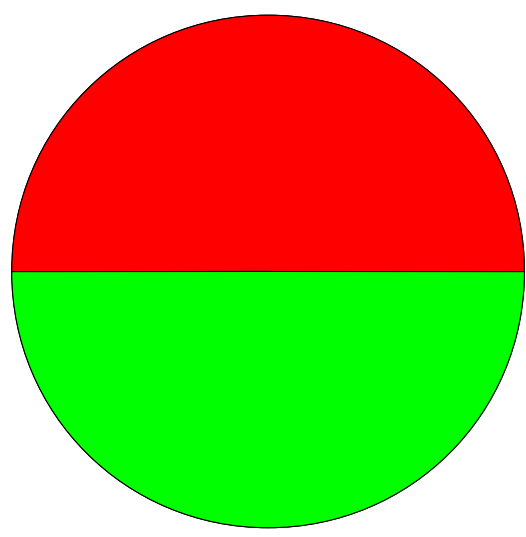

$$
\begin{aligned}
& \text { 0-5 ng/L: } 14 \\
& 5-10 \mathrm{ng} / \mathrm{L}: 12 \\
& >10 \mathrm{ng} / \mathrm{L}: 26
\end{aligned}
$$

APPI with toluene

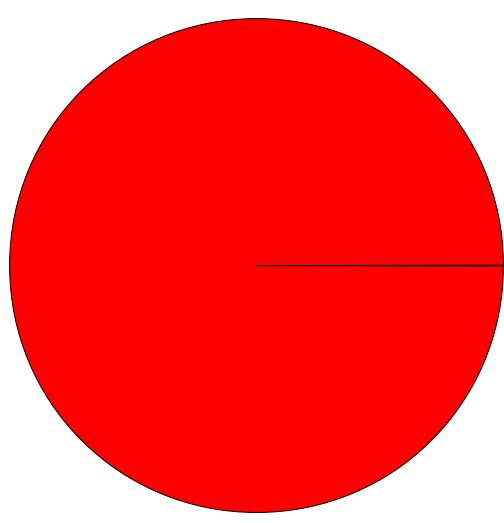

$0-5 \mathrm{ng} / \mathrm{L}: 0$

$5-10 \mathrm{ng} / \mathrm{L}: 5$
$>10 \mathrm{ng} / \mathrm{L}: 47$

Figure 21. Number of compounds with $\mathrm{MDL}$ in $0-5 \mathrm{ng} / \mathrm{L}, 5-10 \mathrm{ng} / \mathrm{L}$ and $>10 \mathrm{ng} / \mathrm{L}$ in HESI and APPI with toluene as dopant 


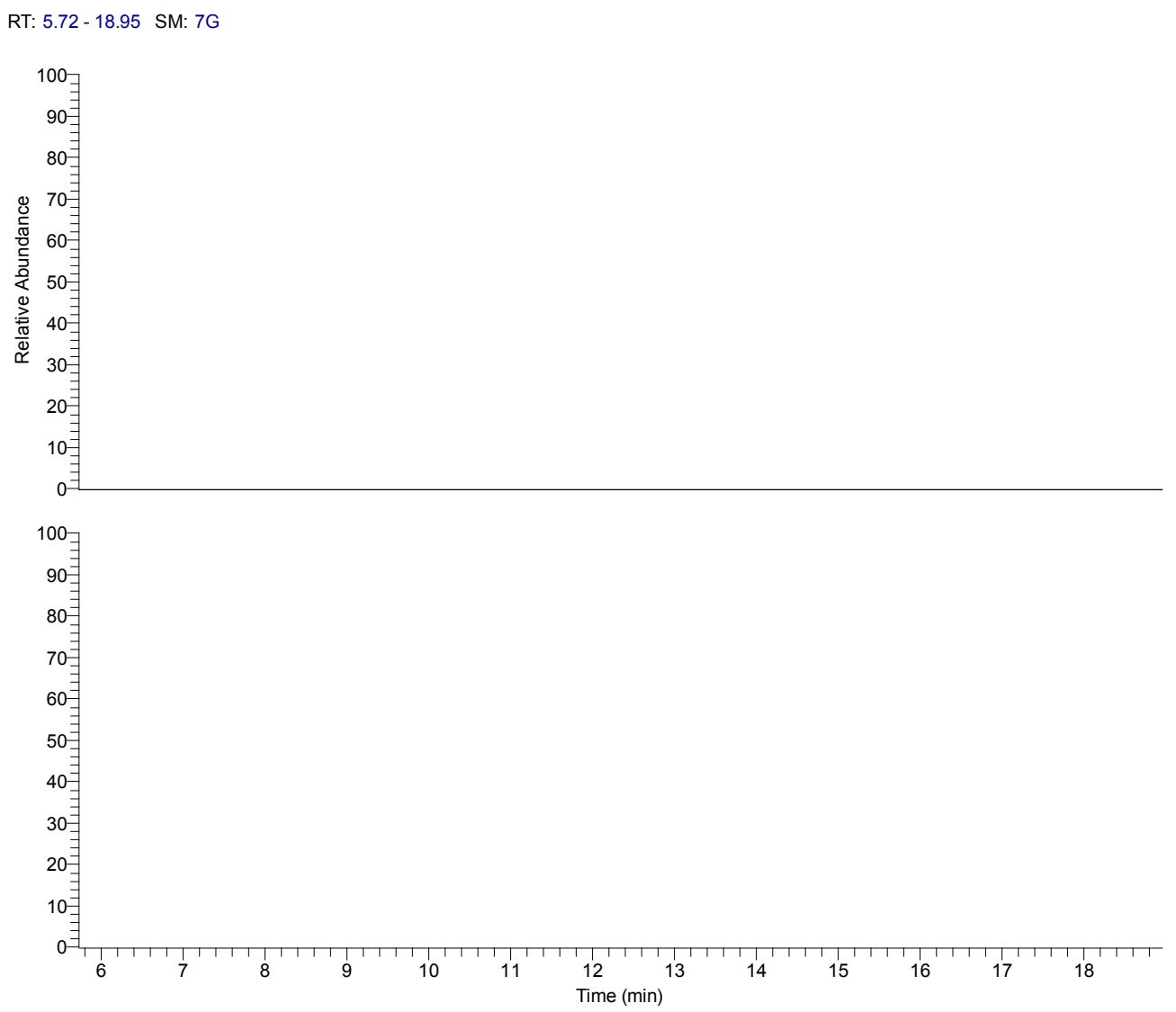

Figure 22. Chromatography of ketoprofen in HESI- and APPI+

\section{Table16. MDLs comparison of different API}

\begin{tabular}{clccc}
\hline & & HESI & APPI toluene & APPI acetone \\
\hline 1 & ketoprofen & 10.0 & 14.7 & 250 \\
2 & naproxen & 74.0 & 15.4 & 15.7 \\
3 & ibuprofen & 11.9 & $\mathrm{NA}$ & $\mathrm{NA}$ \\
4 & indomethacine & 19.2 & 8.6 & 51.0 \\
5 & diclofenac & 8.7 & 9.2 & 382 \\
6 & mefenamic_acid & 2.5 & 6.0 & 339 \\
7 & acetaminophen & 351 & 9.24 & 16.6 \\
8 & salicylic_acid & 23.6 & $\mathrm{NA}$ & $\mathrm{NA}$ \\
9 & antipyrine & 148 & $>250$ \\
10 & propyphenazone & 5.5 & 12.3 & 217 \\
11 & phenylbutazone & 147 & 500 & 500
\end{tabular}




\begin{tabular}{|c|c|c|c|c|}
\hline & & HESI & APPI toluene & APPI acetone \\
\hline 12 & codeine & 6.2 & 354 & 500 \\
\hline 13 & clofibric acid & 23.6 & NA & NA \\
\hline 14 & gemfibrozil & 14.4 & 36.4 & 367 \\
\hline 15 & bezafibrate & 26.0 & 11.2 & 24.1 \\
\hline 16 & fenofibrate & 14.2 & 21.8 & 5.1 \\
\hline 17 & atorvastatin & 6.9 & $>500$ & 156 \\
\hline 18 & mavastatin & 75.1 & $>500$ & $>500$ \\
\hline 19 & pravstatin & 9.0 & $>500$ & $>500$ \\
\hline 20 & fluoxetine & 12.3 & 166 & 388 \\
\hline 21 & paroxetine & 12.2 & 235 & 514 \\
\hline 22 & diazepam & 1.8 & 10.9 & 206 \\
\hline 23 & lorazepam & 6.4 & 20.5 & 31.9 \\
\hline 24 & carbamazepine & 2.8 & 19.9 & 8.5 \\
\hline 25 & primidone & 28.9 & 38.3 & 72.5 \\
\hline 26 & famotidine & 1.8 & $>500$ & $>500$ \\
\hline 27 & ranitidine & 3.5 & 500 & 500 \\
\hline 28 & cimetidine & 4.6 & 154 & 118 \\
\hline 29 & loratadine & 5.6 & 13.0 & 24.4 \\
\hline 30 & diphenhyramine & 4.3 & 33.0 & 500 \\
\hline 31 & butalbital & 189 & NA & NA \\
\hline 32 & phenobarbital & 39.7 & NA & NA \\
\hline 33 & pentobarbital & 32.4 & NA & NA \\
\hline 34 & atenolol & 7.0 & 218 & 29.6 \\
\hline 35 & sotalol & 3.5 & 125 & 387 \\
\hline 36 & metoprolol & 13.1 & 29.6 & 24.9 \\
\hline 37 & propranolol & 13.6 & 22.5 & 341 \\
\hline 38 & timolol & 3.9 & 202 & 10.5 \\
\hline 39 & betaxolol & 19.3 & 224 & 487 \\
\hline 40 & carazolol & 10.0 & 38.2 & 156 \\
\hline 41 & pindolol & 10.2 & 136 & 152 \\
\hline 42 & nadolol & 5.7 & 107 & 6.9 \\
\hline 43 & salbutamol & 3.8 & 357 & 500 \\
\hline 44 & clenbuterol & 4.1 & 15.7 & 141 \\
\hline 45 & enalapril & 3.7 & 6.8 & 20.3 \\
\hline 46 & hydrocholorothiazide & 250 & NA & NA \\
\hline 47 & lisinopril & 25.6 & $>500$ & $>500$ \\
\hline 48 & furosemide & 8.2 & NA & NA \\
\hline 49 & tamoxifen & 42.7 & 324 & 500 \\
\hline 50 & metronidazole & 98.2 & $>500$ & $>500$ \\
\hline 51 & clotrimazole & 6.3 & 29.3 & 140 \\
\hline 52 & glibenclamide & 22.1 & 381 & $>500$ \\
\hline
\end{tabular}




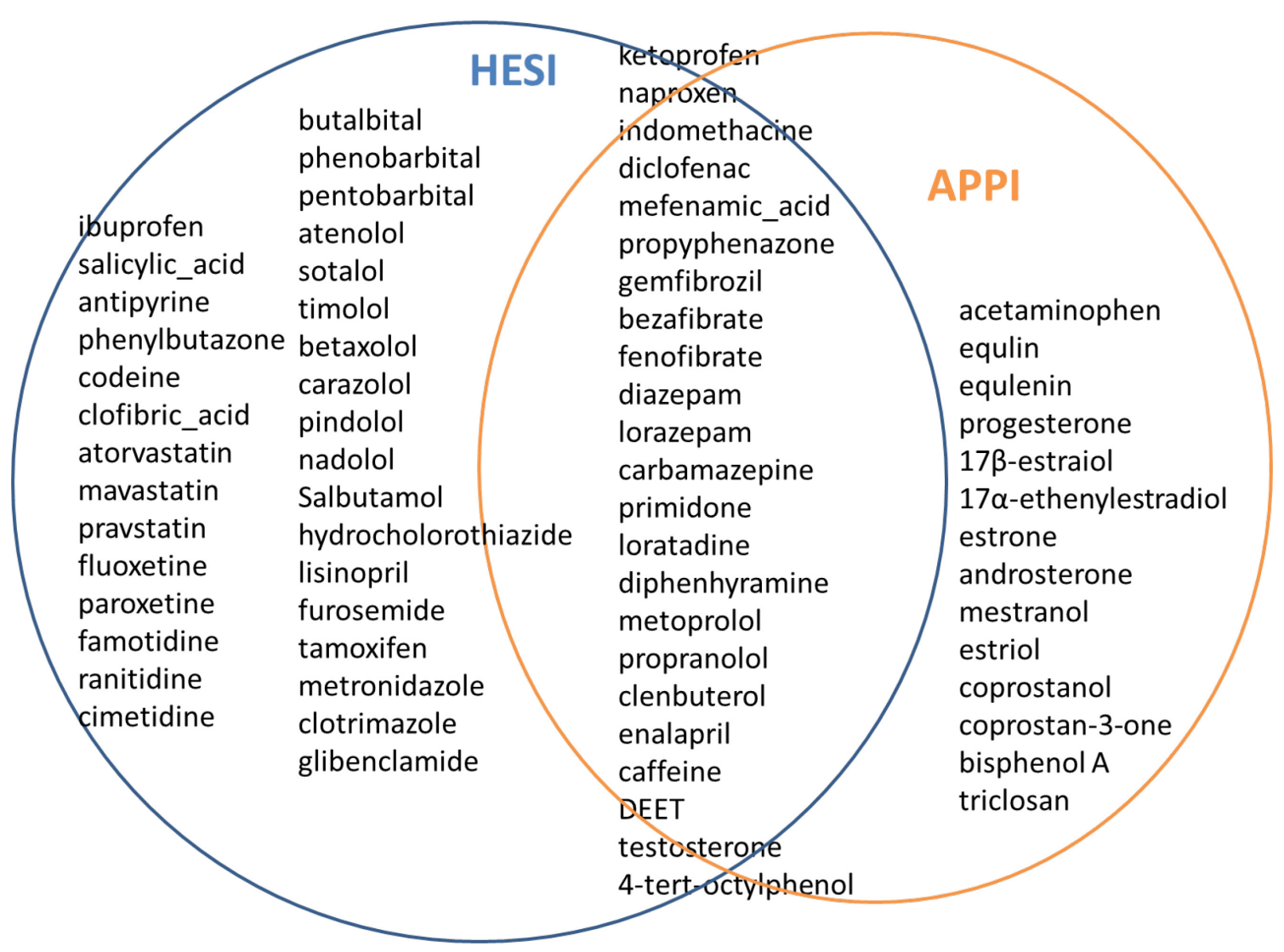

Figure 23. Analytes that can be ionized in HESI, APPI or both

\subsection{Conclusion}

An online-SPE-LC-MS/MS method was developed to detect 52 pharmaceuticals simultaneously. The online-SPE method was able to retain target compounds very well and interference was reduced by the wash step. HESI and APPI were compared by both absolute intensity and MDLs for ionization of 52 pharmaceuticals. Results indicated that HESI was an ideal ionization technique for polar compounds. However, APPI is an alternative ionization technique for some polar compounds that were ionized in positive mode. For simultaneous detection of compounds with various polarities, APPI will be a better choice since 
it showed comparable performance to HESI for some polar compounds and excellent performance for less polar or non-polar compounds.

A summary is shown in table 17 on the basis of comparison of methods developed in previous chapters for analytes. Proper methods were recommended for the detection of analytes. In general, GC/MS is good for nonpolar compounds. For less polar compounds, a derivation step is very important for the analysis of GC/MS. Heated electrospray ionization of LC/MS is appropriate for the detection of polar compounds. APPI with dopant is capable to ionize compounds with various polarities. 
Table 17. Comparison of GC/MS, LC/MS with different ionization sources for analytes

\begin{tabular}{|c|c|c|c|c|c|c|c|}
\hline Name & GC/MS & HESI & $\mathrm{APCl}$ & APPI & \begin{tabular}{cc}
\multicolumn{2}{c}{ LC/MS } \\
APPI & APPI \\
acetone & anisole \\
\end{tabular} & $\begin{array}{c}\text { APPI } \\
\text { chlorobenzene } \\
\end{array}$ & $\begin{array}{c}\text { APPI } \\
\text { toluene }\end{array}$ \\
\hline Ketoprofen & & YES & & & & & YES \\
\hline Naproxen & & YES & & & & & YES \\
\hline Ibuprofen & & YES & YES & & & & \\
\hline Indomethacin & & YES & & & & & YES \\
\hline Diclofenac & & YES & & & & & YES \\
\hline Mefenamic acid & & YES & & & & & YES \\
\hline Acetaminophen & & & YES & & & & YES \\
\hline Salicylic Acid & & YES & & & & & \\
\hline Antipyrin & & YES & & & & & \\
\hline Propyphenazone & & YES & & & & & YES \\
\hline Phenylbutazone & & YES & & & & & \\
\hline Codeine & & YES & & & & & \\
\hline Clofibric Acid & & YES & & & & & \\
\hline Gemfibrozil & & YES & & & & & YES \\
\hline
\end{tabular}




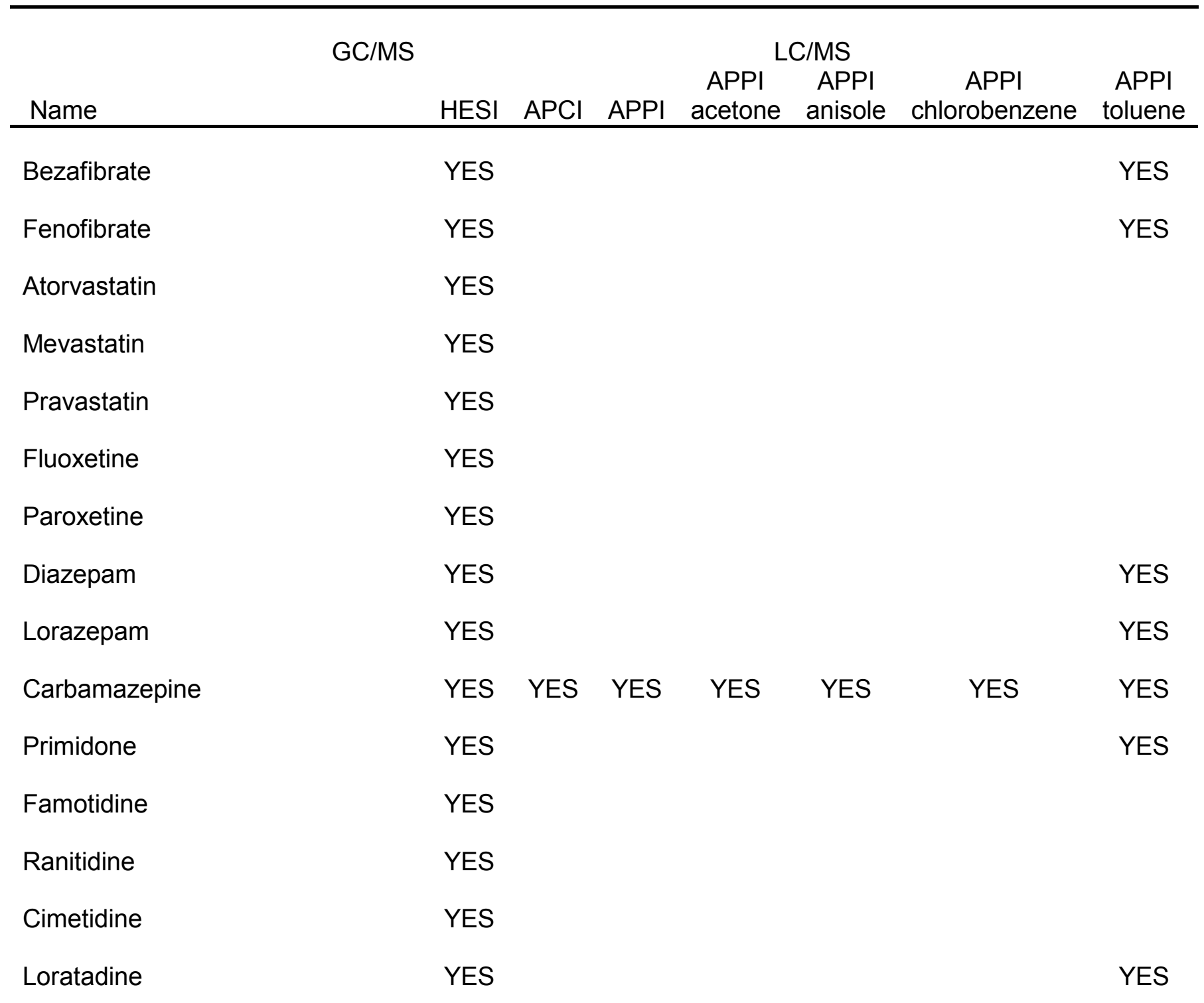




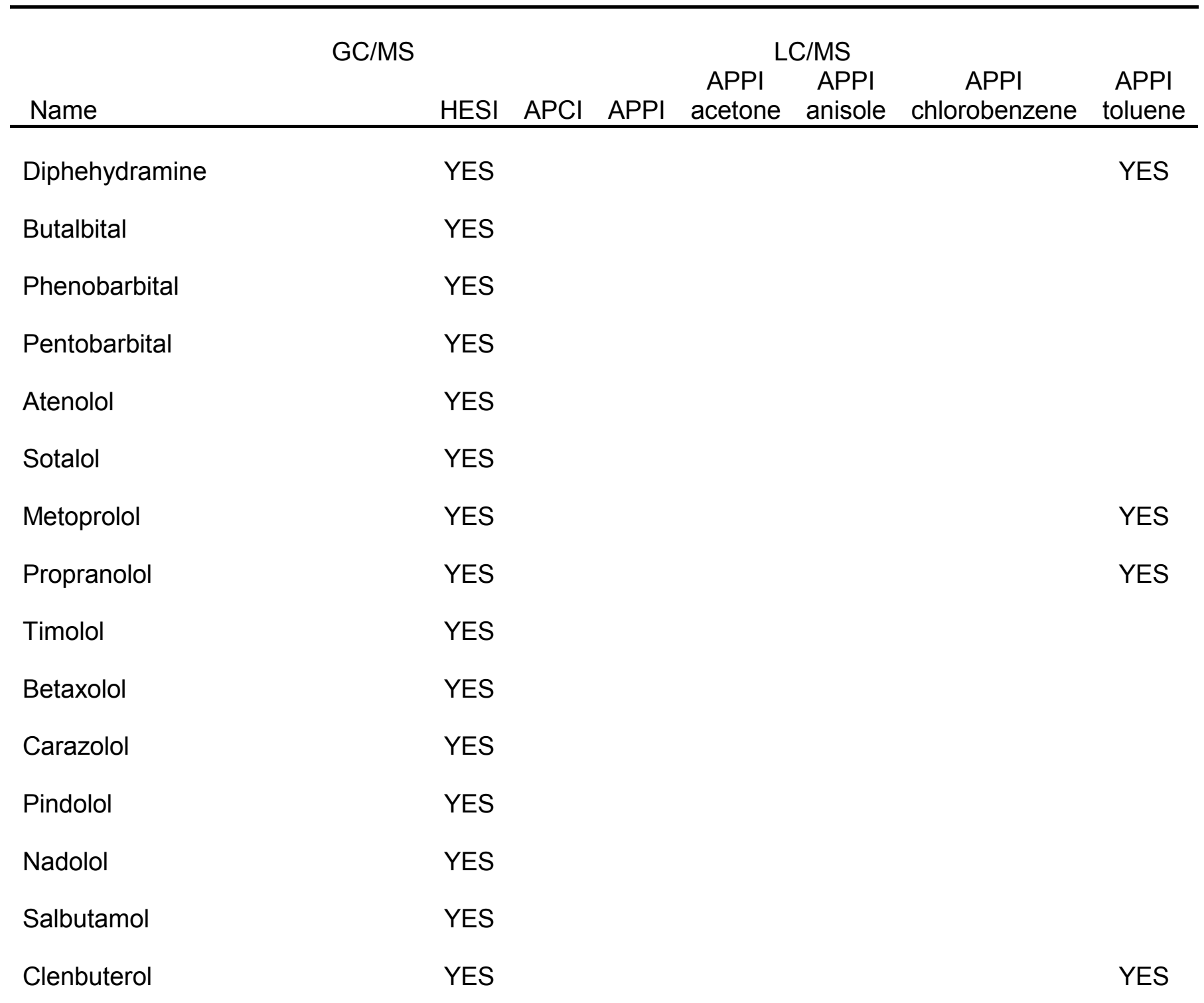




\begin{tabular}{|c|c|c|c|c|c|c|c|c|}
\hline Name & GC/MS & $\mathrm{HESI}$ & $\mathrm{APCl}$ & APPI & $\begin{array}{c}\text { APPI } \\
\text { acetone }\end{array}$ & $\begin{array}{c}\mathrm{C} / \mathrm{MS} \\
\text { APPI } \\
\text { anisole }\end{array}$ & $\begin{array}{c}\text { APPI } \\
\text { chlorobenzene }\end{array}$ & $\begin{array}{c}\text { APPI } \\
\text { toluene }\end{array}$ \\
\hline Enalapril & & YES & & & & & & YES \\
\hline Hydrochlorothiazide & & YES & & & & & & \\
\hline Lisinopril & & YES & & & & & & \\
\hline Furosemide & & YES & & & & & & \\
\hline Tamoxifen & & YES & & & & & & \\
\hline Metronidazole & & YES & & & & & & \\
\hline Clotrimazole & & YES & & & & & & \\
\hline Glibenclamide & & YES & & & & & & \\
\hline Caffeine & YES & YES & YES & YES & YES & YES & YES & YES \\
\hline Triclosan & YES & & & & & & & YES \\
\hline Triclocarban & & & & & & & & YES \\
\hline DEET & YES & YES & YES & YES & YES & YES & YES & YES \\
\hline Bisphenol -A & YES & YES & YES & & & & & YES \\
\hline 4-n-nonylphenol & YES & & YES & & & & & YES \\
\hline 4-t-octylphenol & YES & & & & & & & YES \\
\hline
\end{tabular}




\begin{tabular}{|c|c|c|c|c|c|c|c|c|}
\hline Name & GC/MS & HESI & $\mathrm{APCl}$ & APPI & $\begin{array}{c}\text { APPI } \\
\text { acetone }\end{array}$ & $\begin{array}{c}\mathrm{C} / \mathrm{MS} \\
\text { APPI } \\
\text { anisole } \\
\end{array}$ & $\begin{array}{c}\text { APPI } \\
\text { chlorobenzene }\end{array}$ & $\begin{array}{c}\text { APPI } \\
\text { toluene }\end{array}$ \\
\hline Androsterone & YES & & & & & & & YES \\
\hline Estrone (E1) & YES & & & & YES & & & YES \\
\hline Equilin & YES & & & & & & YES & YES \\
\hline Testosterone & YES & YES & YES & YES & YES & YES & YES & YES \\
\hline Equilenin & YES & & & & YES & & & YES \\
\hline 17- $\beta$-Estradiol (E2) & YES & & & & & & YES & YES \\
\hline 17- $\alpha$-Estradiol & YES & & & & & & & YES \\
\hline Ethynyl Estradiol (EE2) & YES & & & & & & YES & YES \\
\hline Progesterone & YES & & & & & & YES & YES \\
\hline Mestranol & YES & & & & & & & YES \\
\hline Estriol (E3) & YES & & & & & & & YES \\
\hline Coprostanol & YES & & & & & & YES & YES \\
\hline Coprostanone & YES & & & & YES & & & YES \\
\hline Coprostane & YES & & & & & & & \\
\hline Cholesterol & YES & & & & & & & \\
\hline
\end{tabular}




\section{CHAPTER 6}

\section{Occurrence of PPCPs in reclaimed water}

\subsection{Introduction}

Water stress has become a serious problem worldwide because of the rapid population growth on the earth. Properly managed water resources are critical for sustainable development of water supply. In order to improve the management efficiency of water resources, treated waters are commonly reused worldwide for landscape, agriculture, irrigation, recharging, etc. In the United States, treated water has been used in more than 3000 application sites. Over 40 $\times 10^{6} \mathrm{~m}^{3}$ of reclaimed water is used in California every year (Wu et al., 2010) (Xu et al., 2009).

However, potential adverse effects persist when reusing treated water. It is proved that current WWTPs with primary treatment and secondary treatment processes could not remove PPCPs completely as PPCPs have been detected in the effluent of WWTPs (Deblonde et al., 2011). Tertiary treatments such as granular active carbon adsorption, ozonation and catalytic oxidation showed a relatively high removal efficiency of PPCPs in the wastewater, but these treatments are seldom used in current WWTPs (Yoon et al., 2006; Broséus et al., 2009; Pisarenko et al.). Therefore, when reusing treated water, PPCPs could enter the ecosystem and water supply, which may have potential adverse effects to human beings. When treated water is used for irrigation, PPCPs may enter surface water by runoff and cause adverse effects on organism in the aqueous 
environment (Xu et al., 2009). In addition, compounds with strong sorption that are recalcitrant to degradation may remain on the surface of the soil and be uptaken by plants. Research about uptake of human pharmaceuticals in plants grown in soil suggested that compounds introduced by irrigation may be more available for plant uptake and translocation than by biosolid application (Wu et al., 2010). When treated water is used for deep well injection, PPCPs may contaminate ground water, which may be used as a source of drinking water. Thus, it is essential to monitor the presence of PPCPs in treated water targeted for reuse or recharge.

At Florida International University's Biscayne Bay Campus, treated wastewater from the North District WWTP is used for irrigation. The North District WWTP is located at NE 154 Street and is east of Biscayne Boulevard, and it receives wastewater from the North District of Miami-Dade County. The wastewater treatment plant was designed to have a flow of 120 million gallons per day (MGD) with average daily flow around 112.5 MGD. The facilities include screening, grit removal, primary sedimentation, activated sludge treatment by oxygenation and chlorination. Extra filtration (DynaSand Filtration, Leopold Filtration and Tetra filtration) and disinfection are applied to effluents before release to make the reclaimed water ready for use in irrigation. The following study monitored the reclaimed water between January 2011 and December 2011. 


\subsection{Experimental}

Analyte information is shown in table 18. Sample preparation, online SPE procedure and detection method were described in part 4.2 and 5.2. Reclaimed water was collected directly from sprinkler system during January 2011 and December 2011 at Florida International University, Biscayne Bay Campus.

Table 18. Analytes in reclaimed water samples

\begin{tabular}{llc}
\hline GROUP & Name & CAS Number \\
\hline Analgesics and anti-inflammatories & Ketoprofen & $22071-15-4$ \\
& Naproxen & $22204-53-1$ \\
& Ibuprofen & $15687-27-1$ \\
& Indomethacin & $53-86-1$ \\
& Diclofenac & $15307-86-5$ \\
& Mefenamic acid & $61-68-7$ \\
& Acetaminophen & $103-90-2$ \\
& Salicylic Acid & $69-72-7$ \\
& Antipyrin & $60-80-0$ \\
& Propyphenazone & $479-92-5$ \\
Antihyperlipidemics - Lipid Regulators & Clofibric Acid & $50-33-9$ \\
& Gemfibrozil & $76-57-3$ \\
& Bezafibrate & $882-09-7$ \\
& Fenofibrate & $25812-30-0$ \\
& Codeine & $41859-67-0$ \\
& & $49562-28-9$
\end{tabular}




\begin{tabular}{|c|c|c|}
\hline GROUP & Name & CAS Number \\
\hline & Atorvastatin & $134523-00-5$ \\
\hline & Mevastatin & $73537-88-3$ \\
\hline & Pravastatin & $81131-70-6$ \\
\hline \multirow[t]{6}{*}{ Antidepressants and anticonvulsants } & Fluoxetine & $54910-89-3$ \\
\hline & Paroxetine & $61869-08-7$ \\
\hline & Diazepam & $439-14-5$ \\
\hline & Lorazepam & $846-49-1$ \\
\hline & Carbamazepine & $298-46-4$ \\
\hline & Primidone & $125-33-7$ \\
\hline \multirow[t]{5}{*}{ Antihistaminies } & Famotidine & $76824-35-6$ \\
\hline & Ranitidine & $66357-35-5$ \\
\hline & Cimetidine & $51481-61-9$ \\
\hline & Loratadine & $79794-75-5$ \\
\hline & Diphehydramine & $88637-37-0$ \\
\hline \multirow[t]{3}{*}{ Barbiturates - Anticonvulsants } & Butalbital & $77-26-9$ \\
\hline & Phenobarbital & $50-06-6$ \\
\hline & Pentobarbital & $76-74-4$ \\
\hline \multirow[t]{7}{*}{ Beta-blockers -cardiac arrhythmias } & Atenolol & $29122-68-7$ \\
\hline & Sotalol & $3930-20-9$ \\
\hline & Metoprolol & $37350-58-6$ \\
\hline & Propranolol & $525-66-6$ \\
\hline & Timolol & $26839-75-8$ \\
\hline & Betaxolol & $63659-18-7$ \\
\hline & Carazolol & $57775-29-8$ \\
\hline
\end{tabular}




\begin{tabular}{|c|c|c|}
\hline GROUP & Name & CAS Number \\
\hline & Pindolol & $13523-86-9$ \\
\hline & Nadolol & $42200-33-9$ \\
\hline \multirow[t]{2}{*}{ Bronchodilators - Beta agonists } & Salbutamol & $18559-94-9$ \\
\hline & Clenbuterol & $37148-27-9$ \\
\hline \multirow[t]{3}{*}{ Antihypertensives } & Enalapril & $75847-73-3$ \\
\hline & Hydrochlorothiazide & $58-93-5$ \\
\hline & Lisinopril & $83915-83-7$ \\
\hline Diuretics & Furosemide & $54-31-9$ \\
\hline Cancer treatment & Tamoxifen & $10540-29-1$ \\
\hline \multirow[t]{2}{*}{ Antifungals } & Metronidazole & $443-48-1$ \\
\hline & Clotrimazole & $23593-75-1$ \\
\hline Antidiabetic & Glibenclamide & $10238-21-8$ \\
\hline \multirow[t]{7}{*}{ Wastewater Indicators } & Caffeine & $58-08-2$ \\
\hline & Triclosan & $3380-34-5$ \\
\hline & Triclocarban & $101-20-2$ \\
\hline & DEET & $134-62-3$ \\
\hline & Bisphenol -A & $80-05-7$ \\
\hline & 4-n-nonylphenol & $104-40-5$ \\
\hline & 4-t-octylphenol & $27193-28-8$ \\
\hline \multirow[t]{5}{*}{ Hormones } & Androsterone & $53-41-8$ \\
\hline & Estrone (E1) & $53-16-7$ \\
\hline & Equilin & $474-86-2$ \\
\hline & Testosterone & $58-22-0$ \\
\hline & Equilenin & $517-09-9$ \\
\hline
\end{tabular}




\begin{tabular}{llc}
\hline GROUP & Name & CAS Number \\
\hline & $17-\beta$-Estradiol (E2) & $50-28-2$ \\
& Ethynyl Estradiol (EE2) & $57-63-6$ \\
& Progesterone & $58-83-0$ \\
& Mestranol & $72-33-3$ \\
& Estriol (E3) & $50-27-1$ \\
& Coprostanol & $360-68-9$ \\
& Coprostanone & $601-53-6$ \\
\hline
\end{tabular}

\subsection{Result and discussion}

One or more compounds were found in $100 \%$ of the reclaimed water samples.

The reason for the high detection frequency is that the treatment processes in the North District WWTP only include primary and secondary treatments that are not designed to remove microconstituents. Even though extra filtration and chlorination are applied to effluent, PPCPs and hormones still cannot be removed completely. In this one year study period, 33 out of 72 target compounds were detected more than once. The detected concentrations of the target compounds are shown in figure 24 . About $15 \%$ of the concentrations were more than $1 \mu \mathrm{g} / \mathrm{L}$ and $80 \%$ of the high concentrations (>1 $\mu \mathrm{g} / \mathrm{L})$ were derived from gemfibrozil, atenolol, caffeine and bisphenol A. 


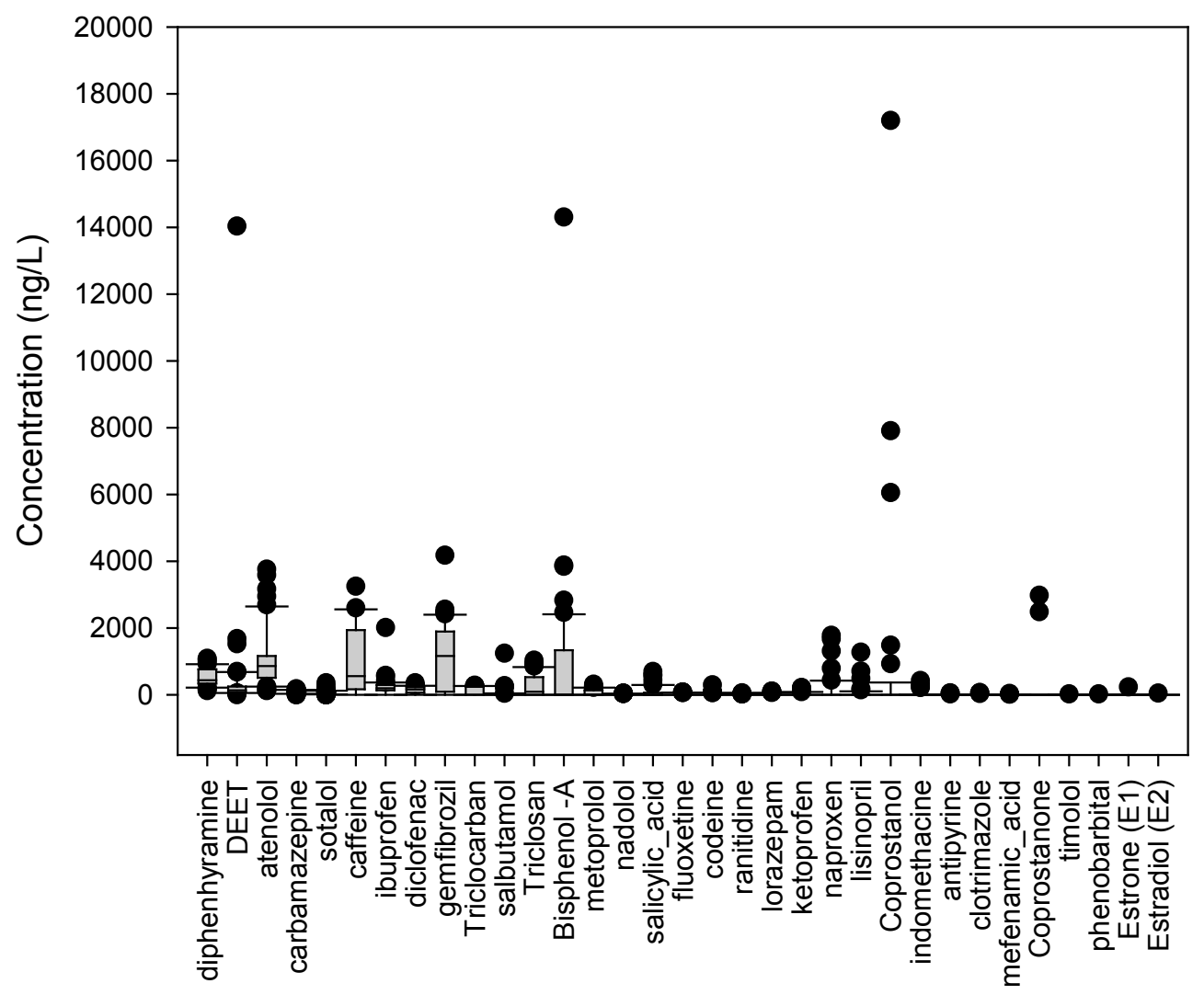

Figure 24. Detected concentration ranges for all compounds in reclaimed water samples.

Among the high concentration compounds, coprostanol, bisphenol A and DEET are the three compounds with detected maximum concentrations that exceeded $10 \mu \mathrm{g} / \mathrm{L}$ (figure 25). Bisphenol $\mathrm{A}$ is known as a weak environmental estrogen, more recent research has demonstrated that bisphenol A may be similar to estradiol in stimulating some cellular responses (Beverly S, 2011). DEET's chronic aquatic toxicity data is available for fish $(8.42 \mathrm{mg} / \mathrm{L})$, daphnia $(5.13 \mathrm{mg} / \mathrm{L})$ and algae (9.65 mg/L) (Aronson et al., 2012). The reported observed effect 
concentrations were hundreds of times higher than the detected concentrations. Only two hormones (estrone and estradiol) were detected in the reclaimed water samples. The detected concentrations of estrone (50.8 $\mathrm{ng} / \mathrm{L})$ and estradiol (58.5 ng/L) were relatively high compared to lowest observed effect concentration (usually few ng/L) (Larsen et al., 2008), but the detection frequency is only $2 \%$. Actually, acute toxicity to aquatic organisms is unlikely to occur because acute effect concentrations are 100-1000 higher than the detected concentrations in the environmental samples.

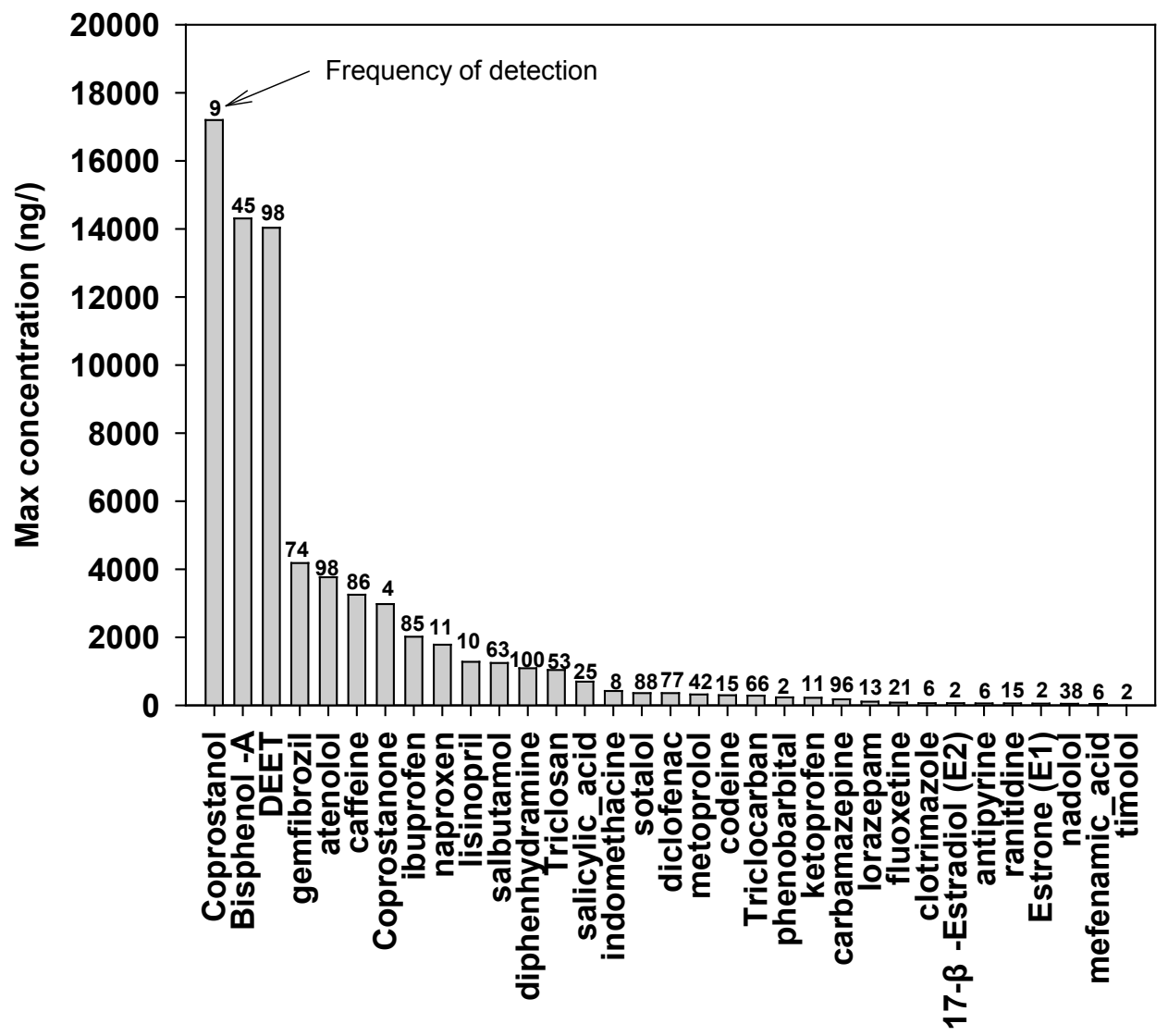

Figure 25. Maximum concentration and detection frequency of compounds in reclaimed water samples 
In addition, the detection frequency is a critical factor since long-term exposure to PPCPs especially compounds with endocrine disruption effects may cause problems even though their concentrations are low. The four most frequently detected compounds were diphenhydramine (100\%), DEET $(98 \%)$, atenolol $(98 \%)$ and carbamazepine (96\%). Diphenhydramine has been reported in water, sediment and fish but the effects of diphenhydramine on aquatic organisms is still lacking. In the reclaimed water samples, diphenhydramine was detected in all the samples all year long with a maximum concentration of $1091 \mathrm{ng} / \mathrm{L}$. A previous study indicated that no-observed-effect concentration of diphenhydramine on reproduction of D.magna is $0.8 \mu \mathrm{g} / \mathrm{L}$, while $17 \%$ of concentrations detected in reclaimed water exceeded $0.8 \mu \mathrm{g} / \mathrm{L}$ and there is no indication of what the effect level could be. Atenolol was detected at a maximum concentration of $3761 \mathrm{ng} / \mathrm{L}$ in $98 \%$ of reclaimed water samples. In reproduction test with Daphnia magna, the most sensitive no-observed-effect concentration of atenolol was $1.8 \mathrm{mg} / \mathrm{L}$ (Küster et al., 2009). Winter and his coworker used fathead minnows as test species and undertook embryo-larval development (early life stage or ELS) and short-term adult reproduction studies. The results of the ELS study showed that NOEC growth and LOEC ${ }^{\text {growth }}$ of atenolol were 3.2 and $10 \mathrm{mg} / \mathrm{L}$, respectively. In the short-term reproduction study, NOEC $C^{\text {reproduction }}$ and LOEC $C^{\text {reproduction }}$ of atenolol were 10 and $>10 \mathrm{mg} / \mathrm{L}$, respectively (Winter et al., 2008). Compared to the toxicity test results, the detected concentrations of atenolol in reclaimed water samples are much lower than the concentration that will cause chronic effect to fish. Carbamazepine is an anticonvulsant pharmaceutical that is commonly found in 
effluent of WWTPs, surface water and drinking water (Heberer et al., 2002; Deblonde et al., 2011). In this study, carbamazepine was detected in $96 \%$ of reclaimed water samples with a maximum concentration of $173 \mathrm{ng} / \mathrm{L}$. To test the chronic effect of carbamazepine, rainbow trout were exposed to three concentrations of carbamazepine $(1.0 \mu \mathrm{g} / \mathrm{L}, 0.2 \mathrm{mg} / \mathrm{L}$ and $2.0 \mathrm{mg} / \mathrm{L})$ for 42 days. Result indicated that at $2.0 \mathrm{mg} / \mathrm{L}$, both physiological condition status and musclebased biomarkers were significantly affected (Li et al., 2009; Li et al., 2010). By comparing with toxicity study, the detected concentrations of compounds in the reclaimed water were generally lower than the lowest-observed-effect concentrations of chronic effects, thus the risk associated with the their occurrence was probably minimal.

Although for a single compound, the detected concentrations was lower than the lowest-observed-effect concentration, most of the time more than one analytes was found in the environmental samples. The resulting additive effects of PPCP mixture may cause observed effects to organisms eventually. In the one year study, more than one target compounds were found in all reclaimed water samples and $13 \%$ of reclaimed water samples had a total concentration of $>10$ $\mu \mathrm{g} / \mathrm{L}$. However, the effect and interactions of PPCP mixture in the environmental samples is still unclear, and further investigations are required.

To obtain a broader view of the results, target compounds were divided into 15 groups on the basis of their general application or origins. The percent of 
detection frequencies of each group are shown in figure 26 . The number of compounds in the group does not reflect the detection frequency. Most of the time, detection frequency was influenced by the usage of compounds and removal rate of the WWTPs. Wastewater indicators, $\beta$-blockers and analgesics/anti-inflammatories were the three most detected groups, which covered $67 \%$ of detection frequency. The three groups also covered $69 \%$ of the total concentration (figure 27). Another group that should be of concern is the lipid regulator group. Even though the percent of detection frequency is relatively low $(6 \%)$, compounds in the lipid regulator group covered $20 \%$ of the total concentration. 


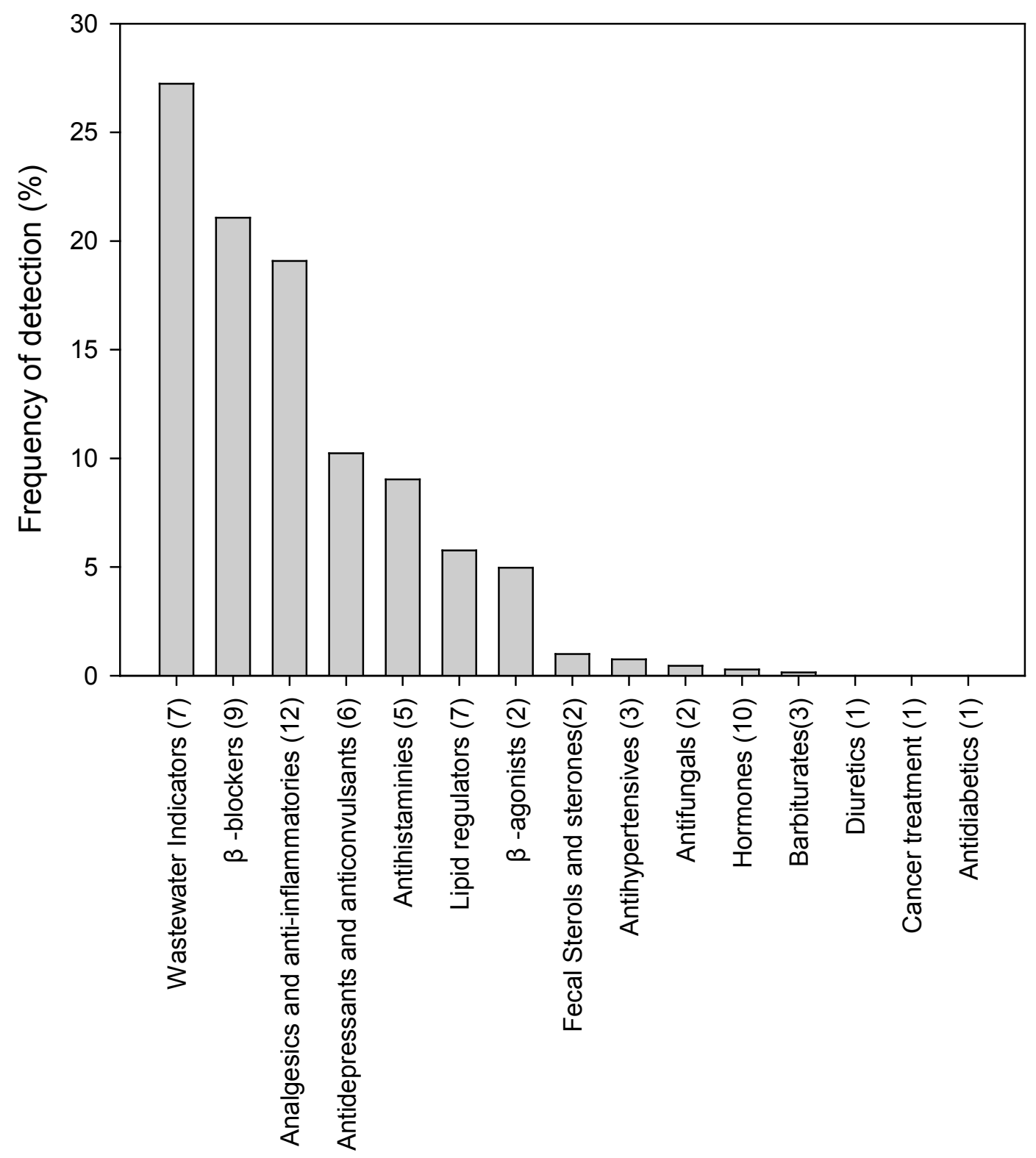

Figure 26. Detection frequency as a percent of different classes in reclaimed water samples 


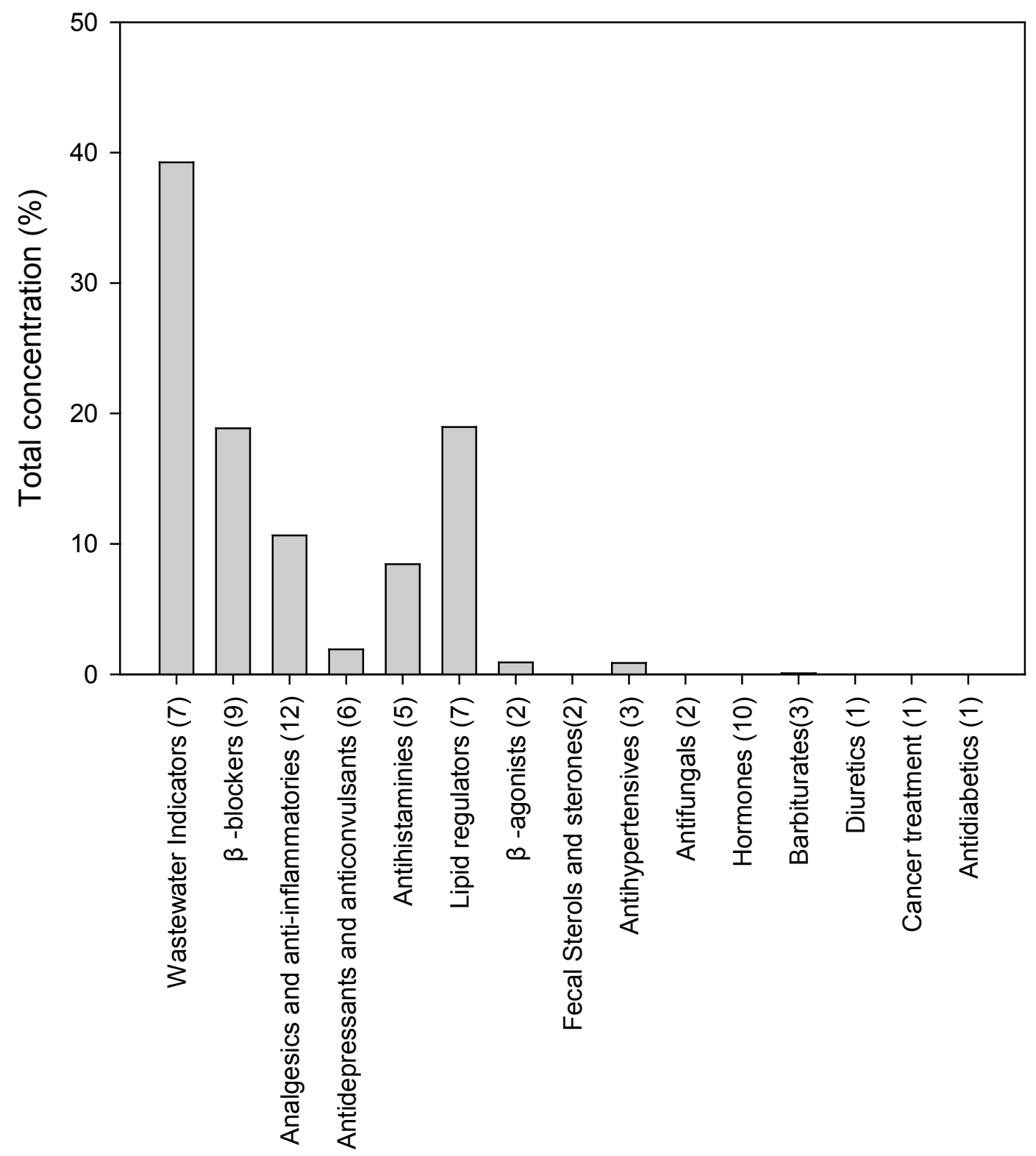

Figure 27. Percent of total measured concentration for each group of compounds in reclaimed water samples 


\subsection{Conclusion}

Methods developed in chapter 4 and 5 were successful applied on simultaneously detection of 71 compounds in reclaimed water samples. The online SPE method was robust, sensitive and reliable, making it suitable for routine analysis of environmental water samples. Reclaimed water samples were collected from the sprinkler system for a year-long period in Florida International University Biscayne Bay Campus, where reclaimed water was reused for irrigation. Analysis results showed that more than one analytes were detected in all reclaimed water samples. About $15 \%$ of the detected concentrations were more than $1 \mu \mathrm{g} / \mathrm{L}$. Among the detected compounds with high concentrations (>1 $\mu \mathrm{g} / \mathrm{L})$, coprostanol, bisphenol A and DEET's maximum concentration exceeded $10 \mu \mathrm{g} / \mathrm{L}$. The four most frequently detected compounds were diphenhydramine (100\%), DEET (98\%), atenolol (98\%) and carbamazepine (96\%). Wastewater indicators, $\beta$-blockers and analgesics /anti-inflammatories were the three most detected groups and these three groups covered $67 \%$ of detection frequency and $69 \%$ of the total concentration. The one-year study confirmed that current primary treatment, secondary treatment, extra filtration and chlorination in North District WWTP could not remove PPCPs completely from effluent. The microconstituents were continuously released to the environment through water reuse. More seriously, the releasing of microconstituents will continue for a long period of time until effective treatment processes are incorporated into the WWTPs. Although the detected maximum concentration of a single compound may not cause acute effect to organisms and the frequently detected compound 
may not cause chronic effect at the detected concentrations, it is still uncertain that treated water reuse is safe for the environment. The reason is that for all reclaimed water samples, more than one compounds was detected and very little is known about the combination effect of PPCPs mixture to environmental organisms. Therefore, instead of doing experiments about the acute and chronic effect of a single compound, more research should focus on the investigation of the combination effects of PPCP mixture at environmental relevant concentrations. The one-year study of reclaimed water provided lots of critical information about compounds that persist in the effluent of WWTPs and their environmental concentrations, which are very valuable for toxicity research in the future. 


\section{CHAPTER 7}

\section{Occurrence of PPCPs in drinking water}

\subsection{Introduction}

Pharmaceuticals and personal care products have been widely reported in wastewater and surface waters worldwide. The occurrence of PPCPs in the environment is a partially result of wastewater discharges. Other sources of PPCPs in the environmental waters include: runoff from agriculture fields, application of veterinary drugs, landfill leachates, etc. Issues concerning the quality of drinking water are important because the sources of drinking water (surface waters, ground water, etc.) might be impacted by the intrusion of wastewaters (Focazio et al., 2008; Fram and Belitz, 2011). The removal efficiency of PPCPs in the drinking water treatment plant varies both among chemicals and between different processes employed in the treatment plants. Advanced technologies such as ozonation (Broséus et al., 2009; Pisarenko et al., 2012) and granular activated carbon (GAC) (Stackelberg et al., 2007b) can remove many compounds, but they cannot eliminate all the contaminations. In addition, advanced technologies are not universally applied to the treatment of potable supplies, even in developed counties. Consequently, several studies have shown the positive detection of PPCPs in the tap water that people are drinking (Mompelat et al., 2009). Although it is not clear yet whether drinking water containing PPCPs at the detected levels is a risk to humans, drinking water

will always be a major public concern because it is a direct route for PPCPs to 
enter the human body. Therefore, a better understanding of occurrence of PPCPs in the drinking water is critical for public health.

The following study summarized results from a comprehensive survey of 720 compounds in 54 tap water samples collected from homes located in the Miami-Dade County area. The results provided a preliminary but informative assessment of the actual concentrations of PPCPs to which people are exposed from drinking water.

\subsection{Experimental}

Chemicals, sample preparation, online SPE procedure and detection method were described in parts 4.2 and 5.2. Briefly, drinking water samples were loaded to the Hypersil Gold aQ preconcentration column and then analytes were back flushed to the Hypersil Gold analytical column. Analytes were then separated and analyzed by tandem mass spectrometry. Personal care products, steroid hormones, sterols and sterones were analyzed with an APPI source, while pharmaceuticals were analyzed with the HESI source. Drinking water samples were collected from the Miami-Dade area between August and October 2011. Information of sampling location is shown in table 19 and figure 28. Water samples were collected by volunteers at their place of residence. Samplers were instructed to open the water valve, let it run for about five minute and to collect the water in a new PET container. Participants were asked to provide an approximate location of their home but not a physical address (street crossings 
only). All samples were immediately frozen or kept refrigerated while transported to the lab.

Table 19. Sample name, sampling date and location

\begin{tabular}{|c|c|c|c|}
\hline Sample name & Sampling date & Latitude & Longitude \\
\hline DW001 & $8 / 22 / 2011$ & $25^{\circ} 46^{\prime} 20.91 " \mathrm{~N}$ & $80^{\circ} 22^{\prime} 6.15 " \mathrm{~W}$ \\
\hline DW002 & $8 / 22 / 2011$ & $26^{\circ} 1 ' 15.59 " \mathrm{~N}$ & $80^{\circ} 8{ }^{\prime} 30.79 " \mathrm{~W}$ \\
\hline DW003 & $8 / 22 / 2011$ & $25^{\circ} 54^{\prime} 20.54 " \mathrm{~N}$ & $80^{\circ} 9^{\prime} 31.89^{\prime \prime W}$ \\
\hline DW004 & $8 / 23 / 2011$ & $25^{\circ} 57^{\prime} 3.51^{\prime \prime N}$ & $80^{\circ} 9^{\prime} 58.40^{\prime \prime W}$ \\
\hline DW005 & $8 / 23 / 2011$ & $26^{\circ} 0^{\prime} 45.46 " \mathrm{~N}$ & $80^{\circ} 9^{\prime} 0.06 " \mathrm{~W}$ \\
\hline DW006 & $8 / 23 / 2011$ & $25^{\circ} 45^{\prime} 34.04 " \mathrm{~N}$ & $80^{\circ} 21^{\prime} 54.13^{\prime \prime W}$ \\
\hline DW007 & $8 / 23 / 2011$ & $25^{\circ} 52^{\prime} 33.72 " \mathrm{~N}$ & $80^{\circ} 7^{\prime} 32.80^{\prime \prime W}$ \\
\hline DW008 & $8 / 24 / 2011$ & $25^{\circ} 33^{\prime} 36.96 " \mathrm{~N}$ & $80^{\circ} 21^{\prime} 4.39^{\prime \prime W}$ \\
\hline DW009 & 8/28/2011 & $25^{\circ} 55^{\prime} 53.30^{\prime \prime N}$ & $80^{\circ} 7{ }^{\prime} 30.34 " \mathrm{~W}$ \\
\hline DW010 & 9/6/2011 & $25^{\circ} 53^{\prime} 59.72 " \mathrm{~N}$ & $80^{\circ} 9^{\prime} 0.36 " \mathrm{~W}$ \\
\hline DW011 & 9/13/2011 & $25^{\circ} 56^{\prime} 35.70^{\prime \prime N}$ & $80^{\circ} 8 ' 21.82 " \mathrm{~W}$ \\
\hline DW012 & 9/13/2011 & $25^{\circ} 54^{\prime} 16.94 " \mathrm{~N}$ & $80^{\circ} 11^{\prime} 31.66 " \mathrm{~W}$ \\
\hline DW013 & 9/13/2011 & $25^{\circ} 51^{\prime \prime 49.99 " N ~}$ & $80^{\circ} 7^{\prime} 28.05^{\prime \prime W}$ \\
\hline DW014 & 9/13/2011 & $25^{\circ} 51^{\prime} 4.95^{\prime \prime} \mathrm{N}$ & $80^{\circ} 17^{\prime} 54.93 " \mathrm{~W}$ \\
\hline DW015 & $9 / 13 / 2011$ & $25^{\circ} 46^{\prime} 17.43^{\prime \prime N}$ & $80^{\circ} 22^{\prime} 19.79 " \mathrm{~W}$ \\
\hline DW016 & $9 / 13 / 2011$ & $25^{\circ} 45^{\prime} 6.11 " \mathrm{~N}$ & $80^{\circ} 12^{\prime} 5.22^{\prime \prime W}$ \\
\hline DW017 & $9 / 13 / 2011$ & $25^{\circ} 54^{\prime} 31.34 " \mathrm{~N}$ & $80^{\circ} 18^{\prime} 31.18^{\prime \prime W}$ \\
\hline DW018 & $9 / 13 / 2011$ & $25^{\circ} 45^{\prime} 46.76 " \mathrm{~N}$ & $80^{\circ} 22^{\prime} 53.87^{\prime \prime W}$ \\
\hline DW019 & $9 / 13 / 2011$ & $25^{\circ} 45^{\prime} 31.28^{\prime \prime N}$ & $80^{\circ} 21^{\prime} 56.43^{\prime \prime W}$ \\
\hline DW020 & $9 / 13 / 2011$ & $25^{\circ} 40^{\prime} 11.52 " \mathrm{~N}$ & $80^{\circ} 26^{\prime} 32.74 " \mathrm{~W}$ \\
\hline DW021 & $9 / 13 / 2011$ & $25^{\circ} 45^{\prime} 39.59 " \mathrm{~N}$ & $80^{\circ} 22^{\prime} 34.44 " \mathrm{~W}$ \\
\hline DW022 & $9 / 13 / 2011$ & $25^{\circ} 46^{\prime} 1.62 " \mathrm{~N}$ & $80^{\circ} 22^{\prime} 26.60 " \mathrm{~W}$ \\
\hline DW023 & 9/13/2011 & $25^{\circ} 59^{\prime} 33.45^{\prime \prime N}$ & $80^{\circ} 15^{\prime} 7.17 " \mathrm{~W}$ \\
\hline DW024 & $9 / 13 / 2011$ & $25^{\circ} 45^{\prime} 56.37^{\prime \prime N}$ & $80^{\circ} 23^{\prime} 46.87^{\prime \prime W}$ \\
\hline DW025 & $9 / 13 / 2011$ & $25^{\circ} 45^{\prime} 44.44^{\prime \prime N}$ & $80^{\circ} 12^{\prime} 9.24^{\prime \prime W}$ \\
\hline DW026 & $9 / 13 / 2011$ & $25^{\circ} 46^{\prime} 58.22 " \mathrm{~N}$ & $80^{\circ} 8 ' 23.03 " \mathrm{~W}$ \\
\hline DW027 & $9 / 13 / 2011$ & $25^{\circ} 53^{\prime} 50.73^{\prime \prime N}$ & $80^{\circ} 18^{\prime} 47.40 " \mathrm{~W}$ \\
\hline DW028 & $9 / 13 / 2011$ & $25^{\circ} 46^{\prime} 36.45^{\prime \prime N}$ & $80^{\circ} 22^{\prime} 27.53 " \mathrm{~W}$ \\
\hline DW029 & $9 / 13 / 2011$ & $25^{\circ} 41^{\prime} 37.49 " \mathrm{~N}$ & $80^{\circ} 21^{\prime} 54.24 " \mathrm{~W}$ \\
\hline DW030 & $9 / 13 / 2011$ & $25^{\circ} 45^{\prime} 44.70^{\prime \prime N}$ & $80^{\circ} 15^{\prime} 49.34 " \mathrm{~W}$ \\
\hline DW031 & $9 / 13 / 2011$ & $25^{\circ} 46^{\prime} 14.82 " \mathrm{~N}$ & $80^{\circ} 11^{\prime} 51.36 " \mathrm{~W}$ \\
\hline DW032 & $9 / 20 / 2011$ & $25^{\circ} 45^{\prime} 16.06^{\prime \prime N}$ & $80^{\circ} 13^{\prime} 13.16^{\prime \prime W}$ \\
\hline DW033 & $9 / 29 / 2011$ & $25^{\circ} 54^{\prime} 14.88^{\prime \prime N}$ & $80^{\circ} 17^{\prime} 57.88^{\prime \prime W}$ \\
\hline
\end{tabular}




\begin{tabular}{|c|c|c|c|}
\hline Sample name & Sampling date & Latitude & Longitude \\
\hline DW034 & $10 / 1 / 2011$ & $25^{\circ} 53^{\prime} 53.45 " \mathrm{~N}$ & $80^{\circ} 13^{\prime} 53.75^{\prime \prime W}$ \\
\hline DW035 & 10/1/2011 & $25^{\circ} 47^{\prime} 0.12^{\prime \prime} \mathrm{N}$ & $80^{\circ} 20^{\prime} 11.02 " \mathrm{~W}$ \\
\hline DW036 & 10/1/2011 & $25^{\circ} 48^{\prime} 43.74 " \mathrm{~N}$ & $80^{\circ} 22^{\prime} 12.05^{\prime \prime W}$ \\
\hline DW037 & 10/1/2011 & $25^{\circ} 50^{\prime} 21.18^{\prime \prime N}$ & $80^{\circ} 22^{\prime} 14.67 " \mathrm{~W}$ \\
\hline DW038 & 10/1/2011 & $25^{\circ} 50^{\prime} 24.33^{\prime \prime N}$ & $80^{\circ} 19^{\prime} 7.10^{\prime \prime W}$ \\
\hline DW039 & 10/1/2011 & $25^{\circ} 53^{\prime} 57.52 " \mathrm{~N}$ & $80^{\circ} 11^{\prime} 39.34 " \mathrm{~W}$ \\
\hline DW040 & 10/2/2011 & $26^{\circ} 7^{\prime} 16.37^{\prime \prime} \mathrm{N}$ & $80^{\circ} 10^{\prime} 47.11 " \mathrm{~W}$ \\
\hline DW041 & $10 / 2 / 2011$ & $25^{\circ} 29^{\prime} 39.38^{\prime \prime N} \mathrm{~N}$ & $80^{\circ} 24^{\prime} 58.93 " \mathrm{~W}$ \\
\hline DW042 & $10 / 2 / 2011$ & $25^{\circ} 28^{\prime} 39.66 " \mathrm{~N}$ & $80^{\circ} 27^{\prime} 56.37^{\prime \prime W}$ \\
\hline DW043 & $10 / 2 / 2011$ & $25^{\circ} 40^{\prime} 10.68^{\prime \prime N} \mathrm{~N}$ & $80^{\circ} 25^{\prime} 57.50^{\prime \prime W}$ \\
\hline DW044 & $10 / 2 / 2011$ & $25^{\circ} 37^{\prime} 36.85^{\prime \prime N}$ & $80^{\circ} 24^{\prime} 53.63^{\prime \prime W}$ \\
\hline DW045 & 10/2/2011 & $25^{\circ} 28^{\prime} 44.81^{\prime \prime N}$ & $80^{\circ} 25^{\prime} 50.04 " \mathrm{~W}$ \\
\hline DW046 & 10/2/2011 & $25^{\circ} 33^{\prime} 56.77^{\prime \prime} \mathrm{N}$ & $80^{\circ} 22^{\prime} 56.38^{\prime \prime W}$ \\
\hline DW047 & 10/2/2011 & $25^{\circ} 36^{\prime} 50.11 " \mathrm{~N}$ & $80^{\circ} 18^{\prime} 58.73 " \mathrm{~W}$ \\
\hline DW048 & 10/2/2011 & $25^{\circ} 43^{\prime} 2.62^{\prime \prime N}$ & $80^{\circ} 16^{\prime} 41.26 " \mathrm{~W}$ \\
\hline DW049 & $10 / 2 / 2011$ & $25^{\circ} 38^{\prime} 40.40^{\prime \prime} \mathrm{N}$ & $80^{\circ} 20^{\prime} 19.40^{\prime \prime W}$ \\
\hline DW050 & 10/2/2011 & $25^{\circ} 40^{\prime} 20.88^{\prime \prime} \mathrm{N}$ & $80^{\circ} 19^{\prime} 21.63 " \mathrm{~W}$ \\
\hline DW051 & $10 / 16 / 2011$ & $25^{\circ} 53^{\prime} 6.04 " \mathrm{~N}$ & $80^{\circ} 9^{\prime} 56.22 " \mathrm{~W}$ \\
\hline DW052 & 10/16/2011 & $25^{\circ} 50^{\prime} 49.93^{\prime \prime} \mathrm{N}$ & $80^{\circ} 11^{\prime} 4.68^{\prime \prime W}$ \\
\hline DW053 & $10 / 16 / 2011$ & $25^{\circ} 47^{\prime} 47.93^{\prime \prime} \mathrm{N}$ & $80^{\circ} 11^{\prime} 23.91 " \mathrm{~W}$ \\
\hline DW054 & $10 / 12 / 2011$ & $25^{\circ} 58^{\prime} 18.44 " \mathrm{~N}$ & $80^{\circ} 9^{\prime} 12.11 " \mathrm{~W}$ \\
\hline
\end{tabular}




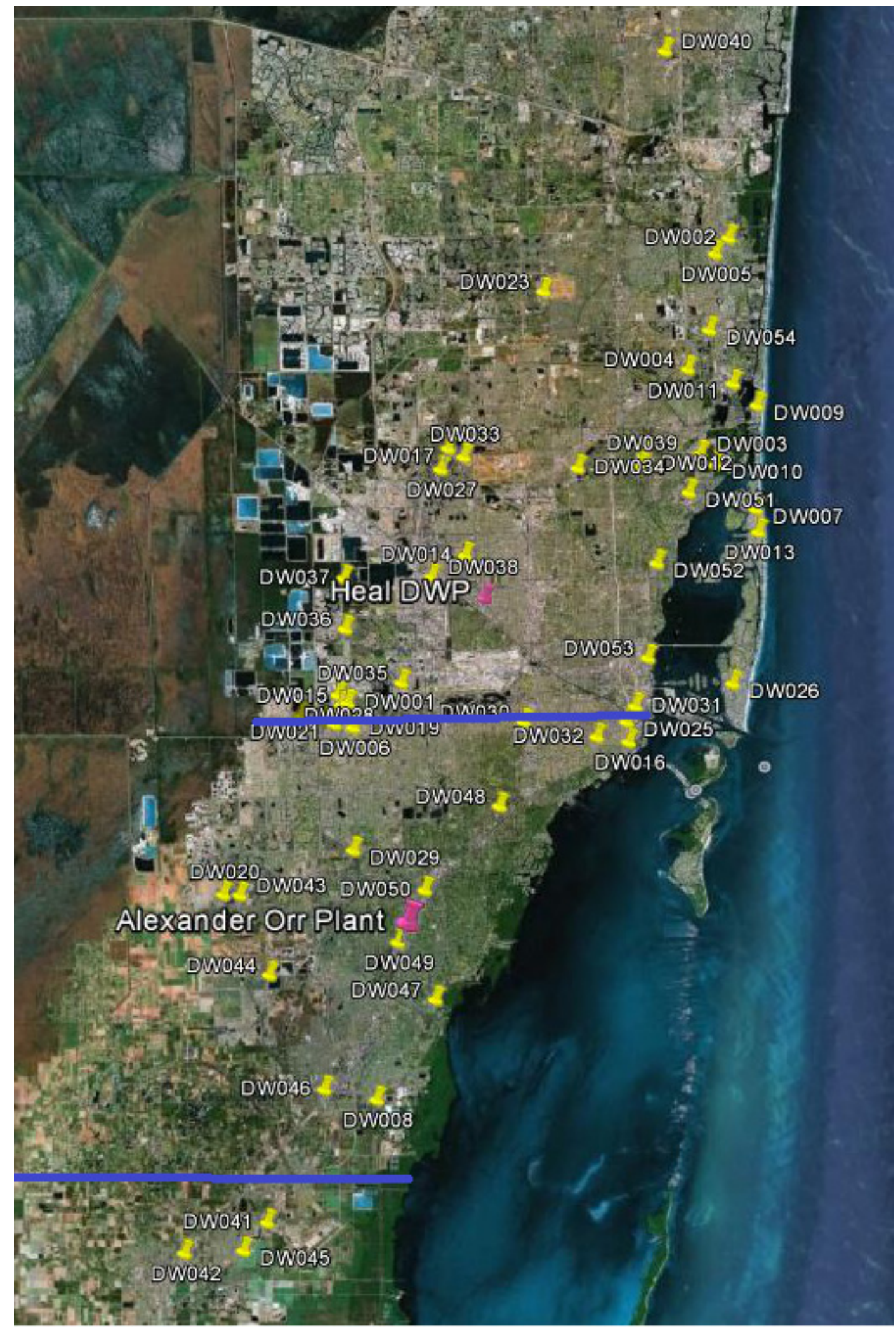

Figure 28. Map showing the collection sites of drinking water samples 


\subsection{Result and discussion}

The water source for the Miami-Dade County Water and Sewer Department (WASD) is the Biscayne Aquifer, which is located just below the surface in South Florida. Approximately 330 million gallons per day (mgd) of water are withdrawn from the aquifer to meet the needs of the community. There are three water treatment facilities in the Miami-Dade County area: the Hialeah and Preston Plant, Alexander Orr Plant and the South Dade Water Supply System. The Hialeah and Preston plant provides drinking water for residents who live north of Flagler Street Up to the Miami-Dade/ Broward line. The Alexander Orr Plant serves people who live from Flagler Street to S.W. 248 Street. The South Dade Water Supply System serves residents south of S.W. 248 Street. The blue line in figure 28 delimits the areas served by different water supply systems. The most common water treatment processes are filtration, flocculation and sedimentation, and disinfection (URL3).

A total of 15 analytes were detected in the drinking water samples and the concentrations are shown in figure 29. At least one analyte was found in $96 \%$ of the drinking water samples. Compared to the concentrations of analytes detected in the reclaimed water or the surface waters, the concentrations detected in the drinking water were much lower. Only the concentrations of salicylic acid, ibuprofen and DEET were found to be more than $200 \mathrm{ng} / \mathrm{L}$. The maximum concentrations of salicylic acid, ibuprofen and DEET were $521 \mathrm{ng} / \mathrm{L}, 301 \mathrm{ng} / \mathrm{L}$ and $290 \mathrm{ng} / \mathrm{L}$, respectively (table 20). The occurrence of PPCPs in the drinking 
water has been reported in other places in the world. A previous study showed that the maximum concentrations of ibuprofen detected in tap water were $3 \mathrm{ng} / \mathrm{L}$, 0.6, 8.5 and $1350 \mathrm{ng} / \mathrm{L}$ in Germany, France, Finland and the USA, respectively (Mompelat et al., 2009). The maximum concentration of DEET found in drinking water samples in the USA is $63 \mathrm{ng} / \mathrm{L}$ (Benotti et al., 2009) and this number is significantly lower than maximum value reported in this study (521 $\mathrm{ng} / \mathrm{L})$. However, DEET is a common environmental contaminant and is very difficult to avoid cross-contaminating samples if the compound is present in the sampling area (kitchens, bathrooms, etc).

Table 20. Maximum concentration of analytes detected in Miami-Dade area and other parts of the world (ng/L)

\begin{tabular}{|c|c|c|c|c|c|c|c|c|}
\hline & $\begin{array}{l}\text { Miami } \\
\text { Dade }\end{array}$ & Finland & France & Germany & USA & Canada & UK & Italy \\
\hline ketoprofen & 179 & $8.0^{\mathrm{a}}$ & $3.0^{5}$ & & & & & \\
\hline ibuprofen & 301 & $8.5^{\mathrm{a}}$ & $0.6^{\mathrm{b}}$ & $3^{d}$ & $1350^{g}$ & & & \\
\hline diclofenac & ND & & $2.5^{\mathrm{b}}$ & $35^{\mathrm{e}}$ & & & & \\
\hline acetaminophen & ND & & $210^{\mathrm{b}}$ & & & & & \\
\hline salicylic_acid & 521 & & $19^{c}$ & & & & & \\
\hline propyphenazone & 9.72 & & & $240^{\mathrm{e}}$ & & & & \\
\hline codeine & ND & & & & $30^{\mathrm{h}}$ & & & \\
\hline clofibric_acid & 65.1 & & & $270^{\dagger}$ & & & & \\
\hline gemfibrozil & ND & & & & & $70^{k}$ & & \\
\hline bezafibrate & ND & & & $27^{d}$ & & & & \\
\hline fluoxetine & 58.4 & & & & & & & \\
\hline paroxetine & 65.9 & & & & & & & \\
\hline diazepam & ND & & & & & & $10^{\prime}$ & $23.5^{\mathrm{m}}$ \\
\hline carbamazepine & 27.8 & & $43.2^{b}$ & & $258^{\prime}$ & $24.0^{\mathrm{k}}$ & & \\
\hline primidone & ND & & & $40^{e}$ & & & & \\
\hline propranolol & 9.58 & & & & & & & \\
\hline betaxolol & 24.0 & & & & & & & \\
\hline carazolol & 11.2 & & & & & & & \\
\hline
\end{tabular}




\begin{tabular}{ccc}
\hline salbutamol & 13.1 & \\
metronidazole & 178 & \\
clotrimazole & 18.5 & $734^{\mathrm{g}}$ \\
Triclosan & $\mathrm{ND}$ & $63.0^{\mathrm{j}}$ \\
\hline DEET & 290 & \\
\hline
\end{tabular}

a (Vieno et al., 2005)

b (Togola and Budzinski, 2008)

c (Vulliet et al., 2011)

d (Stumpf et al., 1996)

e (Heberer et al., 2004)

$f$ (Heberer et al., 1997)

$g$ (Loraine and Pettigrove, 2006)

h (Stackelberg et al., 2007b)

i (Stackelberg et al., 2004)

j (Benotti et al., 2009)

k (Tauber, 2003)

I (Waggot, 1981)

m (Zuccato et al., 2000)

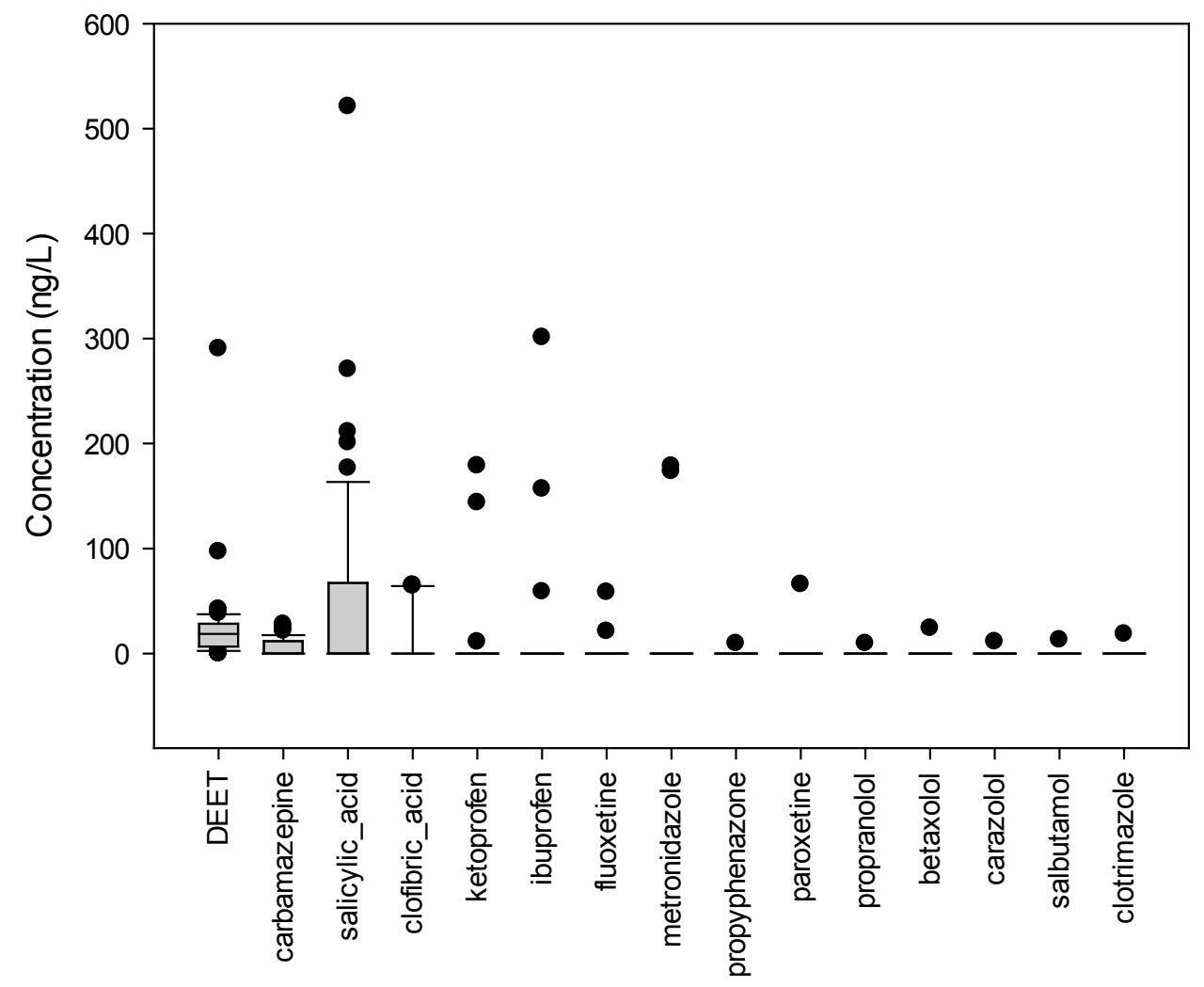

Figure 29. Concentrations of PPCPs in the drinking water samples collected from Miami-Dade County 
The three most frequently detected compounds were DEET (93\%), carbamazepine (43\%) and salicylic acid (37\%) (Figure 30). The high detection frequencies of the three compounds indicated that current drinking water treatment could not remove them completely from the finished water. In a previous study (Stackelberg et al., 2007a), DEET has been reported as one of the most persistent compounds during drinking water treatment. Even the application of ozone and GAC can only partially remove DEET from the finished water. Carbamazepine is another compound that is usually detected in drinking water samples. Research indicated that ozone is an efficient way to remove it but since the removal rate is not $100 \%$, carbamazepine is still persistent in the finished water. DEET and carbamazepine can be used as indictors representing potential contamination of PPCPs. Carbamazepine was detected in $40 \%$ of the tap water samples in the U.S in Benotti's study and 33\% of tap water samples in Montreal boroughs in Canada (Garcia-Ac et al., 2009), which is very close to the detection frequency of carbamazepine in our study (Benotti et al., 2009). DEET's detection frequency was lower in Benotti's study (27\%) than our study (Benotti et al., 2009). Salicylic acid is used as anti-inflammatory drug because of its ability to ease aches and pains and reduce fevers. Salicylic acid is also the key ingredient in many skin care products, such as soap, cleanser, body wash and cream etc., to treat acne, seborrhoeic dermatitis, psoriasis, corns, etc. Currently, very little research is available about the presence of salicylic acid in drinking water. In Vulliet's study, salicylic acid is reported as the most frequently detected compounds in the drinking water samples, however, the maximum concentration 
(19 ng/L) is much lower than the results in our study. Because salicylic acid was detected in the drinking water samples at relatively high concentrations and high detection frequencies, future research should focus more on salicylic acid.

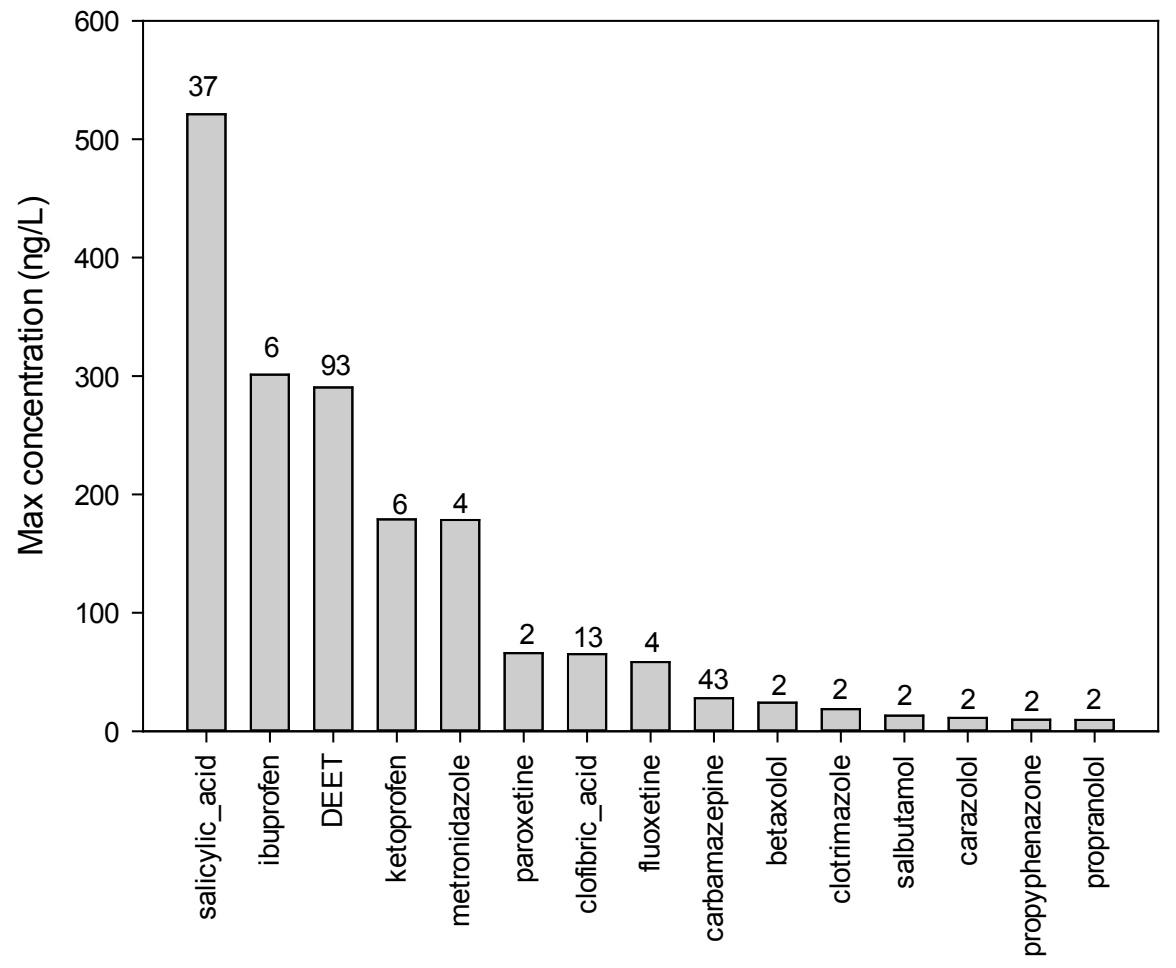

Figure 30. Maximum concentrations and detection frequencies of PPCPs in drinking water samples

To obtain a broader view of the results, target compounds were divided into 15 groups on the basis of their general application or origins. The three most frequently detected groups were wastewater indicators, analgesics and antiinflammatories and antidepressants and anticonvulsants drugs, while the group 
of analgesics and anti-inflammatories covered $56 \%$ of the total concentration (figure 31 and 32). The high detection frequency and high detection concentration resulted from the large amount of daily use and low removal efficiency of drinking water treatment (Benotti et al., 2009).

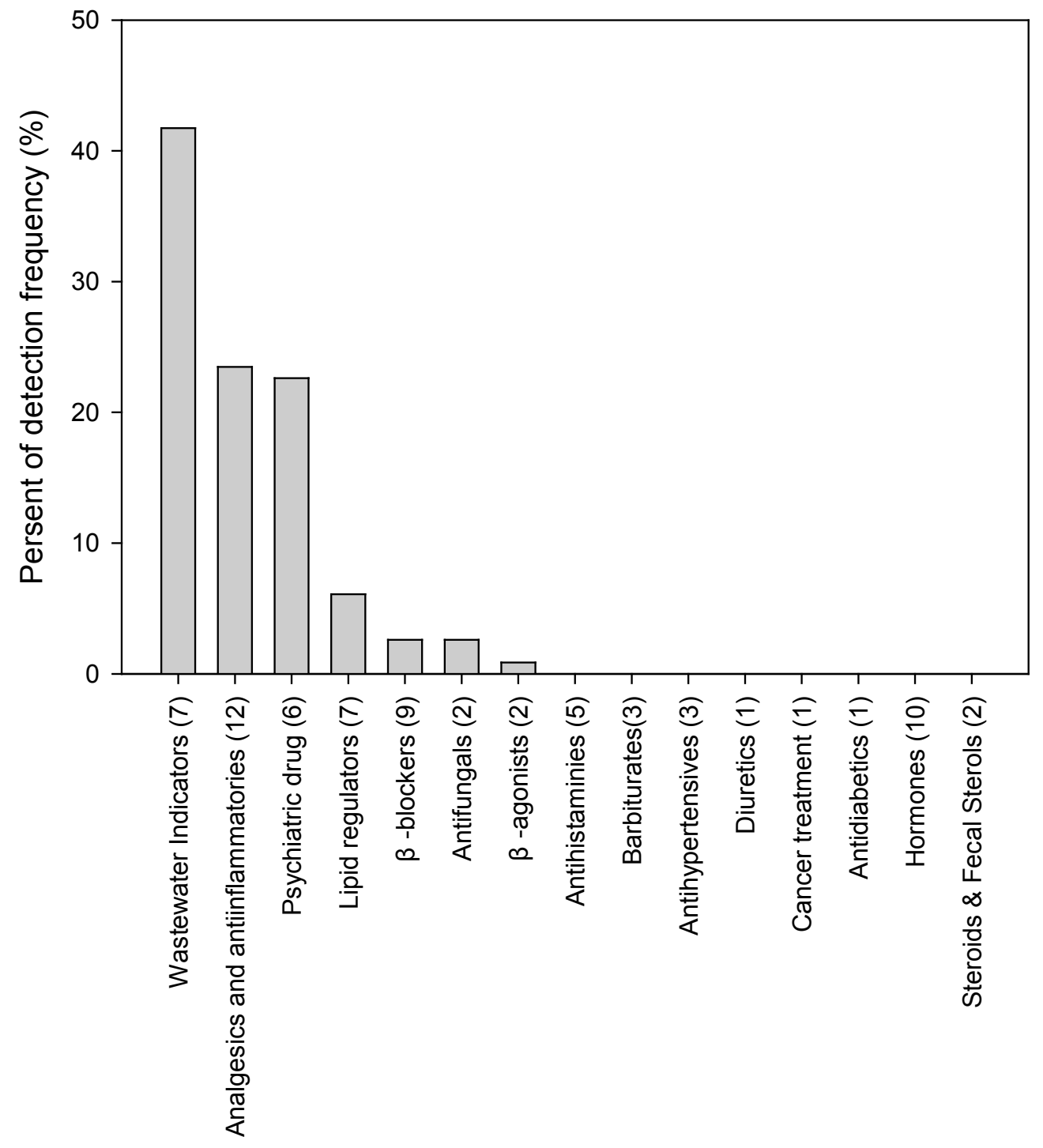

Figure 31. Detection frequency as percent of different classes in drinking water samples 


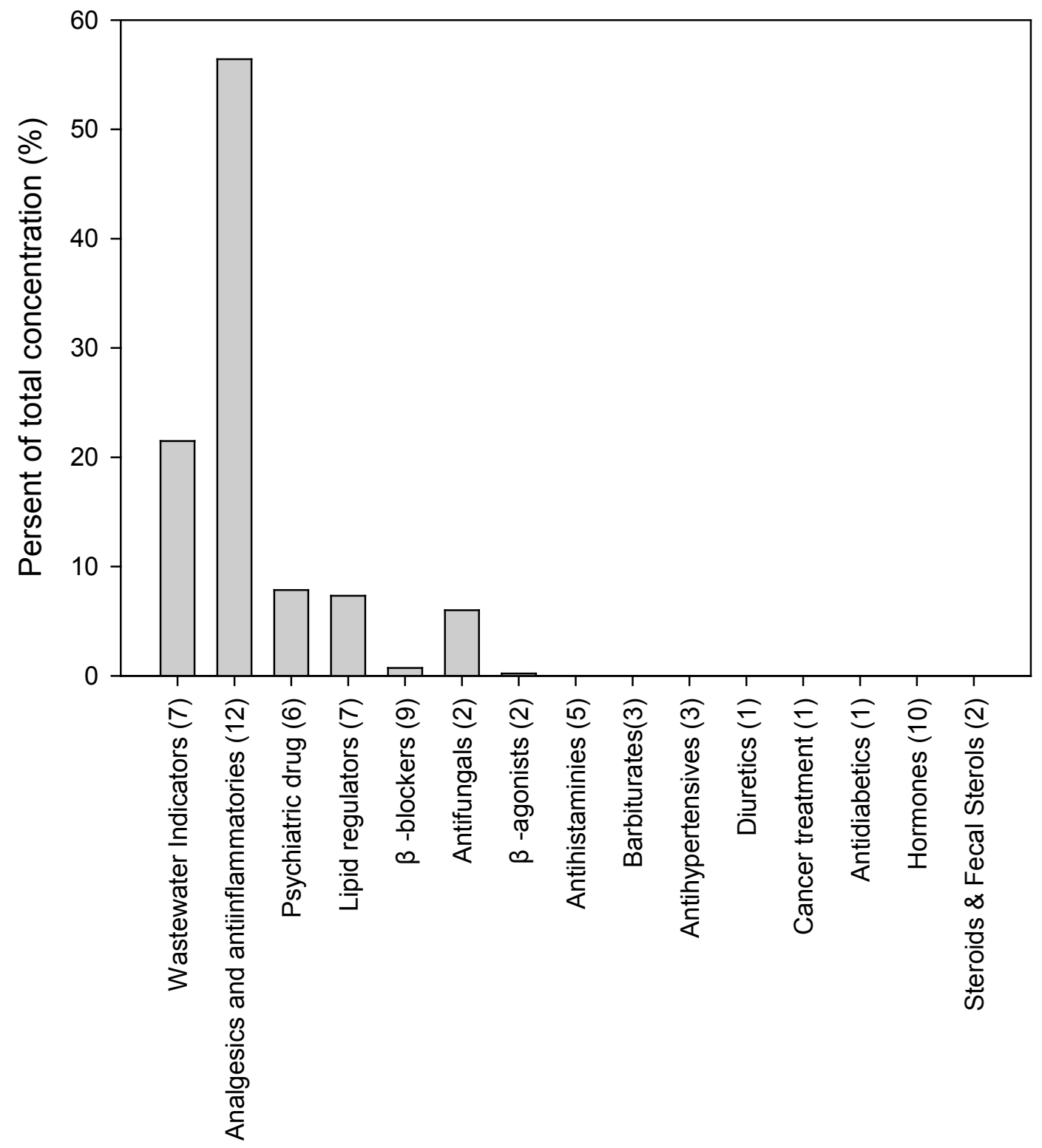

Figure 32. Percentage of total concentration of each class in drinking water samples 
In order to understand the spatial distribution of the detection, sampling sites were shown in figure 33 as dots and the total concentration was indicated by different colors. Grey color represents no analytes detected at the sampling site. Blue color represents the total concentration detected at the sampling sites was between ND and $10 \mathrm{ng} / \mathrm{L}$. Green color represents the total concentration detected at the sampling sites was between 10 and $50 \mathrm{ng} / \mathrm{L}$. Yellow color represents the total concentration detected at the sampling sites was between 50 and $100 \mathrm{ng} / \mathrm{L}$. Orange color represents the total concentration detected at the sampling sites was between 100 and $200 \mathrm{ng} / \mathrm{L}$. Red color represents the total concentration detected at the sampling sites was between 200 and $500 \mathrm{ng} / \mathrm{L}$. Purple color represents the total concentration detected at the sampling sites was more than $500 \mathrm{ng} / \mathrm{L}$. The total concentrations were randomly disturbed at the samples sites. There is no trend in the relationship of the location of sampling sites and total concentrations. Although the total concentrations of three points were more than $500 \mathrm{ng} / \mathrm{L}$, the high total concentrations were contributed by salicylic acid, which may enter drinking water sample after distribution. Results showed that the drinking water quality were similar in the whole Miami-Dade County area, which indicated that similar treatments were applied to source water in different drinking water facilities. 


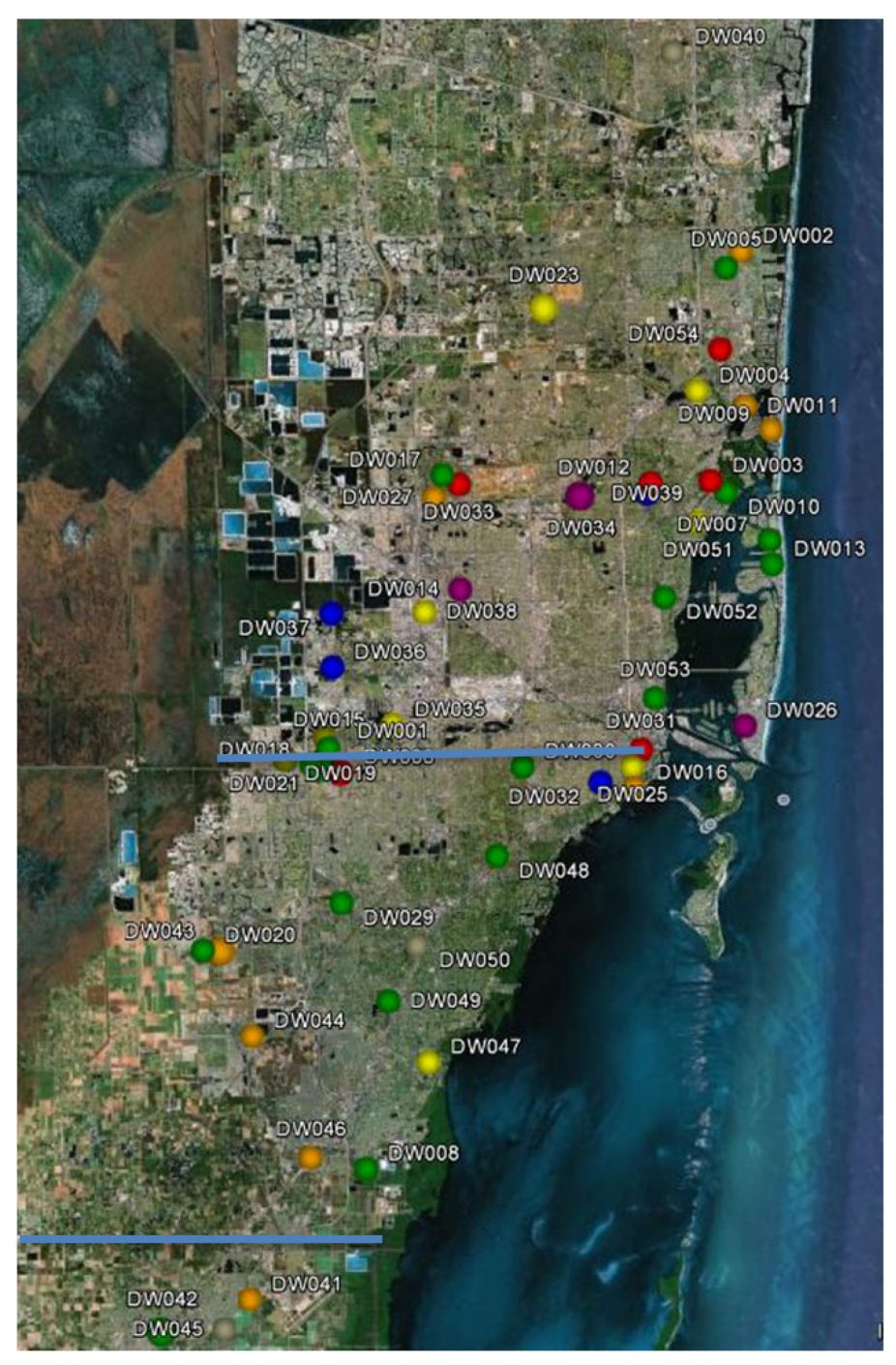

ND

- $0-10 \mathrm{ng} / \mathrm{L}$

- $10-50 \mathrm{ng} / \mathrm{L}$

50-100 ng/L

- $100-200 \mathrm{ng} / \mathrm{L}$

200-500 ng/L

- $>500 \mathrm{ng} / \mathrm{L}$

Figure 33. Distribution of total concentration of analytes in Miami-Dade County 
Results of drinking water sample can be compared to reclaimed water results. Overall, fewer numbers of analytes were detected in the drinking water samples, only 15 analytes compared to 33 analytes in reclaimed water samples. The detected concentrations of analyte in the drinking water were much lower than the detected concentrations in the reclaimed water samples. The three highest maximum concentrations in the drinking water samples were $521 \mathrm{ng} / \mathrm{L}, 301 \mathrm{ng} / \mathrm{L}$ and $290 \mathrm{ng} / \mathrm{L}$ for salicylic acid, ibuprofen and DEET, respectively. While the three highest concentrations in reclaimed water for coprostanol, bisphenol A and DEET were more than $10,000 \mathrm{ng} / \mathrm{L}$. In addition, many analytes were detected at relatively high average concentration in reclaimed water sample while average concentration were close to zero in the drinking water samples (cycled point in figure 34). Although, similar compounds were detected in the drinking water samples, the detection of frequency is lower compared to reclaimed water samples. DEET and carbamazepine were detected in $93 \%$ and $37 \%$ in drinking water samples respectively, while DEET and carbamazepine were detected in $98 \%$ and $98 \%$ of reclaimed water samples, respectively. DEET and carbamazepine could be used as the indicator of contamination of PPCPs because their persistence in both WWTPs and DWPs. However, more studies are needed to establish a potential relationship between reclaimed water and drinking water. 


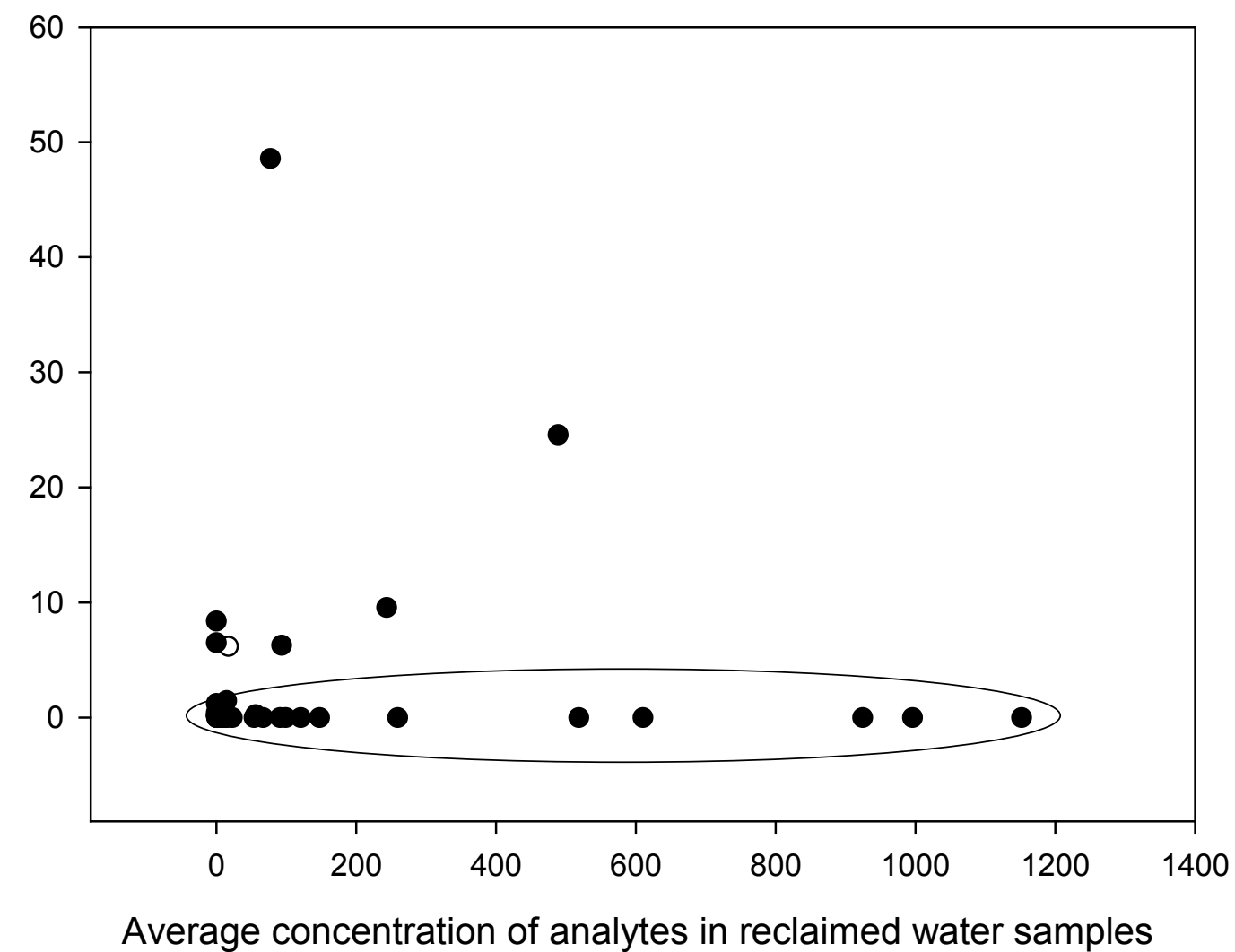

Figure 34. Comparison of average concentration of analytes in drinking water samples and reclaimed water samples

\subsection{Conclusion}

In the study of drinking water, 54 tap water samples collected from the MiamiDade area were analyzed. 15 compounds were detected and more than one compound was detected in $93 \%$ of samples. The maximum concentration of salicylic acid, ibuprofen and DEET were $521 \mathrm{ng} / \mathrm{L}, 301 \mathrm{ng} / \mathrm{L}$ and $290 \mathrm{ng} / \mathrm{L}$, respectively. The three most frequently detected compounds were DEET (93\%), carbamazepine $(43 \%)$ and salicylic acid $(37 \%)$. Results indicated that drinking 
water sources, such as ground water, may be impacted by discharge of wastewater, disposal of biosolids from WWTPs or landfilling. Current drinking water treatments cannot prevent certain PPCPs, such as DEET and carbamazepine, from entering the drinking water system. The quality of drinking water is a public concern since any compound present in the drinking water enters the human body directly. It is the largest threat to human health and longterm effects (80 years) might occur at a much lower concentration than the concentration of therapeutic effects. Adverse effects may be more obvious for children, elderly or pregnant women. However, no data are currently available regarding the risk because of the long period and difficulty of the research. The occurrence of PPCPs in the drinking water is a key issue for water quality. Although there are no regulations for PPCPs in drinking water so far, more research about the occurrence of PPCPs in the drinking water and more studies about the risk of long-term exposure of humans to PPCPs through drinking water are highly desirable. 


\section{CONCLUSIONS}

The overall objective of the study was to detect trace level PPCPs and hormones in the South Florida environment (both aqueous phase and solid phase) using sensitive and reliable detection methods in order to gain a basic understanding on the quality of major environmental compartments with respect to a group of important unregulated emergent contaminants. Four methods were successfully developed to detect analytes in different matrices, including reclaimed waters, surface waters, drinking waters, sediments and soils. By conducting a comprehensive evaluation of a large number of environmental samples, we confirmed that reclaimed water from a typical secondary treatment WWTP routinely introduced a number of PPCPs to the environment at concentrations that could range into the $\mu \mathrm{g} / \mathrm{L}$ during water reuse applications. In addition, the results clearly show that surface waters in South Florida are impacted by several PPCPs at trace level. Although contamination is not widespread, there are clear indications that wastewater intrusions exist in a number of coastal freshwater and saltwater environments. On a positive side, the presence of endocrine disrupting chemicals was less prevalent and usually at levels very close to the method detection limits so that their potential impacts to biological resources are limited both in temporal and geographical extent. Furthermore, some PPCPs were detected in drinking water samples from the Miami-Dade County distribution system. Concentrations were relatively low and some of the compounds may have alternative sources (i.e. salicylic acid) but the presence of low concentrations of carbamazepine with relatively high frequency of detection is a 
conclusive indicator of a connection between wastewater streams and the drinking water sources or the distribution system itself. Because the presence of these compounds in drinking water constitutes a direct route to human exposure, a more detailed survey both in area and time should be conducted.

In summary this study shows that excretion by humans, disposal of unused medicine and application of veterinary drugs does cause PPCPs to enter the sewage collection systems. Low efficiency of removal in the WWTPs leads to the releasing of PPCPs into the environment, in particular in reclaimed water only treated to secondary standards. Despite the fact that most PPCPs are not acutely toxic, their chronic release at low levels combined with their environmental persistence may be cause of potential concern for aquatic organisms in receiving waters under the influence of poorly treated wastewaters. The presence of PPCPs in drinking water is not novel, however in the case of Miami-Dade County where the source for drinking water is the shallow Biscayne Aquifer additional studies should be planned to assure that the source remains isolated from surface or ground waters influenced by treated or untreated wastewater streams. With the increased population growth in South Florida and need for water reuse careful consideration should be given to protect the drinking water sources from further degradation .

In the future, more effective treatments need to be applied to both WWTPs and DWPs to remove PPCPs. Great progress has been accomplished with the use of 
reverse osmosis and advanced oxidation processes. Until then, or when forced by a regulatory framework, the concentrations of PPCPs in wastewater effluents targeted for environmental release and drinking water need long term monitoring . 


\section{REFERENCES}

Aronson, D., Weeks, J., Meylan, B., Guiney, P.D., Howard, P.H., 2012. Environmental release, environmental concentrations, and ecological risk of N,NDiethyl-m-toluamide (DEET). Integrated Environmental Assessment and Management 8, 135-166.

Barel-Cohen, K., Shore, L.S., Shemesh, M., Wenzel, A., Mueller, J., KronfeldSchor, N., 2006. Monitoring of natural and synthetic hormones in a polluted river. Journal of Environmental Management 78, 16-23.

Barnes, K.K., Kolpin, D.W., Furlong, E.T., Zaugg, S.D., Meyer, M.T., Barber, L.B., 2008. A national reconnaissance of pharmaceuticals and other organic wastewater contaminants in the United States - I) Groundwater. Science of the Total Environment 402, 192-200.

Ben-Jonathan, N., Steinmetz, R., 1998. Xenoestrogens: The Emerging Story of Bisphenol A. Trends in Endocrinology and Metabolism 9, 124-128.

Benotti, M.J., Trenholm, R.A., Vanderford, B.J., Holady, J.C., Stanford, B.D., Snyder, S.A., 2009. Pharmaceuticals and Endocrine Disrupting Compounds in U.S. Drinking Water. Environmental Science \& Technology 43, 597-603.

Beverly S, R., 2011. Bisphenol A: An endocrine disruptor with widespread exposure and multiple effects. The Journal of Steroid Biochemistry and Molecular Biology 127, 27-34.

Bos, S., van Leeuwen, S., Karst, U., 2006. From fundamentals to applications: recent developments in atmospheric pressure photoionization mass spectrometry. Analytical and Bioanalytical Chemistry 384, 85-99.

Boyd, G.R., Reemtsma, H., Grimm, D.A., Mitra, S., 2003. Pharmaceuticals and personal care products (PPCPs) in surface and treated waters of Louisiana, USA and Ontario, Canada. The Science of The Total Environment 311, 135-149.

Broséus, R., Vincent, S., Aboulfadl, K., Daneshvar, A., Sauvé, S., Barbeau, B., Prévost, M., 2009. Ozone oxidation of pharmaceuticals, endocrine disruptors and pesticides during drinking water treatment. Water Research 43, 4707-4717.

Burkhardt, M.R., ReVello, R.C., Smith, S.G., Zaugg, S.D., 2005. Pressurized liquid extraction using water/isopropanol coupled with solid-phase extraction cleanup for industrial and anthropogenic waste-indicator compounds in sediment. Analytica Chimica Acta 534, 89-100. 
Cahill, J.D., Furlong, E.T., Burkhardt, M.R., Kolpin, D., Anderson, L.G., 2004. Determination of pharmaceutical compounds in surface- and ground-water samples by solid-phase extraction and high-performance liquid chromatographyelectrospray ionization mass spectrometry. Journal of Chromatography A 1041 , 171-180.

Cai, S.-S., Syage, J.A., Hanold, K.A., Balogh, M.P., 2009. Ultra Performance Liquid Chromatography atmospheric Pressure Photoionization-Tandem Mass Spectrometry for High-Sensitivity and High-Throughput Analysis of U.S. Environmental Protection Agency 16 Priority Pollutants Polynuclear Aromatic Hydrocarbons. Analytical Chemistry 81, 2123-2128.

Cai, Y., Kingery, D., McConnell, O., Bach, A.C., 2005. Advantages of atmospheric pressure photoionization mass spectrometry in support of drug discovery. Rapid Communications in Mass Spectrometry 19, 1717-1724.

Caliman, F.A., Gavrilescu, M., 2009. Pharmaceuticals, Personal Care Products and Endocrine Disrupting Agents in the Environment - A Review. CLEAN - Soil, Air, Water 37, 277-303.

Capdeville, M.J., Budzinski, H., 2011. Trace-level analysis of organic contaminants in drinking waters and groundwaters. TRAC Trends in Analytical Chemistry 30, 586-606.

Carballa, M., Omil, F., Lema, J.M., Llompart, M., Garcia-Jares, C., Rodrouez, I., Goez, M., Ternes, T., 2004. Behavior of pharmaceuticals, cosmetics and hormones in a sewage treatment plant. Water Research 38, 2918-2926.

Castiglioni, S., Bagnati, R., Calamari, D., Fanelli, R., Zuccato, E., 2005. A multiresidue analytical method using solid-phase extraction and high-pressure liquid chromatography tandem mass spectrometry to measure pharmaceuticals of different therapeutic classes in urban wastewaters. Journal of Chromatography A 1092, 206-215.

Christiansen, L.B., 2002. Feminisation of fish. The effect of estrogenic compounds and their fate in sewage treatment plants and nature.

Deblonde, T., Cossu-Leguille, C., Hartemann, P., 2011. Emerging pollutants in wastewater: A review of the literature. International Journal of Hygiene and Environmental Health 214, 442-448.

Diaz, C., M. Silvia, Barcelo, D., 2005. LC-MS2 trace analysis of antimicrobials in water, sediment and soil. TRAC Trends in Analytical Chemistry 24, 645-657. 
Durán-Alvarez, J.C., Becerril-Bravo, E., Castro, V.S., Jiménez, B., Gibson, R., 2009. The analysis of a group of acidic pharmaceuticals, carbamazepine, and potential endocrine disrupting compounds in wastewater irrigated soils by gas chromatography-mass spectrometry. Talanta 78, 1159-1166.

Esperanza, M., Suidan, M.T., Nishimura, F., Wang, Z.M., Sorial, G.A., 2004. Determination of sex hormones and nonylphenol ethoxylates in the aqueous matrixes of two pilot-scale municipal wastewater treatment plants. Environmental Science \& Technology 38, 3028-3035.

Fatta-Kassinos, D., Meric, S., Nikolaou, A., 2010. Pharmaceutical residues in environmental waters and wastewater: current state of knowledge and future research. Analytical and Bioanalytical Chemistry 399, 251-275.

Fent, K., Weston, A.A., Caminada, D., 2006. Ecotoxicology of human pharmaceuticals. Aquatic Toxicology 76, 122-159.

Focazio, M.J., Kolpin, D.W., Barnes, K.K., Furlong, E.T., Meyer, M.T., Zaugg, S.D., Barber, L.B., Thurman, M.E., 2008. A national reconnaissance for pharmaceuticals and other organic wastewater contaminants in the United States - II) Untreated drinking water sources. Science of the Total Environment 402, 201-216.

Fram, M.S., Belitz, K., 2011. Occurrence and concentrations of pharmaceutical compounds in groundwater used for public drinking-water supply in California. Science of the Total Environment 409, 3409-3417.

Garcia-Ac, A., Segura, P.A., Viglino, L., Furtos, A., Gagnon, C., Prevost, M., Sauve, S., 2009. On-line solid-phase extraction of large-volume injections coupled to liquid chromatography-tandem mass spectrometry for the quantitation and confirmation of 14 selected trace organic contaminants in drinking and surface water. Journal of Chromatography A 1216, 8518-8527.

Garcia-Ac, A., Segura, P.A., Viglino, L., Gagnon, C., Sauvé, S., 2011. Comparison of APPI, APCI and ESI for the LC-MS/MS analysis of bezafibrate, cyclophosphamide, enalapril, methotrexate and orlistat in municipal wastewater. Journal of Mass Spectrometry 46, 383-390.

Gardinali, P.R., Zhao, X., 2002. Trace determination of caffeine in surface water samples by liquid chromatography-atmospheric pressure chemical ionizationmass spectrometry (LC-APCI-MS). Environment International 28, 521-528.

Garrison, A.W., Pope, J.D., Allen, F.R., 1976. GC/MSanalysis of organic compounds in domestic wastewaters. Ann Arbor Science Publishers: Ann Arbor,Ml. 
Gentili, A., Perret, D., Marchese, S., Mastropasqua, R., Curini, R., Di Corcia, A., 2002. Analysis of free estrogens and their conjugates in sewage and river waters by solid-phase extraction then liquid chromatography-electrospray-tandem mass spectrometry. Chromatographia 56, 25-32.

Gibson, R., Becerril-Bravo, E., Silva-Castro, V., Jiménez, B., 2007. Determination of acidic pharmaceuticals and potential endocrine disrupting compounds in wastewaters and spring waters by selective elution and analysis by gas chromatography-mass spectrometry. Journal of Chromatography A 1169, 31-39.

Glassmeyer, S.T., Furlong, E.T., Kolpin, D.W., Cahill, J.D., Zaugg, S.D., Werner, S.L., Meyer, M.T., Kryak, D.D., 2005. Transport of Chemical and Microbial Compounds from Known Wastewater Discharges:Potential for Use as Indicators of Human Fecal Contamination. Environmental Science \& Technology 39, 51575169.

Gómez, M.J., Agüera, A., Mezcua, M., Hurtado, J., Mocholí, F., Fernández-Alba, A.R., 2007. Simultaneous analysis of neutral and acidic pharmaceuticals as well as related compounds by gas chromatography-tandem mass spectrometry in wastewater. Talanta 73, 314-320.

Gros, M., Petrovic, M., Barcelo, D., 2009. Tracing Pharmaceutical Residues of Different Therapeutic Classes in Environmental Waters by Using Liquid Chromatography/Quadrupole-Linear Ion Trap Mass Spectrometry and Automated Library Searching. Analytical Chemistry 81, 898-912.

Hanold, K.A., Fischer, S.M., Cormia, P.H., Miller, C.E., Syage, J.A., 2004. Atmospheric Pressure Photoionization. 1. General Properties for LC/MS. Analytical Chemistry 76, 2842-2851.

Hans H, M., 1998. Liquid chromatography-mass spectrometry in forensic and clinical toxicology. Journal of Chromatography B: Biomedical Sciences and Applications 713, 3-25.

Heberer, T., Dünnbier, U., Reilich, C., Stan, H.J., 1997. Detection of drugs and drug metabolites in groundwater samples of a drinking water treatment plant. Fresenius Environmental Bulletin 6, 438-443.

Heberer, T., Mechlinski, A., Fanck, B., Knappe, A., Massmann, G., Pekdeger, A., Fritz, B., 2004. Field Studies on the Fate and Transport of Pharmaceutical Residues in Bank Filtration. Ground Water Monitoring \& Remediation 24, 70-77. 
Heberer, T., Reddersen, K., Mechlinski, A., 2002. From municipal sewage to drinking water: fate and removal of pharmaceutical residues in the aquatic environment in urban areas. Water Science and Technology 46, 81-88.

Hernández, F., Sancho, J.V., Pozo, O.J., 2005. Critical review of the application of liquid chromatography/mass spectrometry to the determination of pesticide residues in biological samples. Analytical and Bioanalytical Chemistry 382, 934946.

Hilton, M.J., Thomas, K.V., 2003. Determination of selected human pharmaceutical compounds in effluent and surface water samples by highperformance liquid chromatography-electrospray tandem mass spectrometry. Journal of Chromatography A 1015, 129-141.

Hohenblum, P., Gans, O., Moche, W., Scharf, S., Lorbeer, G., 2004. Monitoring of selected estrogenic hormones and industrial chemicals in groundwaters and surface waters in Austria. Science of the Total Environment 333, 185-193.

Huerta-Fontela, M., Galceran, M.T., Ventura, F., 2010. Fast liquid chromatography-quadrupole-linear ion trap mass spectrometry for the analysis of pharmaceuticals and hormones in water resources. Journal of Chromatography A $1217,4212-4222$.

Huggett, D.B., Brooks, B.W., Peterson, B., Foran, C.M., Schlenk, D., 2002. Toxicity of Select Beta Adrenergic Receptor-Blocking Pharmaceuticals (BBlockers) on Aquatic Organisms. Archives of Environmental Contamination and Toxicology 43, 229-235.

Ingrand, V., Herry, G., Beausse, J., de Roubin, M.-R., 2003. Analysis of steroid hormones in effluents of wastewater treatment plants by liquid chromatoraphytandem mass spectrometry. Journal of Chromatography A 1020, 99-104.

Itoh, N., Aoyagi, Y., Yarita, T., 2006. Optimization of the dopant for the trace determination of polycyclic aromatic hydrocarbons by liquid chromatography/dopant-assisted atmospheric-pressure photoionization/mass spectrometry. Journal of Chromatography A 1131, 285-288.

Jeannot, R., Sabik, H., Sauvard, E., Dagnac, T., Dohrendorf, K., 2002. Determination of endocrine-disrupting compounds in environmental samples using gas and liquid chromatography with mass spectrometry. Journal of Chromatography A 974, 143-159.

Jelic, A., Petrovic, M., Barcel, D., 2009. Multi-residue method for trace level determination of pharmaceuticals in solid samples using pressurized liquid 
extraction followed by liquid chromatography/quadrupole-linear ion trap mass spectrometry. Talanta 80, 363-371.

Jian-lin, W., Jie, L., Zongwei, C., 2010. Determination of triclosan metabolites by using in-source fragmentation from high-performance liquid chromatography/negative atmospheric pressure chemical ionization ion trap mass spectrometry. Rapid Communications in Mass Spectrometry 24, 18281834.

Kasprzyk-Hordern, B., Dinsdale, R.M., Guwy, A.J., 2008. The effect of signal suppression and mobile phase composition on the simultaneous analysis of multiple classes of acidic/neutral pharmaceuticals and personal care products in surface water by solid-phase extraction and ultra performance liquid chromatography-negative electrospray tandem mass spectrometry. Talanta 74 , 1299-1312.

Kauppila, T.J., Kostiainen, R., Bruins, A.P., 2004. Anisole, a new dopant for atmospheric pressure photoionization mass spectrometry of low proton affinity, low ionization energy compounds. Rapid Communications in Mass Spectrometry $18,808-815$.

Kauppila, T.J., Kuuranne, T., Meurer, E.C., Eberlin, M.N., Kotiaho, T., Kostiainen, R., 2002. Atmospheric Pressure Photoionization Mass Spectrometry. Ionization Mechanism and the Effect of Solvent on the Ionization of Naphthalenes. Analytical Chemistry 74, 5470-5479.

Kim, S.D., Cho, J., Kim, I.S., Vanderford, B.J., Snyder, S.A., 2007. Occurrence and removal of pharmaceuticals and endocrine disruptors in South Korean surface, drinking, and waste waters. Water Research 41, 1013-1021.

Kinney, C.A., Furlong, E.T., Werner, S.L., Cahill, J.D., 2006. Presence and distribution of wastewater-derived pharmaceuticals in soil irrigated with reclaimed water. Environmental Toxicology and Chemistry 25, 317-326.

Kolodziej, E.P., Harter, T., Sedlak, D.L., 2004. Dairy wastewater, aquaculture, and spawning fish as sources of steroid hormones in the aquatic environment. Environmental Science \& Technology 38, 6377-6384.

Kolpin, D.W., Furlong, E.T., Meyer, M.T., Thurman, E.M., Zaugg, S.D., Barber, L.B., Buxton, H.T., 2002. Pharmaceuticals, hormones, and other organic wastewater contaminants in US streams, 1999-2000: A national reconnaissance. Environmental Science \& Technology 36, 1202-1211.

Küster, A., Alder, A.C., Escher, B.I., Duis, K., Fenner, K., Garric, J., Hutchinson, T.H., Lapen, D.R., Péry, A., Römbke, J., Snape, J., Ternes, T., Topp, E., 
Wehrhan, A., Knacker, T., 2009. Environmental risk assessment of human pharmaceuticals in the European Union: A case study with the $\beta$-blocker atenolol. Integrated Environmental Assessment and Management 6, 514-523.

Lacey, C., Basha, S., Morrissey, A., Tobin, J., 2011. Occurrence of pharmaceutical compounds in wastewater process streams in Dublin, Ireland. Environmental Monitoring and Assessment 184, 1049-1062.

Larsen, M.G., Hansen, K.B., Henriksen, P.G., Baatrup, E., 2008. Male zebrafish (Danio rerio) courtship behaviour resists the feminising effects of $17 \beta$ ethinyloestradiol-morphological sexual characteristics do not. Aquatic Toxicology 87, 234-244.

Laven, M., Alsberg, T., Yu, Y., Adolfsson-Erici, M., Sun, H., 2009. Serial mixedmode cation- and anion-exchange solid-phase extraction for separation of basic, neutral and acidic pharmaceuticals in wastewater and analysis by highperformance liquid chromatography-quadrupole time-of-flight mass spectrometry. Journal of Chromatography A 1216, 49-62.

Li, Z.-H., Zlabek, V., Grabic, R., Velisek, J., Machova, J., Randak, T., 2010. Enzymatic alterations and RNA/DNA ratio in intestine of rainbow trout, Oncorhynchus mykiss, induced by chronic exposure to carbamazepine. Ecotoxicology 19, 872-878.

Li, Z.-H., Zlabek, V., Velisek, J., Grabic, R., Machova, J., Randak, T., 2009. Physiological condition status and muscle-based biomarkers in rainbow trout (Oncorhynchus mykiss), after long-term exposure to carbamazepine. Journal of Applied Toxicology 30, 197-203.

Lien, G.-W., Chen, C.-Y., Wang, G.-S., 2009. Comparison of electrospray ionization, atmospheric pressure chemical ionization and atmospheric pressure photoionization for determining estrogenic chemicals in water by liquid chromatography tandem mass spectrometry with chemical derivatizations. Journal of Chromatography A 1216, 956-966.

Lipp, E.K., Jarrell, J.L., Griffin, D.W., Lukasik, J., Jacukiewicz, J., Rose, J.B., 2002. Preliminary evidence for human fecal contamination in corals of the Florida Keys, USA. Marine Pollution Bulletin 44, 666-670.

Lishman, L., Smyth, S.A., Sarafin, K., Kleywegt, S., Toito, J., Peart, T., Lee, B., Servos, M., Beland, M., Seto, P., 2006. Occurrence and reductions of pharmaceuticals and personal care products and estrogens by municipal wastewater treatment plants in Ontario, Canada. Science of the Total Environment 367, 544-558. 
Löffler, D., Ternes, T.A., 2003. Determination of acidic pharmaceuticals, antibiotics and ivermectin in river sediment using liquid chromatography-tandem mass spectrometry. Journal of Chromatography A 1021, 133-144.

Lopez-Serna, R., Perez, S., Ginebreda, A., Petrovic, M., Barcel, D., 2010. Fully automated determination of 74 pharmaceuticals in environmental and waste waters by online solid phase extraction-liquid chromatography-electrospraytandem mass spectrometry. Talanta 83, 410-424.

Loraine, G.A., Pettigrove, M.E., 2006. Seasonal Variations in Concentrations of Pharmaceuticals and Personal Care Products in Drinking Water and Reclaimed Wastewater in Southern California. Environmental Science \& Technology 40, 687-695.

Marchi, I., Rudaz, S., Veuthey, J.L., 2009. Atmospheric pressure photoionization for coupling liquid-chromatography to mass spectrometry: A review. Talanta 78, $1-18$.

Markman, S., Guschina, I.A., Barnsley, S., Buchanan, K.L., Pascoe, D., Muller, C.T., 2007. Endocrine disrupting chemicals accumulate in earthworms exposed to sewage effluent. Chemosphere 70, 119-125.

Martnez Bueno, M.J., Agera, A., Gomez, M.J., Hernando, M.D., Garca-Reyes, J.F., Fernndez-Alba, A.R., 2007. Application of Liquid Chromatography/Quadrupole-Linear Ion Trap Mass Spectrometry and Time-ofFlight Mass Spectrometry to the Determination of Pharmaceuticals and Related Contaminants in Wastewater. Analytical Chemistry 79, 9372-9384.

Matamoros, V., Salvado, V., 2012. Evaluation of the seasonal performance of a water reclamation pond-constructed wetland system for removing emerging contaminants. Chemosphere 86, 111-117.

Metcalfe, C.D., Miao, X.-S., Koenig, B.G., Struger, J., 2003. Distribution of acidic and neutral drugs in surface waters near sewage treatment plants in the lower Great Lakes, Canada. Environmental Toxicology and Chemistry 22, 2881-2889.

Michael, C., 2003. Aquatic ecotoxicity of pharmaceuticals including the assessment of combination effects. Toxicology Letters 142, 185-194.

Mompelat, S., Le Bot, B., Thomas, O., 2009. Occurrence and fate of pharmaceutical products and by-products, from resource to drinking water. Environment International 35, 803-814. 
Nunez, O., Gallart-Ayala, H., Martins, C.P.B., Lucci, P., 2011. New trends in fast liquid chromatography for food and environmental analysis. Journal of Chromatography A.

Pablo Lamas, J., Salgado-Petinal, C., Garcia-Jares, C., Llompart, M., Cela, R., Gomez, M., 2004. Solid-phase microextraction-gas chromatography-mass spectrometry for the analysis of selective serotonin reuptake inhibitors in environmental water. Journal of Chromatography A 1046, 241-247.

Palmgren, J.J., Toyras, A., Mauriala, T., Monkkonen, J., Auriola, S., 2005. Quantitative determination of cholesterol, sitosterol, and sitostanol in cultured Caco-2 cells by liquid chromatography-atmospheric pressure chemical ionization mass spectrometry. Journal of Chromatography B 821, 144-152.

Parrott, J.L., Blunt, B.R., 2005. Life-cycle exposure of fathead minnows (Pimephales promelas) to an ethinylestradiol concentration below $1 \mathrm{ng} / \mathrm{L}$ reduces egg fertilization success and demasculinizes males. Environmental Toxicology 20, 131-141.

Peng, X., Wang, Z., Yang, C., Chen, F., Mai, B., 2006. Simultaneous determination of endocrine-disrupting phenols and steroid estrogens in sediment by gas chromatography-mass spectrometry. Journal of Chromatography A 1116, 51-56.

Petrovic, M., Hernando, M.D., Diaz-Cruz, M.S., Barcelo, D., 2005. Liquid chromatography-tandem mass spectrometry for the analysis of pharmaceutical residues in environmental samples: a review. Journal of Chromatography A 1067, $1-14$.

Pisarenko, A.N., Stanford, B.D., Yan, D., Gerrity, D., Snyder, S.A., 2012. Effects of ozone and ozone/peroxide on trace organic contaminants and NDMA in drinking water and water reuse applications. Water Research 46, 316-326.

Pollack, K., Balazs, K., Ogunseitan, O., 2009. Proteomic Assessment of Caffeine Effects on Coral Symbionts. Environmental Science \& Technology 43, 2085-2091. Pomati, F., Orlandi, C., Clerici, M., Luciani, F., Zuccato, E., 2008. Effects and Interactions in an Environmentally Relevant Mixture of Pharmaceuticals. Toxicological Sciences 102, 129-137.

Rabiet, M., Togola, A., Brissaud, F., Seidel, J.L., Budzinski, H., Elbaz-Poulichet, F., 2006. Consequences of treated water recycling as regards pharmaceuticals and drugs in surface and ground waters of a medium-sized Mediterranean catchment. Environmental Science \& Technology 40, 5282-5288. 
Raffaelli, A., Saba, A., 2003. Atmospheric pressure photoionization mass spectrometry. Mass Spectrometry Reviews 22, 318-331.

Reddersen, K., Heberer, T., Dünnbier, U., 2002. Identification and significance of phenazone drugs and their metabolites in ground- and drinking water. Chemosphere 49, 539-544.

Rice, S.L., Mitra, S., 2007. Microwave-assisted solvent extraction of solid matrices and subsequent detection of pharmaceuticals and personal care products (PPCPs) using gas chromatography-mass spectrometry. Analytica Chimica Acta 589, 125-132.

Ripp, J., 1996. Analytical Detection Limit Guidance \& Laboratory Guide for Determining Method Detection Limits, Wisconsin Deparment of Natural Resources Laboratory Certification Program.

Robb, D.B., Covey, T.R., Bruins, A.P., 2000. Atmospheric Pressure Photoionization: An Ionization Method for Liquid Chromatography Mass Spectrometry. Analytical Chemistry 72, 3653-3659.

Ryu, J., Yoon, Y., Oh, J., 2011. Occurrence of endocrine disrupting compounds and pharmaceuticals in 11 WWTPs in Seoul, Korea. KSCE Journal of Civil Engineering 15, 57-64.

Sabourin, L., Beck, A., Duenk, P.W., Kleywegt, S., Lapen, D.R., Li, H., Metcalfe, C.D., Payne, M., Topp, E., 2009. Runoff of pharmaceuticals and personal care products following application of dewatered municipal biosolids to an agricultural field. Science of the Total Environment 407, 4596-4604.

Schlüsener, M.P., Bester, K., 2005. Determination of steroid hormones, hormone conjugates and macrolide antibiotics in influents and effluents of sewage treatment plants utilising high-performance liquid chromatography/tandem mass spectrometry with electrospray and atmospheric pressure chemical ionisation. Rapid Communications in Mass Spectrometry 19, 3269-3278.

Schummer, C., Delhomme, O., Appenzeller, B.M.R., Wennig, R., Millet, M., 2009. Comparison of MTBSTFA and BSTFA in derivatization reactions of polar compounds prior to GC/MS analysis. Talanta 77, 1473-1482.

Schwaiger, J., Ferling, H., Mallow, U., Wintermayr, H., Negele, R.D., 2004. Toxic effects of the non-steroidal anti-inflammatory drug diclofenac: Part I: histopathological alterations and bioaccumulation in rainbow trout. Aquatic Toxicology 68, 141-150. 
Sebok, A., Vasanits-Zsigrai, A., Helenkar, A., Zaray, G., Molnar-Perl, I., 2009. Multiresidue analysis of pollutants as their trimethylsilyl derivatives, by gas chromatography-mass spectrometry. Journal of Chromatography A 1216, 22882301.

Segura, P.A., Gagnon, C., Sauve, S., 2007. A fully automated on-line preconcentration and liquid chromatography-tandem mass spectrometry method for the analysis of anti-infectives in wastewaters. Analytica Chimica Acta 604, $147-157$.

Shareef, A., Angove, M.J., Wells, J.D., 2006. Optimization of silylation using Nmethyl-N-(trimethylsilyl)-trifluoroacetamide, $\quad$ N,O-bis-(trimethyl.silyl)trifluoroacetamide and $\mathrm{N}$-(tert-butyldimethylsilyl)-N-methyltrifluoroacetamide for the determination of the estrogens estrone and 17 alpha-ethinylestradiol by gas chromatography-mass spectrometry. Journal of Chromatography A 1108, 121128.

Singh, S., Azua, A., Chaudhary, A., Khan, S., Willett, K., Gardinali, P., 2010. Occurrence and distribution of steroids, hormones and selected pharmaceuticals in South Florida coastal environments. Ecotoxicology 19, 338-350.

Stackelberg, P.E., Furlong, E.T., Meyer, M.T., Zaugg, S.D., Henderson, A.K., Reissman, D.B., 2004. Persistence of pharmaceutical compounds and other organic wastewater contaminants in a conventional drinking-water-treatment plant. Science of the Total Environment 329, 99-113.

Stackelberg, P.E., Gibs, J., Furlong, E.T., Meyer, M.T., Zaugg, S.D., Lippincott, R.L., 2007a. Efficiency of conventional drinking-water-treatment processes in removal of pharmaceuticals and other organic compounds. Science of the Total Environment 377, 255-272.

Stackelberg, P.E., Gibs, J., Furlong, E.T., Meyer, M.T., Zaugg, S.D., Lippincott, R.L., 2007b. Efficiency of conventional drinking-water-treatment processes in removal of pharmaceuticals and other organic compounds. Science of the Total Environment 377, 255-272.

Stumpf, M., Ternes, T.A., Haberer, K., Seel, P., Baumann, W., 1996. Determination of pharmaceuticals in sewage plants and river water. Vom Wasser 86.

Sui, Q., Huang, J., Deng, S., Yu, G., Fan, Q., 2010. Occurrence and removal of pharmaceuticals, caffeine and DEET in wastewater treatment plants of Beijing, China. Water Research 44, 417-426. 
Tauber, R., 2003. Quantitative Analysis of Pharmaceuticals in Drinking Water from Ten Canadian Cities. Enviro-Test Laboratories, Xenos Division, Ontario, Canada.

Thomas, H., 2002. Occurrence, fate, and removal of pharmaceutical residues in the aquatic environment: a review of recent research data. Toxicology Letters 131, 5-17.

Thomas, K.V., Hilton, M.J., 2004. The occurrence of selected human pharmaceutical compounds in UK estuaries. Marine Pollution Bulletin 49, 436444.

Togola, A., Budzinski, H., 2008. Multi-residue analysis of pharmaceutical compounds in aqueous samples. Journal of Chromatography A 1177, 150-158.

Trenholm, R.A., Vanderford, B.J., Drewes, J.E., Snyder, S.A., 2008. Determination of household chemicals using gas chromatography and liquid chromatography with tandem mass spectrometry. Journal of Chromatography A 1190, 253-262.

URL1, http://www.epa.gov/ppcp/.

URL2, http://www.fda.gov/forconsumers/consumerupdates/ucm101653.htm.

URL3, http://www.miamidade.gov/water/water-supply-treatment.asp.

Vanderford, B.J., Pearson, R.A., Rexing, D.J., Snyder, S.A., 2003. Analysis of endocrine disruptors, pharmaceuticals, and personal care products in water using liquid chromatography/tandem mass spectrometry. Analytical Chemistry 75, 6265-6274.

Vazquez-Roig, P., Segarra, R., Blasco, C., Andreu, V., Pic, Y., 2010. Determination of pharmaceuticals in soils and sediments by pressurized liquid extraction and liquid chromatography tandem mass spectrometry. Journal of Chromatography A 1217, 2471-2483.

Verenitch, S.S., Lowe, C.J., Mazumder, A., 2006. Determination of acidic drugs and caffeine in municipal wastewaters and receiving waters by gas chromatography-ion trap tandem mass spectrometry. Journal of Chromatography A 1116, 193-203.

Vieno, N.M., Tuhkanen, T., Kronberg, L., 2005. Seasonal Variation in the Occurrence of Pharmaceuticals in Effluents from a Sewage Treatment Plant and in the Recipient Water. Environmental Science \& Technology 39, 8220-8226. 
Viglino, L., Aboulfadl, K., Prevost, M., Sauve, S., 2008. Analysis of natural and synthetic estrogenic endocrine disruptors in environmental waters using online preconcentration coupled with LC-APPI-MS/MS. Talanta 76, 1088-1096.

Vulliet, E., Cren-Olivé, C., Grenier-Loustalot, M.-F., 2011. Occurrence of pharmaceuticals and hormones in drinking water treated from surface waters. Environmental Chemistry Letters 9, 103-114.

Waggot, A., 1981. Trace organic substances in the River Lee in: Cooper, W.J. (Ed.). Chemistry in Water Reuse. Ann Arbour Science, Great Britain, pp. 55-99.

Wang, J., Schnute, W.C., 2010. Direct analysis of trace level bisphenol A, octylphenols and nonylphenol in bottled water and leached from bottles by ultrahigh-performance liquid chromatography/tandem mass spectrometry. Rapid Communications in Mass Spectrometry 24, 2605-2610.

Wang, Y., Hu, W., Cao, Z., Fu, X., Zhu, T., 2005. Occurrence of endocrinedisrupting compounds in reclaimed water from Tianjin, China. Analytical and Bioanalytical Chemistry 383, 857-863.

Weigel, S., Kallenborn, R., Hühnerfuss, H., 2004. Simultaneous solid-phase extraction of acidic, neutral and basic pharmaceuticals from aqueous samples at ambient (neutral) $\mathrm{pH}$ and their determination by gas chromatography-mass spectrometry. Journal of Chromatography A 1023, 183-195.

Welshons, W.V., Nagel, S.C., vom Saal, F.S., 2006. Large Effects from Small Exposures. III. Endocrine Mechanisms Mediating Effects of Bisphenol A at Levels of Human Exposure. Endocrinology 147, s56-s69.

Winter, M.J., Lillicrap, A.D., Caunter, J.E., Schaffner, C., Alder, A.C., Ramil, M., Ternes, T.A., Giltrow, E., Sumpter, J.P., Hutchinson, T.H., 2008. Defining the chronic impacts of atenolol on embryo-larval development and reproduction in the fathead minnow (Pimephales promelas). Aquatic Toxicology 86, 361-369.

Wu, C., Spongberg, A.L., Witter, J.D., Fang, M., Czajkowski, K.P., 2010. Uptake of Pharmaceutical and Personal Care Products by Soybean Plants from Soils Applied with Biosolids and Irrigated with Contaminated Water. Environmental Science \& Technology 44, 6157-6161.

Xu, J., Wu, L., Chen, W., Chang, A.C., 2008. Simultaneous determination of pharmaceuticals, endocrine disrupting compounds and hormone in soils by gas chromatography-mass spectrometry. Journal of Chromatography A 1202, 189195. 
Xu, J., Wu, L., Chen, W., Jiang, P., Chang, A.C.-S., 2009. Pharmaceuticals and Personal Care Products (PPCPs), and Endocrine Disrupting Compounds (EDCs) in Runoff from a Potato Field Irrigated with Treated Wastewater in Southern California. Journal of Health Science 55, 306-310.

Yamamoto, A., Kakutani, N., Yamamoto, K., Kamiura, T., Miyakoda, H., 2006. Steroid Hormone Profiles of Urban and Tidal Rivers Using LC/MS/MS Equipped with Electrospray lonization and Atmospheric Pressure Photoionization Sources. Environmental Science \& Technology 40, 4132-4137.

Yoon, Y., Westerhoff, P., Snyder, S.A., Wert, E.C., 2006. Nanofiltration and ultrafiltration of endocrine disrupting compounds, pharmaceuticals and personal care products. Journal of Membrane Science 270, 88-100.

Zafra, A., del Olmo, M., Suarez, B., Hontoria, E., Navalon, A., Vilchez, J.L., 2003. Gas chromatographic-mass spectrometric method for the determination of bisphenol $A$ and its chlorinated derivatives in urban wastewater. Water Research 37, 735-742.

Zaharie, M., 2006. Occurrences of pharmaceutical and personal care products as micropollutants in rivers from Romania. Chemosphere 64, 1808-1817.

Zuccato, E., Calamari, D., Natangelo, M., Fanelli, R., 2000. Presence of therapeutic drugs in the environment. The Lancet 335, 1789-1790. 


\section{VITA}

Chengtao Wang

April 29, 1982

2000-2004

2004-2006

2006-present
Born, Longkou, Shandong, China

B.A., Environmental Engineering

Nanjing University of Science \& Technology

Nanjing, China

M.S., Applied Chemistry

Nanjing University of Science \& Technology

Nanjing, China

Doctoral Candidate

Florida International University

Miami, Florida

Teaching Assistant \& Research Assistant

Florida International University

Miami, Florida

\section{PUBLICATIONS AND PRESENTATIONS}

Chengtao Wang, Piero R. Gardinali. Occurrence of Pharmaceuticals and Personal Care Products in Surface Water from South Florida Canals and Coastal Environments. Poster presentation, Southeast SETAC Ann. Mtg. Gainesville, FL, 2008

Chengtao Wang, Piero R. Gardinali. Baseline of Pharmaceuticals and Personal Care Products in Surface Water and Sediment in Protected Area in South Florida. Poster presentation, 29th Annual Society for Environmental Toxicology and Chemistry Conference, Tampa Bay, FL, 2008

Chengtao Wang, Piero R. Gardinali. Assessment of Occurence and Potential Effect of Pharmaceuticals and Personal Care Products in Surface Water from South Florida. Platform presentation, American Chemical Society Florida Section 85th Annual Meeting, Kissimmee, FL, 2009

Chengtao Wang, Piero R. Gardinali. Accelerated Solvent Extraction Sediment and Soil for Detection of Pharmaceuticals and Personal Care Products by gas chromatography mass spectrometry. Poster presentation, 30th Annual Society for Environmental Toxicology and Chemistry Conference, New Orlean, Louisiana, 2009 
Chengtao Wang, Piero R. Gardinali. Simultaneous Detection of PPCPs in Sediments and Soils in South Florida by Gas Chromatography Mass Spectrometry. Poster presentation, 31th Annual Society for Environmental Toxicology and Chemistry Conference, Portland, Oregon, 2010

Chengtao Wang, Piero R. Gardinali. Comparison of Multiple API Ionization Techniques for the Simultaneous Detection of Microconstituents in Water by online SPE-LC-MS/MS. Poster presentation, 50th ASMS Annual Meeting, Denver, Colorado, 2011

Chengtao Wang, Piero R. Gardinali. Comparison of Heated Electrospray Ionization, Atmospheric Pressure Chemical ionization and Photoionization for Detection of 69 PPCPs and Hormones in Environmental Water Samples Using On-line Preconcentration Coupled to High Performance Liquid Chromatographytandem Mass Spectrometry. Poster presentation, $7^{\text {th }}$ LC/MS/MS workshop on environmental and food safety, Buffalo, New York, 2011.

Chengtao Wang, Piero R. Gardinali. Comparison of multiple API ionization techniques for the simultaneous detection of microconstituents in water by online SPE-LC-MS/MS. Accepted by Journal of Mass Spectrometry. 2012. 